Florida International University FIU Digital Commons

$12-6-2016$

\title{
Achieving and Maintaining Food Security in the PRC: The Impact on Foreign Policy
}

Paul D. Rittenhouse

pdrittenhouse@hotmail.com

DOI: 10.25148 /etd.FIDC001736

Follow this and additional works at: https:// digitalcommons.fiu.edu/etd

Part of the Asian Studies Commons, Chinese Studies Commons, Food Security Commons, International Relations Commons, and the Political Economy Commons

\section{Recommended Citation}

Rittenhouse, Paul D., "Achieving and Maintaining Food Security in the PRC: The Impact on Foreign Policy" (2016). FIU Electronic Theses and Dissertations. 3260.

https://digitalcommons.fiu.edu/etd/3260 


\section{FLORIDA INTERNATIONAL UNIVERSITY}

Miami, Florida

ACHIEVING AND MAINTAINING FOOD SECURITY IN THE PRC: THE

IMPACT ON FOREIGN POLICY

A dissertation submitted in partial fulfillment of the

requirements for the degree

of

DOCTOR OF PHILOSOPHY

in

INTERNATIONAL RELATIONS

by

Paul D. Rittenhouse

2017 
To: Dean John F. Stack Jr.

Steven J. Green School of International and Public Affairs

This dissertation, written by Paul D. Rittenhouse, and entitled Achieving and Maintaining Food Security in the PRC: The Impact on Foreign Policy, having been approved in respect to style and intellectual content, is referred to you for judgment.

We have read this dissertation and recommend that it be approved.

Thomas Breslin

Zeng Jin

Gail Hollander

Mohiaddin Mesbahi, Major Professor

Date of Defense: December 6, 2016

The dissertation of Paul D. Rittenhouse is approved.

Dean John F. Stack Jr. Steven J. Green School of International and Public Affairs

Andrés G. Gil

Vice President for Research and Economic Development and Dean of the University Graduate School

Florida International University, 2017 


\section{ACKNOWLEDGMENTS}

Many people contributed to the completion of this dissertation. Throughout my course work each of my professors made direct or indirect contributions. My Committee members made direct contributions in time, knowledge, and advice. Most of all I would like to acknowledge Professor Mohiaddin Mesbahi. Dr. Mesbahi provided critical insight into establishing the analytical framework for the study that facilitated its organization, research, and writing. 


\section{ABSTRACT OF THE DISSERTATION \\ ACHIEVING AND MAINTAINING FOOD SECURITY IN THE PRC: THE IMPACT ON FOREIGN POLICY}

By

Paul D. Rittenhouse

Florida International University, 2017

Miami, Florida

\section{Professor Mohiaddin Mesbahi, Major Professor}

The purpose of this dissertation is to examine how the People's Republic of China has used domestic and foreign policy to achieve and maintain food security. This is a formidable task for the PRC given that it has $20 \%$ of the world's population and only $7 \%$ of its arable land. It has been made more formidable by domestic policy errors and its changing position within the international system.

The PRC has evolved from a Marxist revisionist state to one that mixes state capitalism and free enterprise and has become a combination of revisionist and status quo. Such changes lend themselves to process-tracing as a methodology in order to reveal the rationale behind the change and the resulting impact on food security. To capture this evolution, a food paradigm is constructed for various eras that reflect domestic influences on food security. To this is added the international aspect; the choice of what countries it would or could trade with, as needed. Together the domestic and international are combined to obtain a complete view of the food paradigm and resulting food security situation for each era.

In pursuing food security this dissertation will focus on rice, wheat, soybeans, and maize, the prime grains for human consumption and animal feed in the PRC. These 
grains provide much of the caloric intake of the population as well as being the prime reserve products. The results show that these products have been used as a tool of foreign policy to reward or punish other states by adjusting their imports and exports to send political messages as seen fit. The PRC has always maintained a diversified import supply base, but as imports have continued to grow, the supply base is expanding. Expansion is not through land-grabbing but by contract growing by local farmers in less developed countries and leasing land in developed countries, both on previously uncultivated lands. Simultaneously, there are efforts to improve grain production in African countries, among others. Increasing output there will increase total world supply, an indirect benefit to the PRC food security and to its image abroad. 


\section{TABLE OF CONTENTS}

CHAPTER

PAGE

Chapter I - INTRODUCTION. 1

Chapter II - The LEGACY of FOOD SECURITY and the FOREIGN

POLICY of CHINA ...........................................................

Chapter III - MAO ZEDONG and POLITICAL FOOD $\ldots \ldots \ldots \ldots \ldots \ldots \ldots \ldots \ldots \ldots \ldots . . \ldots \ldots$

Chapter IV - DENG XIAOPING and PRAGMATIC FOOD $\ldots \ldots \ldots \ldots \ldots \ldots \ldots \ldots \ldots \ldots \ldots$

Chapter V - FOOD and the LEADERSHIP of the THIRD GENERATION..............199

Chapter VI - LAND GRABS: MAKING LAND MOBILE?....................................257

Chapter VII - CONCLUSION.............................................306

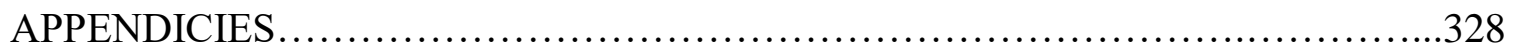

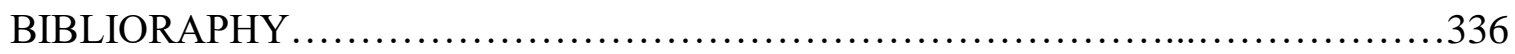

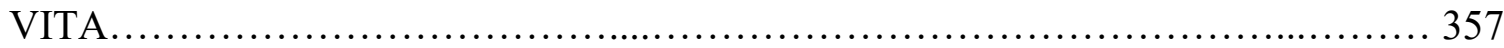




\section{LIST OF TABLES}

TABLE

PAGE

3.1 Indicators of Food Security / Insecurity...................................... 100

3.2 Indirect or Direct Planning Impact on Grain Output............................. 103

3.3 Agricultural Balance of Trade..............................................106

4.1 Material Incentives and the Impact on Grain Output........................... 173

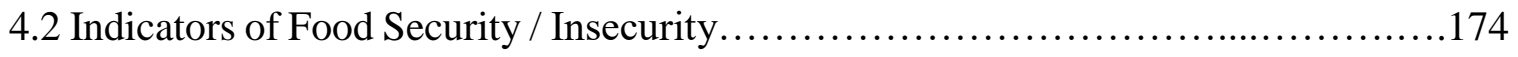

4.3 Agricultural Balance of Trade...........................................174

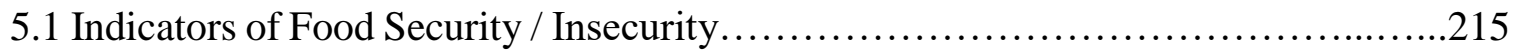

5.2 Grain Production and Arable Land and Self-Reliance............................216

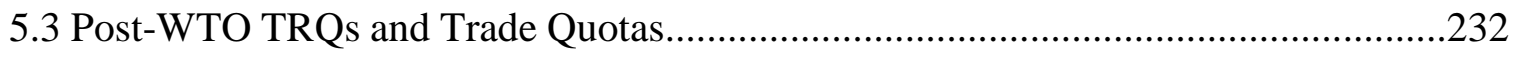

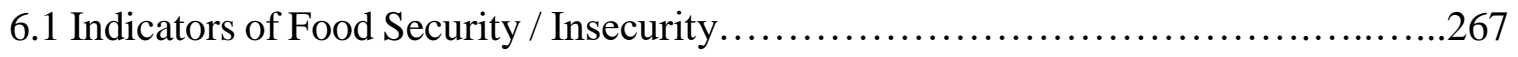

6.2 Grain Production and Arable Land and Self-Reliance.............................269

A1.1 Percentage of Trade Accounted for by Bilateral Trade.........................332 


\section{LIST OF FIGURES}

FIGURE

PAGE

Figure 3.1 PRC Grain Exports to East Bloc.....................................117

Figure 3.2 PRC Grain Exports to West Bloc......................................119

Figure 3.3 PRC Grain Exports to Other Areas...................................123

Figure 3.4 Net Grain Imports and Exports by Region.............................132

Figure 3.5 PRC Net Grain Imports and Exports............................... 134

Figure 3.6 Net Grain Imports and Exports to the Developing World (ex-Latin

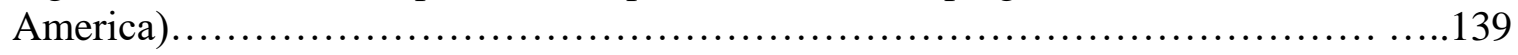

Figure 3.7 Net Grain Imports and Exports....................................144

Figure 4.1 Net Imports and Exports........................................ 182

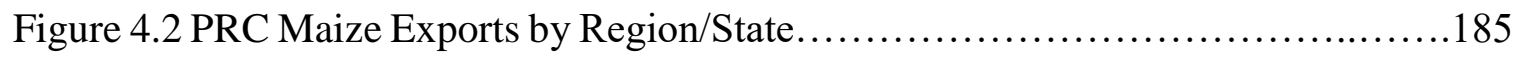

Figure 4.3 PRC Soybean Exports by Region/State.............................. 189

Figure 4.5 Net Soybean Imports and Exports by Region/State......................190

Figure 5.1 Change in Hectares Sown........................................207

Figure 5.2 Net Imports and Exports.......................................210

Figure 5.3 Foreign Direct Investment.......................................212 
Figure 5.4 FIE Exports and Total PRC Exports

Figure 5.5 Self-Sufficiency by Type and Total......................................218

Figure 5.6 PRC Exports to Former East Bloc.......................................2236

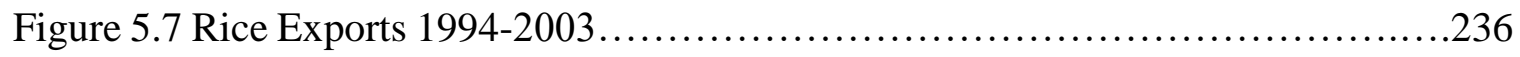

Figure 5.8 Major Wheat Suppliers to PRC.........................................249

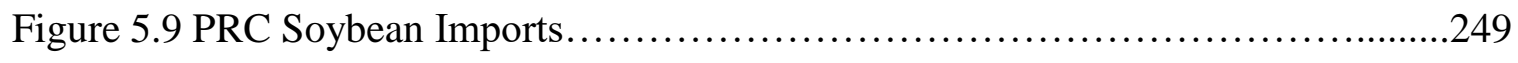

Figure 6.1 Net Grain Imports and Exports..........................................273

Figure A2.1 Net Imports (+) and Exports (-) by Region 1950-2013 _.........................334

Figure A2.2 Net Imports (+) and Exports (-) by Crop 1950-2013 _......................335 


\section{ABBREVIATIONS AND ACRONYMS}

AAPC Advanced Agriculture Producer's Co-operatives

ARF Asian Regional Forum

ASEAN Association of South East Asian Nations

ATDC Agricultural Technology Demonstration Centres

CCP Chinese Communist Party

CMC Central Military Commission

CSM Christian Science Monitor

DPRK Democratic People's Republic of Korea or North Korea

EAPC Elementary Agriculture Producer's Co-operatives

Ha. Hectare

FAO Food and Agriculture Organization

FBS Food Balance Sheets

FDI Foreign Direct Investment

FX Foreign Exchange

FIE Foreign Invested Enterprise

FIRB Australian Foreign Investment Review Board

GDP Gross Domestic Product

GLF Great Leap Forward

GPCR Great Proletariat Cultural Revolution

IGO International Government Organization

IMF International Monetary Fund

NYT New York Times

MENA Middle East and North Africa

MAT Mutual-aid teams 


$\begin{array}{ll}\text { NATO } & \text { North Atlantic Treaty Organization } \\ \text { NGO } & \text { Non-Governmental Organization } \\ \text { PLA } & \text { People's Liberation Army } \\ \text { PLAN } & \text { People's Liberation Army Navy } \\ \text { PRC } & \text { People's Republic of China } \\ \text { PGRS } & \text { Provincial Governors Responsibility System } \\ \text { ROC } & \text { Republic of China or Taiwan } \\ \text { RFE } & \text { Russian Far East } \\ \text { SCMP } & \text { South China Morning Post } \\ \text { SCO } & \text { Shanghai Cooperation Organization } \\ \text { SCS } & \text { South China Sea } \\ \text { SEZ } & \text { Special Economic Zone } \\ \text { SOE } & \text { State-Owned Enterprise } \\ \text { SWF } & \text { Sovereign Wealth Fund } \\ \text { TVE } & \text { Town and Village Enterprise } \\ \text { UNDP } & \text { United Nations Development Program } \\ \text { USD } & \text { United States dollar } \\ \text { WB } & \text { World Bank } \\ \text { WTO } & \text { World Trade Organization }\end{array}$




\section{Chapter I - INTRODUCTION}

Food is an indispensable need for all creatures. In the modern world, states take on the responsibility having food available for its population. This can be accomplished wholly by the state or through a market system or a combination thereof. When a state creates the conditions for a consistent food supply it is said to be food secure. Conditions refer to the domestic policies and trade-offs that affect the growing of crops and raising of livestock plus whatever additional foodstuffs must be imported.

Food is an asset that can be sold or purchased. Normally, states engage in trade when they have surplus food to sell and when they are in a deficit position they purchase food from other states. Whenever food moves from one country to another international relations are involved. Foreign policies, the means a state employs in pursuing its interests, in this case food security, will be crafted to assure food security for those in a deficit position as well as those in a surplus position. The PRC always had a degree of flexibility regarding what countries they purchased food from, and what countries they sold or gave it to. That flexibility permitted trade to be a tool to influence, signal, reward, or punish the states they chose, or did not choose, to engage in trade. Those decisions could be made for food security reasons or for unrelated reasons. So long as a choice existed, the tool carried meaning.

Food security has been an issue in the People's Republic of China (PRC) since its founding in 1949. Food security is an issue the PRC would prefer to solve domestically. When unable to do so, it had to be achieved through engagement with the rest of the world, therefore affecting foreign policy. This dissertation will address the interplay of 
foreign policy and the pursuit of food security to answer the question of how and why foreign policy decisions were made that furthered PRC interests in terms of food security, and its position within the international system.

\section{What is Food Security?}

Human food security is simply having enough to eat, with the proper nutritional and caloric content, to support the population at any stage of life and occupation. It is a basic physiological need, like clothing and shelter, according to Maslow ${ }^{1}$. The Food and Agriculture Organization (FAO) definition is more expansive: "Food security exists when all people, at all times, have physical, social and economic access to sufficient, safe and nutritious food that meets their dietary needs and food preferences for an active and healthy life" (FAO : 2010). Whether the food is grown, purchased, or arrives via welfare is immaterial as long as it is provided. Often, this becomes an issue of distribution (Sen: 7-8). Distribution refers to three separate issues: The need to move food to areas of shortfall which is an economic development issue. It can be an affordability issue caused by higher food prices or reduction in the income of the consumer. Or, it can be the availability of welfare food, either temporary to offset harvest shortages or permanent. $^{2}$

\footnotetext{
${ }^{1}$ Maslow's hierarchy of human needs begins with basic physiological needs (including food) and ascends to safety and security, belonging and social satisfaction, self-esteem, and self-actualization.

${ }^{2}$ Of these two definitions, the FAO definition of food security becomes aspirational when "food preferences" become a requirement to be met in order to achieve food security. Sen's concerns over distribution and entitlements should serve as a reminder that food security will always be an issue with parts of society either on a periodic or permanent basis, a case where food preferences are not an issue and where having enough to eat with proper nutritional and caloric content is the essence of food security.
} 
How would the condition of a state's food security be measured? One measure is the Global Hunger Index which measures the percentage of undernourished, underweight children under five years, and children dying before the age of five. In this index, which excludes the industrialized countries, the PRC has a score of 5.1 ranking it $43^{\text {rd }}$ in the world and above the world average of 14.7 (the lower the score the better). Overall, the PRC score is considered moderate. For comparison purposes, Russia has a score of 4 which is better. The PRC Global Hunger Index score has improved by 50\% since 1990 (Global Hunger Index: 2012).

Another way to measure food security would be total output. Even with a shortage of arable land the PRC is the largest grain producing country in the world due to quite high total output per hectare (ha.). When population is considered, however, the per capita grain production tells a different story.

Food balance sheets (FBS), compiled by the FAO, are another way to measure food security. The object of the FBS is to arrive at the per capita caloric intake available for a country. It includes net domestic production of all categories of food (grains, vegetables, fruits, dairy, and animal), contributions or withdrawals from stocks, imports and exports, uses for seed, animal feed, industry, and processing loss, to arrive at the total calories (of protein, fat, and energy) available for human consumption. ${ }^{3}$ The FBS method of measuring food security is the most complete and comprehensive. However, it fails to account for distribution issues that appear, indirectly, in the Global Hunger Index. By

\footnotetext{
${ }^{3}$ Using grain as an example, the net production of wheat would take the harvested grain and subtract the amount needed for seed for the following season, wastage, processing losses, uses other than food, and animal feed.
} 
definition, the FBS takes into account total output which is a crude measure of food security, yet is also the basis for it.

In pursuing food security this dissertation will focus on rice, wheat, soybeans, and maize, the primary grains for human consumption and animal feed in the PRC. These grains provide much of the caloric intake of the population as well as being the prime reserve products. There are other factors involved in achieving food security including water availability and quality, and elements of climate change. These issues are extremely important but are beyond the focus of this dissertation. However, as with crops other than grains, they will be included should they shed light on the primary topic.

\section{Food Security and the PRC}

The history of China has been one in which the availability of food has always been of paramount concern for the population and the leadership. A subsistence-based agriculture needed good growing conditions to assure the basic means of survival. The imperial leadership needed a surplus to extract from each harvest to support the government's needs, what urban population there was, and to supply the grain reserves that served as insurance against a bad harvest (Li 2007). Without a good harvest, segments of the population faced food insecurity; back-to-back bad harvests could lead to disaster.

The rapid growth in the Chinese population in the last half of the $20^{\text {th }}$ century sent the total to well over a billion. Now, approximately $20 \%$ of the world population lives in the PRC, a country with approximately $7 \%$ of the world's arable land. Historically, China has been able to meet the growing demand for food through expansion of agricul- 
tural activities to unused land. In the current era of modernization, agriculture faces intense competition for arable land. Improved and larger housing, roads, industrial estates, dietary changes related to increasing wealth, and even golf courses all remove land from agricultural pursuits. In the case of dietary changes, increased meat consumption results in increased demand for feed grains, and decreased demand for grain for human consumption. This issue is compounded by environmental concerns including overall pollution, decreasing water quality, climate change, and increasing desertification. Hence, intensive agriculture practices have had to replace extensive practices to increase the food supply.

While China faces these problems, the world does also. There is concern in the world regarding the projected population increase to about 8.3 billion in 2030 from about 7 billion today (Human Development Report, 2011: 165). ${ }^{4}$ How will all of these people be fed? Many people have raised this question, Paul Ehrlich and Lester Brown being two of the most published on the subject. ${ }^{5}$ Couple the total population growth projections and increasing life expectancy, and the pressure on the food supply will grow.

In the years since the establishment of the PRC, the Chinese Communist Party (CCP) pursued a number of agriculture policies to meet the ideals of a communist state, before stepping away from those ideals to meet the growing demand for food as well as economic development. First, there was land redistribution then collectivization to meet communist ideals. Poor performance in agriculture under collectivization led to famine,

\footnotetext{
${ }^{4}$ IFPRI suggests that a population of 9 billion will consume at the rate of 12 billion should consumption trends follow those of the industrialized world. (Global Hunger Index:2012, 4)

${ }^{5}$ Brown's 1995 book, Who Will Feed China? is said to have had a profound impact on the PRC government despite the advances made in the previous 25 years. (Crook: 63)
} 
and the need to sacrifice ideals to improve output. This was accomplished through de-collectivization, freer markets, regional self-sufficiency, farm subsidies, and the limited use of comparative advantage domestically and internationally. Once free of the transitional politics of agriculture, government efforts have been focused on maintaining control of the PRC's food supply to the greatest possible extent. Control relates to both price stability and assured supply. Domestically, regional self-sufficiency directives are an attempt to minimize regional price differentials. The attempt to maintain agricultural land has led to a minimum acceptable amount for agricultural activities, according to the State Council. The national "red line" of 120 million ha. of arable land should not be violated due to concerns over grain security. ${ }^{6}$ Trade in agricultural products, once an action of last resort, is accepted as necessary. However, to maintain as much control as possible, acquiring land in foreign countries to grow crops for consumption in the PRC is being pursued (Zhang, 2011: 2). ${ }^{7}$

All of these policy shifts have been implemented against the backdrop of the PRC attempting to realize its perception of its "rightful" place in the community of states, that of a Great Power. As with domestic agricultural policy adjustments, foreign policy changes have also been occurring. These have ranged from ideologically based "leaning" to the Soviet model then adding Chinese characteristics to that model, forsaking the international system and attempting to create and lead the developing world. Then, the PRC

\footnotetext{
${ }^{6}$ Xinhua, August 14, 2008. Accessed 8/12/13.

${ }^{7}$ International "land grabs" have been reported extensively, yet inconclusively by many newspapers, NGO's, and international organizations such as the World Bank, FAO, IFAD etc. This will be covered in Chapter VI.
} 
reversed itself by seeking protection within the balance of power framework through rapprochement with the U.S. and a pragmatic engagement with the world to assist in the modernization of the PRC (MacFarquhar: 1987; MacFarquhar, 1991).

\section{Food Security Solutions}

In the long term, a state with a food security issue has three choices of how to solve the problem. First, it may pursue a domestic solution, increasing domestic supply. Second, it can look to trade to obtain its food security. There is also a third, but very long-term method; it can take steps to reduce its rate of population growth, so that the long range potential of agricultural capabilities and population are consistent. In this section we will discuss domestic and trade as solutions to achieve food security. Trade, the "low politics" of international relations, requires that we understand the PRC's guiding principles in dealing with the outside world. Once we have determined that, later in the chapter we can look at how food can be used as a tool of foreign policy.

"In the short run with given food supplies, the challenge is buffer stocks, open trade, and transfers to match food availability with individual food needs" (Tweeten: 1999, 482). The PRC tended to rely less on trade and more on buffer stocks and controlling demand to assure food security. Farmers were allowed to keep $250 \mathrm{~kg}$. of grain per adult, with less for children and the elderly, to sustain them until the next year's harvest. Urbanites had their consumption controlled via rationing, starting in 1953 (Rada: 1983, 521) for grain, pork, and oil (Chinn: 1980, 744-8). Food stocks are maintained by the government and continue to be state secrets. Rada references a writer who claimed reserves reached 80 million tons in 1975 , but he believes that was only a target amount and 
in any case was such an extremely large quantity by any measure that it would have been impractical to collect or store (Rada: 1983, 529). These are traditional methods to compensate for poor weather conditions and in some cases to affect the cost of grain.

Longer term, for a country that suffers from food insecurity, the fundamental reason must be that population is too high for the existing productive capacity of its arable land. Domestic solutions to food security may be limited by natural endowments, soil quality, climate, and water availability being the principal ones. With those constraints there are methods to alter the structure of agriculture, the production, distribution, and consumption patterns of a given state.

With respect to production, financial incentives for farmers to produce more are the quickest ways to improve output. Financial incentives can be through higher crop prices, either direct or via subsidies, through lower taxes, or for subsidized inputs. Altering the legal structure of land ownership was another way to increase output. Giving land ownership to the farmer provides incentives to grow more as the farmer will be able to receive the benefit of all of the increased output. The application of science also increase output. Better seeds, the use of chemical fertilizers and irrigation are proven to increase output.

Improved distribution networks of grain can also improve output in two ways. First, they allow for the use of comparative advantage, growing crops in the areas they grow best rather than having to produce a non-optimal mix of crops in order to have some of all types. Second, it allows grain to be moved more quickly and efficiently to areas that find themselves in a short-erm shortage position. Finally, there can be changes in consumption patterns. Financial disincentives can be used to drive the prices of some 
products higher so that consumers will opt for less expensive ones that can be grown in greater quantities.

An indirect way to provide food security is to develop non-agricultural products that can be exported to earn foreign exchange (FX) that can be used to purchase food from abroad. This is a common practice for countries without the natural endowments or an insufficient arable land / man ratio to be self-reliant in food. In the coming chapters we will see how the PRC used all of these techniques in order to increase grain output, as well as disincentives that did not work well.

\section{Theoretical Framework}

Since 1949, the PRC has gone from a Marxist state to a nearly capitalist one; from a revisionist state to nearly a status quo one; from a poor and undeveloped state to the second highest national GDP in the world; from a taker of norms to a maker of norms in international government organizations (IGO); from a state that relied on human strength for economic and military accomplishment to one that uses advanced technology and has nuclear weapons. This study will involve PRC domestic policies, economic development, international politics, foreign policy, and international trade. The best way to approach wide range of disciplines is through process tracing. Process tracing is applicable as this story requires a thick descriptive examination that ebbs and flows over time and is based on qualitative information. (Collier: 2011, 823-830; Bennett and George 1997).

Process tracing has also proved to be appropriate for analytic eclecticism according to Alice $\mathrm{Ba}$; "The process of tracing...particular ideas over time revealed the importance of process... and pattern of ideational-material interactions...” (Sil \& Katzenstein: 2010, 
199). Yet, "It does not make sense to pursue an eclectic approach as a research goal. Rather eclecticism is the unintended result of research that seeks to explain specific events as well as possible" (Schimmelfennig quoted Ba: 2010, 15).

Once process tracing leads the need to seek to explain what has happened, the traditional approaches of realism or liberalism might be employed to identify causation. Should a specific paradigm, theory, or discipline become the sole frame of reference for a study, the foundational assumptions of the chosen paradigm may preclude complete understanding (Sil \& Katzenstein: 2010, 10; Sil: 2000, 1-21). To explain, understand, and gain insight, "analytic eclecticism" is an appropriate approach, especially given the magnitude of changes that have occurred since 1949. Sil and Katzenstein offer pragmatism as the method of inquiry within analytic eclecticism for several reasons. Applying pragmatism to analytic eclecticism, and the study of international relations, first "implies that competing perspectives need to be reformulated in order to facilitate novel efforts to constitute and solve a problem." Second, it bypasses paradigmatic rigidity "in favor of openended efforts to frame, and address socially important problems facing actors in a social world." Third, it "emphasizes creativity in adapting and recombining elements of theoretical knowledge produced by separate research communities." Fourth, it "eschews rigid boundaries and hierarchies in the production of knowledge, encouraging reflection and deliberation..." (Sil \& Katzenstein: 2010,47).

Sil and Katzenstein regard realism, liberalism, and constructivism to be the leading paradigms of international relations and are worthy of inclusion within analytic eclecticism. Marxism also will be noted due to its influence in the early decades of the PRC. 
Given the dramatic changes that have occurred during the PRC era, all four may offer insights into that evolution and will assist in evaluation. Such an approach will assist in evaluation of the food security issue over time, just as the PRC leadership has evolved in its thinking over the same time frame, to address a question that involves multi-dimensional tradeoffs that have practical implications and ultimately can be best explained and understood outside of single paradigm limitations.

\section{Marxism}

The PRC was formed through a successful revolution that brought the victorious Communist Party to power. Marxism addresses human security only through class tensions, the proletariat and peasantry against the bourgeois, and not until that dynamic is superseded by ownership of the means of production by the proletariat and peasantry will that tension be addressed (Pettman: 2005, 10). Marxism was supposed to improve the quality of life for the peasantry and the laboring classes.

The failure of communization, and the Great Leap Forward (GLF) and the need to recover from them introduced the first attempts to soften the impacts of Marxist communal organization. ${ }^{8}$ From this point on, there would be a constant debate on the extent of state involvement in the economy. Put another way, where should the PRC be in relation to the communism / socialism / capitalist continuum. The debate continues today but is focused only on the socialist / capitalist end of the spectrum.

\footnotetext{
${ }^{8}$ This was the time that Deng Xiaoping used the phrase "it does not matter whether the cat is black or white as long as it catches mice," a metaphor for ideology not mattering so long as the results were positive.
} 
The Marxist fixation on class tensions left little room for any discussion of foreign policy. The successful conclusion of Marxist theory would have worldwide government by and for the proletariat without national distinction, thereby obviating the need for foreign policy. Lenin supplied a foreign policy aspect to Marx when he created the Comintern as a vehicle to "promote class war everywhere outside Russia, to convert imperialist war into civil war, and to further the cause of world revolution" (Hopper: 1941, 737). While this was essentially a Russian / USSR foreign policy, it provided a prescription of action for future communist governments. The PRC continued this tradition during Mao's reign, particularly in Southeast Asia.

\section{Realism}

Classical realism holds that units (states) are differentiated, rational, and therefore interested in acquiring power in order to protect their interests, of which the primary one is survival of the state. To assure survival, the acquisition of power is an unending task, made necessary by an anarchic world full of surprises. How much power is needed to survive is an unanswered question, knowable only once states engage in conflict. Therefore, realists seek relative gains in all material capabilities. In that way they are always gaining on those with more power or lengthening their lead in power. Hans Morgenthau, a leading realist, includes human nature in his realism and applies morality to his realism. Human nature, the fundamental traits shared by humans, is at the root of man's objective laws and will be challenged only by those willing to risk failure. Morality enters as a principle that must be acceptable to both man and the state. The morality of one state is not necessarily more moral than that of another (Morgenthau: 1978, 12-3). With respect 
to trade-- a key aspect in this dissertation-- classical realism maintains that trade exists because the state permits it, and in an anarchic world, only the state alone can provide for its best interests. Shambaugh calls realists in the PRC "'China Firsters', caring little about the interests of other countries or constituencies in world affairs" and maintains that they are the dominant school of PRC international relations thinking (Shambaugh: 2013, 31).

Neorealism or structural realism posits that the international system is controlled by major powers, each with the overriding goal of survival in an anarchic world. Survival requires power. But contrary to classical realism, the amount of power required is only that sufficient for survival, not a never-ending acquisition of it. When one state or a group of aligned states become too powerful, neorealism maintains that the other major powers will align to balance the perceived power of the other(s), thus keeping the international system in balance and away from war (Waltz : 2006, 116-23). The problem with neorealism is that it operates only at the international level considering great powers and dismisses domestic and leadership considerations of states. Waltz explicitly says that neorealism is a systemic theory that precludes reduction in the level of analysis to the unit or individual levels, and therefore foreign policy as well (Waltz : 2006, 121-3).

Neoclassical realism offers the best approach within realism as a whole. While accepting the neorealist structure of Waltz, neoclassical realism explicitly accepts the idea that domestic policies have a bearing on the foreign policies of states. "It explicitly incorporates both external and internal variables....adherents argue that the scope and ambition of a country's foreign policy is driven first and foremost by its place in the international system and specifically by its relative material power capabilities....however, 
that the impact of such power capabilities on foreign policy is indirect and complex, because systemic pressures must be translated through intervening variables at the unit level." (Rose: 1998, 146) Lobell et al maintain that states "conduct foreign policy based upon their assessment of relative power and other states' intentions, but always subject to domestic constraints....threat assessment, strategic adjustment, and policy implementation are inherently difficult and may entail considerable bargaining within a state's leadership and with other stakeholders within society" (Lobell, Ripsman, \&Taliaferro: 2009, 25-6). Further, under both Mao and Deng Xiaoping, the unit level was driven by their position or the prestige of the leader, a further reduction in level of analysis.

Neoclassical realism provides us with a systemic view of world politics while incorporating foreign policy, which will add the reductionist aspect Waltzian neorealism discounts, to better understand the interactions between systemic, regional, interstate, and domestic issues in play continuously and at times of changes in the PRC food policy. After all, PRC foreign policy is predicated on its domestic policies and situation. Former PRC Foreign Minister Qian Qichen made the statement, “diplomacy is an extension of internal affairs" (quoted in Gurtov: 2010, 14).

Given China's "century of humiliation," (1840-1949) it would seem that neoclassical realism would be the proper lens through which to evaluate the PRC's foreign policy and food security. However, given the increasing involvement of the PRC in the organizations that encompass an incomplete (and always incomplete) form of world government, realism should be questioned as the only appropriate lens. Liberalism may provide additional insights unavailable to a strictly realist point of view. 


\section{Liberalism}

Liberalism, especially in regards to trade, will play an important part in this study. The "bottom-up" approach of liberalism runs counter to realism. It looks at the individual as a relevant actor and at how individuals coalesce into groups and make collective decisions. It incorporates this into views of economics and world politics (Keohane, 2002).

Liberalism is characterized by its belief in markets and in trade and that trade reduces the probability of conflict. Regarding to trade, liberalism sees it as mutually beneficial and directed from the bottom up to take advantage of market opportunities. Liberals see absolute gains from trade as being beneficial; this contrasts with the realist view that successful trade results in achieving relative gains. The PRC treatment of trade has spanned both the realist and liberal paradigms and neoliberal institutionalism within the framework of liberalism, as evidenced by its membership in the World Trade Organization (WTO), World Bank (WB), and the International Monetary Fund (IMF). By joining these IGOs, it must abide by the rules and norms of the organization. Theory holds that states that join international organizations are able to achieve more as the behavior of states moves closer and closer to the expectations of the organization (Karns \& Mingst: $2010,42)^{9}$. Regime Theory also holds that regime members are less likely to use coercion against another member (Russett \& Oneal: 2001, 193-6), and that trading states are less likely to engage in conflict (Russett \& Oneal: 2001, 145-8).

\footnotetext{
${ }^{9}$ A realist institutionalist would maintain that the PRC joins these international organizations in order to change the organization from the inside and remake it into an organization corresponding to the way the PRC sees the world.
} 
Another element of liberalism is the decreasing efficacy of military power to settle disputes. This is manifested in the globalized world where power projection is more difficult due to distance and the trade regime that currently exists, which, though still with problems (especially in times of real or perceived crisis), uses the market to allocate scarce resources (Keohane \& Nye: 2001, 23-5, Rosecrance: 1986, 16). Perhaps the world is approaching a point where economic competition will supersede dispute resolution by force.

As coercive power is becoming less efficacious the use of soft power is increasing. Nye refers to co-optive power as getting others to want what you want. It can be accomplished through the use of soft power resources: culture, ideology (ideas and practices worth emulating), and international institutions (Nye: 1990, 167). The PRC has a strong interest in soft power and pursues it through its development model: non-interference in domestic affairs of other states, and promotion of Chinese culture (Cho \& Jeong: 2008, 456). ${ }^{10}$ Soft power is and will be important in the discussions on food security and foreign policies of the PRC, especially within the developing world. The PRC, consistent with its desire to lead the developing world, has invested resources and people in Africa to improve agriculture there. This can payoff for the PRC by increasing the gross availability of food in the world (most likely) or by becoming an export market for African food products. It also provides the PRC with additional allies, especially in UN voting. It

\footnotetext{
${ }^{10}$ Cho and Jeong acknowledge Nye's work on soft power as a catalyst in the PRC's thoughts and pursuits of the subject. They point out that China scholars eventually decided Nye's version of soft power was an American version and that the PRC needed to develop soft power tailored to the needs and abilities of the PRC.
} 
is worth mentioning here that while soft power can be a tool for getting others to want what you want, if not done well it can demonstrate that your way is not to be followed.

Liberalism is important in understanding the way that the PRC has come to interact with the rest of the world in regards to trade, interdependence, soft power, and how it operates within the context of IGOs where food is an issue of importance. Liberalism offers a way of looking at today's world from an economic power base as opposed to a military based power.

\section{Constructivism}

Constructivism, with its focus on identity, ideas, and agency, appears to be the paradigm that will help close the gap between paradigms and to offer understanding of the many changes that the PRC has implemented.

The PRC has the long history of imperial China on which to draw for its identity. ${ }^{11}$ However, to differentiate itself from the past, Mao denigrated previous aspects such as the Confucian hierarchical society in order to move the PRC into an egalitarian future. At the same time, in identifying initially with the Soviets, Mao, as Deng did later, added the aspect of "Chinese characteristics" to communism and a market-based economy, respectively. Not only did this separate the PRC from standard understandings of those terms, it served to add the exceptionalism or uniqueness of the Chinese past to the

\footnotetext{
${ }^{11}$ The foreign policy of Imperial China provides an excellent example of constructivism. The superiority of the Chinese state (identity) was acknowledged by tributary states that in turn received trading privileges. In following the procedures laid down by China (norms) the system continued and served to maintain a peaceful relationship (interests). Further, tributary states tended to apply the same system to other states, furthering the established normative behavior. See Chapter II for more detailed information on the tributary system.
} 
PRC present. The changes that have occurred in the PRC are the result of ideas and the effect of agents modifying the structure or patterns of behavior that were in place at the time. None had a greater impact than Mao as an agent, but the structure that his agency created was weak. He took action based on his desires and beliefs but could not transcend the imperial structure and culture created over the previous 2000 years. The unintended consequence of Mao's choices was the modification of his egalitarian and revolutionary goals. The intended goals of Deng, to re-introduce material incentives to production, were successful, yet potentially brought with them the unintended consequence of desire for political liberalization. As the PRC has engaged with the world, accepting the norms of IGOs has modified its behavior. Simultaneously, it has attempted to modify international behavior in seeking to modify IGO norms.

Constructivism will be used to work with the ideas and identities associated with the PRC and its leadership. One could say that the PRC continues to be in a stage of constructing its identity. As mentioned above, it has taken on several since 1949. Implicit in that is the change of interests that accompanies the change in identity. Personal identities, "tell you and others who you are and they tell you who others are" (Hopf: 1998 175). Identities are formed intersubjectively, an interaction between the self and the other. States have identities also, intersubjectively determined that give other states an indication of behavior predictability, a need to prevent chaos (Hopf: 1998, 174). When identities are not determined intersubjectively, a state's internal perception may be inconsistent with the perception of other states, and chaos or misunderstanding and its consequences may occur. 
Wang uses textbooks to depict the CCP version of national identity. The national identity narrative of the PRC, depicted in textbooks, was first one of the triumph of the revolution and class struggle. This continued until the 1989 Tiananmen incident which served as the catalyst for revision. The revision of textbooks was completed by 1991 and stressed victimization of China by the West and had a strong dose of nationalism. ${ }^{12}$ Wang sees the change in the presentation of national identity as also giving the $\mathrm{CCP}$ a reason for being following Tiananmen (Wang: 2008, 790).

Increased nationalism serves to cause overreaction to real or perceived provocations limiting the PRC's flexibility on the domestic and international fronts. But it is also consistent with the PRC position of non-interference in the internal affairs of other states (and therefore the internal affairs of the PRC).

Interests are derived from identity. States pursue their own interests in order to maintain state-society arrangements, which serve to constrain their foreign policies. To do so, state survival, autonomy over resource allocation, economic well-being, and collective self-esteem are the overriding interests of the state (Wendt, 2003: 235-7). Issues faced by the PRC (and many other countries) are the trade-offs that must be addressed within domestic resource allocation to be successful in meeting the other interests consistent with identity. Wendt may be correct that satisfying those interests constrains foreign policy. However, the natural endowments of the state may also serve to enhance foreign policy options as well as to constrain them.

\footnotetext{
${ }^{12}$ Wang cites Callahan saying that the National China Library maintained that no new "national humiliation" books were published between 1947 and 1990 (Wang : 789).
} 
The litany of changes within the PRC since its inception is extensive. At the international system level, it has aligned with both superpowers and has twice followed independent foreign policies. At the state level, its economic approach has moved from egalitarian to materialist; at the individual level, from the charismatic leadership to a bureaucratic one. The PRC actually has a dual problem in its identity. Not only does it have to construct / confirm a national identity, it must also maintain the identity and interests of the CCP. To maintain power, the ideology-driven $\mathrm{CCP}$ is the institution that has moved towards materialism to improve the economy and the living conditions of the citizens. That movement is incomplete given the high Gini coefficient, rule by man not law (especially with regards to private property), and a political system facing small but increasing demands for additional popular input.

The emphasis on ideas, identity, interests, and agency and the state-society relationship that constructivism emphasizes will add an important element to this study. It provides a means to dig into the thoughts of actors at the unit level and the resulting thoughts and actions that apply to the unit operating in the international system. This will be important in any study of China given its relative reclusiveness starting in the Ming Dynasty and its attempt to reestablish itself as a Great Power.

\section{Constructing a Food Paradigm}

To understand the dynamics of the PRC food supply, a food paradigm will be constructed. The food paradigm will be the attributes and policies of the country that the government employs, or influences, to achieve (or fails to achieve) food security for its 
citizens. It is a function of natural endowments and the result of the state-society relationship, food production and distribution capabilities or economic development, and population size. At any point in time, the existing food paradigm can be evaluated to determine the efficacy of its ability to deliver food security, the outcome of the strategies and tactics used to meet the objective of food security. Operating under policies of autarky and self-reliance, the food paradigm would be strictly a domestic issue. Under conditions of self-sufficiency, trade with the rest of the world would make up for domestic production shortfalls in the food paradigm. ${ }^{13}$

Each of the elements of the food paradigm is inter-related where a change in one can have either a positive or negative impact on the other(s). The origins of the food paradigm, excluding natural endowments, can be found in domestic politics and economic

\footnotetext{
${ }^{13}$ Self-reliance and self-sufficiency present definitional problems. Using FAO definitions, self-sufficient "implies meeting food needs, as far as possible, from domestic sources and minimizing dependence on trade." Self-reliant "takes into account the possibility of international trade...implies maintaining some level of domestic production plus generating the capacity to import from world markets as needed" (FAO, 2000). These two terms tend to be used interchangeably. When Ministry of Agriculture states that the PRC is 95\% self-sufficient in grain and imports will make up the shortfall, there is a dependence on imports. Implicit in the PRC comment is that they will have sufficient resources to pay for the imported grain, most likely from the earnings of other exports. This meets the need for imports in both FAO definitions. According to the FAO, the term "self-reliant" should have been used.

The Chinese term for self-reliance is zili gengsheng meaning "regeneration by one's own efforts" (Kerr : 2007,6). In the initial decades of the PRC, self-reliance was the development modality. The rebirth of the Chinese nation and the birth of the PRC were to be achieved internally. Foreign elements were eliminated in some areas and used as little as possible in others, thus ending the foreign domination of the previous 100 years. Development could occur anyway just as the People's Liberation Army (PLA) was successful against the Japanese and the Nationalists by being self-reliant, so could the PRC as a whole. Wu defines the PRC as "a country committed to a policy of self-reliant development [that] will not engage in the type of transactions that would undermine its goal of national independence or violate its own unique developmental vision" where that vision is a "militarily strong, economically self-sufficient, and politically autonomous China" (Wu : 1981, 452).

Self-reliance and self-sufficiency are not only applied to the PRC as a whole but also to regions within the country. This resulted in a low level of regional specialization and division of labor and therefore the absence of comparative advantage. Following the departure of the Soviets, economic development policy was based on import substitution and self-reliance. Trade was considered a residual activity to be engaged in so long as imports and exports were balanced (Wu : 1981, 458).
} 
development, both of which are based on ideology that sets constraints on domestic politics and economic development methods. The elements of the food paradigm are the result of or influenced by the state ideology and the economic development model selected to achieve modernization.

\section{Natural Endowments}

The most basic aspect of the food paradigm is whether a state is sufficiently endowed with the natural resources (arable land, soil quality, and climate) to support its population. Arable land is not a static situation; it can be increased through irrigation or the introduction of crops that can grow in less arable lands as well as other ecological adjustments such as re-forestation. Increases are medium-term enhancements for agricultural output and add only marginally to the stock of arable land. Irrigation is limited by availability of untapped water sources and may require significant investment, i.e. dams. Arable land can also be diminished by alternative uses. This can occur quickly regardless

of rules in effect to prevent it. Alternative uses represent a greater threat to food security than does the benefit of increasing arable land, especially in the short term. Within the food paradigm, changes in arable land will be dealt with in economic development and domestic politics.

\section{Domestic Politics}

In the PRC, domestic politics reflect the political discussions that occur at the highest levels of government. The outcome of such discussions demonstrates which faction enjoys the power to implement its programs. It is at this level that decisions are 
made and the speed at which they are implemented determined. Splits within the leadership have generally been over the speed and extent of changes. Liu Shaoqi thought collectivization proceeded too quickly while Mao thought it was too slow. When Mao's policies failed, as during the GLF, power switched to Liu, Deng, and Chen Yun until Mao was able to regain the upper hand. Similarly in later years, Deng wanted to accelerate the pace of reforms but was held back by leftists who objected to the extent of reforms in the domestic economy or by those who objected to the speed of reforms. Despite political recriminations for those who differed with Mao over the economy and Deng over CCP control (in stopping the 1989 protests), major changes have occurred in ideology through domestic politics that have not been successfully replicated elsewhere.

The transition from state-centered redistributive economies to a market-based distributive system has had differing results in different areas, Russia, Eastern Europe, and the PRC. The means have differed but only in the PRC was there economic change without a change of regime. Tsou maintains that regime type and the state-society relationship are "...separate dimensions of a political system. While the regime type remains the same, state-society relations can undergo important changes....This is one reason why those who use this concept (1) do not see any possibility for radical change without a revolution and (2) cannot adequately explain changes in state-society relations that have been initiated or at least supported by those in power." (Cited in Cui: 2000, 197). In the PRC, there has been no revolution and state-society relations have changed, but remain weighted towards the state.

Sun maintains that the success that the PRC has had in transforming its economy while maintaining the regime has come about for several reasons. 
“...Chinese reform has been the subject of ceaseless ideological debates...the debate over the legitimacy of the market economy, the debate over the stock market system..., and the debate over privatization...This ideological background constitutes an extra cost of reform. To minimize this cost, the reformists have adopted two strategies. The first is to incorporate new reform plans or new elements of the market into the preexisting ideology. An example would be the concept of 'socialist market economy'. The second strategy is to 'put aside the debate,' which in practice means being able to do something, but not able to talk about it" (Sun: 2008, 108).

This explains the start and stop progress in reforms as reformers wait for conservatives to catch up or for reforms to prove their effectiveness. It also explains the language of change and the use of the term "with Chinese characteristics" rather than the mixing of ideological terms.

Regardless of the overall orientation of domestic politics, there are always differences of opinion on how best to address specific issues. Even if they are ideologically consistent, there will be disagreements to be resolved on policy implementation. For example, agreement on the need to invest in industrial modernization in the PRC may be the agreed-to policy. Yet, the allocation of funds among heavy industry, light industry, and agriculture was contested among differing points of view (Lardy:1995, 180-4). 


\section{State-Society Relationship}

The state-society relationship refers to the distribution of power between the state and society (Kang and Han: 2008, 50). ${ }^{14}$ The actual measurement of power would come from the relationship of public goods provided either by the state or by society (Kang and Han: 2008, 38). In a totalitarian state all public goods would be provided by the state. Prior to the onset of reforms in the PRC, the public good of housing was provided by the state; the danwei provided housing through the workplace for urban residents and through the commune for rural residents. When the state was the only legal buyer of crops in the PRC, the state provided the public good of allocating food to its citizens. In contrast, a market-driven state would rely on society for most public goods.

There has been radical change in the structure of the economy as well as the options available to the population, for example, in terms of choice of work and in the freedom to travel. These "freedoms" were granted by the state in order to affect modernization and improve opportunities for lives to improve. Society has acquired a larger degree of power (or choice) versus the state. But the state continues to have the ability to re-impose itself on society, but probably not to the degree of pre-reform times.

Civil society is the realm of the social, economic, and moral order that lies outside of state control. In the PRC, civil society is not what would be expected in a democracy.

\footnotetext{
${ }^{14}$ The state-society relationship is included as a key variable in both domestic politics and the food paradigm. At the domestic political level, it represents for all aspects of state's relations to society. Within the food paradigm, it represents only those aspects concerned with food security. For example, at the domestic political level, the state-society relationship might include a state-sponsored medical care scheme that would not have a bearing on the levels of food security nor the food paradigm. A plan to maintain a certain amount of land for agriculture, created at the domestic political level, would have an impact on food security and therefore would be considered part of the food paradigm.
} 
One might take the position that there is no civil society in the PRC unless it is granted by the government, which in effect maintains state control. Miller maintains the PRC has a corporatist model of civil society that "emphasizes communication and cooperation between state and society instead of a social field independent of the state. In addition, corporatism emphasizes a monopoly of functional organizations instead of free competition among social organizations. Such functional organizations can negotiate with the state for their members' sake on the one hand, and on the other hand they must make a commitment to enforce public policies among their members" (Miller cited in Kang and Han: 2008, 50).

As opposed to the corporatist model, or the totalitarian model where the state has complete control of the power in the state-society relationship, Kang and Han offer a model of graduated controls for the PRC, predicated on the perception of threats to the state. "...the government implements different control strategies with respect to different social organizations according to their different challenging capabilities and the character of public goods they provide." Politically antagonistic organizations would be banned as they have publicly challenged the government. Trade unions and community organizations that have the potential to challenge the government would be converted to quasigovernmental organs to increase control. Religious organizations with a strong possibility of challenging the state would be limited in their growth. Business and commercial associations and official Non-Governmental Organizations (NGO) are capable of only a weak 
challenge and provide public goods; they are encouraged and supported by the government. Grassroots NGOs and informal organizations with no capability to challenge are simply ignored (Kang and Han, 2008, 49). ${ }^{15}$

The PRC offers additional state-society relationship challenges. What the central government says and does may differ from the actions of provincial and / or local authorities. In the commercial realm, the central government may agree to intellectual property protection at the international level but there is no enforcement at the local level. In the area of agriculture, maintaining arable land may be accepted at the national level but converting farm land to a housing complex may offer locals a profit opportunity they cannot resist. The center / periphery issue within the PRC is one that has plagued China for a long time despite the power of the state.

The state-society relationship in the PRC has changed significantly in some areas and only marginally in others. For purposes of the food paradigm, the change to a more market-based economy has given the farmers the choice of crops to grow and the population more choice in the foods they consume, as opposed to what the rationing system provided. This, as we will see, has altered consumption habits and created a knock-on effect that has impacted the food paradigm.

\footnotetext{
${ }^{15}$ The graduated control model also provides the government an instrument of policy. For example, control of trade unions can be used to reduce the call for worker safety at times or be used as an instrument to enforce safety issues or increase wage levels.
} 


\section{Population}

The population aspect of the food paradigm is closely aligned to the state-society relationship and demonstrates the continuing power of the state. Population growth can be subject to national policies to influence or compel human reproduction, internal migration, immigration, and emigration that affect the total population. The demographic transition, the change from a high fertility / high mortality condition to one of low fertility and low mortality is generally attributed to industrialization, urbanization and individualism (Johnson-Hanks: 2008, 302) and more recently to government social programs. Despite conditions that were not conducive to demographic transition, discussions on population control began in the 1950 s, at a time when a growing population was considered a sign of national power.

Control of internal migration was recognition of the inability of the state to feed an urban population greater than what existed at the time. That said, such constraints may have prevented the development of extensive urban slums, not an uncommon occurrence in the developing world.

\section{Economic Development}

The structure of agriculture is influenced by the structure of the economy and vice versa. A state with $80 \%$ of the population involved in agriculture, barely above subsistence level, is an underdeveloped economy. Modern economies today tend to have less than $5 \%$ of the population involved in agriculture with the majority involved in secondary and tertiary pursuits. 
Grain production and economic development were a symbiotic relationship. Economic development was in need of increased agricultural production for the raw materials of light industry, a stepping stone to heavier industry. Additional food would need to be provided for an urbanized workforce, required for modernization and industrialization. Additional knowledge and skills would be needed to operate an economically developing economy and in a developed economy. The supply of labor for this undertaking would have to come from the rural population, those who grew the food. What FX was needed to facilitate development would have to come from agricultural exports.

For international political reasons the PRC selected the Soviet model of development, probably a poor, but politically correct choice. Self-reliance, the second option, did not fare well either. It was not until nearly 30 years later that a development model, modelled after successful development policies of its neighbors, did the PRC find a route to what had been sought in 1950 .

Overall, the reforms beginning in 1979 have loosened state control over parts of the economy. Allocation of state funds towards public goods, particularly in transportation, has improved economic efficiency. Together these changes have increased the production and distribution capabilities of the PRC. Explicit in economic development is the need and desire to become involved in international trade. The PRC could no longer afford to be both self-reliant and to develop economically. Food production and distribution are elements of the national economy that have benefitted from these changes. 


\section{Summary of the Food Paradigm}

The food paradigm tells us the results of the thinking about the food supply and the policies implemented to reflect that thinking and supply the population of the PRC with domestically produced food. Changes in total population are slow and the natural endowments are very slow. Changes in the production and distribution capabilities can change more rapidly. That rate of change depends to some extent on the state-society relationship which itself can change rapidly but most likely is adversely impacted if it changes too often or without sufficient forethought. All elements of the food paradigm are directly related to the domestic politics, including ideology, of the PRC. The interactions between the elements of the food paradigm are shown below in Figure 1.1.

Figure 1.1

Domestic Elements and Interactions of the Food Paradigm

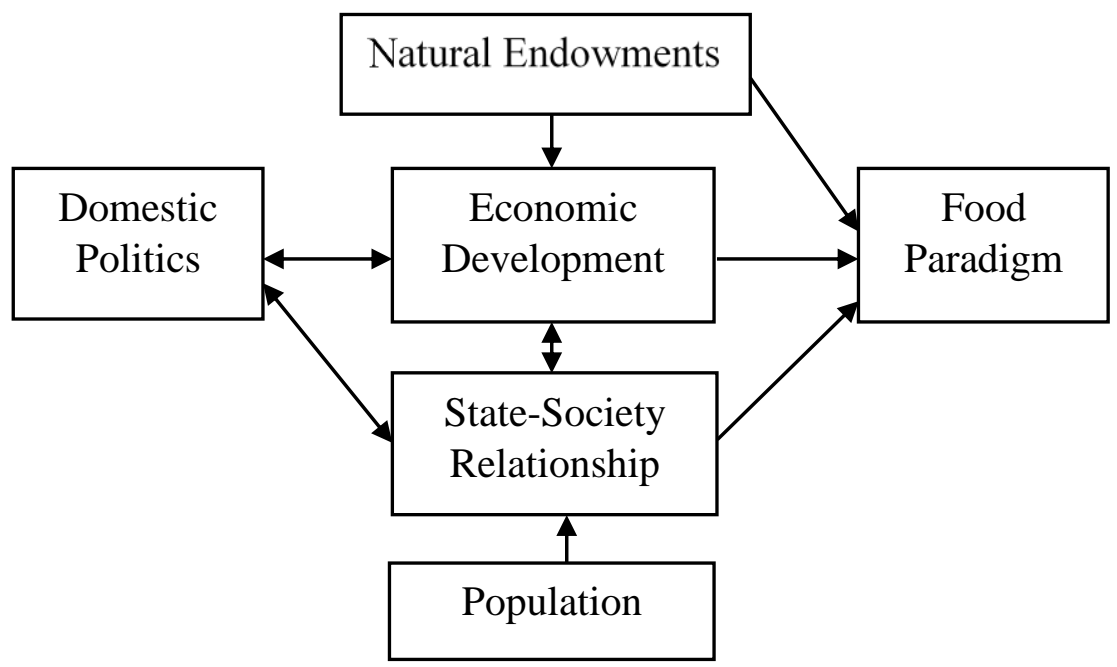




\section{The International System}

The food paradigm is the domestic effort to achieve food security. If that is not possible, a state will be forced to step outside of its boundaries in pursuit of food and that brings a food-deficit state into the international system. The international system is the arrangement of states based on material capabilities and the way in which they ally themselves for mutual protection in an anarchic world. Alliances replace the need for each state to rely on self-help for survival and instead create a larger entity with greater material capabilities, a joint effort for survival. During the Cold War, a bi-polar situation, alliances were built around the USSR and the US in order to balance relative power. Even

though the PRC deserted the USSR, that did not automatically put it into the US bloc as it pursued its own foreign policy. The collapse of the USSR resulted in a uni-polar world that continues to exist today.

Of course, the entire world was not included in this bi-polar standoff. The NonAligned Movement (NAM) presented an alternative to the Cold War for many states, especially in the developing world. The PRC was active in this movement even when a Soviet-bloc state.

The Cold War limited contact among states in an opposing bloc. There was limited economic contact, contact among citizens, and at times between diplomats from each bloc. When a state had the need to trade, it tended look within its bloc first prior to considering a state from the other. As will be seen, the PRC engaged in ongoing trade with Western European countries both of the West Bloc as well as those of the Soviet Bloc. 
Trade was not only influenced by the Cold War but also by the mutual histories of potential partners. The PRC established trade relations with Japan for grain and other items from early on. Within seven years after Japan was driven from China following eight years of occupation, the two began trading again. Though citizens had suffered under the Japanese, the government needed items that Japan had to offer. Yet, trade with North Vietnam was small and irregular due to historical differences and the fact that the Vietnamese sided with the Soviets following the Sino-Soviet split.

\section{Foreign Policy}

Foreign policy--the strategies and tactics used to meet the self-interested national objectives of the state--has its origins in both the domestic arena and the within the international political system. The principal question here is how are the national interests of the state determined? This section will address views of PRC foreign policy including the formal and informal, the roles of culture and geography, foreign policy formulation, and the foreign policy of food. It will conclude with the risks that international trade may present, both to the buyer and the seller.

\section{Views on PRC Foreign Policy}

The PRC gives primacy to domestic policy. "For the People's Republic of China, foreign policy definitely stands in second place as compared with domestic political and economic concerns" (Feurwerker: 1972, 9). As cited earlier, in 1990, then Foreign Minister Qian Qichen maintained "diplomacy is an extension of internal affairs." This is 
quite similar to Sutter's comment that China makes its foreign policy from the inside-out while the US, in contrast, makes its from the outside-in (in Dosch: 2010, 62).

Wang Qingxin views PRC foreign policy as having four cultural roots from the Chinese past: an emphasis on moral conduct, pragmatism, aversion to the use of force, and a preference for defensive rather than offensive conflict. Moral conduct encompasses establishing and maintaining a good society based on harmonious human relations and social harmony. It is a top-down-driven ideal emanating from the highest levels of government to the lowest levels of society. The government serves as an example that the rest of society should follow. Pragmatism refers to moderation as opposed to extremism and the willingness to compromise to maintain harmony among men; flexibility is a key. Aversion to the use of force places conflict as a secondary issue of government; force should not be necessary if the government is virtuous. The preference of defense over offense in conflicts follows the prior point in that defensive war creates social conditions that favor the defender and that a defensive struggle has a tactical advantage over the aggressor (Wang: 2000, 145-52).

A common thread that appears within Chinese informal political ideology is, “...[a] complex of cultural values, preferences, prejudices, predispositions, habits, and unstated but widely shared propositions about reality that condition the way in which political actors behave" (Levine: 1997, 34). Since the first Opium War, the informal ideology has been: 1) The Chinese are a great people and a great nation; 2) the Chinese nation deserves a much better fate than that experienced in the modern world; 3 ) China should receive compensatory treatment for past injustices; 4) as a great nation, China naturally occupies a central position in world affairs and must be treated as a great power; 5) 
China's national sovereignty must be respected and that precludes foreign criticism of China's internal politics; and 6) China's special virtue is not based on expediency but on immutable principles that express universal values such as justice and equity" (Levine: 1997, 43-4).

As opposed to the informal ideology, the formal ideology of the PRC is rooted in Marxism-Leninism. It is "unquestionably the dominant ideology in shaping and informing views, preferences, expectations, and assumptions of the Chinese Communists...[it] consists of a fairly small number of interrelated central propositions that constitute an orthodoxy that is defined...by defense of the central doctrines against the heresy of large or small deviations as it is confronted with major competing ideologies" (Levine: 1997, 33$4)$.

The precedence of the informal over the formal ideology "in foreign policy derives from the fact that the attitudes it encompasses unite otherwise contending Chinese political elites, including those who subscribe to opposing formal ideologies. Thus it tends to be consensual rather than decisive." (And changes more slowly.) "Informal ideology is part of a generic Chinese nationalism rooted in a sense of Chinese national identity that developed historically over a very long period, and the current characteristics in the course of the past century and a half" (Levine: 1997, 43).

Together, the cultural norms of an ancient society, the informal ideology of the "century of humiliation", and the formal ideology of Marxism-Leninism provide three elements that influence the thinking of the PRC with regards to foreign policy. It would be difficult to argue against the most important element being that of pragmatism and flexibility. The dramatic changes that have occurred in foreign and domestic policy since 
1949 require both. One cannot help but think that using the modifier "with Chinese characteristics" is the flexible way to bridge some of the divides between the formal ideology and what has become reality. ${ }^{16}$

The physical security of the PRC is of course a constant priority, as it is for all states. The means to security can vary, and must take into account the domestic issues as PRC foreign policy flows from inside-out. Lu maintains that security and economic development have been policy constants though with differing emphases and different times (Lu: 1997, 155-6). China has learned that to be a comprehensive power it must be a multidimensional one. Strength in a single area, say industrial power, does not make a comprehensive power (Shambaugh; 2013, 5-6).

Nathan and Scobell see the security of the PRC in terms of outwardly expanding rings of concern starting with domestic concerns over demography and maintaining order. The second ring includes countries adjacent to the PRC (22 in total). The third consists of the regional groupings with interconnected foreign policy interests and with them brings the PRC into contact with US, Russian, and EU interests (45 countries and 6 regional systems). The fourth ring encompasses the rest of the world including areas with significant natural resources. (Nathan and Scobell; 2012, 3-7). Here again we see the priority of security being based on domestic stability before it expands outwards. Once expanding outwards, the concern is first for the adjacent countries, those whose proximity

\footnotetext{
${ }^{16}$ For a discussion on "Chinese characteristics" and IR theory in the PRC, see Song and Chan, "International Relations Theory in China", in Hu, Chan, \& Zha (eds), China's International Relations in the $21^{\text {st }}$ Century.
} 
can impact the PRC domestically, and ultimately, due to the need to import natural resources from around the world, we see the potential impact on domestic development, growth, and stability issues.

A long-standing foreign policy principle is Five Principles of Peaceful Coexistence, a major foreign policy initiative from the mid 1950's. It entailed: 1) Mutual respect for sovereignty and territorial integrity; 2) mutual non-aggression; 3) non-interference in internal affairs; 4) equality and mutual benefit; and 5) peaceful coexistence. This served two different purposes at two different times. First, it was an attempt to reach out to the non-communist countries of Asia. "At that time, the principles were intended to strengthen relations with neutral countries such as India and Burma and to mollify Southeast Asian governments who were fighting Communist insurgencies and worried about fifth-column potential of Chinese minorities within their borders." Second, following the Cold War, it came to mean "an alternative to the American conception of a new world order in which international regimes and institutions would limit the rights of other sovereign states to pursue policies at variance with American interests and values." (Nathan and Scobell :2012, 28). ${ }^{17}$

\footnotetext{
${ }^{17}$ In the author's opinion, the Five Principles can be spun to justify most PRC actions regardless of actions, hostile or not.
} 


\section{Foreign Policy Formulation}

The establishment of PRC foreign policy, like many aspects of PRC life, has varied with the persona and prestige of the man in charge at the time. However, there is a decision-making structure in place consisting of a formal and informal structure.

The paramount leader has the ultimate decision-making authority in foreign policy decisions. ${ }^{18}$ The paramount leader is assisted by the informal "nuclear" group, one or two persons hand-picked by the leader. This group has the ultimate decision-making power regardless of Politburo decisions. The Standing Committee of the Politburo is the highest official foreign policy decision-making institution, though full Politburo approval is needed for major foreign policy decisions. Standing Committee decisions are based on consensus but in reality end up being unanimous. Those with a highest rank or authority always had greater say in any matter. The Foreign Affairs Leading Small Group (FALSG) serves as a "decision-making consultative" group that will put forth policy options and proposals for the Standing Committee. It includes not only decision-makers but also top departmental personnel. It is considered to be very influential. This group now has five subgroups consisting of government, party, military, economic and trade, and propaganda, in part reflecting the widening scope of foreign affairs in an interdependent world (Lu; 1997, 8-13) (Shambaugh: 2013, 63). Additionally, the National Security

\footnotetext{
${ }^{18}$ The term paramount leader refers to the titles of Chairman of the CCP and General Secretary of the CCP. Mao was Chairman. After his death, that title was abolished and the title of General Secretary of the CCP replaced it (Nathan and Scobell ; 2012, 41).
} 
Leading Small Group (NSLSG) was established in 2000 with a mandate that includes internal as well as external security. Membership in the NSLSG and FALSG is similar (Shambaugh: 2013, 64).

The above presents a picture of a vertical organization where a relatively few people are involved in formulating and approving foreign policies. Under Mao, policies directives came only from Mao or Zhou En-Lai, and Zhou took personal responsibility to carry them out. While Mao may have consulted and needed to consult with other leaders in the early 1950's, by the mid- 1960's “...Mao at the pinnacle of political power would make all major decisions by himself. The Politburo Standing Committee was but a rubber stamp" (Lu: 1997, 86).

Deng's return to power in 1978 provided him with the same decision-making powers that Mao had enjoyed. And he exercised them, overruling others to initiate the Tiananmen crackdown. But for the most part he relied on consultation with others (Nathan and Scobell: 2012, 43). To accomplish this, the organization and strength of the bureaucracy needed to be augmented, institutionalized to avoid the disruption of Maoist policies and to meet the needs of opening PRC doors to the outside world. This required enhanced understanding of the non-PRC world as well as policy options that required expertise in various disciplines as opposed to correct political interpretations.

Hudson suggests that regime type, interest in foreign policy, and situation type (crisis or not) indicate the extent of individual leaders to direct foreign policy (Hudson: 2007, 38). In the cases of Mao and Deng, the regime type clearly would allow them to make foreign policy unitarily. Mao did and was able to bring the rest of the Standing Committee with him. Deng had relatively less power and preferred to be consultative but 
had sufficient power to get his way. Both were more concerned with domestic issues yet played balance-of-power politics. Mao tended to manufacture crises (Quemoy and Matsu and skirmishes with the Soviets) while Deng invaded Vietnam. But Deng primarily engaged the international community to support his reforms.

Shambaugh maintains that foreign policy decisions are made only by senior leadership and ministries. Intelligence organizations, localities and state-owned corporations involved in international commerce, and society would serve only as groups attempting to influence decision makers (Shambaugh 2013, 62-3). One would think that food security issues would be policy decisions, or a series of decisions that would be agreed to and monitored by senior leadership, yet were formulated at ministry levels with input from influencing groups. Only in the case of a foreign policy message being sent via trade in agricultural goods would decisions be reserved to the pinnacle of power.

\section{Foreign Policy of Food}

We now need to examine how food, specifically grain, can be used as a tool of foreign policy. First of all, grain is not a natural resource, it is an annual product that defies political control. ${ }^{19}$ Control is a function of weather, individual decisions by farmers (depending on their freedom to decide) around the world, and the distribution system that is used to transport it. Despite thoughts that food could be a resource, similar to oil as a coercive power, it cannot as the major grain exporters are liberal democracies that do not control grain production (other than by influence) and distribution, which is carried out

\footnotetext{
${ }^{19}$ Political control can be exercised by governments by dictating what crops are to be planted. They can also influence those decisions with incentives. Governments, as of yet, are unable to control weather.
} 
by the private sector. ${ }^{20}$ Further, most countries produce grain and there will always be those that can export (Paarlberg: 1978: 4-5). The grain trade fluctuates with output and in most cases the grain market is too thin to use it as a source of power (Nau: 1978, 778).

Grain may not be the source of power as oil is, but it can be a diplomatic tool. Nau holds that grain can be used in diplomacy to influence the structure of international food systems including production, distribution, consumption, and private vs. public transactions. Grain transactions may also be used for non-food reasons such as the accumulation of FX, to manipulate domestic prices, or to further other (and not necessarily connected) objectives (Nau: 1978, 777). Wallensteen is more direct and maintains "the structural possibility of turning an economic asset into a political instrument" requires four conditions to exist simultaneously; scarcity, supply concentration, demand dispersion, and action independence, the capability to take action defined by the supplying state itself. By no means does this suggest that when such conditions exist that grain will be used as a political weapon, only that they must exist to be used as such (Wallensteen: $1976,277-9) .^{21}$

The denial of food has been a weapon of warfare for thousands of years. Following WWII, the avoidance of starvation has become an international norm that the nations

\footnotetext{
${ }^{20}$ During the Nixon administration, Secretary of Agriculture Earl Butz suggested that the US could use its agricultural strength in much the same way that OPEC had used oil.

${ }^{21}$ Wallensteen and Paarlberg, writing in the 1970s, have differing points of view on US dominance of the grain trade. As mentioned above, Paarlberg holds that there are a number of grain exporters in the world and Nau backs that up by calling the international grain market thin. Wallensteen maintains that the dominant position the US holds needs to be tempered as it approaches the ability to use grain as a political weapon. Since that time, as will be seen, other countries, Brazil in particular, have increased their share of the world grain market. However, the US remains the largest exporter of grains and most likely, given weather conditions, the only country to addrress shortages in a meaningful way.
} 
of the world have the capacity to accomplish. "There has been and remains a prevailing consensus that famine situations are extraordinary and that they should be met by extraordinary means. To fail to do would be gross immorality according to world-wide standards" (Hopkins and Puchala: 1978, 601-2). Famine relief may have become a moral international norm, but the denial of food in war-torn areas continues as a means of conducting warfare despite any moral considerations.

If we ignore Wallensteen's criteria for conditions that could make grain a political weapon and view them independently, we can see how grain can be used as a tool of foreign policy to influence, reward, or punish another state. In the case of scarcity, the US and the USSR have had several situations where grain purchases from the US had an impact. In 1963 there was a crop failure in the USSR and Kennedy tried to sell grain to the USSR to advance the prospects of détente. He was hindered in that effort by domestic objections and requirements to ship half of the intended purchase on US-flagged ships and the purchases were half what was intended. Eight years later, also in pursuit of détente, Nixon attempted to sell grain to the USSR. This met with demands for renewal of export controls but also from farmers who wanted sales to continue; it was profitable for them (Paarlberg: 1978, 8-9). The US tried to influence the Soviets in their time of scarcity but were unable to take full advantage due to domestic concerns. Interestingly, this is also an example of Wallensteen's action independence, or the failure of it, a fear that he expresses due to US dominance of the international grain market. 
In 1973 the US embargoed soybean shipments to Japan to avoid domestic inflation. ${ }^{22}$ Japan was in need of new suppliers and found Brazil a willing supply partner. By 1976 Brazil's share of world soybean exports rose to 30\% from 5\% (Paarlberg: 1978, 16). Again, we see the impact of the domestic situation on international trade. Control of domestic inflation resulted in, effectively, a new supplier in a commodity previously dominated by the US. Japan punished the US and demonstrated that new suppliers could be created.

In 1960 the US reduced the sugar quota for Cuba. The US was the major buyer, almost a case of monopsony. This was a punishment of the Cuban revolution of the previous year and there was nothing Cuba could do about it (Wallensteen: 1976, 279-80). Buyers can exert influence, and it can hurt when the target has no action independence. Finally, the intended consequence of actions may not have the desired result. India was a buyer of US wheat, and the US wanted it to make structural changes in its crop production in order to increase output. The Indians dragged their feet on reforms and the US retaliated by waiting until the last minute to renew the annual quantities available to India. This irritated senior leaders of India who reacted by speaking out against US foreign policies, and as there was heated debate in India on the reforms, it made them more difficult to enact (Paarlberg: 1978, 12-3). In this case, playing "hardball" in attempts to influence led to a failure of the intended result.

With grains, there are a limited number of suppliers that have the annual ability to export in large quantities. With wheat, this is normally the US, Canada, and Australia,

\footnotetext{
${ }^{22}$ The US harvest was smaller than anticipated which led to an increase in prices. Exports to Japan would have further reduced the domestic supply that in turn would increase domestic prices and inflation
} 
the latter two having less ability than the US. A smart buyer would reward its primary supplier with annual purchases and maintain multiple suppliers by purchasing some from each annually. Purchasing some amount from each will keep each supplier happy. The buyer can punish the supplier by reducing planned purchases.

When there are few buyers, the tables are reversed and the supplier will need to maintain good relations the buyers. The buyers can punish by refusing to buy, reducing normal volumes, or demanding discounts. The smart supplier will do its best to make sure that each of the buyers buys some volume from it so that it develops a reputation as a dependable supplier.

In agriculture there are two other major considerations. Annual output depends mostly on the weather and anticipated transactions-- either buyers or sellers may have the upper hand in negotiating transactions in any year or series of years. Therefore, transactions at market prices tend to be the best way for each to proceed with the relationship. Yet, there is still room for either side to make concessions should there be an opportunity to influence, reward, or punish as appropriate. The second major consideration is the domestic farmer. All states prefer to be in control of their own food supply. Keeping the farmer profitable, with as few subsidies as possible, is a primary concern and one that is always a consideration in domestic policy as well as in international politics. 


\section{International Trade and Its Political Risks ${ }^{23}$}

The international trade in grain has been a fixture of life for thousands of years. However, in the modern world the amount of grain traded internationally is a small fraction of the total production. There are several reasons that the trade in grain is relatively small. Grain is an inexpensive and bulky commodity that spoils and that is expensive, relative to the cost of the grain, to transport. Various types of grain grow in every area in the world and in all countries but the smallest city-states. The local grain preference type tends to be a function of what grows in that area and reduces demand for non-traditional out-of-area grains.

The denial of food has always been a weapon of war. Siege warfare has been used from Masada to WWII. The UK decided to rely on food imports to free agricultural labor and make them available for the Industrial Revolution. In both WWI and WWII, the Germans attempted to blockade the UK and have an insufficient food supply drive them from the battlefield or make a separate peace. Simultaneously, the Nazis attacked the USSR to obtain a source of grain, Ukraine. Destruction of the crops that supply soldiers as well as the local populations was used in the $20^{\text {th }}$ century and in the millennia past.

\footnotetext{
${ }^{23}$ The comments on trade apply to other commodities and products as well as grain.
} 
A state that must rely on food imports to supplement domestic production runs the risk of becoming dependent on other states for basic human needs. There are many definitions and variations of dependency. ${ }^{24}$ For this dissertation the definitions of scholars Keohane and Nye will be used.

Keohane and Nye offer two approaches to interdependence. First, the traditional realist approach in which military power takes precedence to assure a state's survival. ${ }^{25}$ Second, a liberal approach. Complex interdependence, they maintain, is more representative of the interconnected world that exists today. The traditional realist approach uses a series of terms to reflect increasing levels of complexity in trade-related activities. First is interconnectedness. This is simply the normal apolitical trade that occurs between consenting states and does not have costly ramifications to either party. Second is dependence. A state becomes dependent on another state when it is "determined or significantly affected by external forces." In such a case the cause of the dependency may be inadequate domestic endowments, and the remedy may come from foreign sources. Such a situation is common given the unequal dispersion of natural resources around the globe. Third is interdependence or mutual dependence, a situation where there "are reciprocal costly effects of transactions" between the trading states. Both the costs and the gains

\footnotetext{
${ }^{24}$ For a discussion of the use of the terms depend, dependency, and interdependence, see Baldwin "Interdependence and Power: A Conceptual Analysis" in International Organization, Vol. 34, No. 4 (Autumn, 1980), pp. 471-506. He examines the common usage and the usage used within the field of international relations and its sub-field of political economy of these terms over time, beginning with Machiavelli. He finds a wide variation in the usage of the terms (and even contradictory usage) over time.

${ }^{25}$ It is difficult to not include economics in this approach. As economics is the allocation of scarce resources, it seems impossible to have sufficient power to survive without paying attention to state income and its allocation in order to build a sustainable state that is not subject to internal decay as well as a military that is not dependent on external sources of military advancement.
} 
from these transactions are not necessarily the same for each state. (Keohane and Nye: 1989, 9-10).

Whenever interdependence becomes uneven, the condition of asymmetry can occur. In such a situation, one side will increase its influence or leverage over the other. It can be a source of power that can make the disadvantaged side do what it would not otherwise do. The power aspect of interdependence is split into two dimensions by Keohane and Nye, sensitivity and vulnerability.

McMillan distills Keohane and Nye's sensitivity interdependence to "the extent to which one country is affected by the actions of another" and vulnerability interdependence to "the extent to which a country can insulate itself from the costly effects of events that occur elsewhere" (McMillan: 1997, 34). Both include costs and time for adjustments to mitigate a situation. Solutions to issues of sensitivity can be addressed through more or less normal means such as alternative sources of supply, using existing reserves, paying more than before, and creating domestic sources of supply. In the case of vulnerability, the extent of the cost and time will be greater to remedy the situation. Vulnerability, and especially asymmetric interdependence, also carries with it a strategic aspect which in turn increases the potential for violent conflict as demonstrated by the Japanese attack in 1941 following economic embargos by the US. In response to the Middle East oil embargos of the early 1970's, the US threatened violence in the event of further such activities.

The liberal view that Keohane and Nye present they call complex interdependence. It contains three characteristics: 1) There are now multiple channels of connections among states. These occur with interactions of persons, businesses, and institutions 
among nations, as well as governments across the globe. Each group has its own priorities that influence government behaviors and lessen the efficacy of military options within foreign policy. 2) There is an absence of hierarchy among issues. State survival is no longer only military security. What happens internationally has domestic implications, and both need to be considered when devising solutions. IGOs, (e.g., WTO, IMF, WB) may pursue the needs of member states that conflict with the needs of other groups of states or the needs of certain member states. Foreign policies must address not only national interests but special interest groups that transcend international boundaries. This is especially true in liberal democracies. 3) In the developed world the use of military force has diminished. These states do not fear an attack that would threaten their survival. Nuclear weapons acted as a deterrent during the Cold War but did not stop proxy wars, yet the US and USSR did not permit those conflicts to slide out of control. Survival has expanded to include economic and ecological issues, including those that would damage the victor as well as the vanquished in war (Keohane and Nye: 1989, 24-9).

In times of peace when trade can provide foodstuffs not readily available from domestic production, then comparative advantage in trade can be an international source to fulfill domestic needs, a situation of interconnectedness, or apolitical trade. Yet, should the international situation change, inadequate food supplies could quickly become an asymmetric vulnerability. Therefore the question must be asked as to whether food is a strategic good in times of war and peace?

There are several definitions of a strategic good ranging from scholarly to practical. Baldwin maintains that it is "anything that is needed to pursue a given strategy and that is relatively inefficient to produce at home" (Baldwin: 1985, 214-5). During the 
Cold War, Thomas Schelling stated "The most peace-like of civilian goods will be 'strategic imports' to the Russians, if the Russians plan to consume some of them and find them difficult to produce. For in that case any saving that accrues to the Russian economy through the gains from trade is a saving in resources that can be applied to military or other use" (quoted in Forland: 1991, 197). Eisenhower claimed that "if our opponent needs something badly, then that something is strategic" (quoted in Reuveny \& Kang: 1998, 586). Baldwin's definition rests on comparative advantage while the other two rest on denial of anything to one's enemy.

Ripsman and Blanchard define strategic goods as "materials that are essential for national survival or defense." Relying on other states for strategic goods constitutes vulnerability interdependence (Ripsman and Blanchard: 2000, 60). They then address strategic goods by means of testing "the level of a state's vulnerability to a disruption of trade relations with an adversary and the adversary's potential supporters in the event of war by considering whether it would be able to access sufficient quantities of the goods that are essential for the pursuit of national objectives if the links were terminated" (Ripsman and Blanchard: 2000, 58). This definition suggests that domestic sources of all, or nearly all, food needs should be available at all times.

When discussing complex interdependence during the Cold War, Keohane and Nye noted that "force is not often an appropriate way of achieving other goals (such as economic and ecological welfare) that are becoming more important" (Keohane and Nye: 1989, 27-8). In international politics, the traditional referent object of security has been the survival of the state. Since the end of the Cold War, there has been an expansion of the referent objects of security to include threats unrelated (potentially) to military 
threats. Buzan et al, introduced the concept of non-traditional security through several books beginning in 1991. ${ }^{26}$ Their proposed sectors for non-traditional security include the military, political, economic, societal, and environmental sectors. They maintain that within the non-traditional categories are issues that if not addressed can pose an existential threat to the referent object. An existential threat requires securitization. "In theory, any public issue can be located on a spectrum ranging from non-politicized (the state does not deal with it... and it is not... an issue of public debate...) through politicized (...the issue is part of public policy, requiring government decision and resource allocations...) to securitized (...an existential threat, requiring emergency measures and justifying actions outside of the normal bounds of political procedure)" (Buzan et al: 1998, 234).

For securitization to occur, it requires a speech act by an actor declaring a referent object existentially threatened, a securitizing move. For such a move to become securitized, it needs the audience to arrive at the same conclusion. If that does not occur, securitization does not happen and the issue remains simply politicized. Securitization calls for actions that require "breaking the rules", actions that may occur through consent or coercion (Buzan et al: 1989, 21-31). In the chapters that follow, we will see securitization attempts succeed and fail. ${ }^{27}$

\footnotetext{
${ }^{26}$ Buzan, B., People, States, and Fear, 1991; Buzan, Waever, O., deWilde, J., Security: A New Framework for Analysis, 1998.

${ }^{27}$ Maintaining the position of the CCP is always an objective in PRC domestic and foreign policy. A securitization attempt would be expected to be one where CCP survival is the referent object. Another way to look at this is the securitization of aspects of Chinese society that form a threat to the nation and therefore indirectly to the CCP, the current ruling dynasty. Another question that arises, who is the securitizing actor and who is the audience? Referent objects may come from the state or functional areas within. In the case of the PRC, the securitizing actor will most likely be the President, Premier, or a member of the Standing Committee of the Politburo. The audience will most likely be the functional actors that will be responsible
} 
From the realist perspective, it is possible to see Buzan's non-political, political, and securitization characterizations fitting with Keohane and Nye's definitions of interconnectedness, dependency, and sensitivity and vulnerability, respectively. Similarly, from the liberal point of view there is also a fit with complex interdependence with nontraditional security. Keohane and Nye imply an increasing variety of threats where military force is not applicable to solve contemporary problems, while Buzan et al extend existential threats beyond state survival by force to non-traditional threats to survival of the referent object and that could ultimately end up being the state.

Buzan locates food problems in the environmental sector. As might be expected, this sector is complicated and concerned with a variety of issues: disruption of ecosystems, energy problems, population problems, food problems, economic problems, and civil strife resulting the aforementioned issues. Food problems include production issues affected by ecological degradation, consumption problems related to population and migration, and distribution problems that are impacted by poverty, economic development, and periodic shortages caused by normal weather issues (Buzan et al: 1989, 74-7). To this we must add the impact of issues of ideology and politics.

Buzan's securitization approach suggests that an existential threat and Ripsman and Blanchard's definition of a strategic good are essentially the same. However, Buzan's approach allows for anticipation of an existential threat via politicization prior to securitization. Politicization falls in the area of sensitivity interdependence, recognition that a potential issue exits and that addressing it early can relieve the state of more costly

for mitigating the threat. There will be no participation from society as a whole is an authoritarian or totalitarian state where there is no public policy debate. 
measures involved with securitization or vulnerability. Ripsman and Blanchard also assume that strategic goods can be identified when a state is subject to sensitivity vulnerability (Ripsman and Blanchard: 2000, 65), but it lacks the foresight that Buzan incorporates. Identification of strategic goods and mitigation of the potential threat can require decades of planning and implementation.

Over time, the basic paradigm of the PRC with regards to food security has shifted from one of autarky to self-reliance and to one of self-sufficiency at the $95 \%$ level (Tuan and Ke, 1999:17)... a paradigm shift, and one that necessitates international engagement and therefore foreign policy to achieve food security.

When we combine the food paradigm with the international system and foreign policy, we get the relationship below in Figure 1.2.

Figure 1.2

Elements and Interactions of the Food Paradigm

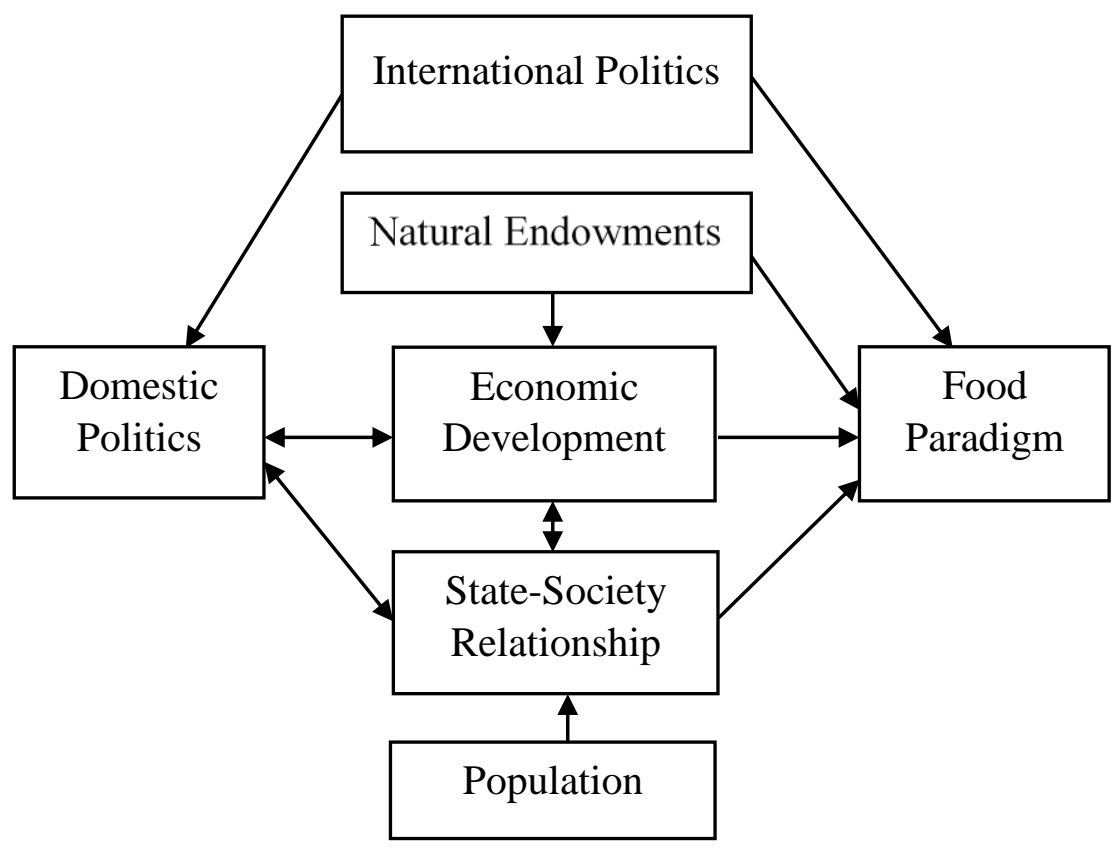




\section{Organization}

This dissertation will be organized chronologically so as to provide the relevant background and evolution of Chinese / PRC thoughts and learnings on food security. The time to 1949 will focus on the traditional methods and organization of providing foods as well as the failure of that system, a major factor in the rise of the CCP. The post-1949 era will be broken down into periods based on the leadership, Mao, Deng and then the third and fourth generations. Each period will follow three threads: 1) The evolving PRC food security situation; 2) the domestic and international political situations at the time; and 3) the interactions between the foregoing that disclose food security's effect on foreign policy and foreign policy's effect on food security.

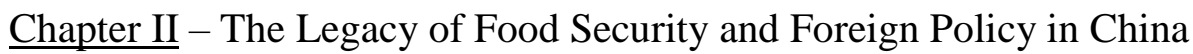

This section will serve as background for the chapters that follow. It will discuss the traditional means of food security and the conduct of foreign policy in imperial China.

\section{Chapter III - Mao Zedong and Political Food}

This chapter will explore the foreign policy changes resulting from the domestic food paradigm successes and failures and their impact during the tumultuous times of Mao's rule. This is a period of agricultural output increases resulting from land redistribution followed by a drastic failure brought on by collectivization and ill-conceived development plans. Similarly, the PRC position in world politics experienced wild swings in alignment with the East, West, and non-aligned. Changing alliances, famine, and the 
prestige of Mao made this period of food security and insecurity one that has shaped views on food security ever since.

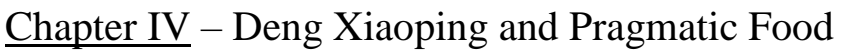

The Deng era runs from approximately 1978 to $1993 .^{28}$ As Mao's era was driven by domestic political considerations against the background of the Cold War, Deng's era was driven by domestic development concerns and achieving the goals of the Four Modernizations, which included agriculture. ${ }^{29}$ The pragmatic approach recognized the inadequacy of the previous food paradigm and added material incentives to increase output; it was the first change of many in the structure of PRC agriculture. Pragmatism appeared in the conduct of PRC foreign policy. The PRC engaged the West in order to learn from the more advanced industrialized countries not only as buyers of technology but as students of what China had missed out on over the of the previous hundred years. This period also brought with it the recognition that population increases were no longer drivers of strength but rather a potential vulnerability, that recognition in turn leading to the imposition of the one-child policy.

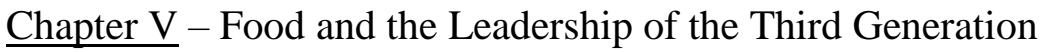

The paradigm of food security started as one of self-reliance but transformed into one of self-sufficiency, reflecting the success of high-labor-content crops for export. ${ }^{30}$

\footnotetext{
${ }^{28}$ Deng's second return from political exile occurred in 1977 while Mao's chosen successor, Hua Guofeng, was still in power. Deng assumed power in 1978 having forced Hua from office. From his return on, he was one of if not the most influential leader in the PRC.

${ }^{29}$ The Four Modernizations included agriculture, industry, science and technology, and national defense.

${ }^{30}$ Self-sufficiency can have two meanings for our purposes. First, it can be reflective of the domestic source of food products, $95 \%$ self-sufficiency in grain would mean that $5 \%$ was imported. This is the
} 
This chapter will deal with the efforts currently underway to assure food security. Domestically, there has been a reversion to provincial autarky, self-sufficiency, or self-reliance by central government declaration plus an attempt to stabilize the alternative uses of agricultural lands. Internationally, the PRC joined the WTO, a move that was expected to hurt PRC agriculture due to lower protective tariffs, and new efforts have been made to secure grain outside of the bounds of normal trade.

\section{Chapter VI - Land Grabs - Making Land Mobile?}

The term "land grab" refers to the acquisition of farm lands in a second country to raise crops for consumption in the first. ${ }^{31}$ Crops grown do not enter the domestic or international markets but go directly to the investing country. What makes this a questionable policy is that most of the land acquisition has been in countries suffering from food insecurity.

The 2008 spike in food prices, especially rice, sent a chill through the rice-dependent world. The rolling panic which started in India spread throughout Asia and eventually to Africa, South America, and Europe. It was nearly coincidental with this panic that news reports began to spread about states purchasing or leasing land in other states to provide grain for home countries. Purchasers were said to include sovereign wealth funds and state-owned companies as well as private enterprises. The PRC was

\footnotetext{
meaning employed by the PRC. Second, self-sufficiency can also refer to whether the state is self-sufficient when taking into account its domestic production plus its exports minus its imports. In this case, a state would be self-sufficient if it had sufficient funds to pay for imports.

${ }^{31}$ Within the PRC, "land grabs" refers to illegal or adequately compensated acquisition of land, generally farm land, used by local elites for alternative uses.
} 
one of the states reported to be purchasing land in other states to supply themselves (von Braun \& Meinzen-Dick). This chapter will examine the food security issues.

\section{Chapter VII - Conclusion}

This chapter will serve two purposes. First, it will offer an answer to the question of whether food security issues have influenced foreign policy, the objective of the dissertation. Second, it will speculate as to whether the PRC trusts trade in grain as a longterm solution to a worrying problem and potential vulnerability. To date, the PRC has become a constant trading country in grain for import and horticulture for export. Whether or not a sensitivity turns into a vulnerability will depend on population and income levels, the demand, and the supply. The supply is where the vulnerability manifests itself. $^{32}$ Maintaining the "red line" of agricultural land helps but fails to address the quality of the land for either agricultural or alternative uses. Foreign land acquisition has an uncertain future as an exclusive food source. Current domestic policies discourage comparative advantage domestically. Pollution and its effects will hang over the PRC for years to come.

\footnotetext{
32 This assumes that population growth controls remain in effect until the actual population begins to decrease.
} 


\section{Chapter II - The LEGACY of FOOD SECURITY and the FOREIGN POLICY of CHINA}

This chapter will present the traditional Chinese food paradigm and conduct of foreign policy. It serves as an historical frame of reference that sheds light on aspects of food security and foreign policy that influence PRC attitudes and policies today. The food paradigm will focus on the state-society relationship, production and distribution capabilities, and population. We will see food security issues of the past, along with an example from the late $19^{\text {th }}$ century that will reappear in subsequent chapters dealing with the rule of the PRC. The foreign policy section will address the "tribute system," an imperial method of maintaining peace with its neighbors and policies employed when peace could not be maintained.

\section{The Chinese Food Paradigm in History}

In this section we shall examine the Food Paradigm that existed up through the Qing Dynasty (1644-1911). The system that existed contained many aspects of what current governments do to assure a consistent food supply for the population. However, a major difference is the advancement in technology, especially as it relates to transportation.

\section{$\underline{\text { Traditional State-Society Relations }}$}

The hierarchy of society and the state-society relationship in Chinese history have long been key aspects of the food paradigm. Its origins can be found in the writings of 
Confucius and Mencius and echoed by most rulers throughout imperial times. The authoritative hierarchy of society starts with the ruler and goes in order to his ministers, then to the provincial officials, followed by the local gentry, and finally to the common people (Shih: 1988, 605-7). Away from government, the same authoritative hierarchical construct exists within the family unit, or lineage, headed by the senior male in an extended family household. A social hierarchy also existed generally relating to occupation. Government officials were at the top followed by peasants, artisans, and merchants. The senior position of the peasant indicates his importance in a subsistence-based agricultural society. Confucius had nine points of directions for the ruler to attend. Three of these are important to the subject at hand: 1) Identifying himself with the interests and welfare of the whole body of public officers - the creation of loyalty; 2) showing himself as a father to the common people - exertion for the good of the state; and 3) encouraging the introduction of useful arts - for sustaining revenue and wealth for the state (Lin,Y.: 1966, 119-20). ${ }^{33}$ The prosperity of the common people keeps them content that in turn fuels the coffers of the state through tax payments, which are managed by the public officials with the same objectives as the ruler.

In a subsistence-level agrarian society dependent upon tax revenue in grain from the vast majority of the population, the ruler best able to sustain his rule assures a constant supply of food. The importance of a stable food supply remained a constant

\footnotetext{
${ }^{33}$ Other six of Confucius directions are: Cultivating his personal conduct; honoring worthy men; cherishing affection for, and doing his duty toward, his kindred; Showing respect to high ministers of state; showing tenderness to strangers from far countries; and, taking interest in the welfare of the princes of the Empire.
} 
throughout imperial times. This objective is demonstrated in the following quote: “...the legendary origins of the Chinese state emphasize the control over nature achieved by the ancient sage emperors" (Li: 2007, 2). Control over nature meant control over flood and famine through water control projects and grain storage to protect against shortages and provide seed for the coming planting. This was a demonstration of moral legitimacy by an emperor. Ancient writings demonstrate this responsibility: From the Book of Lord Shang, writing about the Qin dynasty (221-206 BCE): “...the way to organize a state well is, even though the granaries are filled, not to be negligent in agriculture..." (DeBary: 1999, 194). From the Song Dynasty (960-1279 CE) “...in ancient times, people had to have [a reserve of] nine years' food supply. A state was not considered a state if it did not have a reserve of at least three years' food." (DeBary: 1999, 603). In the $18^{\text {th }}$ century Qing Dynasty: “Indeed the state's success in creating massive stores of grain to mitigate seasonal fluctuations in grain availability and to counteract scarcities in years of poor harvest, positively increased popular expectations that it could intervene to protect the subsistence requirements of the population" (Wong: 1997, 224).

\section{Ever-Normal Granaries}

The ever-normal granary system and the emphasis on water control were the two principle avenues to assure a supply of food. The grain storage system originated with Mencius or before (Li: 2007, 3). It was not successful each time it was tested but on the whole functioned as an accepted element of the state-society relationship. That relationship was based on society taking responsibility for grain output within a market setting. The state provided three functions related to control of the cost and availability of grain: 
First, it entered the market at seasonal times of shortage or abundance to maintain price levels. Second, it maintained an inventory of grain to be used in case of a poor harvest. Third, it provided a "safety net" for the poor through charity granaries.

Ever-normal granaries were to be located in each county of each province and were stocked by purchases from local growing areas. They were supplemented by community granaries and charity granaries. Community granaries were stocked with private contributions and made seasonal sales for consumption and / or seed to local farmers. The charity granary was also financed by local contributions for reduced price grain and loans. Local contributions were from local elites as well as merchants and resellers. Charity granaries also served to keep the inventory "fresh" with discounted sales but also capped the sales at $30 \%$ of the beginning inventory. In times of shortage the $30 \%$ ceiling could be breached. The spread and efficacy of the community and charity granaries fluctuated over time. In times of shortage, tribute grain could also be transferred to suffering areas. ${ }^{34}$ The grains that were stocked varied by region with wheat, millet, and sorghum the primary grains in the north plus tribute grain in the form of rice. The Yangtze River is generally considered the dividing line between north and south. Southern areas stored predominantly rice, though after 1760 an equivalent amount of silver was stored, and little grain, in order to purchase needed foodstuffs (Li: 2007, 194). The granary system reached its apex during the $18^{\text {th }}$ century under Qing rule.

For most of imperial times, grain circulation was managed by the market: merchants and re-sellers in the private sector. Granaries, operated under the auspices of the

\footnotetext{
${ }^{34}$ The area around Beijing is not a major agriculture producing area. Beginning in the Sui Dynasty, as the Beijing population grew, grain, as taxes, was shipped north to provision Beijing and the surrounding area.
} 
emperor, generally bought and sold grain seasonally in order to keep prices stable.

Stocking was generally from local production but was sometimes moved out of area to balance prices or as relief shipments to shortage areas. Merchants played a role here, buying and selling grain within and outside of local markets. Merchants ranked at the bottom of the Confucian hierarchy but were depended upon by the state to act morally in times of shortage and to forsake profit for the general welfare of society. As the merchant was in business to make a profit, his motivation could differ from that of the state's desire to maintain the general welfare. When there was an imbalance between supply and demand, there was always an opportunity to move grain to an area where the price was higher. One might expect that the low status of the merchant class within the social hierarchy was a reflection of such occurrences or the fear of such.

In the $18^{\text {th }}$ century, the state gained more control over community granaries and was able to use reserves to equalize prices and supply locally and across the empire. This was accomplished by monthly reports of grain prices, weather, and harvest reports from all prefectures to the central authorities who could then reallocate grain reactively or proactively as they saw fit (Wong: 1997, 113). In addition to providing information, the system still relied upon the state to convince local elites to "play roles defined for them by the state in accordance with Confucian moral sensibilities" (Wong: 1997, 119). Wong summarizes the system as a demonstration of “...the state's capacity to construct a massive and sophisticated structure to influence the material welfare across diverse locals...it...sustained for many decades as a complex system of grain mobilization, storage, transfer, and distribution" (Wong: 1997, 117). An important aspect of state involvement was utilization of power to coerce movement of grain out of the local growing area. 
Movements out of area carried with it the fear of shortages and of price increases in the originating area.

Yet, at the apex of the granary system questions were raised by the state concerning the cost of storage, whether the system impacted the rising cost of grain, whether market forces might work best, whether the system was assisting the target population or whether reduced grain costs simply benefited those who could afford the grain or who were involved in deception. The morality of the system's intent was colliding with the cost of running the system (Li: $2007,166-7) .{ }^{35}$

It was not until the 1920s and 1930s that China earned the name "Land of Famine" (Lee: 2011, 134, Li: 2007, 307). However, this is not meant to imply that famine was uncommon prior to the $20^{\text {th }}$ century, Chinese history is littered with famine. "No other civilization has had such a continuous tradition of thinking about famine, and no other nation's modern history has been so influenced by hunger and famine" (Li: 2007,2).

\section{Water Control}

Controlling water was the second moral function of the emperor. Rain was needed for a good harvest and control of rivers was needed to prevent flooding that could be as disastrous as the absence of rainfall for the food supply. Water control encompassed the construction and maintenance of levees and dikes, irrigation projects, and dredging should waterways become over-silted. Maintenance of the water control systems was a key to the long-term effectiveness in achieving and maintaining food security.

\footnotetext{
35 This is similar to the discussions around PL 480 in the US, some 300 years later, concerning the cost and efficacy of grain storage by the government.
} 
The adequacy of maintenance varied over time and could be a factor in the fall of an emperor or dynasty.

China's rivers generally run from west to east, and, as would be expected, they were the most efficient means of transportation. This was especially true of low value bulk items such as grains. The major north-south waterway was the Grand Canal which ran $1700 \mathrm{~km}$. from Hangzhou to the Beijing area. It was constructed during the Sui Dynasty to facilitate the movement of tribute grain to the Beijing area. The shipment of tribute grain to Beijing moved permanently from the Grand Canal to a sea route in 1840 . However, the canal continues in operation today.

Perkins uses historical documents to ascertain the extent of water control projects. His conclusion is that the bulk of water control projects occurred between the $10^{\text {th }}$ and $13^{\text {th }}$ centuries and were concentrated in the east. He finds this logical as that was the location of most of the population and explains the expansion of rice production in that area (Perkins: 1969, 62-3). As will be seen, this development is also unfortunate in that currently the center of population is also the best agricultural land. ${ }^{36}$

\section{$\underline{\text { Production and Distribution }}$}

China's climate is quite varied, ranging from extremes of tropical in the extreme south to frigid in the extreme north bordering Siberia. What grain crops were planted tended not to be an issue as climate and soil dictated that. The introduction of crops from

\footnotetext{
${ }^{36}$ Prior to the advent and use of chemical fertilizers, manure was the prime fertilizer for crops. A concentration of people and farm animals was therefore required for farming to be successful. The concentration of people in the best farming areas is a result of necessary farming practices of the past.
} 
the Western Hemisphere began in the $16^{\text {th }}$ century. These included maize, potatoes, and peanuts that provided additional sources of calories from land considered marginal for traditional crops. Cotton, a cash crop, was introduced in the $17^{\text {th }}$ century $(\mathrm{Li}, 2007,90)$. The map below shows the prime growing areas for various crops.

\section{Plate 2.1 Agricultural Map of the Peoples Republic of China}

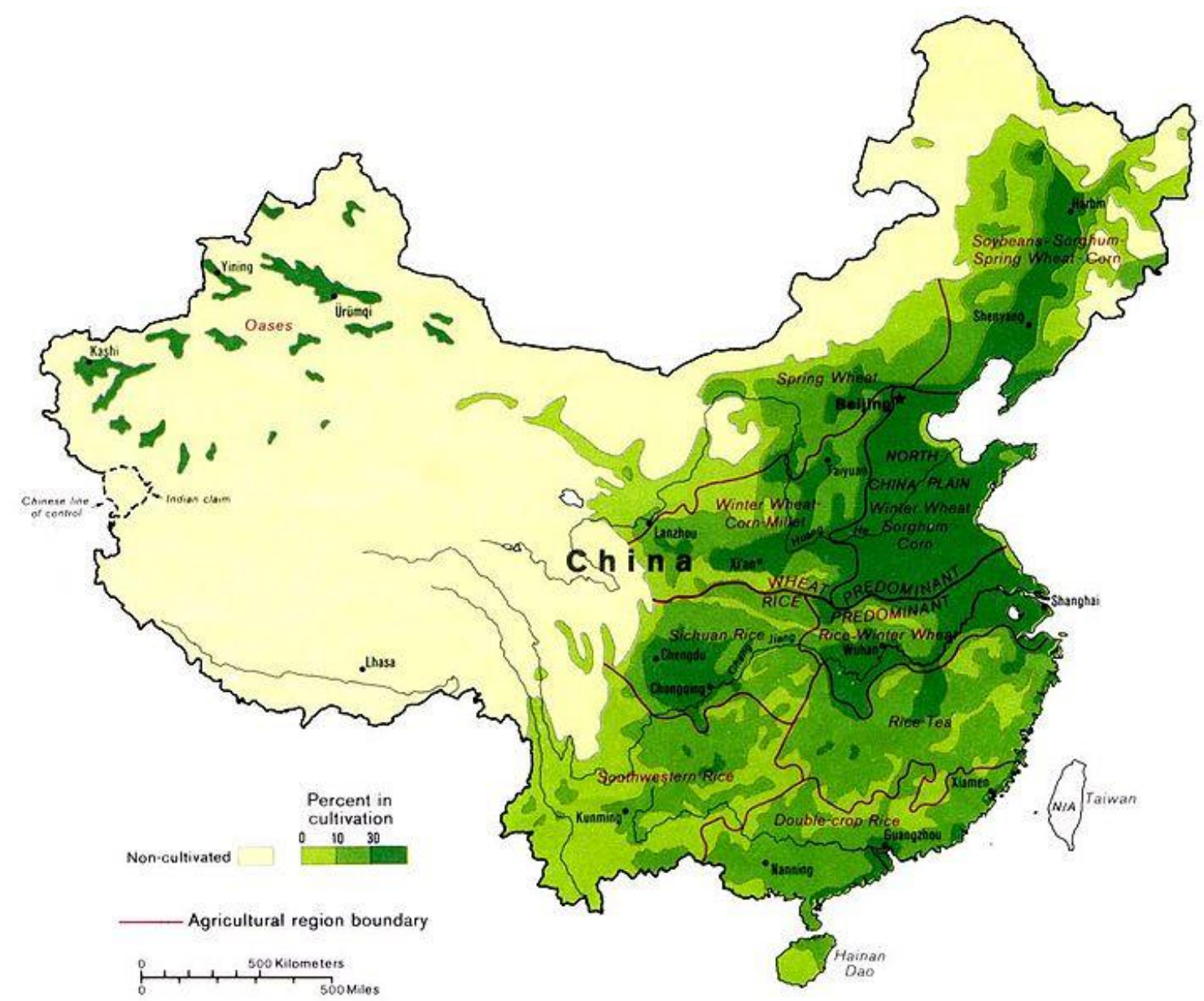

Source: www.kas.ku.edu/archivedsite/chinese_food/food_images/china_agricultural_86.jpg

In the $18^{\text {th }}$ century, there were production choices to be made: whether to plant grain or cash crops, mainly cotton, oil seeds, and tea. While there were no directives on 
what a farmer should plant and even with the ever-normal granary system to protect against grain shortages, too much planting of cash crops in a local area could raise the specter of food shortages in the future.

There was an element of change occurring: the commercialization of agriculture and the monetization of rural China. An accelerant of this was the change of the land tax to one paid in cash rather than one paid in grain. Such payments necessitated the need to sell crops for cash, even for the farmer who consumed all he harvested, therefore increasing commercialization. The planting of cash crops increased. Crop specialization increased and with that long-distance trade had to increase to distribute food supplies sufficiently. Along with the commercialization / monetization of agriculture came the increased commodification of land. (These changes started with the increase in population which will be addressed below.) By about 1840, all tea, half of raw silk, and a quarter of raw cotton were commercially distributed. Rice lagged behind at only 10\%, (Rowe: 2002: 512-16) possibly a recognition by the farmer and the community of the fears of a food shortage.

In the $18^{\text {th }}$ century, there was significant long-distance trade between grain surplus and grain deficient regions. This trade generally followed river routes along the major rivers and via seaborne trade from Manchuria to eastern coastal cities and imports from Southeast Asia to southern coastal cities (Myers and Wang: 2002, 612). Areas along the river and canal-borne trade were where the commercialization of China grew quickest.

As mentioned above and regardless of the degree of commercialization of agriculture, in times of shortage or price instability, grain from the harvest or the ever-normal 
system could be moved from the local area to where it was expected to be consumed.

Even in normal times, there was a continual fear of food insecurity among the local populations. The perceived or actual over-planting of cash crops or shipments out of the local area would raise the fear of shortages and / or higher grain prices. The distribution issue related to trade in a subsistence-based agricultural economy concerned local versus long-

distance trade. Fears could manifest themselves in the blockage of grain shipments out of the local areas. The same or related issues will continue to appear as we move further into the $21^{\text {st }}$ century.

\section{$\underline{\text { Population }}$}

While the PRC is concerned about feeding its population, this has not been a problem throughout Chinese history. This first major increase in population occurred during the period of the high Qing when the population doubled from 225 million to 450 million between 1750 and 1850 (Lin, J.: 1995, 273). Prior to that time there had been a number of positive changes to Chinese agriculture. In the $11^{\text {th }}$ century, the introduction of Champa rice from Indochina allowed for double cropping (two crops per growing season) and even triple in some cases (Lin, J: 1995, 269; Freeman: 197,146). Champa rice was also rather drought resistant and allowed for the expansion of rice growing areas to non-traditional rice growing areas. There were also technological advancements such as iron-tipped ploughs and seed drills (Lin,J., 1995). Extensive agricultural increases could also occur as peasants moved into adjoining lands previously unexploited.

Increasing population did have an effect on agriculture; it had to keep up to feed the increase. It did so in part in 1860 when Manchuria, the traditional Qing homeland, 
was opened to Han immigration for the purpose of increasing agricultural activities. Population increases bring additional labor that can lead to higher outputs. However, Boserup suggests that this applies to the south where incremental labor increases rice output but not to the north where yields remain constant (Li: 2007, 75). Hsu maintains that output kept up with population growth due to a switch to more labor-intensive crops such as corn and sweet potatoes (Hsu: 1982, 25). These are predominantly northern crops, which suggests corn and potatoes increased the caloric output of the land. The efficiency of agriculture did suffer. In the 1930's, US rice production per capita exceeded that of China by a factor of ten (Hsu: 1982, 27).

There were still negative aspects of population growth. Population was growing faster than cultivated acreage. The cultivated land-man ratio dropped gradually from four $m u$ per person in about 1590 to about 2.70 in the latter half of the $19^{\text {th }}$ century. ${ }^{37}$ Elvin sees the increase in population during the Qing as having an adverse effect on agriculture. Extensive practices resulted in decreasing marginal productivity of new, but less productive, lands. The increase also developed into a high-level equilibrium trap, a situation where each incremental unit of labor results in decreasing output per unit. The only way to escape such a trap is to convert from traditional practices to modern practices (Elvin: 1973, 311-15). According to Lin: "The pattern of Chinese agriculture that was practiced up to modern times essentially was established by the Song Dynasty (960-1279)” (Lin, J.: 1995, 279).

\footnotetext{
${ }^{37} \mathrm{~A} m u$ is a standard Chinese land measure equal to $1 / 6$ of an acre.
} 
Elvin extends his argument in favor of a high-level population trap beyond agriculture to the economy as a whole. He maintains that population growth and an essentially stagnate economy brought about conditions where the use of technology could not provide a sufficient return on investment. Manpower was inexpensive and there was no need to replace it. Therefore, steamships and railways could not replace the efficient river-borne junk traffic. Nor could railways incorporate rural areas' traditional means of overland transport. The only way to cure such a situation was to increase market size, one that incorporated foreign demand and therefore drove employment and the need for labor-saving technology (Elvin: 1973, 312-18)..$^{38}$

The increase in population had other positive and negative effects. Handicraft production became a monetary earner for rural households, especially with spinning cotton, a natural outgrowth of cotton production. Urbanization increased rapidly. With respect to food, the additional mouths became easier to feed in more concentrated areas than in rural areas, and more people became available for an industrialization drive if one materialized. Unfortunately, the commodification of land and the need to pay taxes in cash resulted in a higher level of land concentration and "landlordism" and tenant farming, an aspect of Chinese society that would serve to increase rural poverty and serve as one rationale for revolution.

\footnotetext{
${ }^{38} \mathrm{Lin}$, in addressing the question of why China did not industrialize prior to Europe, given its relative head start and population size, attributes it to two reasons. First, pre-modern technological advancement comes via observation and tinkering while modern technological advancement comes through application of the scientific method. Population size increased the opportunity for pre-modern advancement. Second, the imperial education system focused on memorization of extensive Confucian texts and their application to passing imperial exams to prepare themselves for government service. Thus, the best and the brightest had no time to devote to activities required to further accumulation of human capital nor did the promotion system within the bureaucracy encourage such activities (Lin: 1995, 284-6).
} 


\section{An Example of Issues Facing the Food Paradigm}

The following example illustrates many of the issues discussed above, including economic development of transportation, the transfer of grain out of the local area, planting of cash crops rather than grain, natural barriers, and eventually a scarcity of FX. All of this can be illustrated by the rice trade between Guangxi and Guangdong in South China in the second half of the $19^{\text {th }}$ century. Along with these limitations come historical issues with the grain trade as well as those that will face the PRC government.

Southern China was isolated from points center of the country by the Nanling Mountains, through which there were only two passes; neither was conducive to the transport of grain in any quantity. The Southern province of Guangdong was reliant on its neighboring province to the west, Guangxi, for its rice. The dependency was due to the conversion of land to silk production and general commercialization in Guangdong. In the $18^{\text {th }}$ century, $8 \%$ of Guangxi rice production was reserved for Guangdong and the arrangement worked well. Guangxi had excellent river transportation to Guangdong and the granaries functioned as they did further north. However, this long-distance trade was a source of worry to Guangxi residents and the arrangement fell apart. This led to Guangdong relying on rice from SE Asia for its staple food. This worked well until a railroad was built through a Nanling pass which brought with it a new set of problems. The people of Guangdong preferred imported rice but were forced, because of import duties, to consume domestic rice. The rationale was to reduce imports to preserve FX and to be self-sufficient in grain. However, just because there is a railroad pass through the mountains did not mean that rice could be supplied from the north. Rail cars, locomotives, and efficient management were also required, and they were in short supply. Ultimately, 
lower quality northern rice needed to be shipped by sea in order to have sufficient quantities available (Lee: 2011, 16-31). Such issues would become important in the $20^{\text {th }}$ century and beyond under dynastic, Nationalist, and PRC governments.

\section{$\underline{\text { Summary of the Traditional Food Paradigm }}$}

The state-society relationship regarding food was a shared responsibility among the farmer, the merchant and the state. The farmer was always in charge of the selection of crops to be planted; the merchant distributed grain both within and outside of local growing areas. The state controlled the ever-normal granaries which were used to control prices, provide emergency relief in times of shortage and to supply the poor. The respective roles of the merchant and the state were not permanent and would vary over time. With respect to water control, the state carried out that function through the contribution of corvee labor supplied by the population. Water control by the state was an effort to create the conditions in which grain production and distribution would flourish.

Within a subsistence-based agriculture economy the fear of insufficient food was always in the mind of the peasant. The system could not guarantee a consistent food supply. The food supply was always subject to domestic turmoil, corruption, a lack of effective communication to warn of shortages as well as to move grains to affected areas, and of course the vagaries of the weather. Yet, the system did recognize the mutual needs of the rulers and the ruled. The state could not exist without the tax receipts from the population and the peasant would be worse off without the safety net provided by the state and the water control projects it initiated and maintained. 
A subsistence economy implies one where there is not much wealth. There was wealth but it was concentrated within a small section of society, excluding the nobility and its officials. The implementation of tax payments in cash rather than grain exacerbated the concentration of wealth in favor of the landowning class. While this was an attempt to monetize the rural economy thereby breaking the hold of the mono-culture subsistence farming (Rowe: 2002, 512), it had a negative effect on the peasant, especially those at the margin. Monetization forced more and more peasants into tenant farming and closer to the margins of society. Meanwhile, landowners increased their control of the land and their wealth.

As might be expected, views of the food paradigm shifted with class. For the less

well-off, “...grains are not something to play with or waste, any child who does not finish the grains in his or her bowl is told that his or her future mate will be one with a pockmarked face" (Chang, K.: 1978, 10). For the elite, food was a virtue that could be observed or ignored at will. At the government level, morality appears as a function of granaries and water control. In the following statement, morality (in terms of consumption) is used to save the dynasty: "Overindulgence in food and drink is a sin of such proportions that dynasties could fall on its account" (Chang, K.: 1977, 10).

\section{Traditional Foreign Policy}

Traditional Chinese foreign policy has been influenced by geography, a dominant culture, and Confucian hierarchy. The culture and Confucian hierarchy are developments of the Chinese civilization and have operated within a large but limited geography for 
most of Chinese history. Together, these three influences have led to the "tribute system," the accepted way that China has managed its foreign policy throughout its Imperial times. This section takes a quick look at China's geography and then explores how China has conducted its foreign relations with neighboring states and tribes to maintain its dominant position and peace in the past up to the mid- $19^{\text {th }}$ century when a declining Qing Dynasty ran afoul of British trade interests.

\section{Geography}

The geography of China was beneficial for the development of the Chinese state. The eastern border is the East and South China Seas, both of which provide a barrier to foreign invasion. Historically it was a formidable barrier but developments in Europe eventually made that coastal barrier a long and poorly defended series of entry points. Except for southeastern China and its border with Vietnam, the southern border is mountainous and jungle-covered, which again presents a formidable line of defense. Western China is again defended by mountain ranges west of Sichuan with deserts and mountains farther west. It was only during the Ming (1368-1644) and Qing Dynasties that China moved beyond the desert barrier to the mountain barriers of Tibet and Xinjiang. ${ }^{39}$

The north was a different story. It was inhabited by nomadic tribes with whom nearly all dynasties fought border wars and did not always win. The terrain was treeless

\footnotetext{
39 The Tang Dynasty (618-906 CE) expanded to include part of what is now Xinjiang but did not hold it. The Yuan Dynasty (1271-1365) included Mongolia, Xinjiang and Tibet but these were Mongol areas incorporated with China proper and ruled by the same Khan.
} 
grasslands which facilitated mounted cavalry that Chinese forces could neither easily defend nor defeat. Early attempts to keep marauders out led to the building of defensive walls starting in the $7^{\text {th }}$ century BCE and continued in fits and starts through the Ming Dynasty. This was an expensive and ineffective defensive strategy. Both the Yuan (1261-1365) and Qing Dynasties were established by northern invaders.

The core area of China, lost only during the Southern Song Dynasty (1217-1279 $\mathrm{CE}$ ), provided material resources that allowed China to prosper and develop economically. Brantly Womack suggests that the "solid center" of China in Asia, as opposed to the "liquid center" of the Mediterranean Sea, gave China an advantage that the developing states of the West did not have. This allowed the Chinese always to be close to their center of power (Womack : 2012,39). There was no need to travel as what they needed they had at hand. Others needed to come to them.

\section{$\underline{\text { Tribute System }}$}

China was usually the dominating power in its region, following consolidation, from the Qin Dynasty onwards. Its dominance came from its material strength, its culture, and the position of its ruling emperor. Its material strength was a function of size, wealth, industry, and military might. More lasting and influential over the longer term was China's cultural dominance. Chinese writing style, the Chinese calendar, similarities in food and dress, Confucian and Buddhist beliefs, and similarities in governmental organization spread to neighboring states (Spence: 1991, 118). These influences were strongest in Korea, Vietnam (Wang, Y.K.: 2012, 148), and Japan (Zang and Buzan: 2012, 18). 
The hierarchical nature of Confucianism is manifested at its apex by the emperor, the "Son of Heaven" and the ruler of all under heaven (tianxia). The morality and virtue of the emperor set himself and China apart from other states and tribes. As the emperor was the universal ruler on earth, it followed that any state having dealings with China could not be treated as equal (Feuerwerker: 1973, 44). ${ }^{40}$ Those polities not accepting Chinese culture and ideology were considered barbarians.

The combination of material, culture, and ideology made China, from the earliest imperial times, the leading civilization in East Asia. It created a long-lasting Sino-centric region of the world. From this dominant position, the question we need to address is how this dominance was manifested in China's foreign policies.

The term "tribute system" was coined by Fairbank and Teng in their 1941 article concerning Qing foreign policy. The tributary system was: “(1)...a natural outgrowth of the cultural pre-eminence of the early Chinese, (2) that it came to be used by the rulers of China for political ends of self-defense, (3) that in practice it had a very fundamental and important commercial basis, and (4) that it served as the medium for Chinese international relations and diplomacy" (Fairbank and Teng: 1941, 137).

The basic operation of the system demanded that an envoy of a state or polity request an audience with the Emperor. ${ }^{41}$ Upon approval, the supplicant would appear bearing tribute gifts of local products and bow to the Emperor in accordance with rituals that

\footnotetext{
40 "The tianxia referred to was limited to the areas surrounding the Chinese empire, which roughly correspond to what we call today Northeast and Southeast Asia and parts of Central Asia" (Zhang : 2009, 554).

${ }^{41}$ The Chinese Emperor could also initiate contact with a potential tributary. However, the net result was the same.
} 
acknowledged his superiority. The Emperor would reciprocate with gifts to the supplicant, oftentimes in excess of what was received. In return for the tribute, the foreign polity would receive trading privileges with China that would be carried on between merchants of China and representatives of the tributary state. From the point of view of the Chinese, participation in the tributary system was an acknowledgement that the non-Chinese polity accepted the superiority of Chinese culture and that the Emperor was the ruler of all under heaven (Fairbank and Teng : 1941, 137-8). The barbarians or Sinicized states received trading rights for a period of time and only in the places designated by China.

Included within the tributary system was an established hierarchy. The most Sinicized states, Korea and Vietnam, were at the top of the tributary pecking order as they were more Sinicized than Japan. Japan ranked higher than other tributaries for the same reason. These rankings also served to establish rankings between and among states when dealing with each other absent China (Kang: 2010, 57). Kang divides trade with China into four categories: Tribute, the ceremonial part in which the lower-ranking state presented gifts and acknowledged the superiority of China; official trade, that conducted by officials from China and the tributary state, immediately after the acceptance of tribute; private trade, that which occurred between individuals under the rules established by the tribute system; and finally, illegal trade, that which involved smuggling and piracy. Private trade accounted for the bulk of all trade (Kang : 2010, 109).

Continuous trade would require an ongoing series of tribute missions. Korea sent nearly three missions per year between 1637 and 1874 (Feuerwerker: 1973, 46). In 1587, Ming records indicate that there had been trade missions from 123 polities during that 
dynasty. However, many were one-off events relating to the discovery voyages of Cheng Ho. Neighboring states tended to have missions every three to five years. (Fairbank and Teng: 1941, 151-4).

By and large, the tribute system was a land-based system that ignored sea-borne trade. Sea-borne trade in early Imperial times was immaterial. The Ming had forbidden sea-borne trade in 1424 . Thus, tributary trade was the only legal foreign trade. While never completely stopped, junk trade out of Southeast China began to flourish again during the Qing Dynasty. The inability to control the junk trade led some formerly tribute states to abandon paying tribute as they were able to engage in China trade with Chinese merchants operating far from the center of power (Chan, H.K. :1968, 414) (Fairbank and Teng: 1941, 202).

While Fairbank and Teng addressed the Qing Dynasty and the evolution of the tribute system from the Ming, it must be realized that this practice has its origin back in the Bronze Age (Fairbank and Teng: 1941, 137). Why did it last so long and was it the basis for Chinese foreign policy over that time frame? Cultural preeminence is one aspect, a non-material one. China had the material goods that others did not; the preeminence of its agriculture and industry provided that. Be it grain, silk, or metal arrowheads, these were not items that the surrounding nomads and aboriginals had, nor did they have the ability to produce. As long as the Chinese had superior material resources, they were able to dictate the norms and rules of the tributary system (Wang, Y.K: 2012, 139). Because of China's central location and the workings of the tributary system, its foreign relations were predominantly bilateral rather than multilateral. 
China was not all powerful within its region for all of its history. Internal power struggles, dynastic change, and poor governance, among other reasons, could weaken an emperor or dynasty. At such times, external states or tribes could present an existential threat to the existing rulers. Tibetans, the Xiongnu, Jurchens, and Mongols provided threats and dominated China from time to time. In times of weakness, China paid tribute to the leading power of its region. "[It] was at times a form of 'payoff' to keep weaker Chinese regimes in power" (Swaine: 2010, 2).

At times, China was conquered by outside forces. The Yuan Dynasty was formed by Mongols and the Qing by Jurchens, both successful invaders from the north. From the start of the Yuan Dynasty to the fall of the Qing, China was only ruled by Han Chinese for 276 of 651 years. Yet, the cultural domination of the Chinese civilization continued as foreign conquerors gradually adopted the traditional Chinese culture and ways of governing.

\section{Mutual Benefits}

The hierarchical nature of Confucian thinking and China's ability to dictate the rules provided China an enviable position during periods of domination. For the Emperor, the tribute system legitimated his rule as the Son of Heaven for China while forcing a tributary to acknowledge the superiority of the Chinese Emperor to the tributary emperor. There could be no equality between Emperors as Confucianism, through the tribute system, precluded equality. The tributary state was treated as a vassal state (Fairbank and Teng: 1941, 140; Feuerwerker: 1973, 44). There was little material benefit to the Chinese Emperor from trade. It was mostly carried out by merchants, a low ranking 
occupation in the Confucian hierarchy, though through various taxes imposed at various times, some revenue could flow to the state.

The tribute system served as a method for the Chinese to control its neighbors through trade provided that the neighbor acknowledged the superiority of the Emperor and the civilization, a combination of material and non-material resources. "By allowing foreigners to pay tribute, it was hoped, they would be transformed into civilized peoples and pose no threat. This cultural transformation served as a defense mechanism to protect China from foreign attacks" (Wang, Y.K: 2012, 148).

A foreign state was of no interest to China unless there was a relationship between the ruler of that entity and the Chinese Emperor. Whether or not there was a relationship depended on distance from the Chinese capital, whether or not they shared a common border, and whether that country was important to the defense of China (Wang, G.:1998, 301). Similarly, whether or not a tributary state was considered a vassal was most likely a function of its distance from China as well as the state of material capabilities of both at any time. Gao Mingshi has suggested that China considered vassal states from three viewpoints indicating importance to China: an inner vassal area, an outer vassal area, and a temporary non-vassal area (Zhang, F.: 1968, 554-5). Ban Gu illustrates this premise: "...the Emperor does not govern the barbarian peoples, their tribute shall not be refused, but they shall not be subjected to governance outside of the Middle Kingdom" (Zhou: 2010, 153).

For China, the tribute system was to provide legitimacy and security. Legitimation of a Sino-oriented world through the legitimation of the Emperor comes from the offerings of tribute and from the highly ritualized submission of the tribute to the Emperor 
and his acceptance of it. Security is addressed through Sinization of the tribute states and avoiding strategic over-reach beyond the inner vassal area. Yet, China was sufficiently conscious of the outer vassal area to prevent another state from governing an outer area. Here we have the origins of a tribute-based foreign policy but still incomplete foreign policy.

As mentioned above, the main benefits received by the tributary were the trading privileges which enabled them to obtain goods from the more advanced Chinese. If a tributary state was under attack from another state, they could call on the Chinese to help repel the invaders (Wang Y.K: 2102, 148). The Ming came to the aid of Korea twice in the late $16^{\text {th }}$ century to repel Japanese invasions (Huang, R.: 2004, 564-74).

Under asymmetric conditions between China and its periphery, Womack suggests that the tributary state would acquire an additional benefit. China would recognize the autonomy of the tributary while the tributary gave deference to the material capabilities of China. This was a necessity as granting autonomy without deference would not work for China and granting deference without recognition would not work for the tributary (Womack, B. : 2009, 101-2). Granting autonomy refers to self-management of the internal affairs of the tributary by the tributary. When China would come to the defense of a tributary under attack from another state, it served to maintain / strengthen that tributary relationship with that state and simultaneously signal to other tributaries China's position of "ruler of all under heaven." 


\section{China's Foreign Policy and Conflict}

The tribute system was used to obtain recognition and security for China, in effect, an inexpensive purchase of security. However, not all states were tributaries and some fluctuated back and forth, the northern borders were never secure, and the material and non-material superiority of the Chinese state fluctuated over time. In addition to the tribute system, other instruments of policy could also be employed, those of pain and of pleasure.

China's national interest also required military means to protect existing tributaries and to punish those reluctant to join the system or those who sought to leave it. Most importantly, it was needed to secure the northern borders. Failure to do so presented an existential threat. At various times during the imperial period, armies of multiple hundreds of thousands of soldiers were raised to counter the threats from the north. The use of military force was common. China was involved in 3790 recorded wars between 1100 BCE and the fall of the Qing in 1911 (Breslin: 2001, 1). China was able to enlist tributaries to fight common enemies as they did with Korea against the Jurchens in Manchuria during the Ming Dynasty (Clark, D.N. : 1998, 289) They also used a divide-and-conquer strategy in the north against the Mongols who were plagued with internal tribalism (Chan, H.L.: 2004, 226-7). An alternative strategy was to encourage the barbarians to fight the barbarians to assure they did not attack China.

Scholars, starting with Fairbank and Teng, have viewed the tribute system as one that was defensive in nature. The expansion of China from its Qin era size to its size in 1911 suggests that there was an expansionary tendency to go along with a defensive trib- 
ute system. This is true even when excluding the additional territories added when foreign dynasties, the Yuan and Qing, were forced out. This can partly be explained by migration into unoccupied areas, migration that diluted the existing populations, tributaries being voluntarily absorbed to China, or by conquest. Expansion into the southwest of today's China was a reaction to the local governance in the aboriginal regions of Yunnan and Kweichow (present day Guizhou). Constant internal disputes, oppression of locals by their chiefs, and attacks on Hans led to an invasion to restore order which resulted in administrative inclusion into China. Migration to Taiwan by individuals and then their families effectively colonized the island to the distress of the original inhabitants. Rebellion by aboriginals and Han eventually led to armed suppression and further expansion by China in Taiwan. Expansion into the northwest was facilitated by incompatible Mongol tribes that the Qing warred against so long as it was in their interest to do so. Final control took about 35 years. (Zelin: 2002, 227-8)

Whenever a large army was raised, either to meet a threat, conquer additional territory, or to function as a standing army, the costs could be exorbitant and were financed by higher taxes. This was an invitation to domestic instability. A way to eliminate or reduce the cost of inflicting pain was to use pleasure, an alternative method of influencing the course of foreign affairs. Traditional sources of pleasure included bribes, lavish entertainment, brides to neighboring states to establish or prolong good state-to-state relations, and sex. (Breslin: 2002, Chapter 1). Of course, both sides of any conflict are subject to the pleasure aspect of diplomacy and, as with pain, the lasting impact is always questionable. 


\section{Chapter III - MAO ZEDONG and POLITICAL FOOD}

This chapter will address the food and foreign policy relationship during the rule of Mao from 1949 through the short period of rule by Hua Guofeng in $1978 .{ }^{42}$ This period is anything but consistent in both domestic and international relations. Yet, there are overriding objectives in both cases that originated with Mao and extended through his successors, some to the current times.

The first section will examine the food paradigm that existed during this period. It is a time of rapid change in the ability to feed the population and ranges between success and failure. Second, the international political system will be examined. This is the time of the Cold War, the cold and sometimes hot war for hegemonic supremacy between the Soviet Union and the US as well as their allies. As a participant in the Cold War, the PRC had its own interests and foreign policy to satisfy those interests. Within the foreign policy existing at the time, the existence of food security or insecurity in the PRC will be examined. In times of food security, food could be used to finance economic development or be exported. The choices of export destinations by an authoritarian or totalitarian government are highly likely to be political decisions, an extension of foreign policy. Similarly, in times of food insecurity, obtaining adequate food supplies from other states are likely to be limited by the existing foreign policy. In either case, one might expect that domestic changes related to the food paradigm at the time might trigger a change in foreign policy or those changes in the PRC's relationship to the international system might result in re-thinking the food paradigm.

\footnotetext{
${ }^{42}$ As Mao appointed or anointed Hua as his successor, he will be considered as part of Mao's rule. Hua, who ordered the arrest of the Gang of Four, was a transitional ruler between Mao and Deng.
} 


\section{The Food Paradigm During Mao's Time}

The construction of the food paradigm under Mao is a reflection of the organization of the state as a whole. The adoption of the Soviet model of the economy and society and its adaptation to the PRC's circumstances dominated this time period. Domestic politics, those of the CCP, were at the fore of decisions. Government control and the communist philosophy required the state-society relationship to shift to greater state control and to penetrate deeply into private lives. The economic development that was considered a key to CCP survival failed yet the CCP survived. On the other hand, while Mao lived many years and was in control most of the time, he set the stage for the dismemberment of many of the policies he implemented.

\section{$\underline{\text { Domestic Politics }}$}

In 1949, the PRC was a poor, war-ravaged country. The Nationalist government and the communist revolutionaries had been fighting off and on prior to the Japanese invasion of 1937. Following WWII, they re-engaged for a final showdown that the CCP won. They inherited a backward devastated land, a population with a low rate of literacy and one that was $80 \%$ rural eking out a subsistence living. The citizens, and especially the rural population, were about to endure more than many could endure.

From the outset, the PRC placed significant emphasis on several factors. First was the consolidation of the revolution. This took two forms: Breaking the hold or influence of the rural elite was accomplished through land redistribution and improving the 
lives of the population as a whole through modernization and economic development (Teiwes, 1995, 51). Second was the need to make good on the CCP claim to rule all of China (Fairbank: 1995, 22). Therefore, they needed to reclaim territories lost to colonization (Hong Kong and Macau), those lost to short-lived independence movements (Tibet and Xinjiang), those lost to the Soviets at the end of WWII (Manchuria and Dalian), and of course Taiwan to conclude the revolution.

The domestic politics of the PRC during the reign of Mao were dominated by Mao, ideology, and the conversion to communism. The conversion of the economy and society would have profound effects on all aspects of life in the new country. The senior leadership, primarily Mao and the Politburo Standing Committee, were generally in agreement on the policies to be initiated and followed. When disagreements occurred, they tended to be in the speed with which programs were implemented. There was concern that rapid implementation might lead to mistakes that would damage the credibility of the CCP. Yet, Mao was in charge. His leadership in fighting the Japanese and defeating the Nationalists solidified his position (Teiwes 1995, 60). When Mao suffered personal setbacks from failed policies, he was always able to make a comeback and pursue his ideals for what China should become. What the PRC has become is in many ways the antithesis of Mao's vision.

The magnitude and extent of domestic political change from 1949 through Hua's time as Chairman of the CCP was extreme. It featured land redistribution, and was aimed at the rural gentry. The "100 Flowers" rectification campaign was directed at intellectuals. Collectivization and the GLF were directed at the rural population to wipe out remaining vestiges of capitalism. Both contributed to famine. Finally, the Great Proletariat 
Cultural Revolution of 1966-1976 (GPCR) was directed at the urban population and leadership that had advocated material incentives to increase agricultural output during and after the GLF. Purges of top leaders and seemingly constant rectification campaigns directed at those viewed as deviating from Mao's line were an ongoing reality. These will be dealt with below, primarily in the discussion of the state-society relationship and the production and distribution capabilities of the PRC during this time.

\section{$\underline{\text { State-society Relationship }}$}

"One great difference between China before and after 1949 would be the material means such as radio, other communications, and police firepower could be combined with ideological sanctions in the Soviet totalitarian form. This combination would now let the CCP state penetrate Chinese society as never before" (Fairbank 1995, 47). At the time, the two most intrusive changes in the state-society relationship were the hukou system and collectivization of agriculture.

\section{The Hukou System of Control}

The first change in the state-society was the initiation of the hukou system, a system that required registration of the entire population. Registration provided the state the means to control unwanted internal migration. The hukou system is an extension of the traditional baojia system in place since ancient times, a registration system that linked a person's residence to that of the family, along with elements of the Soviet internal passport. Ultimately, the hukou system linked a person's registration to his place of work, the 
danwei for urban residents, and to the lowest collective unit for the rural population (Cheng and Selden, 1994; 645).

Citizens were categorized by whether they were agricultural or non-agricultural workers and whether they were local or non-local (Chan and Buckingham 2008; 587-9). Changing one's registration category was controlled. The rationale for such population control came from two sources. First, it prevented the rural population from migrating to the cities in search of work. This kept unneeded workers at home when there was unemployment in the cities. In the event that additional urban labor was needed, private arrangements were eventually replaced by government recruitment. It also provided an opportunity for the government to entice (then compel) urban residents to return to rural areas when there was unemployment coupled with a good harvest. Second, it kept the urban governments from having to provide food, housing, schooling, and healthcare for more people than were needed, benefits unavailable in rural areas.

Initially, enforcement came through having the proper papers permitting one to work in a place or be in a place. Ultimate enforcement came with the imposition of rationing. By 1955, grain and most foodstuffs plus cloth and cotton were rationed. Rations could only be obtained in the place of one's official registration. Rationing was only applicable to urban residents, or government employees working in rural areas. The rural population had to feed themselves. Government assistance would only help rural residents in the event of severe food shortages (Cheng and Selden: 1994, 656-8). The ration received per urban household was a function of the age mix of the household residents and the occupation of the working members, the more physical the work the greater the ration. A household with a large number of workers could actually receive an allotment 
greater than they could consume. The purchase of non-staple items such as furniture and consumer durables required local government approval (Chinn: 1980, 747).

All this resulted in extreme bifurcation of society, "a spatial hierarchy of urban places and prioritizing the city over the countryside..." (Cheng and Selden: 1994, 645). Urban residents had housing, education, retirement, and healthcare provided by or subsidized by the government. Agricultural workers had to live off of their harvests (that which was not required to be sold to the government) and provide for their own housing. Supplemental foodstuffs could be purchased at local markets but only during times when those markets were permitted to exist. Education and medical care were spotty at best. Following collectivization, food, education and medical care were provided by the collective.

\section{Collectivization}

The hukou system kept the rural peasants from migrating to the urban areas and the collectivization process allowed for deeper penetration of the state into the hinterlands than ever before. The progression to collectivization of agriculture was supposed to be a step-by-step process covering three phases; land reform, mutual aid teams, and semi-socialist co-operatives. Participation in each phase, following land reform, was to be voluntary. After all, many poor peasants had just received their land and would not be willing to give it up so soon (Walker: 1966, 9).

Land reform had been under way during the civil war in CCP dominated areas prior to formation of the PRC. It was expanded to the rest of the country and completed by 1952 . The land reform had two purposes. First, it was a means of putting land into 
the hands of the poor peasants, those who were landless and served as agricultural labor for landlords or rich peasants. With their own land and their ability to reap the benefits of their own labor, the recipients of the land were assumed to produce more grain than otherwise would have occurred. Second, it was a way of defusing the power of the landlord class, a natural opponent of the CCP (Walker: 1966, 3-4). By 1952, 300 million peasants had received 50 million ha. of land (Wang and Davis: 2000, 21)

Mutual-aid teams (MAT) were the first step in the collectivization process. They were the voluntary grouping of five to seven households that would pool their resources of land, labor, and whatever machinery or animals they had during busy times of planting and harvesting. All in all, this was a natural method of addressing the nature of farming. By the end of 1954, there were 10 million MATs comprising 58\% of peasant households. Elementary Agriculture Producer's Co-operatives (EAPC) consisted of about 30 households and 13-20 ha. of land. Membership was voluntary, land and resources were pooled, and profits were divided based on land, labor, and tools contributed. Land and tools were still privately owned and private plots were allowed. By mid-1955 there were 630,000 EAPCs comprising 17 million households.

Advanced Agriculture Producer's Co-operatives (AAPC) consisted of four to eight EAPCs. It is at this point that the state-society relationship started to change. Households were required to give up title to their land and other capital goods. Income was based on labor contributed, private plots were allowed, and households were able to keep hand tools to work the private plots. Members lost their ability to decide what to produce and where to sell. Management was centralized. By late 1957, there were about 735,000 AAPCs encompassing about 119 million households. 
The final step was the creation of communes, an amalgamation of AAPCs into 24,000 communes comprising about 5,000 households apiece and 4,000 ha. of land. Membership included $99 \%$ of all rural households. No private plots were permitted. Ownership of all assets belonged to the commune. No non-commune work was permitted. Income was a function of labor contributed. The commune became a branch of the government, the place where all decisions were made with respect to commune operations (Wang and Davis: 2000, 22-5). A key reason for the creation of the commune was the ability to mobilize larger work forces to work on rural projects such as water projects including canals and dams (Lin: 1990, 1233-4).

Simultaneously with the march towards communization, the state was increasing the amount of grain it took from the farmer. During the period of land reform, $10 \%$ of production was procured by the government at a government-established price. That price increased 25\% from 1950 to 1953 . The government had to compete with the stillexisting private market for grain. Coincident with the arrival of MATs, the quota was raised to 25\% and in 1957 it reached 75\%. Between 1953 and 1957, the government procurement price increased only 10\% (Lardy: 1983, 30). With communization, all production belonged to the commune (state). The commune served the same purpose as the urban rationing system regarding food: it controlled demand.

Each step of the way the state-society relationship was altered with the state taking a larger and larger role in the production and distribution of public goods. However, it could not be maintained. The rapid transition to the commune presented problems with management of such large undertakings. There were issues between poor and middle-income peasants concerning the value of their contributions. Over-enthusiastic cadres were 
often opposed to peasants opting out and used coercion to maintain membership. ${ }^{43}$ Finally, managing an organization of 5,000 households would present problems for even the most astute manager; cadres were frequently in management positions due to political considerations rather than management abilities (Walker: 1966, 10-12).

The dramatic fall in grain production from 1959 through 1961, the period of the GLF, led to loosening of control in rural organization. As early as 1959, private markets were re-opened in rural areas. Private plots in communes were re-introduced in 1960, and the commune itself permitted devolution of decision-making to the production brigade level, 20-30 households (Lin: 1990, 1234). In 1961, decision-making moved further down the commune organization structure to the production team. In effect, the communization era was over as communes began to operate as MATs / EAPCs while still maintaining their governmental function. It was not until the reform period of Deng that the commune ceased to exist.

\section{$\underline{\text { Economic Development }}$}

The economic development of the PRC was a top priority of Mao and the CCP leadership. Improving the lives of the citizenry was the primary method of securing the

\footnotetext{
${ }^{43}$ Justin Lin Yifu looks at the failure of communes from a higher level. He maintains that it was the elimination of the right to withdraw from communes in 1958 that led to a reduction in output. This right let efficient farmers withdraw and avoid the issue of free-riders within the commune system. Yet the success of the commune rested upon efficient labor input. Without that right to withdraw, the commune would not disintegrate but neither would it flourish, " in a one-off game, staying idle [or reducing one's labor input] is the rational option" (Lin: 2102, 95).
} 
revolution, and economic development was one of the means. It also served to demonstrate to the world that China was again going to be a leading state in the world. As Mao had chosen to "lean" towards the Soviets, it follows that using the Soviet model of economic development was natural. Was the Soviet model one to be emulated by the PRC? At the times of their respective revolutions, the Russian population was $70 \%$ urban while the PRC was 80\% rural (Lieberthal: 1995, 300). The agricultural output of Russia was $480 \mathrm{~kg}$. per capita per year in 1928--the start of Soviet collectivization--while China's was only $220 \mathrm{~kg}$. in 1952, barely at subsistence levels (Keuh: 2006, 708). The absence of grain to export to earn FX to pay for modernization was a significant problem for the CCP.

While the PRC had aligned itself with the USSR for ideological reasons, there were other reasons also. Soviet industrialization in the 1930's was the most rapid for any country to date (Goldman: 1980, 55). Soviet agriculture, from 1928, showed impressive gains in output (Wilber: 1969, 91-2). The Soviet model of economic development was to concentrate on the development of heavy industry - iron, steel and the like. Both the USSR and PRC adhered to a policy of "selective development" of heavy industry under conditions of austerity (Tang: 1967, 1118). Light industry and agriculture would receive much less investment and would support the development priority. The Soviets allocated $42 \%$ of investment capital towards the development of heavy industry. The PRC allocated 48\%. (Lieberthal: 1995, 303). Perhaps this was a function of Mao's ego: an attempt to demonstrate to the Soviets that the CCP could achieve "developed" status faster and better than its benefactor. In addition to resources being directed to heavy industry, they 
were also directed to the development of scientific and technical skills, and the application of up-to-date technology for priority sectors. Agriculture was to be exploited for the benefit of heavy industry. Domestic trade, services, residential housing and maintenance suffered from relative neglect. Capital to finance such investment would come primarily from domestic sources as opposed to trade and aid (Prybyla: 1970, 113-5). ${ }^{44}$

In order for the policies to be successful, agriculture needed to supply excess foodstuffs (that not needed for consumption by the producers) to feed the urban workers, to provide inputs for light industry (for example, cotton and tobacco), and to be used for trade in exchange for industrial inputs or technology. The maximum that can be extracted from the peasants serves to limit, or is the bottleneck, to meeting industrialization goals (Tang: 1967, 1124-28). The situation created by heavy-industry-first policies of PRC economic development, at the expense of agriculture, served to undermine the ultimate goal.

The emphasis on heavy industry ran counter to previous statements by Mao. In his 1943 report On Coalition Government, Mao stated: "It is the peasants who constitute the main market for China's industry. Only they can supply foodstuffs and raw materials in great abundance and absorb manufactured goods in great quantities" (quoted in Lardy: 1983, 15). When he put the investment emphasis on heavy industry, he continued to maintain that agriculture was a market for industrial output. Yet, his only real attempt to stimulate agriculture was though social changes and bureaucratic means (Lardy: 1983, 15-6). This situation was exacerbated by the "scissors effect", keeping the prices paid for

\footnotetext{
44 The application of technology was combined with the heavy use of unemployed or underemployed labor to take advantage of the availability of labor while judiciously using scarce capital.
} 
grain low and the prices for all other items high. This eliminated the peasant as a purchaser of light industrial products (consumer goods) and limited the potential for light industry to contribute to the economic development of the country.

As would be expected, the path to economic development and the role of agriculture were much debated at the senior levels of the CCP. Liu Shaoqi maintained that collectivization should only occur once sufficient mechanized equipment existed to offer the farmer an incentive to join collectives (Chao: 1970, 16-7). Mechanization would permit more efficient use of large-scale farming and ease the labor burden on individual farmers, an incentive to voluntarily join the collective. One must also assume that such a policy would provide excess labor for industrialization. Chen Yun, who was responsible for the economy, was in favor of a more balanced approach to development with more investment in light industry and agriculture. ${ }^{45}$ Chen's view also included a thoughtful and rational transition that emphasized the need to avoid rash advances (Vogel: 2005, 12-3). Nor did Chen think that collectivization would improve overall agriculture output; collectives were not superior to individual farms. However, he supported collectivization as it would be easier to procure grain from collectives as opposed to individual farms (Chao: 1970, 33). In 1955, Mao's opinions carried the most weight, and the speed of collectivization was increased without additional mechanization and without adjusting investment between sectors of the economy. After all, the factor endowment that the PRC had in abundance was agricultural labor so who needed mechanization? Further, voluntary movement to the collectives was better than Chen expected.

\footnotetext{
45 This approach is similar to Bukharin's recommendations in the USSR. Chen spent several years in Moscow studying the Soviet economy.
} 
Collectivization, the governing of the collectives by cadres and the projects implemented by the cadres, taken together, produced the disaster of the GLF. Oftentimes disasters have many causes; the GLF is not an exception. First, the culture of reporting results of the harvests was not one of what was actually produced but rather which reporting entity could surpass the target by the most. This was bravado or fear of reprisals for not meeting objectives. Reporting more than the actual served to justify the $\mathrm{CCP}$ and its leadership and the decisions they had made. Unfortunately, when those false claims were accepted as true they led to improper follow-on decisions. Second, the projects that the collectives were able to undertake given their large memberships took the members from their primary tasks of growing crops. Insufficient attention led to reduced output, especially at crucial times in the planting - harvesting cycle. Third, directives from Beijing to improve output did the opposite. Close planting, deep plowing, increasing multiple cropping (more than one crop per year on the same piece of ground), and inappropriate pairing of crops in multiple cropping caused decreases in output. Mao was an advocate of close planting and deep plowing while the planners in Beijing altered cropping patterns without sufficient knowledge of what farmers had learned over thousands of years of experience. Fourth, the CCP operated a planned economy and planning extended down to the collectives. Collectives were basically to be self-sufficient and to provide most, if not all, of its food needs, regardless of the growing conditions. "Local economic units soon began to promote their own self-sufficiency without regard to the needs of other localities and the flow of goods between localities. In a sense, China reverted to its traditional localism" (Prybyla: 1970, 283). Finally, rural markets continued to exist in the PRC until 
communization. Mao was concerned that capitalism was gaining momentum in rural areas and needed to be stomped out. The elimination of local markets and the private plots that supplied them removed an alternative source of grain supply and income for individuals that existed until that time.

The GLF was a disaster. The resulting famine claimed between 15 and 60 million lives. ${ }^{46}$ Mao's prestige within the ranks of the $\mathrm{CCP}$ was diminished at the highest and the lower levels. The Soviets withdrew their technical assistance without warning to emphasize their displeasure at the path the $\mathrm{CCP}$ was taking. This action was a major blow to PRC economic development and to Soviet - PRC relations, one that would lead to a shift in the international political system, and one that was not repaired for decades. Mao recognized that mass mobilizations do not work for economic development but retained his faith in mass mobilizations for political ends (Lieberthal: 1995, 319-21).

Recovery from the disaster came through several channels. Collectivization was maintained but there were changes in management, economic liberalization, and the reallocation of resources among economic sectors. Planting and compensation decisions were delegated downwards to the production brigade level in 1960 and then to the production team level in 1961, essentially the level that existed during the MAT period (Chao: 1970, 64) ${ }^{47}$ Private plots totaling about 5-7\% of commune land were reinstated. Prices paid for grain after fulfillment of taxes were increased 27\% (Lardy: 1995, 388).

\footnotetext{
${ }^{46}$ For a discussion of the number of deaths and births forgone plus relief efforts, see Lardy in Cambridge History of China, pp. 372-8.

${ }^{47}$ In 1962, the production team was reaffirmed as the official institution of the rural sector. Individual households had been farming allocated commune land independently, though they had to provide a percentage of the harvest to the production team. Mao was adamantly opposed to the household system (Chao: 1970, 65).
} 
Rural markets were reopened for all agricultural commodities except grain, cottonseed, and oil seeds (Prybyla: 1970, 352).

The structural changes were simple in principle; agriculture became the priority followed by light industry and then heavy industry. Heavy industry still received the largest share of investment capital, but investment in agriculture and light industry did grow at faster rates. Improvement in agricultural output would feed the people and provide inputs to light industry whose profits could be used to fund the sector that needed it most. Plus improvement would provide for exports to earn FX that could be used to purchase technology and raw materials in short supply or unavailable in the PRC. Agriculture first would be the mantra of the CCP for decades. To prioritize agriculture, Chen wanted to resort to comparative advantage and plant specific crops in areas with high and stable yields. Self-reliance was not a smart economic policy (Lardy: 1995, 391). In such areas, the emphasis would be on improving the productivity of the existing land through the use of chemical fertilizers, pesticides and insecticides, improved seed, the development if transportation capabilities (railways, roads), and improved mechanization (Prybyla: 1970, 359-66).

At this point, with the withdrawal of Soviet technicians, aid, and credits, that selfreliance became necessary. There was insufficient FX to import much and no interest by non-communist countries to assist the PRC. This was reality, yet the need to import was there; self-reliance was not autarky. "The doctrine of self-reliance hinges on the postponement of the revolution of rising expectations; it is part and parcel of a broader philosophy of austerity... [However] failure to make use of foreign technological and scientific advances, to benefit from some measure of derived development will tend to bring 
about much wasted effort, a rediscovery of things long since known elsewhere, an artificial restriction of developmental inputs." Domestically, self-reliance was confidence in the people to continue the task of development. Internationally, it was avoiding dependence that might occur with too much foreign assistance (Prybyla: 1970, 399-400).

The agriculture-first policy continued under Mao's watch. GLF food shortages were made up by imports beginning in 1962 and have continued since. Agricultural output did not reach pre-GLF levels until 1965. Mass political mobilizations continued; the GPCR being the post-GLF high point. The GPCR was directed at the urban population and had little impact on food output. Perhaps Mao feared a repeat of the food shortages of the GLF. However, the GPCR did negatively impact the efficiency of the rail network and the movement of food to the cities. The 1960's were also the time of the "green revolution," a period of new strains of seed that greatly improved the output of both rice and wheat. The use of green revolution seeds and the focus of the GPCR on urban areas limited any negative impact on food output during the GPCR.

Lardy neatly sums up the output of agriculture during the Mao period by dividing it into periods of direct planning and indirect planning. ${ }^{48}$ Direct planning, or production planning, was "characterized by the imposition of detailed sown area and output targets and specific cropping patterns by higher-level authorities on production units" (Lardy: 1983,19). To meet production targets incentives were not employed; command from above was considered sufficient. Little attention was paid to efficient allocation of resources and farmer income. Inefficiency was rampant, and output and income declined.

\footnotetext{
${ }^{48}$ One could also refer to direct planning as further encroachment by the government on the state-society relationship while indirect planning refers to the society, via a market system, providing more public goods.
} 
Direct planning was attempted first in 1956, utilized in 1958-60 during the GLF and from 1966 to 1977 . Other than during the initial years of the PRC, direct planning was used when Mao was in complete charge.

Indirect planning “...relies essentially on state manipulation of credit, procurement contracts, taxes, and prices. State procurement prices are the major policy instrument used to influence the growth and composition of farm output..." (Lardy: 1983, 189). The use of incentives gave farmers the options as to what crops to plant, which encouraged the use of comparative advantage, when to use credit, and whether to sell their after-tax output to the local market or to the government. Farmers acted to maximize their income, which maximized output. The indirect method was used prior to 1956 , when there was no other choice, and during the recovery from the GLF to 1965 . Once there was a choice, indirect planning was used only when Mao was in a period of relative weakness.

“Overall, Mao left China largely self-sufficient and possessed of the sixth biggest economy in the world" (Terrill: 1993,446-7). Yet, the PRC's ranking was the result of its large population. On a per capita income basis it was 190 USD in 1978, approximately $10 \%$ of the world average.

\section{$\underline{\text { Population }}$}

Population, especially as it relates to population control, would seem to be an aspect of the state-society relationship. Controls on internal migration are one aspect but control of human reproduction by the state is the ultimate intrusion by the state into society. However, population has its own place in the food paradigm as the total population 
of the PRC is roughly a quarter of the world total, dramatically affects food security, and has been the subject debate within the CCP since its early days.

In 1949, Mao was confident that the PRC could clothe, feed, house, educate, and employ the population. This was consistent with the CCP's pro-natalist policies during WWII and with the Soviet post-war policies; both driven by the high loss of life caused by the war. However, in 1952, attitudes began to change. The elite wanted access to birth control. There was a move to comprehensive planning which included the rural-urban split, and there was increased anxiety concerning the ability to feed the entire population. In 1953, Deng came out in favor of birth control. In 1955, birth control was promoted on a purely economic basis. Without some control, people's livelihoods, the welfare of the country, and that of following generations would be adversely impacted. While these policies were generally aimed at urban areas, Chen Yun advocated a twochild policy for both urban and rural households.

With the Twelve Year Agriculture Plan population control--euphemistically called birth planning--came into being. This included delaying marriage and spacing the births of children. Speaking of the need for population control, Mao maintained “...if we wait until the population reaches 800 million to carry it out, it will be too late. [We must] achieve planned births step by step" (quoted in White: 2006, 39).

The disaster of the GLF must have raised anxiety levels concerning the ability to feed the people. Concern for the agricultural output was joined by concern for the number of mouths to feed. In 1962, birth planning was expanded to densely populated rural areas (suburbs) which included the two-child maximum and later marriage. Zhou Enlai was 
prominent in promoting these policies. During the GPCR, interest in birth planning varied inversely to grain production results. Senior leadership retained an ongoing concern about the ability to supply sufficient food for the population. After the initial years of the GPCR, birth planning flourished. However, birth planning does nothing to satisfy the immediate need for food. The radicalization of the time led to promoting self-sufficiency as opposed to comparative advantage and a return to direct planning for agriculture. This included reversing the reforms (private plots and rural markets) that had been introduced to aid in the recovery from the GLF, lessened the immediate output of food. This was partially offset by a reduction in industrial crop production in favor of grain.

In 1975, the limit on births was put at three for rural households and remained at two for urban households (White: 2006, 19-61).

\section{Analysis of the Food Paradigm During Mao's Reign}

The food paradigm, from a domestic point of view, was a roller coaster of success and failure. ${ }^{49}$ The key question is whether or not there was food security or insecurity in the

\footnotetext{
${ }^{49}$ There is a general problem with agricultural production and trade numbers as well as financial numbers for the PRC during the period of 1949 through 1987. In general, PRC numbers suffer from incompleteness, inaccuracy (both based on methods of calculation as well as obfuscation), changes in category definitions, not reported, and restatements of figures, all of which make it difficult to generate a series of production, trade, or financial figures that is consistent over time. In some cases, a series of figures will be generated by an institute or scholar to the point in time the work was published with no subsequent continuation using the same sources or methods. The source of all numbers will accompany each presentation of figures and the sources identified, as would be expected. However, there will be years when no figures are available or the sequence of figures is not or appears not to be consistent.

With regards to agriculture production numbers, those from 1958 through 1960 are quite suspect. Generally they are not reported, otherwise they are attempts retroactively to approximate them. Those from 1949 to 1957 either come from the PRC government or are approximated by scholars. (A number of scholars have used a variety of sources to approximate obvious reporting issues.) Production numbers are also suspect for the period of the GPCR when they were not always reported due to the chaos at the time. The FAO has published Food Balance Sheets for the PRC since 1961. However, many of its numbers are a three-year average rather than annual numbers. In some cases, annual figures can be obtained.
} 
PRC. As shown in Table 3.1, through 1958, based on domestic production only, grain consumption per capita was increasing, in spite of population growth. However, the PRC

\begin{tabular}{|c|c|c|c|c|c|c|c|c|c|c|}
\hline \multicolumn{11}{|l|}{ Table 3.1} \\
\hline \multicolumn{11}{|c|}{ Indicators of Food Security / Insecurity } \\
\hline Year & $\underline{1949}$ & 1950 & 1951 & $\underline{1952}$ & $\underline{1953}$ & 1954 & $\underline{1955}$ & $\underline{1956}$ & 1957 & $\underline{1958}$ \\
\hline$\%$ change in total grain output (1) & & $17.1 \%$ & $23.8 \%$ & $1.2 \%$ & $2.5 \%$ & $1.8 \%$ & $8.2 \%$ & $4.9 \%$ & $1.0 \%$ & $2.6 \%$ \\
\hline$\%$ change in population & & $1.9 \%$ & $2.0 \%$ & $2.1 \%$ & $1.4 \%$ & $3.3 \%$ & $3.1 \%$ & $2.2 \%$ & $2.9 \%$ & $2.1 \%$ \\
\hline $\mathrm{K} /$ cal consumption per capita per day (2) & & 1,742 & 1,856 & 2,083 & 2,048 & 2,041 & 2,232 & 2,326 & 2,217 & 2,248 \\
\hline Year & $\underline{1959}$ & $\underline{1960}$ & $\underline{1961}$ & $\underline{1962}$ & $\underline{1963}$ & $\underline{1964}$ & $\underline{1965}$ & $\underline{1966}$ & $\underline{1967}$ & $\underline{1968}$ \\
\hline$\%$ change it total grain output & $-15.0 \%$ & $-15.3 \%$ & $2.8 \%$ & $8.1 \%$ & $6.3 \%$ & $10.6 \%$ & $3.7 \%$ & $9.7 \%$ & $1.9 \%$ & $-4.1 \%$ \\
\hline$\%$ change in population & $1.8 \%$ & $-1.5 \%$ & $2.9 \%$ & $1.3 \%$ & $1.4 \%$ & $0.1 \%$ & $2.1 \%$ & $2.5 \%$ & $2.8 \%$ & $2.9 \%$ \\
\hline $\mathrm{K} /$ cal consumption per capita per day (3) & 1,920 & 1,378 & 1,415 & 1,526 & 1,594 & 1,666 & 1,797 & 1,865 & 1,817 & 1,758 \\
\hline Year & $\underline{1969}$ & $\underline{1970}$ & 1971 & $\underline{1972}$ & $\underline{1973}$ & 1974 & $\underline{1975}$ & $\underline{1976}$ & 1977 & $\underline{1978}$ \\
\hline$\%$ change it total grain output & $1.0 \%$ & $13.7 \%$ & $4.2 \%$ & $-4.0 \%$ & $10.4 \%$ & $3.8 \%$ & $3.6 \%$ & $0.4 \%$ & $-1.0 \%$ & $7.8 \%$ \\
\hline$\%$ change in population & $2.9 \%$ & $2.8 \%$ & $2.7 \%$ & $2.5 \%$ & $2.4 \%$ & $2.2 \%$ & $2.0 \%$ & $1.7 \%$ & $1.5 \%$ & $1.4 \%$ \\
\hline $\mathrm{K} / \mathrm{cal}$ consumption per capita per day (3) & 1,731 & 1,840 & 1,845 & 1,828 & 1,897 & 1,893 & 1,909 & 1,875 & 1,914 & 2,062 \\
\hline \multicolumn{11}{|l|}{ Sources } \\
\hline $\begin{array}{l}\text { 1) Grain production 1949-1951 } \\
\text { 2)From (Piazza: } 1986,83-4) \text { ) th } \\
\text { 3) Source: FAO Statistics Divisi } \\
\text { Shaded areas indicate years in which pop }\end{array}$ & $\begin{array}{l}\text { Chen: } 196 \\
\text { ugh } 1960 \\
\text { n - Food }\end{array}$ & alance Sh & oductio & 952-197 & PRC Sta & Statistica & ureau, & ious ye & & \\
\hline
\end{tabular}

was food insecure as measured by average daily calorie consumption; the FAO maintains that the minimum calories intake per day should be $2200^{50}$. The establishment of communes and the GLF crushed output and created famine. Per capita calorie intake decreased almost 30\% from 1958 to 1961 and per capita grain consumption fell by $27 \%$.

Trade numbers by weight, when available, seem to be consistent. They do suffer from omissions and periods of no reporting. During the time of state control of all exports and imports, tonnage numbers are generally available from Ministry of Foreign Relations and Trade. Permission for private international trade was granted in 1983 and from that point agricultural shipments are based on value and collected and published by Customs. From 1987 on, there are good figures for tonnage shipments both to and from specific countries. Prior to that point, source and destination of shipments are not always available.

Financial numbers suffer the same issues regarding availability. They are complicated by barter transactions and the pricing of products during the intra-Soviet bloc trade.

${ }^{50}$ National statistics for caloric intake should represent the age distribution of the population as well as the activity levels the population is required to perform in employment. The figures used here and in Table 3.1 do not necessarily reflect that. The recommended caloric intake per day was 2200 at the time; later it was increased to 2300 per day. 
Consumption of domestic grain production per capita did not achieve the 1958 levels until 1977. Rural per capita consumption of grains lagged urban consumption by up to nearly $50 \mathrm{~kg}$ per year in 1952. By the end of Mao's era, the gap had closed to less than $15 \mathrm{~kg}$. per year (Wang and Davis: 2000, 144). Grain is not unique; rural consumption lagged urban for nearly all categories. Not only did the PRC food insecurity continue, it also reached existential concerns for the CCP.

Recovery from the GLF was hampered by the decreasing arable land per capita. Obviously a significant cause of this decrease was due to population increases but also because of GLF policies and arable land being removed from production by economic development. Food insecurity would have been worse without the application of science. The conversion to the use of chemical fertilizers and hybrid rice and wheat seeds provided for yield increases that offset the loss of arable land. Domestic chemical fertilizer output increased 600-fold and imported chemical fertilizer increased 63-fold between 1950 and 1978, albeit from a very low base. Higher yielding "dwarf" rice hybrid seeds were introduced in the PRC in the mid 1950's. ${ }^{51}$

Why did grain output decline and remain low from 1958 until the end of Mao's reign? Lardy's periods of direct and indirect planning provide a view of material incentives, and government top-down planning impacted output. In Table 3.2, where the shaded areas represent times of direct planning, we can see production react to material

\footnotetext{
${ }^{51}$ Dwarf rice is shorter which keeps the plant from falling over and produces more kernels per plant.
} 
incentives. ${ }^{52}$ The average annual price increase for grains and the government procurement percentage of the output provide the key information. ${ }^{53}$ From 1949 through 1952, the output per capita increased $69 \mathrm{~kg}$ per year. This was a period marking the end of the civil war, land redistribution, and one year of government mandated price increase, all under indirect planning. From 1952 through 1957--a period of continuing price increases, the imposition of mandatory government procurement and an aborted attempt at communization--during this time per capita production increased by $18 \mathrm{~kg}$ per year. Other than the year of attempted communization, it was a time of indirect planning. From 1957 through 1960, the period of the GLF, communization occurred, price increases were reduced, government procurement increased, and direct planning was in full swing. The result was a reduction of $60 \mathrm{~kg}$ per capita per year of grain output.

The recovery period from 1961 through 1965 marked a return to indirect planning, price increases and reduced government procurement. The result was an increase in grain output per capita of $48 \mathrm{~kg}$ per year. From 1965 through 1976 in the time of the GPCR, there was a return to direct planning. However, it was much less radical than the GLF in rural areas. Grain price increase continued but at a lower rate while government also continued but at a reduced rate. After an initial fall in grain output during the most

\footnotetext{
${ }^{52}$ The total grain production shown in this table includes rice, wheat, coarse grains (including maize), soybeans, and potatoes that are converted to grain equivalents. This reflect the need for seed for the following year's crop that will come from the current crop, uses for animal feed, processing and waste or spoilage. What you see for output on a per capita basis is not what you get to eat.

${ }^{53}$ The typical farmer would keep approximately two thirds of his output for personal consumption. As the government procurement percentage approaches one third of the output, there is nothing left to sell in the private market, if the private market is operating. Should there be additional grain left to purchase following household consumption and required sales to the government, the government would still purchase whatever the farmer was willing to sell. At times purchase price was the same as the required sale price or higher.
} 
chaotic years of the GPCR, production recovered with increases in grain output of $24 \mathrm{~kg}$ per capita per year.

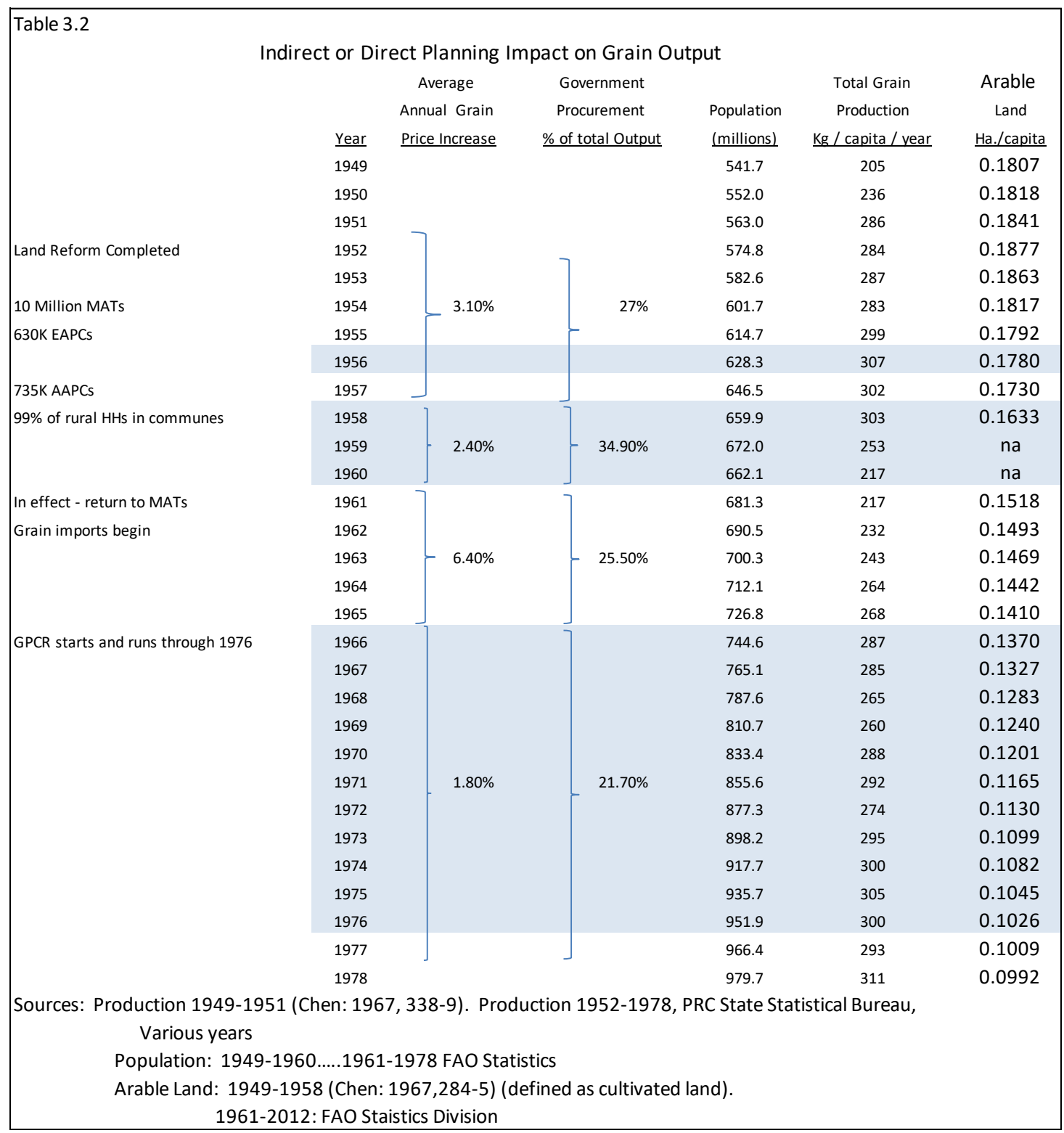

Under direct planning, the net result was a reduction in grain production per capita by $36 \mathrm{~kg}$ per year $(-60+24)$. Under indirect planning there was an increase of $135 \mathrm{~kg}$ 
per capita $(69+18+48) .{ }^{54}$ Therefore, it is safe to say that output reacted positively to the increases in prices for grain, a material gain.

Similarly, a reduction in forced government procurement provides a greater opportunity to sell excess production in the open or less restrictive local markets where prices are higher. These three factors provide a strong incentive for the farmer to produce more. When the opposite occurs, the choice of what to plant is not in the hands of farmers and prices are government established and government is the sole buyer, production falls. ${ }^{55}$ As previously mentioned, free markets for some grain products did not exist. In such cases, the government created a multi-tiered pricing system. Once a farmer met the required sales to the government, additional sales could be made to the government at a higher price. In this way, though there was a single buyer, the farmer still had an incentive to produce more. With the onset of the GPCR, the government procurement actually fell rather than increase as it had done in previous direct planning times. This was due to the imports of grain that began in 1961. That grain went to the coastal cities relieving the pressure on the rail system as well as easing the strain on the rural population caused by government extraction. Reduced forced procurement, even though price increases were reduced, did lead to higher outputs, though at a lower rate than could have been achieved. Direct planning periods have led to a reduction in arable land even though the highest level of collectivization was, in part, to provide manpower to increase the output

\footnotetext{
54 The years 1977 and 1978 are excluded as they are transition years.

${ }^{55}$ It should be noted that there is a lag time between policy changes and changes in output. Hence, one sees the highest output, at the time, during the first year of the GLF and the lowest output a year after the return to indirect planning.
} 
of the land with water collection for irrigation when needed and to control flooding. But water collection activities also turned farmland into ponds. The GLF-caused famine led to an absolute decrease in population in 1960. Yet the next mass campaign, the GPCR, led to an annual population growth of $2 \%$ to $2.9 \%$ per annum over the first eight years, an increase of $23 \%$ over the average population growth rate when compared to the first nine years of the PRC.

Continuous population growth influences the arable land per capita available to grow food but also the amount of food production per capita. The ability to increase output in light of the rising population comes from multiple cropping and the use of chemical fertilizers and hybrid seeds. Direct and indirect economic planning has a more immediate impact on output. In times of indirect planning, when the farmer chooses what to plant and a market exists to value output, the higher the annual price increases for grain the higher the output as measured in total grain production per capita.

A key question in the area of economic development is whether the PRC was able to leverage its agricultural economy to export and generate FX that would allow technology imports (Mellor and Johnston: 1961, 588). As can be seen in Table 3.3, this was accomplished during the first ten years. The situation was reversed when extensive grain imports were required to offset the production shortfalls of the GLF and continued, reducing the agriculture balance of trade thereafter. It should be noted that agriculture exports are all inclusive of agricultural products, not just grain. Included are silks, tung oil, hides, and tea, among others. Implicit in these agricultural trade surpluses, the PRC was self-reliant in agricultural production whenever the balance was positive even though there were imports. When negative, self-sufficiency is implied. 
Table 3.3

\begin{tabular}{cccccccccccc}
\multicolumn{8}{c}{$\begin{array}{c}\text { Agriculture Balance of Trade } \\
\text { (millions USD) }\end{array}$} \\
\hline$\frac{1950}{96}$ & $\frac{1951}{127}$ & $\frac{1952}{235}$ & $\frac{1953}{495}$ & $\frac{1954}{474}$ & $\frac{1955}{639}$ & $\frac{1956}{736}$ & $\frac{1957}{581}$ & $\frac{1958}{689}$ & $\frac{1959}{753}$ \\
$\frac{1960}{488}$ & $\frac{1961}{-292}$ & $\frac{1962}{-184}$ & $\frac{1963}{-189}$ & $\frac{1964}{-70}$ & $\frac{1965}{132}$ & $\frac{1966}{422}$ & $\frac{1967}{355}$ & $\frac{1968}{286}$ & $\frac{1969}{804}$
\end{tabular}

Was this the best that could be accomplished? Huang et al maintain that agriculture's potential was not realized. Top-down institutional planning and the emphasis on self-sufficiency did not allow comparative advantage in what products were produced where, therefore negating any opportunity to trade with the world products where a cost or quality advantage was present (or could be developed). The top-down planning also established how much of what product was to be exported based on an annual plan, not what was available and financially viable to export.

Finally, the currency was overvalued. ${ }^{57}$ Huang et al go further and suggest than none of the agriculture objectives supporting economic development was achieved. While output increased, consumption was insufficient to meet the UN minimum requirement of 2300 calories per day. It failed to provide labor to the non-agricultural sector due to the hukou system. It failed to provide raw materials for light industry as evidenced by

\footnotetext{
${ }^{56}$ Source: Kirby, R.H., “Agricultural Trade of the People's Republic of China 1935-69”, Foreign Agricultural, Economic Report, Economic Research Service, Washington, DC, Aug., 1972.

${ }^{57}$ For a discussion on the currency values during the Mao period, see Lardy ("Chinese Foreign Trade," The China Quarterly, No. 131. 692-3).
} 
the need to ration clothing. And it failed to increase incomes, or was not allowed to (Huang, Otzuka, and Rozelle: 2008, 469).

The net result of Mao's rule regarding food security is mixed. Domestic rice production increased by about $50 \%$ and wheat production more than doubled. Yet the population increased by $80 \%$. Increases in yields allowed per capita consumption of grain to remain approximately constant from 1957 to 1977, excluding the GLF disaster. Yet, this is a time of gross government mismanagement. The large number of deaths due to starvation during the GLF, attributable to direct planning, excessive extraction to keep the wheels of heavy industry turning, false reporting of production, adding non-agriculture tasks to rural workers, forced communization, and the creation of Potemkin farms to fool touring officials as to the failure of the GLF delayed remedial action. Society became justifiably suspect of the state's abilities to provide public goods at the level the state desired.

Despite the initial increases in food production, the PRC was experiencing food insecurity. As shown in Table 3.2, the population was growing quickly, the arable land per capita was declining, and economic and political issues complicated production. The most striking indicator of food insecurity was the low level of caloric intake per capita per day. Estimated for the initial years of the PRC, the post-1958 average daily caloric intake of energy did not exceed the initial year's estimates until 1978 and were still below the FAO recommended level of 2200 per day in 1971 (Perisse: 1981, Table 1) ${ }^{58}$, a

\footnotetext{
${ }^{58}$ National statistics for caloric intake should represent the age distribution of the population as well as the activity levels the population is required to perform in employment. Perisse's statistics represent a composite of developing countries. Smil, using China demographic statistics, found that the China need for caloric intake was 2210 calories per day in 1983 (Smil: 1986, 29).
} 
chronic deficit in food consumption. The only way to address this issue, at least in the short term, was to import grain. Importing brings the international politics into the equation.

\section{International Politics and Food Security}

Foreign policy is formed by both domestic politics and international politics. This section will examine the international system and the phases of PRC foreign policy during Mao's reign. The international system is the world of states into which the PRC was born in 1949. It encompasses the relations among states ranging from diplomacy to trade to conflict to migration as well as the transmission of ideas (Buzan: 1993, 331). For each foreign policy period, "high politics,"-- relating to national security--will be addressed first as they will influence the "low politics," relating to trade and investment (Cooper: 1972, 18). In the realm of food security, these two areas of international politics will overlap; national security depends not only on maintaining political independence but also on the ability to provide food supplies for the population. In the case of the PRC, the inability of the CCP-directed economy to provide food for the population presents an existential threat to the CCP (Buzan: 1998, 100-4). Therefore, attention must be paid to trade relations as trade was essential for the PRC in its economic development, food se-

curity, the choice of trading partners, and PRC's position in the international system. The result will be the influence of foreign policy on food security and the influence of food security on foreign policy. 


\section{The International System}

The Cold War, from the creation of the PRC to the unraveling of the USSR, dominated the entire period of Mao's rule and most of Deng's. The Cold War pitted the US vs. the USSR, each with its own allies, in a struggle for hegemonic superiority. The nuclear capabilities of the two superpowers deterred each other as well as the core allies of both. ${ }^{59}$ As a result, direct conflict between the USSR and US was avoided. Nuclear deterrence, however, did not stop either superpower from engaging in conflict via proxies or directly with a state on the periphery of the other's bloc. The US fought against USSR and PRC-backed forces in Vietnam and Korea, while the USSR's invasion of Afghanistan resulted in US arms support for Afghanis. Additionally, both superpowers backed opposing sides in African, Asian, and South American conflicts (Tow: 1997, 117).

The PRC played a major role in the ebb and flow of the Cold War. It fought the US in Korea as a member of the Soviet bloc. It fought border skirmishes against the Soviets while following an independent foreign policy. It backed the sides opposing either the US or USSR in Africa and Asia, and it finally leaned towards the US to balance Soviet power. ${ }^{60}$ The PRC also depended upon the Soviets for economic development during its first decade of existence and later, after the death of Mao, successfully relied on the developed world for economic development.

\footnotetext{
${ }^{59}$ Core allies of the US included NATO countries plus Japan, Taiwan, Korea after 1950, and the neighboring states of the US. The USSR core allies included the Warsaw Pact countries plus other bordering states.

60 Nakajima suggests that Mao leaned towards the Soviets for the following reasons: 1) The risk of China moving towards US may have provoked strong reaction from Stalin. Tensions between US \& USSR were strong and USSR bordered China. Russia was strong and China weak. 2) Mao may have felt that it was necessary to solidify his position within the CCP. 3) Yalta had produced a treaty with the Nationalists in which the Soviets had recovered Tsarist rights in Manchuria, including railroads and the naval base at Pt. Arthur (Dalian) which might remain under Soviet control. 5) Stalin had met with Kao Kang (the CCP
} 
The PRC did not blindly follow either the Soviets or the US. Either one posed a grave threat to the PRC; operating together they posed an existential threat. Preventing a US - USSR alliance against the PRC and preventing encirclement by either or both was of great importance. Hence, from a position of relative weakness, Mao tended to play one off against the other or as in imperial times, find defense through the barbarians fighting each other (Kissinger: 2012, 101-4). Mao dealt with more than just the superpowers. He also pursued an independent foreign policy; by attempting to take a leadership role in the non-aligned movement among countries emerging from colonialism in Asia and Africa.

In the following sections, the foreign policies of the PRC during the times of Mao will be examined in greater detail. PRC scholar Wang Jisi identifies three eras of PRC foreign policy that encompass Mao’s rule: 1) "Two Camps"; 2) “opposing imperialism, revisionism, and reactionaries of all countries"; and 3) "Three Worlds", this only being made public late in Mao's life. I would prefer to call the second era the "Opposition" era for the sake of brevity. But I would also include the "Third World" era. The PRC made efforts to become a leader of the developing world as early as 1955 at the Bandung Conference. This effort suffered ups and downs over time but has been a consistent PRC policy since at least 1955 to the present. It was influenced by the eras Wang identifies and by international politics in general, yet leadership of the developing world still continues as a goal. It also provides the PRC with a readily available platform from which to criti- 
cize either superpower or developed countries should the situation call for PRC opposition to either their actions or inactions, especially when relating to economic imbalance in the world. These are not discrete periods of time as foreign policies overlap and have periods of time during which they are stressed and others when they are conveniently overlooked. For example, rapprochement with the US, starting in 1971, was not the starting point for engagement with others in the Western bloc. The PRC was engaged economically with states in Western Europe and with Japan within several years of the forming of the PRC.

In examining these different foreign policies, we shall first look at the "high politics"-- those relating to national security and then look at "low politics"--those relating to trade, especially the grain trade and food security.

\section{Two Camps Policy Foreign Policy and Food Security 1949-1958}

Robinson suggests several themes in PRC, or Maoist, foreign policy. Based on the mandate to rule and a relatively compliant populace, the dominant themes were national unity, socialist revolution, export of communist revolution, pro-Soviet and antiAmerican rhetoric and actions, and restoration of Chinese primacy in Asia. Yet the prime driver of foreign policy was domestic politics. Mao's dominating personality and his need for constant political campaigns were one domestic influence as was the weight of the past. Additionally, what was learned during and after the formation of the $\mathrm{CCP}$, and ideology were influential (Robinson: 1997, 556). Notably absent is economic development which Robinson maintains was superseded by politics. Lurking in the background 
was the need for state survival (Kirby: 1997, 19) and, according to Whiting, reactive rather than well-planned foreign policy (in Tow: 1995, 124).

This period is a combination of Two Camps and Third World policies. From the Two Camps point of view, cooperation with the Soviets was the predominant foreign policy alignment. The East Bloc was the predominant trading partner. The Korean War, ostensibly agreed to by North Korea and the Soviets, presented the PRC with a potentially existential issue as UN sanctioned troops (primarily American) approached the PRC border. The PRC entered the war which quickly resulted in a stalemate along the original and soon-to-be permanent border between North and South. Nakajima maintains that exposing the PRC to a hostile neighboring state, the US or a US-backed South Korea, and Soviet assistance during the war in the form of the sales of obsolete arms to the PRC created the first issues between the Soviets and the PRC (Nakajima: 1995, 270-82). Still, the Soviets continued to support the PRC with trade credits, though less than smaller countries in Eastern Europe received, turn-key plants and equipment, and technical assistance. Yet, the drift apart continued following Khrushchev's denunciation of Stalin and his “cult of personality" which Mao viewed as a criticism of himself, Soviet disagreements over the PRC's domestic political campaigns and development plans, and the GLF also contributed (Nakajima: 1995, 284-7). Withdrawal of Soviet advisors in the midst of their work increased the split and led to the self-reliant development strategy of the PRC. The final nail in the coffin of the Sino-Soviet alignment was the signing of the Nuclear Test Ban Treaty between the US and USSR, a move interpreted by the PRC as being aimed at the PRC and leading to the PRC publically declaring that the USSR nuclear protection was no longer valid (Yahuda: 1968, 93). 
Just as it was in the interest of the PRC to keep a hostile state (Korea) away from its border, the same applied in the south where Zhou Enlai attempted to secure the PRC's southern border via neutralization. ${ }^{61}$ Zhou considered the anti-colonial war against the French in Indo-China a risk to PRC economic development and security as the US had intimated that they would come to the aid of anti-Vietminh forces in Vietnam if necessary. This risked replacing French forces with American forces at the PRC border; a risk that the PRC could not afford and had reacted to militarily when presented with the same issue in Korea. Neutralization would come with a French pull-out and the states of Vietnam, Laos, and Cambodia being declared as neutral in the great power struggle of the time. No foreign troops would be permitted in any of the three countries nor would any foreign bases, a key concern of the PRC in insulating itself from a US threat. Such an agreement came to pass from the Geneva Conference which ended in the withdrawal of France from the newly independent states of Vietnam, Laos, and Cambodia. This neutralization in effect provided the PRC with buffer states on its southern border which would allow time, estimated by Zhou as fifteen years, for the PRC to develop into an industrialized state from an agricultural one (Shao: 1986, 483-505). For what Zhou called the "zone of peace" to function well, keeping US bases from bordering states, required the addition of India and Burma that came in 1954 and 1960, respectively, following agreements on contested borders (but not all contested borders with India) (Shao:1979, 327 and 336) .

${ }^{61}$ This is reminiscent of the tribute system in that it was a bordering region, relatively close to the capital, and consisting of states that could come under the influence of the PRC, not as vassal states but eventually ones that come under PRC regional hegemony. Similarly, it was defensive in nature. 
The Third World aspect of policy, an attempt to become the leader of the newly independent countries and the developing world, primarily Asian and African, was kicked off at the Bandung Conference in 1955. While Zhou's efforts appear to have been made with all integrity, he was not the final arbiter for the PRC: Mao was. Zhou's approach was eventually over-ridden by Mao who reverted to arming militants abroad, as he had done previously with the Vietminh. The PRC was to support local communist groups against the existing governments in Malaya, Indonesia, and Thailand among others. Soon the PRC had border skirmishes/wars with India in 1959 and 1962 (Hinton: 1997, 360-2). An attempt to convene a second Bandung Conference in 1965 fell apart as the PRC refused India's request to include the USSR as it was not an African or Asian state. While the second Bandung Conference failed, the desire to lead the developing world remains in the interest of the PRC to this day.

How did food enter into the foreign policy of the PRC during the Two Camps period? There are two distinct time frames within this period: First, the period of increased grain output. Second is the period of the GLF famine. During the first period, from 1950 through 1958, grain output per capita increased nearly 50\% while the population increased more than 21\%. By 1956, caloric intake per day had met FAO guidelines. The increases in grain output led not only to meeting the FAO guidelines but also permitted grain exports in addition to other agricultural products.

The PRC needed to trade. Grains, industrial crops, and other primary products were used to pay for technology needed for economic development. "Export is for the sake of import, which, in turn, is for the socialist industrialization of our country" (Yeh Chi-chuang quoted in Hsiao: 1977, 10). Grain exports to the West provided FX or barter- 
based trade while grain exports to the East Bloc yielded barter trade. Yet, trade is not solely for economic development funds; "foreign trade is also a weapon of international political struggle" (from a PRC textbook quoted in Hsiao: 1977, 9). Imports and exports could be used to gain influence in other countries and in special situations to circumvent trade restrictions. To accomplish economic development and wage an international political struggle, the PRC needed to control the production, distribution, and consumption of grains at home. It took full control of imports and exports of grains by 1952 when all international foodstuffs transactions came to be managed and executed through National Cereals, Oil and Foodstuffs Import and Export division of the Ministry of Foreign Trade. This gave the government full control (excepting smuggling) over what was bought or sold, the source or destination, and the cost or price (Crook et al: 1999, 46). This organization increased the state-society balance in favor of the state and allowed the state to manage the political nature of international trade as well as control of FX earnings. As was shown in Table 3.3, the PRC balance of agricultural trade from 1950 through 1958 grew by nearly $700 \%$ indicating a level of success in using agriculture to generate FX earnings that could be used to import technology.

The international political system affected the composition of PRC trading partners. Prior to the onset of WWII, trade was concentrated with what Dernberger calls the West, the total comprising 94\% China's exports, in dollars, in $1930 .{ }^{62}$ The USSR accounted for only $3.4 \%$. The ascendency and political orientation of the PRC necessitated a change in trading partners. The Soviet Bloc accounted for $20 \%$ of trade in 1950 . This

\footnotetext{
${ }^{62}$ This includes Western Europe, North America, and Japan plus the colonial areas of those countries in Asia and present day Thailand.
} 
rose to $75 \%$ in 1956 , a major change in just six years (Dernberger; 1969, 135). In agriculture trade, prior to WWII, China was an importer of grains from the US, Argentina, and Australia, and rice from Thailand, Burma, and Indochina. Exports went primarily to Hong Kong / Macao, the UK, and Japan (Kirby:1972, 13,18). ${ }^{63}$

The decision to "lean" towards the Soviets brought with it a Cold War defense provided under the umbrella of Soviet nuclear capabilities as well as acquiescence to Soviet foreign policies within the international system. This represented the best interests of the PRC in terms of ideology. Marxist ideology, land redistribution specifically, and the termination of civil war led to an increase in agricultural production and food security by 1956. Aligning with the Soviets was a foreign policy decision to side with an ideological like-minded state by committed communists. There can be little doubt that land redistribution would have occurred in any case as it was a CCP policy in areas they controlled during the civil war. Therefore, the increase in agricultural production was ideologically driven rather than the result of foreign policy. Foreign policy decisions related to Korean War participation served to reduce potential trading partners during the US embargo for all goods but as has been seen, many US allies continued to trade in foodstuffs and nonstrategic goods with the PRC. Trade with the West Bloc provided FX badly needed by the PRC to support its economic development.

\footnotetext{
63 An examination of trade agreements from the early years of the PRC shows trade of agricultural products and other primary products with the USSR and the East bloc, as well as with Western Europe for certain machinery, metal, chemicals, vehicles, pharmaceuticals, etc., items and technologies unavailable in the PRC. PRC trade with less developed countries than itself tended to be the reverse; PRC industrial goods were traded for those countries' agricultural products (Dernberger:1959, 163-206).
} 
Within the Soviet bloc there was an emphasis on balanced trade between individual countries on a barter basis. If there was settlement in cash, it was in roubles that were most often useless outside of the East bloc. Barter trade and the East-Bloc trade arrangements made it difficult to accumulate hard currency and inhibited the development of triangular or multi-lateral trade, a situation where comparative advantage comes into play. The Soviets provided credits and used barter trade for Chinese products including rice and soybeans while supplying the PRC with technological goods, manufacturing plants, and technical training. The composition of trade, grain for technology, was not balanced trade. The issuance of credits to the PRC served to balance trade on the books but only by increasing the amount of debt owed to the Soviets. This will become an issue in the latter half of the Two Camps foreign policy.

As can be seen in Figure 3.1, the prime grain trade with the East Bloc was with the Soviet Union and several other East Bloc countries. Prior to 1954, all grain exports were rice. Beginning in 1954, soybeans were added to the export mix, maize

Figure 3.1

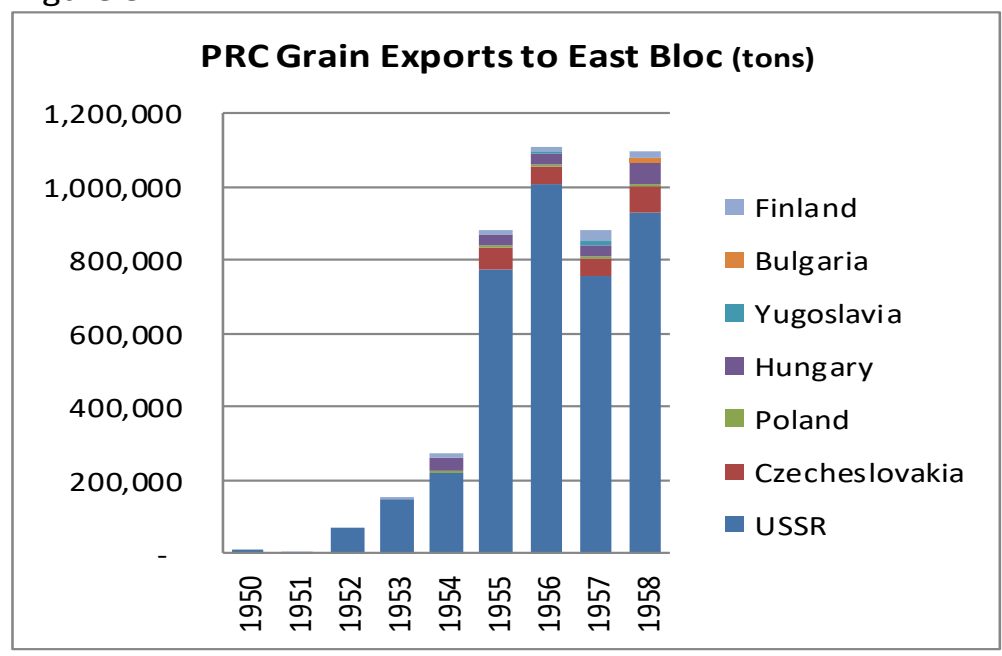

was added in 1958, though very little. There were no grain imports by the PRC from any East Bloc countries during this time period. It is interesting to note that Yugoslavia became an importer of PRC

soybeans in 1956, 1957, and again in 1959. Tito had broken with Stalin in 1948 and was 
pursuing independent economic and political policies based on nationalism. Mao denounced Tito "to assure a suspicious Stalin and realist Stalin that Mao entertained no Titoist ambitions of his own as a national communist" (Yahuda: 1997, 276). Under Khrushchev, in 1955 Tito was welcomed back into the Soviet Bloc and was supported by Mao also. However, this accommodation was not to last long as Tito objected to the use of force in dealing with the Polish and Hungarian uprisings in 1956, leading the PRC to break with Tito as Mao supported the intervention in Hungary (Whiting: 1959, 105-6). Though the shipments of soybeans are not a large quantity, the timing leads to the idea that trade resulted from political reconciliation and is concluded for the opposite reasons. Given that the break in relations came in 1956, it appears that the trade agreement covered several years and the PRC did not renege on its commitment even after political issues arose, a behavior that would be repeated in the future. Intra-East Bloc politics could lead to notable changes in amity and enmity within the Bloc; another example will be seen during the GLF.

In summary, PRC trade within the East Bloc had three aspects that were a result of foreign policy decisions. First, there were the technological needs of the PRC if it was to develop economically. The PRC could only turn to the USSR for these items due to its foreign policy decision to align itself with them. Second, there is the issue of payment to the Soviets for its assistance. Agricultural products, primarily grain, were most of what it had to trade. This was not an issue during this time frame but the steady accumulation of debts to the Soviets increased the costs of moving away from the Soviets politically. Finally, while not using trade as a weapon, it was used as a signaling device to indicate ap- 
proval or disapproval to the Soviets or other East Bloc states of their ideological and political behaviors. In effect, these served as warnings of more difficult times to come in the Sino-Soviet relationship.

Exports to the West, shown in Figure 3.2, offered the PRC the opportunity to earn FX, an asset that could be used to purchase needs or repay debts anywhere. Despite the US trade embargo trade conducted with West Bloc European countries was primarily for soybeans, beginning in 1951, with marginal amounts of rice and maize near the end of the period. Japan was by far the leading importer of PRC grain.

Figure 3.2

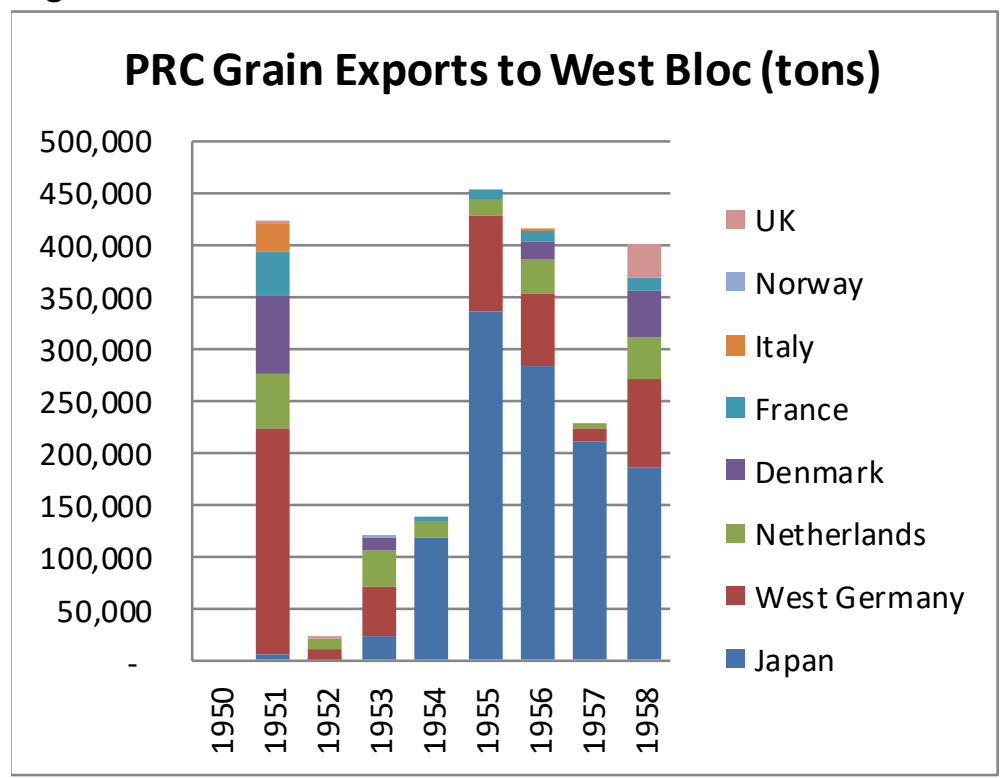

In January 1950, the

UK became the earliest

Western state to recognize

the PRC. Concerns over

the sum of British business

investment in China and the

hopes of getting along with

the CCP led to the recogni-

tion (New York Times: 1/8/1950, 127). ${ }^{64}$ Diplomatic relations were not a guarantee of trade just as trade was not subject to having diplomatic relations, especially in agricultural trade.

\footnotetext{
${ }^{64}$ The UK and PRC relations were at the charge d'affaires level only, not the ambassadorial level. From the UK point of view, this constituted diplomatic recognition. The PRC point of view was that it was not diplomatic recognition.
} 
PRC trade with Japan is a curious issue. First, PRC - Japan relations continued to be affected by the Sino-Japanese war of 1894-5 and the occupation of China from 1937 through the end of WWII. ${ }^{65}$ Second, approximately six weeks following the end of the US occupation of Japan, Japanese businessmen approached the PRC seeking a restoration of trade. Despite the PRC's hard feelings towards Japan, this agreement occurred about a year before the cessation of hostilities of the Korean War where the two main belligerents were the US and PRC. This war also accelerated the post-war economic development of Japan as Japan served as a staging area for US troops involved in Korea and fighting the PRC (Schaller: 2004, 146-170). The trade agreement commenced in 1952 and was interrupted in 1959 and 1960 before resuming. The initial trades were barter arrangements between the PRC government and private Japanese companies with the PRC supplying primary goods in exchange for primarily industrial goods (New York Times: 6/3/1952, 3). The trade hiatus resulted from Japan - PRC - Taiwan arguments concerning the relative statuses of PRC and Taiwanese trade officials in Japan, a forerunner of similar issues between the PRC and other states regarding Taiwan.

The PRC also reached out to the US during the Korean War for trade. Minister of Trade Yeh Chi-chuang called for ending the US-imposed trade embargo as the PRC needed to trade with the West to facilitate economic development and that trade opportunities between the US and PRC were good (New York Times: 10/2/52, 3). This overture was not accepted by the US due to the existing war between the two but even if it had,

\footnotetext{
${ }^{65}$ Another possible point of contention is the Treaty of Versailles in that the German concession in Shandong was awarded to Japan rather than being returned to China.
} 
grain products surely would not have been traded as the US was the major agricultural producer in the world and the PRC grain output was on the rise through $1958 .{ }^{66}$

The fact that agricultural trade did exist between the PRC and members of the West Bloc demonstrates that foreign policies can also be overcome by need, in this case FX. The attempt to establish trade relations with the US, most likely a publicity stunt, was rebuffed; an indication that at least at this time the foreign policy of the US was less shakable than the PRC's.

Agriculture trade with South East Asia was a return to or a continuation with traditional trading partners. It served political purposes as well. Zhou's "Zone of Peace" on the southern and southwestern borders served to keep foreign forces away from PRC borders. Further away from bordering states, the spirit of Bandung and the foreign policy desire to lead the newly or soon-to-be independent states of Asia and Africa led to trade and in some cases economic assistance. ${ }^{67}$ The PRC sought to gain influence in these areas through exchanges of high-level official visits between the PRC and other countries, through participation in trade fairs, trade and payment agreements, and buy-now pay-later schemes. These activities were meant to demonstrate the superiority of the PRC economic system, promote closer political relations, and ultimately to lure south and South East Asian states away from the West and towards the communist camp (Shao: 1959, 2). For both areas, trade in grain was part of that effort.

\footnotetext{
${ }^{66}$ A reason for trade with the US or other West Bloc countries would be due to a lack of physical distribution capabilities within the PRC and the cost of internal transport.

67 This paid off in 1971 when support from newly independent countries in Africa and Asia provided much of the vote that placed the PRC in the UN.
} 
Barter trade, rice for rubber, occurred with Ceylon, Malaysia, and Indonesia. Ceylon ignored the UN embargo and began shipping rubber to the PRC in 1952. Malaysia and Indonesia began trading following the lifting of the embargo in 1956. The ricefor-rubber trade with Ceylon in the post-Korean War years removed Burma as a prime supplier to rice-insufficient Ceylon, leaving Burma with a glut of rice (Wong: 1975, 492). It was at that point that the PRC stepped in and purchased rice from Burma (Shao, C.L: 1959, 10), a friendly gesture to a neighbor. The PRC continued purchasing Burmese rice and eventually ended up, in 1962, using Burmese rice to pay for Ceylonese rubber (Wong: 1975, 494). ${ }^{68}$ Shipments of rice to a few African countries began during this time period with shipments extending through times of PRC famine.

India was an early trading partner of the PRC, which shipped rice and sorghum to India during a food shortage there (Shao, C.L., 1959, 7). But India was also a rival for developing world leadership and a state bordering the PRC with unresolved border disputes that would result in armed conflict. ${ }^{69}$ Pakistan, which leaned to the West, was also a food trading partner with the PRC. Exports of rice to Pakistan commenced in 1956. The first exports of rice to Africa started in 1958.

\footnotetext{
${ }^{68}$ Shao C.L. maintains that the PRC trade in SE Asia was also an attempt to woo those states away from capitalist suppliers. The USSR led a similar effort in India and Burma. The Burmese had became disenchanted with the PRC as PRC re-sold rice imports from Burma to traditional Burmese markets in addition to Ceylon, at lower prices (Shao: 1959, 11).

${ }^{69}$ In 1962 the Soviets appeared to be neutral in this border dispute, rather than siding with their fellow communist state, so the conflict, in addition to addressing border issues, became a PRC desire to diminish the prestige of Nehru in the eyes of the developing world and "humiliate Mr. Khrushchev in the eyes of Communists by showing that his friendship for India could not prevent China from attacking her" (The China Quarterly: 1963, No.13, 260).
} 
Trade with Hong Kong deserves special mention. In this period, reported trade with Hong Kong was not as important as it was to become. Financially, trade offered an opportunity to earn FX, both through trade as well as remittances. Politically, it offered a way to obscure the source of PRC exports and imports, therefore allowing embargoes to be by-passed. For example, Hong Kong was supposed to be the source of rice shipments to the Philippines and South Vietnam beginning in the 1950's (Shao, C.L:1959,4-5). Singapore would also serve a similar function later. ${ }^{70}$ Exports to "other" areas are shown in Figure 3.3, below.

Figure 3.3

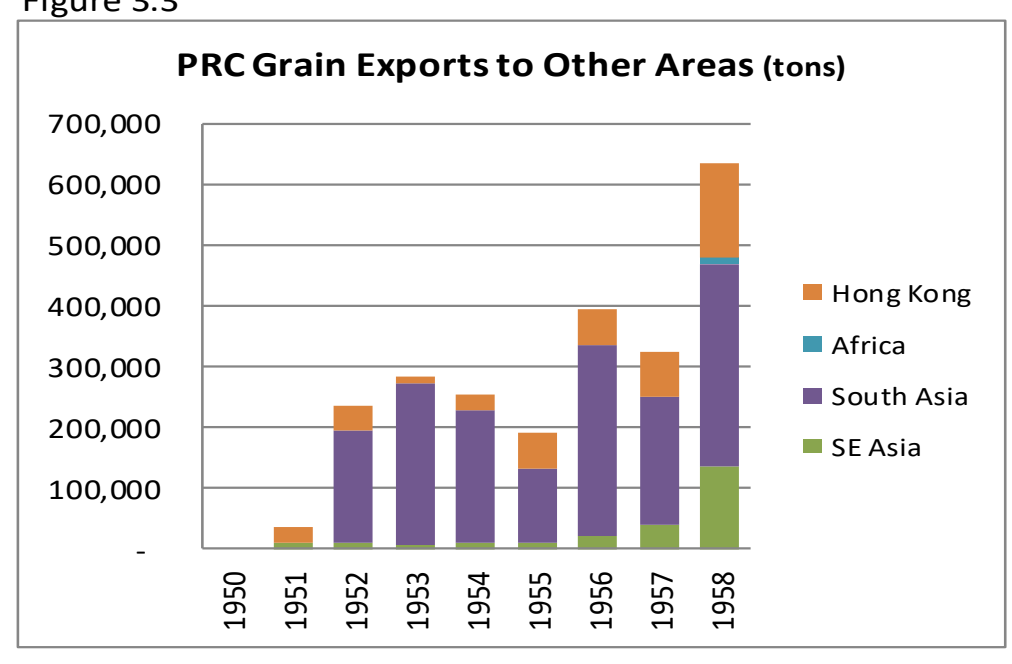

Grain was not imported as a general rule. In addition to rice imports from Burma, small amounts of rice and maize were imported from Cambodia. Argentina sold wheat to the

PRC in 1954, a one-off transaction. In 1958 China purchased 128,000 tons of wheat, the vast majority coming from Canada and bits from Australia and France. While these transactions might be viewed as a harbinger of things to come, major and sustained imports of grain did not occur until 1961.

\footnotetext{
${ }^{70}$ In addition to Hong Kong, trade with former British colonies could also provide FX as they tended to use or have access to pounds sterling.
} 
In summary, this period sets the stage for future action and reaction. Ideology, the Cold War, and tradition entered into the PRC foreign policy and food security. For our purposes, the achievement of food security was derived from ideology; Marxist land redistribution increased grain output and brought domestic food production to FAO-recommended levels, in aggregate. This allowed for exports of rice, soybeans and other agriculture-based exports to facilitate industrial development.

The Cold War limited the PRC to obtaining technology from the Soviets and East Bloc with few options from the West. This increased PRC dependency on and created debts to the Soviets; a situation that would be addressed in the near future. For this period, exports of grain and agricultural products helped pay for Soviet assistance in economic development. PRC rice and soybean exports to Western Europe and Japan permitted the PRC to obtain non-strategic goods from the West as well as FX.

Neither ideology nor the Cold War prevented the PRC from using grain imports and exports to re-establish traditional trading links with South East Asian neighbors. Nor did it stop the PRC from pursuing its desire to lead the developing world, a desire that used limited grain shipments as a tool of influence in the international political struggle.

\section{Foreign Policy and Food Insecurity 1958-1963}

The latter stage of the Two Camps foreign policy is a transition period to the Opposition foreign policy when the Soviets along with the US would be opposed by the PRC. It is the time of increasing tension between the PRC and USSR, an intra-Bloc dispute. The disputes were personal between Khrushchev and Mao, especially over Stalin's 
legacy. They were historical regarding the overall relationship between the two countries, both pre- and post-PRC triumph in the civil war, and they were doctrinal over communism. The PRC thought of the USSR as being a revisionist communist state while the PRC strove to implement communization better and quicker that the Russians had (Chen: 2009, 58). Mao went against the advice of Khrushchev and the Russians and ended up with an economic disaster and famine. ${ }^{71}$

The PRC entered the communist bloc as a partner junior to the USSR, which had both historical and institutional seniority and Stalin's personal seniority as the longestserving national leader within the Bloc. Upon Stalin's death, Mao became the senior national leader within the Bloc (Wittfogel: 1962, 679-81). Mao's disdain of Khrushchev led him to think of himself as the leader of world communism (Chen: 2009, 56). Wittfogel goes on to attribute the GLF to the USSR's scant financial support of the PRC's economic development when in 1954 they provided the final loan, after which the PRC would have to earn its own way through trade and for assistance on a pay-as-you-go method. These changes in support necessitated rapid communization to enable the state to extract more from the agriculture sector to finance the industrial sector. Rapid communization of agriculture had been a failure in the USSR, which advised against the PRC pursuing such a policy. Khrushchev's public criticism of the PRC communization plan (to Americans, no less) cited the failures of the initial USSR communization efforts and made PRC-Soviet matters worse (Wittfogel: 1962, 687-8).

\footnotetext{
${ }^{71}$ Khrushchev had warned Mao about the need to use material incentives to maintain or increase agricultural output (Wittfogel: 1962, 690).
} 
Chen has a different point of view and suggests that the GLF had its origins in the Cold War. Once the USSR stated that it would surpass the US in steel production, Mao looked at Great Britain, the second-ranking capitalist country, as a target to surpass in steel production more quickly than the Soviets would pass the US. Simultaneously, versus the Soviets and Khrushchev, Mao needed "to demonstrate the superiority of socialism in the People's Republic, to prove the genuineness of Chinese communism in contrast to Soviet revisionism, and to return China to equal status with the other great powers" (Chen: 2009, 57-8). ${ }^{72}$ Moving even with the number two capitalist country in steel production by demonstrating its superior form of communism necessitated the participation of all citizens. Communization of agriculture was the means.

These two explanations of the origins of policies that created the GLF were international in scope; competition with the Soviets for leadership of world communism in one case and the Cold War in the other. In both cases, Mao found rapid communization as the proper response and caused the PRC to look inward to surpass the Soviets and upon its failure then to look outward to recover. Outward did not mean the Soviets or the East Bloc. Relief from food insecurity caused by the GLF would come primarily from the West.

\footnotetext{
${ }^{72}$ If Mao's collectivization plan had worked and demonstrated the superiority of PRC communism as opposed to Soviet communism, could the PRC have replaced the USSR as the leader of the East Bloc and then by definition the prime defender of the East against the West? This is unlikely for material reasons. The Soviets were technologically superior to the PRC in most areas of industry, including substantial leads in military arms and delivery systems. The PRC would not present an existential threat to the US. Further, if the PRC was able to exercise significant influence / control over a degraded USSR, it is still unlikely that the Soviets would enter into war against the West that would threaten Soviet' existence. However, in a non-material sense, success would likely earn Mao the ideological prestige throughout the East Bloc that he coveted.
} 
1958 represents the transition from an increasingly food secure PRC to one of food insecurity resulting in the GLF famine. ${ }^{73}$ This led to daily caloric intake falling $24 \%$ on average between 1959 and 1962 and 32\% in 1960 alone from the high point in 1956. In the previous period, the grain trade was used for economic development and for influence. In this period, grain exports served to reduce debts and to buy the PRC's way out of being a junior partner of the Soviets in the communist world.

The domestic structural problems related to international trade as well as international political issues that turned the trade in grains on its head. The domestic structural issue was a result of the direct planning process. In putting together the annual economic plan, grain exports were identified as a percentage of the output planned. Commitments for export would then be with foreign customers solely based on the plan prior to what was actually produced. Therefore, when the crop fell short of expectations, even disregarding overstated harvests, there was always a possibility of excessive exporting of a crop leading to domestic shortages. There were inventories of grain from which to draw in cases of output shortages, as in the imperial period with the ever-normal granaries. Should there be consecutive years of overstated harvests, excessive exports, and resulting overstatement of inventories, disaster could occur...and did. ${ }^{74}$

\footnotetext{
${ }^{73}$ Estimates from famine deaths are estimated between 15 and 60 million. The higher estimates generally include births that did not occur as a result of the famine.

${ }^{74}$ A common excuse for poor outputs during the GLF was the weather; droughts and floods caused the dramatic fall in grain output. However, as the fall in output occurred in all growing areas nationwide, one must conclude that drought struck the entire country. This is highly unlikely.
} 
Chen states that Mao deliberately chose agricultural exports as the way to accelerate repayment of Soviet loans (Chen: 2009, 74) ${ }^{75}$ Using agriculture was an obvious choice as total agriculture-based products exceeded $65 \%$ of all exports. ${ }^{76}$ After all, a chief economic planner, Bo Yibo, after revising downwards initial output estimates, projected total grain output to rise to $375 \mathrm{mmt}$ in 1958 and $400 \mathrm{mmt}$ in 1959, a substantial increase over the $185 \mathrm{mmt}$ in 1957 (Chen: 2009, 62) as well as a greater amount to extract from the peasantry. Additionally, the GLF famine caused the output of other primary and industrial products to decrease also, further precluding those types of products as a means of repayment. Soviet advisors were not withdrawn until 1960; therefore the Soviets were aware of the food shortages in the PRC and offered to postpone payments (Chen: 2009, 74). This Soviet offer was not accepted by the PRC. Neither was a vague US offer by Kennedy (we will consider, if they ask).

1958 was a crucial year. Inflated production figures misled trade officials leading to commitments to export grains from the previous and following years that did not exist in actuality. Soviet disgust with PRC domestic policies, among other intra-East Bloc concerns, led to a pullout of Soviet technicians installing new plants and training the workforce. The desire to rid the PRC of debts to the Soviets led to an acceleration of grain shipments to the USSR. The PRC shipped a total of $4.78 \mathrm{mmt}$ of rice (milled equivalent) and 990,000 $\mathrm{mt}$ of soybeans to the USSR in 1959 and 1960. To all countries,

\footnotetext{
${ }^{75}$ An option would have been to default, but that would have damaged PRC prestige internationally. It was also in the interest of the PRC not to default as it had given loans to other developing countries; defaulting on debts to the Soviets would have given debtors of the PRC an excuse to default on loans from the PRC.

${ }^{76}$ Total agricultural products includes tea, tobacco, and textiles (including footwear) here. These other non-grain but land, using products impacts the amount of food grains grown. 65\% is the lower boundary of Eckstein's estimates of the PRC's export composition (Eckstein:1966, 114-5).
} 
the PRC exported more than $6.1 \mathrm{mmt}$ of rice and $2.3 \mathrm{mmt}$ of soybeans in those two years (Kirby: 1972, 65). In these two years, many Chinese starved. The relative increase in grain exports, at this crucial time, can be seen graphically below.

The decision to increase grain shipments to the USSR during the famine, or not to delay them, was most likely an act of bravado on Mao's part or that of the leadership. At best, it was a false statement that the PRC knew what it was doing socially and economically, most likely a true statement that it could get along without the Soviets, and at worst, a statement based on pride or ambition. We have already seen that Mao thought of himself as the world leader of communism. Whether he was or not, Khrushchev was still the leader of the USSR, the first country to adopt communism, one with 40 years of communist experience, a superpower, and the country most closely associated with communism. What Mao thought is most likely what the rest of the world, outside of the PRC, would not agree with. The GLF did present Mao with an opportunity to lead the comunist world if he could succeed in communizing faster with better results than the Soviets. ${ }^{77}$

\footnotetext{
${ }^{77}$ Could Mao have been the leader of international communism? Womack suggests that if leadership is "the ability to coordinate compliance, then the surplus of attention enjoyed by regional or global power poses an interesting dilemma....if ...international power is the ability to get another state to do something that it would not otherwise do, and that international leadership is the habitual exercise of international power, then the dilemma is that the use of rewards and sanctions reduces the capacity for sustainable leadership." The solutions to that dilemma are: 1) lead in directions that others would wish to follow. Common goals and mutual benefit do not impose compliance or cost, so rewards and sanctions are unnecessary. 2) institutionalization of international norms and procedures...leader can disappear behind protocol and precedent and leadership becomes sustainable as the system itself. (Womack: 2010,104). Based on Womack's discussion of leadership, Mao could not have succeeded in achieving his goal. Few states were willing to follow him and none allied itself for an extended period of time. His allies within the East Bloc depended on which country was having issues with the USSR and had been pushed away by Moscow. Another intra-Bloc issue could easily change that relationship, for example, the PRC's short alignments with Yugoslavia and Albania. Further, institutionalization of norms within the East-Bloc would be an anathema to Mao and his constant revolutions.
} 
The GLF was unsuccessful and diminished the prestige of Mao within the CCP as well as within the East Bloc. ${ }^{78}$

The tonnage shipped to the USSR and the rest of the world seems like a large amount but on a per capita basis with a population of 670 million or so, it was a drop in the bucket. In any case, if widely known at the time, it might have destroyed a weakened state-society relationship. ${ }^{79}$ Similarly, the imports that followed were also a drop in the bucket. What is different is that those imports went to the urban population located along the east coast, readily accessible by ship, thereby leaving more grain (less extraction) for the rural population and decreasing the pressure on an inefficient domestic transportation system.

To relieve the emergency food insecurity situation, the PRC began imports of wheat from the West Bloc and Argentina. This was not new; France, Argentina, Canada, and Australia had shipped small amounts previously, but this time the PRC imported on average $3.8 \mathrm{mmt}$ per year from the West and Argentina through the end of Mao's rule. ${ }^{80}$ Imports of grain have continued since then, indicative of ongoing food insecurity or the inability to be self-reliant. The sudden and dramatic change in grain imports is shown below. The US continued to be avoided for relief grain shipments, a continuation of Cold

\footnotetext{
${ }^{78}$ Mao should have paid more attention to Khrushchev's criticisms of rapid communization and looked at other East-Bloc agricultural success. An article in early 1962 on communist food crises stated that only Poland and Yugoslavia had "anything like a good record in food production and they have achieved it by abandoning the collective farm system and turning land back to the peasants" (Harsh: 1962, 1).

${ }^{79}$ Trains transporting grain to the USSR in 1961 were attacked by starving peasants (Becker: 1996,155).

${ }^{80}$ The USSR shipped 300,000 $\mathrm{mt}$ of wheat to the PRC in 1961-62 to assist in famine relief. The USSR was a net grain exporter until 1963 .
} 
War international politics. The purchase of grain was not a foreign policy change between the PRC and the West as it involved non-strategic goods, from the point of view of the West, but it was a step outside of the norm with regards to quantity. Imports increased food security in urban areas and indirectly in rural ones. As purchases continued, the specter of food dependency would increase. The dramatic shift between exports and imports of grain, for all of Mao's rule, is shown in figure 3.4, below.

Yet this is not the full story. Albania had objected to Khrushchev's denunciation of Stalin as had Mao and started Albania down the path to doctrinal differences with the Soviets. Khrushchev retaliated by cutting trade, including grain shipments, creating a food shortage in Albania. In the midst of the famine of the GLF, Mao came to the rescue of the Albanians by diverting grain purchased from Canada and France to relieve Albania's problem. ${ }^{81}$ The Christian Science Monitor (hereafter CSM) reported that 20,000 mt of wheat purchased from France in 1960 was diverted to Albania (Sheldon: 1961, 1). Fifty-eight tons of Canadian wheat were diverted from the PRC to Albania (Eckstein: 1966, 165), most likely in 1961 or 1962 . Australian officials raised concerns that wheat shipments to the PRC were being used to repay Soviet loans (Norman: 1961, 12). We have seen that the amounts of grain that the PRC imported did not amount to much on a per capita basis nor did the exports to the USSR during the GLF. Diversion of grain pur-

${ }^{81}$ These shipments do not appear in PRC shipments or Albania receipts. 
Figure 3.4

Net Grain Imports (+) and Exports (-) by Region (tons)

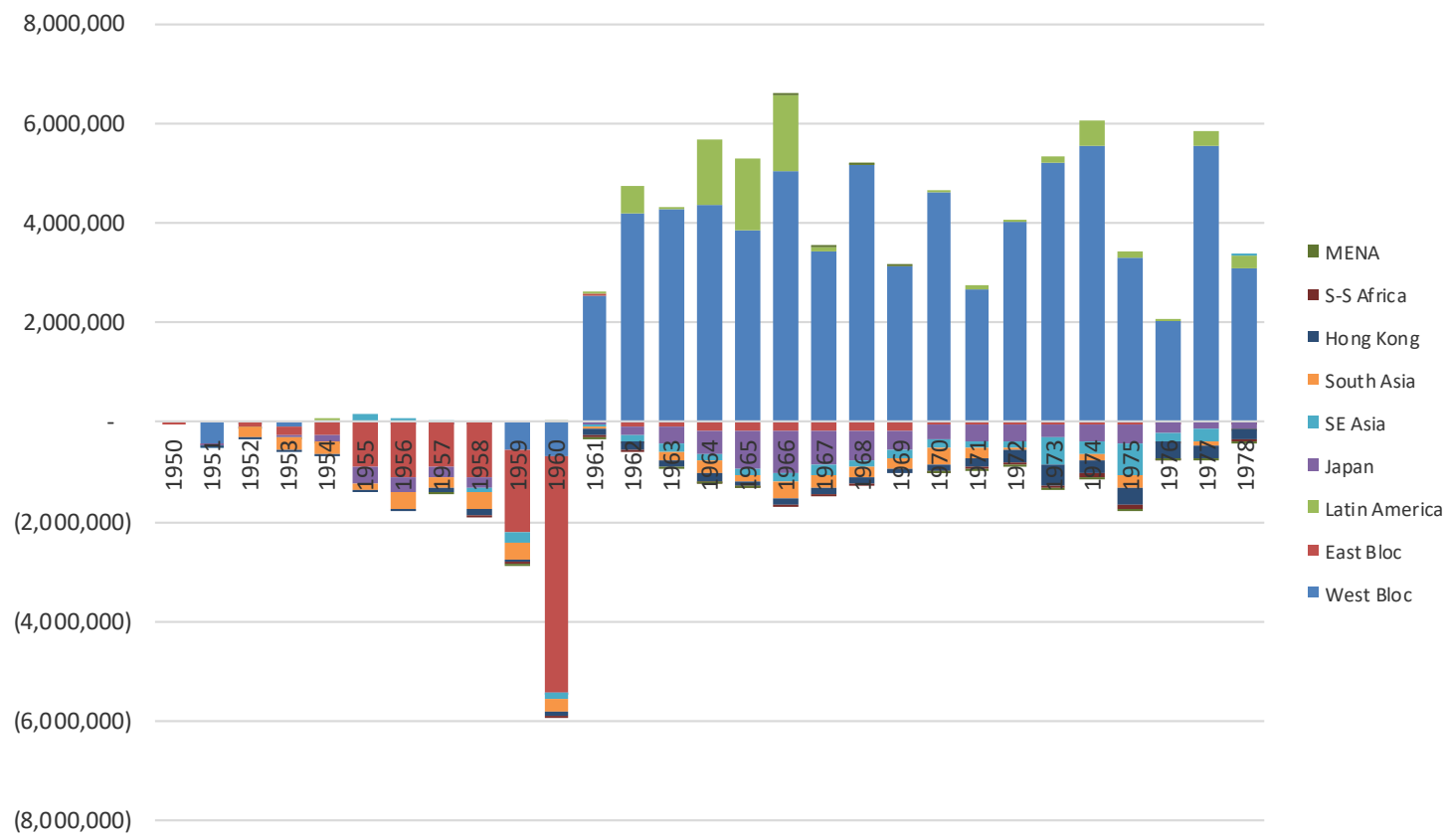

chases to Albania further demonstrates that Mao was more interested in the intra-East Bloc political system and his ability to influence it than the welfare of his citizens.

Cuba had joined the East-Bloc in 1959. The PRC welcomed them by commencing rice-for-sugar trade in 1961 at the height of food insecurity. It must be suspected that this was an attempt by Mao to gain influence with Castro or reduce Soviet influence. Exports of rice, soybeans, and maize all decreased after 1960; the largest decrease was to the USSR. Hong Kong had a significant increase as it was a source of FX. ${ }^{82}$

The domestic aspects of the recovery from the GLF were discussed earlier. They must be mentioned again as the cure for some of what ailed the PRC was a retreat from the high point of communization by the partial restoration of rural markets, private plots

${ }^{82}$ Another source of FX was the sale of PRC gold and silver reserves. 
within communes, increased grain prices, and reduced extraction. Mao's domestic prestige was damaged and he retreated from overt CCP management temporarily. This did not mark the high point of Mao's domestic influence as he was to return and bring forth the GPCR to punish those who led the retreat from communization's high point. There should be no doubt that Mao realized that Khrushchev's criticisms of the GLF were correct, yet by 1964 Khrushchev had been ousted and Mao was not the leader of world communism but he was actively planning the GPCR.

The PRC foreign policy directed at the Asian nations and developing world was a continuation of pre-PRC trade, as well as part of Zhou's efforts to solidify the southern and southwestern borders as well as to create a zone of influence. This included steps to limit Soviet penetration in some cases and the US in others. Influence included purchasing and selling grain to the region and in quantities that did not impact overall food security but served to assist border areas, as shown in Figure 3.5. The area of most importance was the acquisition of rubber during the embargo with Ceylon and then bringing the source closer to home after the embargo with rice-for-rubber trade with Malaysia and Indonesia. Rice exports to these states fell off during the recovery phase from the GLF then fluctuated among the three, depending on the political situation.

The PRC had begun shipments of grain to a few African countries prior to the GLF, part of the spirit of Bandung. The amounts were inconsequential in total. Some countries continued to receive shipments during and immediately after the GLF. In total, 
the foreign policy of the PRC towards Asia and Africa had a minimal impact, in the total scope of the disaster, on overall food security. ${ }^{83}$

Figure 3.5

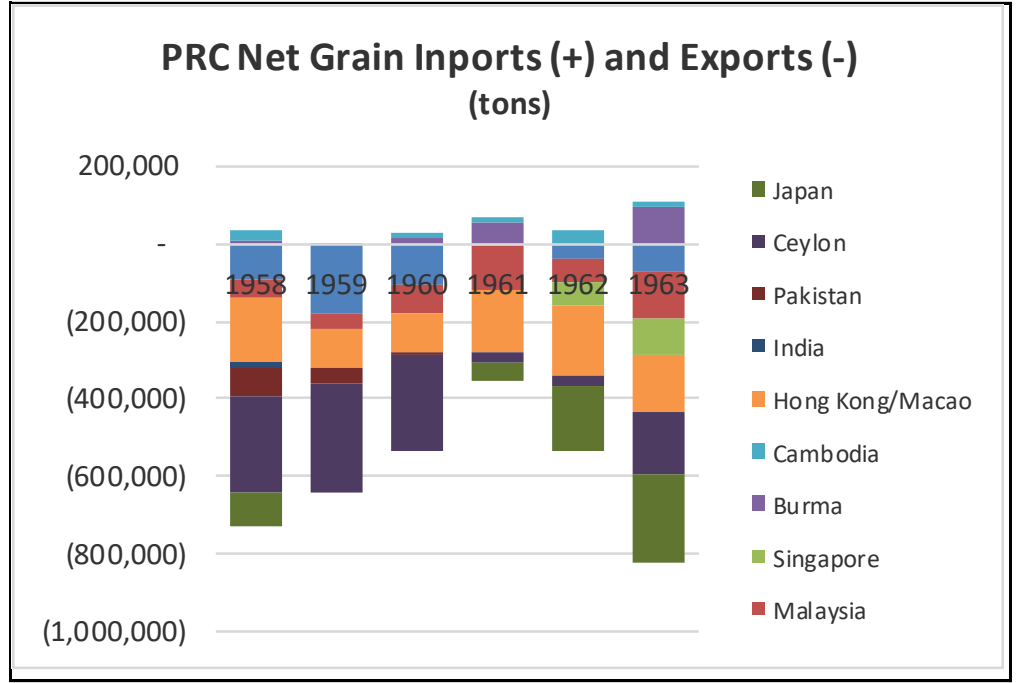

To summarize the 1958-1963 period, food insecurity again became a problem for the PRC, thus limiting the trade options necessary to feed the population and continue economic development. Mao's

personal goal, to lead the communist world, coupled with the means, communization, are the principal causes of food insecurity. The extent was further exacerbated by Mao through accelerated repayments of debts to the USSR as well as intra-Bloc political motivations that transferred imported grain to Albania, a foe of Khrushchev. Grain was used as a weapon of intra-East Bloc political struggle but its effects were felt internally by its own citizens. Relief came from the West, the enemy, and Latin America. ${ }^{84}$ Depending on the West may not have been pleasant for Mao but other than Argentina, most wheat growing areas are in the West.

\footnotetext{
${ }^{83}$ Though not related to overall food security, the PRC did purchase coffee and cocoa from Africa to encourage two-way trade and balance FX. They also bought a significant amount of tobacco from Tanzania following a failure to sell the crop and sold a significant amount of sugar to Sudan at a discounted price due a lack of Sudanese FX (Snow: 1997, 288).

${ }^{84}$ The Soviets also contributed wheat in 1961-2.
} 


\section{Opposition Foreign Policy and Food Security: 1963-1972}

This is the period of opposition: opposition to Soviet revisionism and imperialism resulting from the clash over Soviet aid, the Nuclear Test Ban Treaty, and the Soviet's peaceful coexistence with the US. ${ }^{85}$ There was also opposition to US imperialism and the US in general. In an interview in 1966, Zhou stated that the PRC would not provoke a war with the US but would react to US aggression anywhere in the world and that the PRC was prepared for war and should one break out there would be no boundaries (China Quarterly: July, 1966, 218-9). Yet, this is also the period in which the initial softening of the US position towards the PRC begins. Other than the off-and-on discussions among diplomats in Warsaw, the elimination of passport restrictions for US scholars traveling to the PRC and other communist countries was a first step in the reduction of the isolation of the PRC policy while maintaining the containment aspect of US policy (China Quarterly: April, 1966, 218). Subsequent steps in the same direction would include abstaining, rather than vetoing, the PRC admission to the UN and the relaxation of US trade restrictions, both in 1971. PRC efforts in the same direction included inviting the US table tennis team to visit the PRC and the invitation to Nixon to visit the PRC.

Harding sees the relationship between the PRC and a diverse number of developing states as client states serving four principal interests for the PRC: 1) some were faraway outposts that provided the PRC a presence in a geographic area, such as Albania for Eastern Europe or Tanzania in East Africa; 2) protectorates where the PRC guaranteed

\footnotetext{
${ }^{85}$ It is interesting to note that the PRC call for peaceful coexistence among nations did not apply between the US and USSR, the leaders of the Two Camps.
} 
security, North Korea; 3) allies in Asia, such as Burma, that were counterweights to regional rivals such as India; and, 4) insurgencies, where the PRC provided material and political support, most often those that could pressure the Soviets or the US (Harding: 1997, 384-7), or Taiwan.

The support for the international communist movement is evident in various areas. Mao had differed from the USSR in the pursuit of revolutionary interests; he was now free to pursue them (Zagoria: 1962, 172). In SE Asia, the "zone of peace" became a zone of PRC-supported insurgencies ("Ten Years of Chinese Communist Foreign Policy": 1968, 1-4). Communist parties were supported in Thailand, Burma, Indonesia, India, and Malaysia. Revolt in some countries was encouraged. ${ }^{86}$ In Africa, Burundi expelled PRC diplomats for payments to rebels in the Congo and for implication in the assassination of an ex-Burundi leader. Kenya seized 75 tons of PRC arms destined for Uganda. Dahomey (now Benin) and the Central African Republic broke diplomatic relations over support for domestic communist revolutionaries, and a coup in Ghana resulted in the PRC embassy staff being reduced to 18 from 200 plus (China Quarterly, various issues 1965-66). These activities certainly violated the Peaceful Coexistence doctrine of respect for sovereignty and non-interference in the domestic affairs of other states.

More subtle activities were employed within the Soviet bloc to emphasize disapproval of Soviet activities. Aid to Albania continued. The USSR invasion of Czechoslovakia earned stern rebukes from the PRC as well as fears that the Brezhnev Doctrine (the

\footnotetext{
${ }^{86}$ The communist party in Indonesia, in combination with President Sukarno, attempted to overthrow the anti-PRC army generals of Indonesia in 1965. The attempt failed and led to the overthrow of Sukarno and a long period of animosity between Indonesia and the PRC.
} 
right of a communist country to intervene in a communist country tending towards capitalism) might also be applied against the PRC. At the same time, the border issues between the PRC and the USSR were increasing and would soon turn into multiple skirmishes in the Heilongjiang border area as well as the Xinjiang border area in the west.

The GPCR commenced in 1966 bringing with it an increase in domestic influences on foreign policy. The radicalism of the time, including the takeover of the Ministry of Foreign Affairs, the recall of all ambassadors but the ambassador to Egypt, the burning of the UK embassy in Beijing, border skirmishes with India, fomenting riots in Hong Kong, and quarrels with 32 different countries (China Quarterly: October, 1967, 221-3). The GPCR demonstrated that international relations were not only reactive to US and USSR foreign policies but also to their own domestic politics.

From the high point of grain production in 1958 and the high point in export tonnage in 1960, production did not reach 1958 levels again until 1964-5 and exports until 1966. A major difference was the continuous importation of wheat in excess of the tonnage exported. From 1962 through 1978, imports of wheat ranged between 1.15 and 4.4 times the tonnage of grain exported. By 1978, per capita consumption of grain was about the same as 1957.

This period includes part of the GPCR which commenced in 1966 and ended in 1976 and was aimed at the urban population. The target was urban but there was carryover into the rural areas. Grain production remained essentially flat on a per capita basis despite a $27.8 \%$ increase in population and a $25.1 \%$ decrease arable land, a positive achievement during a turbulent time. 
If the PRC continued to import grain in such quantities, how could it achieve a positive balance of payments in agriculture? One reason is the dramatic increase in the level of fruit and vegetable exports that more than quadrupled between 1961 and 1973. The value of net fruit and vegetable trade exceeded net grain trade from 1967 through 1973 (FAO Statistics). The export of labor-intensive fruit and vegetables was a good use of comparative advantage.

Grain imports came almost exclusively from the West after 1966. The PRC was not only a "taker" in the global grain trade; it could also be a "chooser." Canada and Australia were wheat suppliers to the PRC from 1958. Canada established diplomatic relations with the PRC in 1970 while Australia hesitated until 1972 due to its traditional relations with Taiwan. In 1971, the PRC declared: "China would continue to consider Canada first as a source of wheat as imports needs arose" (CSM: 7/9/1971,2). Three days later, the PRC told Australia they would be given equal consideration upon establishing diplomatic relations (Burns: 7/12/1971,1). That did not occur until late 1972. In 1970, Australia shipped about 2.2 million tons of wheat to the PRC. From 1971 through 1973, it shipped about 400 thousand tons. The traditional Australian two-track policy of antiPRC high politics and the continuing trade of "low politics" had ceased to work.

During the Opposition period, politics caused decreased rice imports from Burma as the PRC export of revolution practices upset Burma. Cambodia was a minor supplier to the PRC but the complications in relations were brought on by the Vietnam War and the overthrow of Sihanouk. Small amounts of maize were purchased from Cambodia, Zambia, and South Africa in the early 1960's but most maize imports were from Argentina. 
Grain exports went primarily to the West. Of that portion, about half was to Japan, the largest customer for PRC soybeans. Exports to Hong Kong continued to increase and were generally bound for third countries.

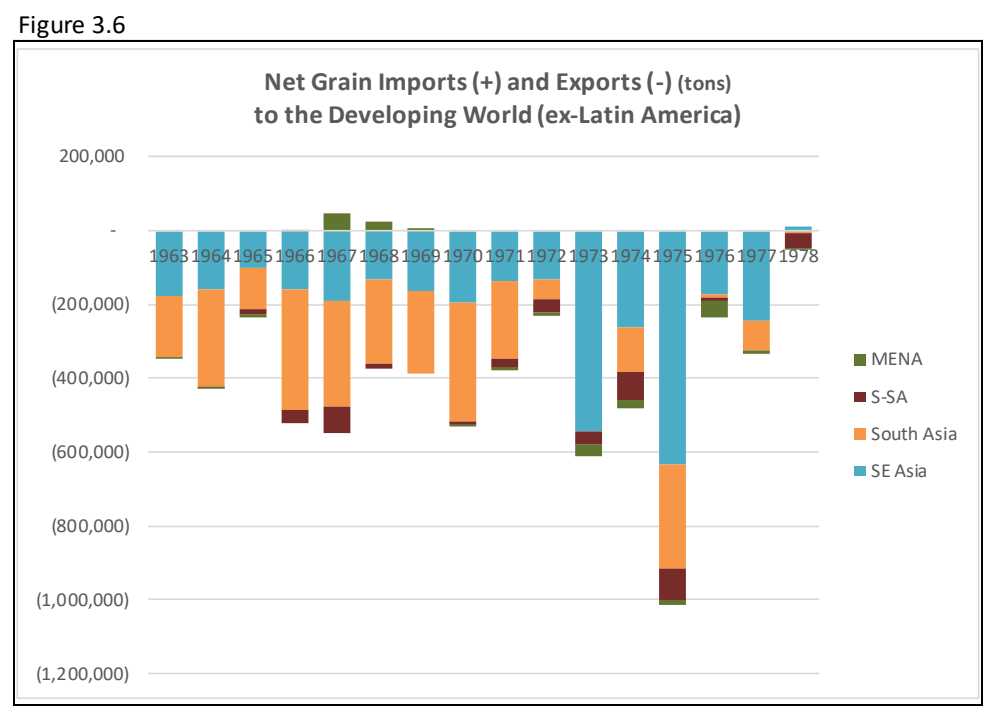

Exports to other than the West tended to ebb and flow with politics as shown in Figure 3.6. The rice trade with Indonesia ceased from 1965 through 1971 due to PRC meddling in the internal affairs of Indonesia. Trade

with Ceylon (soon to be re-named Sri Lanka) began a gradual decline after 1971 following a resumption of the rubber - rice trade with Indonesia. Trade with the Middle East and North Africa (hereafter MENA), Jordan and Lebanon in the 1963-4 time period increased in 1970 with the addition of four more MENA countries. ${ }^{87}$ Increased shipments to the MENA appear to support Harding's contention that foreign policy wanted to establish influence regionally for influence and to create problems for the superpowers. Tensions in that region were rising between Israel and Arab countries and the US and USSR

\footnotetext{
${ }^{87}$ As opposed to trade with Africa for rice, exports to MENA countries tended to be for time frames or four to six years. Trade with African countries tended to be for one to two years and for minor quantities. Exceptions to this are Tanzania, Mali, and Benin, which took larger quantities on a more regular basis. From the early 1960's through the Three Worlds period there was a steady stream of African leaders, as well as the leaders of other recently independent countries, visiting Beijing in search of aid and trade. Most every issue of The China Quarterly carries a list of those supplicants.
} 
were intimately involved on opposite sides. The CSM reported that the PRC had diverted wheat purchased from Australia to Egypt at the conclusion of its 1967 war with Israel. No quantity was given but it did emphasize the PRC's need for the wheat for its own consumption and that the wheat had been purchased with scarce FX (Cooley: 1970, 6). From 1963 to 1969 , Cuba was the leading, and sometimes only, East bloc importer of PRC rice. The end of Cuban rice - sugar trade came via a trade dispute over committed quantities as well as the PRC paying down debts to the USSR with re-exports of Cuban sugar. Through the conclusion of Mao's rule, grain trade with East bloc countries ceased, a political decision resulting from the increasingly acrimonious relationship between the USSR and PRC.

In sum, the Opposition time was one of agriculture stability on a per capita output basis, a continued need for imported grain, and the political decision to involve the PRC in the internal affairs of many other countries, so long as it politically helped the PRC or damaged the Soviets or the US, and with luck, both. However, in an opposite vein, it was the time of approaching rapprochement with the US, and in terms of food security, another arrow in the quiver to fight food insecurity.

Three Worlds Foreign Policy and Food Security: 1972-1978

Wang's next theme in PRC foreign policy is Three Worlds that ran from the early 1970's through the early 1980's. It was elucidated in a UN speech by Deng in 1974. Three Worlds maintained that political independence could only be maintained by control of any country's own resources. Without economic independence, political independence is incomplete and insecure. To be successful, the developing world needed to become 
self-reliant by depending on the abilities of its own people, move up the value chain from unprocessed primary products by adding additional value, and use foreign aid to assist in such endeavors so long as it did not reduce sovereignty (The China Quarterly: 1974, 6424). Of course, this is how the PRC developed and it stood ready to assist those who requested assistance.

The early part of this period was one of change for the PRC. It gained admission to the UN and the Security Council in late 1971 and used that forum to rail against the two superpowers and their hegemonic intents. Nearly simultaneously, rapprochement with the US occurred, starting with the lifting of the trade embargo against the PRC by the US and culminating in Nixon's visit to China in $1972 .{ }^{88}$ Lifting the trade embargo provided the PRC with a new trading partner, the US, and also access to the premier agricultural nation in the world. Perhaps most important was the altering of the balance of power. While the PRC leaned to the Soviets in 1949, with rapprochement they leaned towards the US. This leaning, never a treaty, increased the PRC security by eliminating the possibility of a two-front war, no threat from the US, a clarification of Japan's defense status in the Pacific (part of US plans and not independent), and a one-China policy so long as it occurred peacefully. The cost was the cessation of diplomatic relations initi-

\footnotetext{
${ }^{88}$ Formal diplomatic recognition would not occur until 1979.
} 
ated by North Vietnam and Albania (Pollack: 1997, 426). The PRC had become a balancer in the international system (Shambaugh: $1997,198-9)^{89}$. These international activities took place during the GPCR, albeit after the most contentious times, which passed in 1969.

The Three Worlds theme was most evident in the PRC's anti-Soviet anti-superpower rhetoric concerning its involvement in Africa, a third world area that the PRC identified with. This was especially true in Angola where the Soviets and the Cubans deployed troops and the Chinese supplied arms. In an interview with the Sunday Times (London), Vice-Premier Li Hsien-nien stated: "'Some of our friends are suspicious of our words about Russia but some agree with us now that Russia has shown its hand in Africa'.... If the Russians try to expand anywhere in the world China will inevitably get involved, but in Africa on the whole all we can do at present is give political support and to expose the Russian sinister motives and crimes. The Russians may take advantage of

\footnotetext{
${ }^{89}$ The neorealism of Waltz states: "Balance-of-power politics prevail whenever two, and only two, requirements are met: that the order be anarchic and that it be populated by units wishing to survive" (Waltz: 2004,121 ). Anarchy, the absence of authority above the level of the state, is an assumption among realists. Therefore the need for the PRC to balance with the US against the USSR has to be for survival, the result of an accumulation of issues with the Soviets including hostile encounters, the failure of the PRC to develop economically, and the internal issues related to succession and the Lin Biao affair. The offensiverealism of Mearsheimer suggests that the balancing be either offshore balancing or buck-passing in order to maximize the state's never ending acquisition of power. Buck-passing would infer that the PRC would pass its defense to the US to deter war but if war occurred the PRC would not be involved (Mearsheimer: 2004, 157-9). This would allow time to develop economically while avoiding the destruction from war. Offshore balancing would bring the PRC defense against the USSR but in the event of war, they would be involved. The balance of power rationale for the PRC was offshore balancing and could not have been buck-passing. The PRC would be involved in any conflict given its long border with the USSR and given the recent history of China, defense could not be outsourced without severe damage to the ruling perceived capabilities of the CCP.
} 
some African nations but I must make it clear that we cannot help them much in a big way"” (quoted in Hook, Yahuda, and Wilson: 1977, 460-1). ${ }^{90}$

In the area of food trade, several ominous signs began to appear as shown in figure 3.7. From 1972 through 1978, imports of maize increased to 4.5 million tons while exports were only 600 thousand tons. From 1950 to 1972, the PRC maize trade was about break even, 1.25 to 1 million tons in favor of imports. Similarly, net exports of rice fell from 640 thousand tons in 1975 to less than half that from 1976 through 1978. Finally, soybean imports exceeded soybean exports in 1974 and 1977, a dramatic reversal and possibly a trend. The PRC had run an agriculture products trade surplus since 1966, excluding 1974, through 1976 and was facing a string of deficits beginning in 1977. Within PRC agriculture trade, import sources for wheat, maize, and soybeans were exclusively from the West and Latin America. Again, the source was less a political decision than the fact of where these crops were grown in sufficient quantity to supply the PRC. On the export side, Hong Kong's share of exports grew steadily during this period. Otherwise, the West, Japan, SE Asia, South Asia, and Africa were the destinations for a combination of rice, soybeans, and maize that in total were decreasing and decreasing grain as a weapon of international struggle.

\footnotetext{
${ }^{90}$ Note the similarities in this statement in reference to the USSR and Zhou's comments referring to the US on page 72 , the PRC would react to either superpower any place in the world.
} 


\begin{tabular}{|c|c|c|}
\hline & Net Grain Imports (+) and Exports (-) (t & \\
\hline $7,000,000$ & & \\
\hline $6,000,000$ & & MENA \\
\hline $5,000,000$ & & - S-S Africa \\
\hline $4,000,000$ & & - Hong Kong \\
\hline $3,000,000$ & & - South Asia \\
\hline $2,000,000$ & & - SE Asia \\
\hline $1,000,000$ & & - Japan \\
\hline- & & - Latin America \\
\hline$(1,000,000)$ & $19731974 \quad 1975$ & - East Bloc \\
\hline$(2,000,000)$ & & West Bloc \\
\hline & & \\
\hline
\end{tabular}

What accounts for the increase in imports and decrease in exports? The growing population and decreasing ha. of arable land is an obvious reason. This was offset by increased yields. Still, since 1949 the population had grown by $80 \%$ while arable land had decreased by $45 \%$, an unsustainable trend.

There were two areas of concern. First, the program of self-reliance in the area of agricultural production increasingly needed imports to offset the growing population, a situation that might become a dependency on foreign sources of supply for grains. In times of heightened international tensions, grain could become a strategic good. Second, industrialization had been retarded by the Sino-Soviet split and would have to catch up at some time. Having light or heavy industrial products to export provides FX to use for grain imports but industry and agriculture compete for land and increasing industrialization exacerbates the arable land problem. The re-start of industrialization was just around the corner under Deng XiaoPing. 


\section{Conclusion}

During Mao's tenure, food security ranged between a success and failure in terms of domestic policies. In the case of failure, it was exacerbated for international political reasons with the Soviets and probably by Mao's ego. Relief came from the capitalists of the West. At best, the results were mixed, provided one did not lose life during land redistribution or the GLF.

The food supply in total (and grain in particular) was a strategic good throughout, for several reasons: First, as seen in Chapter II, food insecurity, or the fear of it, had a part of every generation for a very long time. Second, at the conclusion of WWII in 1945 and the revolution in 1949, food security was an issue. Mao's solution was land redistribution to the peasants from the "landlord" class; a solution that worked in terms of grain production. Third, in addition to fueling human activity, agricultural production was needed to produce an excess that could be extracted to feed the urban population, to export to earn FX, to provide raw materials for industry and to repay loans and credits to the Soviets, the ideological ally of the PRC. Grain production was the bottleneck that needed to be overcome to finance industrialization. By applying Ripsman and Blanchard's definition of a strategic good to the subject at hand; "[grain is] essential for national survival and defense [and modernization]," we have the challenge Mao and the CCP faced, especially following collectivization.

As would be expected for a strategic good, Mao pursued domestic solutions to assure food security with two main domestic policy initiatives. One was positive and the 
other negative. Land redistribution was positive. Though brutal, it transferred land ownership from the rural elite to the peasants and led to a substantial increase in grain output. The peasant was able to reap what he had sown, an incentive that worked in improving food security. Between 1950 and 1958, output increased to the point where per capita availability of k/cal reached 2200 per day. Grain exports were able to increase gradually during this time, also.

Agriculture was able to earn FX directly or to acquire needed foreign materials through barter. Barter was common with Japan and exports to Western Europe were for FX. Trade with these countries was more advantageous than trade within the East Bloc where barter was the preferred method of settling accounts. The value assigned to traded commodities in the East Bloc could be suspect. It cannot be said that trade with Western Europe and Japan was politically incorrect. This was a time when communist parties in both areas were considered viable political alternatives. Receiving goods from another communist country might help local communist parties. Grain was also available to ship to India to assist during a period of shortage but also to gain influence with a newly independent state and one that would eventually contest the PRC for leadership in the nonaligned movement. Rice was barter for rubber with Ceylon when the PRC was under a strategic goods embargo during the Korean War.

In sum, land redistribution demonstrated that food security concerns could be met by domestic policies adjustments. The PRC did not suffer from interdependent sensitivity as it was able to react quickly to the situation it inherited on its own. Grain was a strategic good, not only for feeding the population but for fulfilling the tasks that agriculture, 
in general, needed to, to advance the country economically and to maintain the dominance of the CCP.

The negative aspect was mandatory collectivization that followed right behind in 1958. The result was GLF famine killing tens of millions. Collectivization and its reversal to the MAT level, were the principal domestic policy issues related to grain production after 1958. Famine relief was required and the need was exacerbated by Mao's desire to remove any means of Soviet financial pressure on the PRC, as he repaid loans by exporting grain in mid-famine. Emergency relief was needed and was purchased from the West, not the US, but its grain growing allies, Australia, Canada, France and Latin American grain producer, Argentina. While this may have hurt CCP pride, it was an absolute necessity if it was to remain in power as its legitimacy was under question. ${ }^{91}$ The PRC has been an importer of grain ever since 1961.

Despite the shortage of grain, Mao remained political. In addition to repaying debts to the Soviets with scarce grain, he also tried to score political points against the Soviets by transferring grain intended to reduce famine conditions to Albania. Albania was involved in a dispute with the Soviets that Mao could use to antagonize Moscow.

The reversal of collectivization did not bring a sudden return to prior levels on a per capita basis. Grain production per capita in 1958, $303 \mathrm{~kg}$ per year, was not exceeded until 1978. It was also in 1978 that available k/cal per day reached the levels of 1954. The PRC became dependent on the rest of the world for grain from 1960 through the end

\footnotetext{
${ }^{91}$ The Soviets were also a potential emergency supplier. However, the Sino-Soviet split precluded that option. Even if Mao had asked the Soviets for wheat, they were not in a position to be much help. The PRC imported more wheat than the Soviets exported to its normal customers from 1961 through 1963 and the Soviets were a net importer of wheat in 1964 and 1965.
} 
of Mao's reign. The PRC was in a situation where it could not insulate itself from the need for grain imports from grain rich countries, a situation of vulnerability interdependence. As seen previously, the amount of imports was not that great as a percentage of total output. However, the imports went to cities on the coast and the CCP needed to assure sufficient grain supplies to avoid urban demonstrations that could lead to de-legitimizing the CCP.

The major post-WWII shift in the international system occurred with PRC - US rapprochement in 1972 . The PRC, now an enemy of the Soviets, faced a potential twofront conflict with the US and USSR. Creating diplomatic relations with the US, that included recognition by the US of a one China policy, reduced that threat and in fact created a tacit defense arrangement against the USSR.

Rapprochement with the US opened the door to the leading agricultural country in the world. This had two positive benefits for PRC food security. First, it removed the possibility of the US forcing Europe and Canada to stop shipping grain to the PRC for international political reasons. Second, it increased the number of potential trading partners for grain as did the amount available. Being interdependent on a greater number of states reduces the risk of dependency on one. In the debate over the English Corn Laws, Macaulay reasoned that dispersion by geography and by country lessens the possibility of dependence occurring due to politics and weather (Hirschman: 1969, 8-9). With that came the ability to influence grain producing states by adjusting the quantities purchased. As we have seen and will see, this is a useful tool for the PRC. ${ }^{92}$

\footnotetext{
92 With each additional grain supplying country that the PRC engaged, a dependency was created between the farmers of the supplying country and the PRC. What would be interconnectedness from a PRC point of
} 
The PRC remained a grain importer. However, while they remained a taker they also became a chooser of the supplying country. Rapprochement improved this situation. It gave them an increased degree of influence among supplying countries as its purchases could be directed towards those states it wished to influence, reward or punish. The one country that the PRC avoided punishing was the US; it was both a breadbasket and a defender.

view, for total wheat purchases, became a dependency for the farmer that counted on the farm lobby, his agent, to convince the government to acquire and maintain the PRC as a customer. 


\section{Chapter IV - DENG XIAOPING and PRAGMATIC FOOD}

\section{Introduction}

This chapter will focus on Deng Xiaoping as leader of the PRC, who was for all practical purposes, Mao's successor. It marks a period of reform from the intensely political times of Mao to one where expertise superseded political conformity and the efforts of the CCP were directed at improving the lives of its citizens through economic development. For the CCP, it marked the transition to an authoritarian state from a totalitarian one (Teiwes: 2002, 63).

The senior leadership of the PRC had not seen much of the world other than the USSR. ${ }^{93}$ Deng did travel following his second return to governing and learned how far the PRC had fallen behind the West and the Japanese. "The more we see, the more we realize how backward we are...the basic point is: we must acknowledge that we are backward, that many of our ways of doing things are inappropriate, and we need to change" (Deng quoted in Vogel: 2011, 218).

For Deng to reform the ways of doing things required an ideological shift by the CCP away from communism to a more market-driven economy. Implementation of the shift would be a long process, but once it started to take hold the reforms and opening to the outside world could proceed. The rural sector suffered from excess agricultural labor and stagnant output and needed reform to assure food security. Opening the economy to outside influences would speed-up economic development and replace the technology

${ }^{93}$ Both Deng and Zhou Enlai had worked in France after WWI. 
and know-how that had failed to keep pace with the developed world. Opening would require a foreign policy that supported the domestic agenda and provide an international climate that would facilitate achieving the modernization goals.

Deng's impact would be greatest on the domestic front as he dismantled many of Mao's policies and sought to reduce the egalitarian nature of PRC society (Ash: 1988, 533) beginning with agriculture. On the international front, Deng inherited Mao's rapprochement with the US and used it effectively to facilitate development. His foreign policies, like his domestic policies, were aimed at improving the PRC's position on the world stage and that did not preclude reconciliation with the USSR.

This chapter will address the issues of: 1) how Deng's reforms addressed food security and relieved the pressure on agriculture to finance modernization; 2) the role that foreign policy played in Deng's reforms; and 3) how food security influenced PRC foreign policies and how foreign policies influence food security.

\section{The Food Paradigm under Deng}

This section will address the domestic efforts to improve food security through increasing the supply and decreasing the demand for food. This was the second time since the founding of the PRC that demand, rather than just supply, became a method of addressing food security. Domestic politics provided the opportunities for the PRC to pursue development strategies that were contrary to those of Mao. Implementation of those strategies drove domestic food production higher and that in turn freed excess agricultural 
labor to be available for rural industry and to populate the export-led economic development strategy in coastal areas. Deng was able to solve the challenge that Mao faced decades earlier.

\section{$\underline{\text { Domestic Politics }}$}

Mao's chosen successor was Hua Guofeng, who had taken over as Premier following the death of Zhou Enlai, and became Chairman of the CCP and Chairman of the Central Military Commission (CMC) following Mao's death. Hua's downfall had much to do with the "two whatevers," whatever Mao did or said was to be followed by the CCP. ${ }^{94} \mathrm{He}$ was outmaneuvered by Deng and forced into early retirement in 1981.

Deng had been purged twice during the GPCR for a total of seven years but he had never been stripped of his party membership. He returned from his second exile in 1977 as a vice-premier taking responsibility for science, technology and education, activities which drove the country forward (Vogel: 2011, 149). Chen Yun, a possible successor to Hua, was instrumental in securing the return of Deng to the government following Mao's death. Deng had been active in the post-1949 CCP, longer than any of the other potential candidates for Hua's position, and was a former military commander from revolutionary times, an attribute that gave him great credibility among the older party elite.

\footnotetext{
${ }^{94}$ The "two whatevers" were used to delay Deng's second rehabilitation. Mao had dismissed Deng and whatever Mao did or said must be followed according to Hua who had risen to the top of the CCP during the GPCR. He was outmaneuvered by Deng and the older cadres, such as Chen Yun. They wanted to "exorcise the Cultural Revolution from the system" (Lieberthal: 1995, 135).
} 
Further, Deng never affirmed the GPCR, and by not doing so had the credibility to restore order and move the country forward (Vogel: 2011, 149). Both Deng and Chen would play important roles in remaking post-Mao PRC (Teiwes: 2002, 70-1). ${ }^{95}$

How did the decision-making at the senior levels of the CCP evolve under Deng's leadership? Shirk looks at the institutionalization of the political process under Deng and finds that he did improve the institutions of political leadership via term limits for the highest government and party posts, mandatory retirement age, and competition in elections for Central Committee members, among others. Yet, he did not go particularly far. His own authority flowed from his position as pre-eminent leader until 1994 when his health deteriorated too much to continue, not from his designated positions which were vice-premier until 1980, Politburo Standing Committee member until 1987, and CMC Chairman until 1989. She also notes “...Deng promoted institutionalization only so far as it did not limit his own authority" (Shirk: 2002, 301).

Teiwes echoes Shirk in stating that even though Deng maintained a more consultative style than Mao, his words were to be obeyed. He quotes political scientist Yan Jiaqi: "Whatever Deng Xiaoping says must be carried out, unless it is not feasible" (Teiwes: 2002, 61). The qualification of feasibility is a striking difference from Mao.

The other and perhaps most important difference from Mao was that Deng's primary motivations were to improve the lives of the citizens of the PRC and to maintain

\footnotetext{
${ }^{95}$ For a detailed discussion on the domestic PRC politics see The Nature of Chinese Politics: From Mao to Jiang, J. Unger (ed). This discusses a variety of approaches in examining the nature of PRC politics by top China scholars.
} 
control of the PRC by the CCP. ${ }^{96}$ Deng would use the power of his pre-eminence to institute economic reforms, to dismiss Hu Yaobang and Zhao Ziyang, both of whom were Deng protégées and General Secretaries of the CCP, to restore order in Tiananmen Square in 1989, and in post-Tiananmen times restart the PRC engagement with the world starting in 1992.

Deng was an important leader of the PRC as he was responsible for a fundamental change in domestic politics, the ideological shift from Mao's time. This shift allowed for the rural reforms and the "opening" to the outside world. In this section we will examine the ideological shift. The rural reforms and the implementation of the one-child policy will be addressed in the state-society section and the opening in the economic development section. Each of these changes had a bearing on the food security of the PRC, directly or indirectly.

\section{Ideological Shift}

The ideological shift that was required for Deng's reforms had domestic and international aspects. On the domestic side, it meant abandoning the communist egalitarian approach in favor of decentralization of the economy and the use of material incentives to drive production in agriculture and industry. Internationally, it meant abandoning Mao's

\footnotetext{
${ }^{96}$ Recall that improving the lives of the citizenry was a priority of Mao at the beginning of the PRC. Mao's method was ideologically based and assumed that development could occur under collectivization and selfreliance. Deng's method would be de-collectivization, material incentives, and opening to the world.
} 
self-reliance approach to development in favor of specialization, joining in the international division of labor, and accepting increasing interdependence with the rest of the world (Wu: 1981, 469).

Domestic politics of the time recognized the need for change in the priorities of the PRC as they related to economic development, the role of the $\mathrm{CCP}$, and dealing with the legacy of Mao. Deng first used the Zhou Enlai slogan of the "four modernizations," modernization of agriculture, industry, science and technology, and national defense to guide his efforts (Lieberthal: 1995, 130-1). By 1978, he had obtained wide agreement among his growing number of supporters regarding domestic politics and economic development. Politically, cadres persecuted unjustly during the GPCR were to be rehabilitated, class struggle and mass movements would no longer be used for policy implementation, and the rigidities of Mao Zedong Thought were to be tempered. Economically, development was key. Restoration of institutions necessary to run the economy was urgent; agricultural development was needed which meant the closure of the communes; incentives were needed to improve output in all economic sectors; and an opening to the outside world rather than self-reliance was needed to facilitate development (Lieberthal: $1995,129)$.

Opening to the outside world explicitly required opening to trade which required overturning the traditional Marxist-Leninist and Maoist aversion to trade. The Leninist view was that the world was divided into two groups, the rich and the poor nations of the world. Trade between the rich and poor would result in the exploitation of the poor by the rich. Maoist aversion sprung from Lenin in that trade would result in either the PRC being exploited or the exploiter, a Manichean dilemma. Rethinking trade led the PRC to 
Ricardo's comparative advantage which is based on the Labor Theory of Value that Marx also used and therefore increased its acceptability, ideologically. While acceptable, there were still debates over whether both sides of a trade would benefit. The eventual rationale became that poor states could also benefit from trade even while they were being exploited by the rich state, so international trade was acceptable. However, the method of evaluating whether trade was fair became the trade balance between one state and another where trade equality would require equal imports and exports (Ma: 1986, 291-305). The PRC attempted to maintain this bi-lateral equality as will be seen in several instances to be mentioned.

While Deng may have had overall agreement from those who supported his programs, the extent of the changes and the speed of implementation were always a subject for debate. He lacked an overall plan (Lieberthal: 1995, 126), and the waters were uncharted, leading Deng to approach reform by "crossing the river by feeling the stones." As a result, the process of economic reform was a start-and-stop, advance-and-retreat process. Apart from the political aspects, fundamental economic necessities were part of the back and forth. Chen Yun was in charge of the economy but limited himself to macroeconomic issues, not micro issues, meaning incentives. Chen knew reforms were needed but was also politically conservative. His conservative instincts were manifested in macroeconomic issues such as avoiding foreign debt, maintaining sufficient FX, and not spending more than the state collected in taxes. He acted as the financial brake when his conservative financial instincts were threatened.

Politics was also a constraint. Of Deng's four requirements for modernization, there was a strong bias towards the political: 1) A firm and consistent political message; 
2) political stability and unity; 3) hard work with a pioneering spirit; and 4) a contingent of officials with "unswerving socialist orientation" and "professional knowledge and competence" (Vogel: 2011, 360). Similarly, when he was running into conservative opposition in 1979, he issued his Four Cardinal Principles stressing the need to be "in conformity with: 1) Marxist-Leninism Mao Zedong Thought; 2) the socialist road; 3) continuation of the people's democratic dictatorship; and 4) absolute political domination by the CCP" (Lieberthal: 1995, 135) ${ }^{97}$ The legacy of Mao remained strong so that it was necessary to placate the conservatives to maintain the legitimacy of the CCP. The most important of the Cardinal Principles was the final one, domination by the $\mathrm{CCP}$, one that all of the senior leadership would agree to all the time. The others would become less and less relative as the reforms were successful and were expanded.

\section{$\underline{\text { State }- \text { Society Relationship }}$}

The state-society relationship changes during Deng's time were mixed. Politically, reforms brought a reduction in politics as "reformers sought to permit a non-political sphere of activity for individuals, drop class labels, use in-egalitarian distribution systems and conspicuous consumption as incentives for more work and creativity, rekindle interest in knowledge and technical skills...”(Lieberthal: 1995, 297). Economically,

\footnotetext{
${ }^{97}$ One favorite saying of Deng's was to "seek truth from facts." This is actually a quote from Mao but one that Deng could use to satisfy conservatives yet simultaneously use to discredit non-fact based decisions of Mao.
} 
there was a chipping away of the state power through increased personal choice, especially among farmers. Yet, personal choice was usurped to the greatest extent via the one-child policy.

\section{Rural Reforms}

The ideological shift away from a rigid communist-based society came from a realization by the ruling elite that the policies of Mao had hindered the overall development of the PRC and that fundamental change would be necessary begin the journey to modernization. The first move in that direction was rural reform, the single most important reform as it relates to food security. Rural reform meant escaping the commune system.

Restructuring of the rural areas consisted of two separate policy changes: first, decentralization of farming operations and second, the reform of the state purchasing and marketing system that eventually led to the use of market pricing of agricultural products.

The communes had produced behaviors that were detrimental to agricultural output. Free-riders were able to reduce participation while enjoying the benefits of others' labor, and the commune itself could lead to mismanagement of the commune and/or the abuse of power by management, the lowest level of government in the PRC. To eliminate these practices, two policies were implemented in 1979 to provide material incentives to boost output and efficiency. The first was to change compensation within the commune to each according to his work performed from each according to his need, an attempt to end the free-rider problem. Second, the production team was upheld as the ac- 
counting unit and the arbiter of production (what and how much is to be planted) including labor contracts within each group. ${ }^{98}$ The amount of land allocated to private plots was also increased. However, this policy change did not include and actually forbad allocation of land to specific households. Both of these policies were enacted to combat egalitarianism, a fundamental element of traditional communism. The principal objection to these measures was the inability of the smaller production teams to carry out largescale projects, mainly water control projects that the commune would have been able to conduct with control over a much larger workforce. Objections by commune management manifested themselves through ignoring or only partially implementing the changes at the local level (Ash: 1988, 530-3).

The next step in the dissolution of the communes occurred in September of 1980 when contractual agreements between households and the communes were created: the household responsibility system (HRS). This was not a nationwide change but one targeted only at poor areas disillusioned with the communes. However, it was readily accepted by many as indicated by its adoption by $30 \%$ of the productions teams nationwide within three months and $90 \%$ within 15 months. This program did allocate land to specific households. Households had to meet quotas (turned over to the commune) and pay taxes after which they were free to dispose of any surplus. ${ }^{99}$ As would be expected, thire-

\footnotetext{
${ }^{98}$ Recall that making the production team the accounting level within the commune was initially put in motion to relieve the GLF famine.

99 The commune had to meet a quota set by the government which was allocated to production teams and ultimately to households.
} 
turn to essentially private farming caused ideological issues and difficulties in implementation in some areas. In 1984, commune land was redistributed for private farming, and the land leasehold was extended to 15 years from its initial three years to encourage private investment in farming to increase agricultural output. ${ }^{100}$ Previously, the three-year contract encouraged maximization of the short-term output at the expense of sustainable outputs. (Ash: 1988, 534-7).

Communes were not eliminated by fiat. It was a step-by-step process that began in 1979. A key aspect was the separation of government from economic administration. This was done initially in Sichuan with the re-establishment of township government to replace commune governance. This ended the ability of the commune to interfere in the economic aspects of production, and eliminated the economic borders of the commune. ${ }^{101}$ Between 1982 and 1984, the number of communes fell to 249 from 54,352 while the number of townships grew to 91,171 from basically zero (Ash: 1988, 539). The peasants had the opportunity to chip away at the power of the state in the state-society relationship and they took it. The commune simply melted away.

The end of the commune also held out the opportunity for increased output in another way. Many communes had developed into self-reliant organizations producing all

\footnotetext{
${ }^{100}$ Kueh equates the reforms to the 1949-52 land reforms both in terms of output and institutions (Kueh: 2006, 717).

${ }^{101}$ The economic border of the commune is a reflection of what Donnithorne refers to as the "cellular economy" of the PRC, the emphasis on self-reliant communes or regions. In effect, this makes the country into a group of provinces and the provinces into a group of counties and the counties into a group of communes or townships, each responsible for all of its needs. Such practices reduce agricultural output through growing inappropriate crops for a specific area and are also reflective of the inability to transport crops throughout the country, reducing comparative advantage opportunities.
} 
of their needs. Without that constraint, the agricultural sector was free to develop into a situation of comparative advantage in crop production. However, an enabler for this was the development of a better transportation infrastructure to permit the timely and efficient transfer of grains from point of origin to point of need, an issue of economic development and time. ${ }^{102}$

\section{Material Incentives of Rural Reforms}

Deng's initial agricultural reforms began in 1978. Up to this time, what to plant and how much to produce (in sown acreage) was determined by the state, what Sicular refers to as mandatory plans. ${ }^{103}$ Upon harvest, the farmer had to sell a mandatory quota of his output to the government at a government set price. This was referred to as "unified procurement," reflecting all purchases by state entities. After fulfillment of the quota, what was not kept for consumption could be sold to the government at prices established by the government but at above quota prices, an incentive for the farmer to increase output. For grain, the local grain bureau, a state agency, was the only buyer of grain. No individual or organization, other than the grain bureau, was allowed to engage in grain transactions or long-distance transport of grain (Sicular: 1995, 1022). This system of production and procurement provided little incentive for increasing agricultural production and little opportunity to increase the quality of life in rural areas; that required additional material incentives.

\footnotetext{
102 On Deng's return after his first exile from power he tackled the rail problems that were plaguing efficiency at a major rail hub, the result of factional disputes during the GPCR (Vogel: 2011, 109).

103 This is different terminology for what Lardy called direct planning in Chapter II.
} 
Material incentives in agriculture consisted of three components: 1) giving the farmer the choice of what to plant (in 1978); 2) using prices to stimulate or retard production of different crops; 3) moving away from a single government-run distribution channel towards freer and eventually free markets. These steps were gradual just as all of the reforms in the post-Mao were as can be seen in Table 4.1.

For grain and cotton, the implementation of the incentives was slower than for other agriculture products. Grain production was essential to feed the population and cotton was a major input into the textile business, an area where Deng would concentrate light industry for domestic consumption and export. Only in 1985 were mandatory quotas eliminated for these products though the level of mandatory quotas had been decreasing (Sicular: 1988, 678). Other agriculture products had been freed from mandatory quotas beginning early in the reform period. Rather than mandatory quotas, production targets were to be used for planning purposes by the state. This necessitated the use of price incentives to assure an adequate supply.

Pricing was the direct material incentive for farmers to increase output. In 1979, prices for grains were raised $30 \%$ for quota sales and $50 \%$ for above-quota sales. Quota prices for rice, wheat and maize remained constant through 1984 while soybean increased another $50 \%$ in 1981 before declining $15 \%$ for two years starting in 1984. Above-quota prices increased for wheat, maize, and soybeans in 1978 and in 1979 for rice, wheat, maize, and soybeans and then remained constant through 1984. In 1981, the premium for above quota soybeans was eliminated. In 1984, grain output per capita reached an alltime high (Sicular: 1988, 680-6). 
The third component of reforms provided additional market channels, other than the government, for grains and therefore the possibility of even higher prices than the above-quota price. ${ }^{104}$ Since 1977 , the private market, other than the periodic local markets that had been re-introduced to help alleviate food shortages during the GLF, had been available to growers of minor crops: fruits, vegetables, and meat. In 1982 it was expanded to grains. Following fulfillment of quota sales to government entities, trade in grains locally and long distance by individuals, commercial entities, and collectives was authorized. Sales to state commercial entities were at negotiated prices. The farmer then had an opportunity to sell quantities above the quota to the government at the abovequota price, a negotiated price, or at the market rate (Sicular: 1995, 1022). Generally, but not always, each price was better than the previous for the farmer, yet each carried additional risk. In effect, this created a market price for at least a portion of production. The amount of production available to the market, other than through increased output, came from reductions in the grain quota and tax by $20 \%$ between 1978 and 1982 and from a reduction in the number of planned procurement commodities by the state (Sicular: 1988, 688).

The elimination of mandatory quotas for grain led farmers to plant additional cash crops. The sown area for grain crops fell $3.5 \%$ while the sown area for cash crops increased by $13.1 \%$ from 1984 to 1985 , evidence that the farmer reacted to the cumulative changes in material incentives. In 1985, total agricultural output grew $4.1 \%$, but the level of grain and cotton production fell 7.6\%, prompting the government--concerned about

\footnotetext{
${ }^{104}$ Without additional channels of distribution, the government enjoyed monopoly or monopsony pricing.
} 
grain self-reliance and subsidy costs--to re-impose mandatory production targets to ensure contract fulfillment (Sicular: 1995, 1023, Lin: 1992, 34). ${ }^{105}$ By 1991 state control again began to loosen. ${ }^{106}$ Grain bureaus became self-supporting grain trading companies with pricing authority. Grain ration shops were contracted out with responsibility for profit and loss. Flat grain output levels at the end of Deng's rule set the stage for inflation in foodstuff, an issue for Jiang Zemin. The back and forth on grain production restrictions are indicative of "crossing the river by feeling the stones."

In total, the HRS, planting choices, price increases, and increasing the possible marketing channels were improving agricultural output. By the end of 1984, grain output had increased to $407 \mathrm{mmt}$ from $306 \mathrm{mmt}$ in 1978. Of the gain in output, nearly $47 \%$ was attributable to the HRS and 32\% was attributable to the use of fertilizer (Lin: 1992, 45). ${ }^{107}$ Science and incentives increased output.

\section{The One-Child Policy}

The concern over poor agricultural output was addressed via the HRS and incentives. The other half of the food security equation, the extent of the population that agriculture had to support, was addressed simultaneously. Concerns over population growth

\footnotetext{
${ }^{105}$ Increasing grain purchases at above quota prices and negotiated prices were not offset by price increases in grain ration shops selling to the public. This resulted in subsidies for farmers and consumers reaching $24 \%$ of the state revenues (Sicular: 1995, 1023).

106 The back and forth on grain production and distribution restrictions are indicative of the start-and-stop, advance-and-retreat of reform implementation as the PRC "crossed the river by feeling the stones".

${ }^{107}$ Fertilizer was made available to farmers at reduced prices and as an incentive for early fulfillment of the quota.
} 
tended to follow years of poor harvests. During the GPCR, harvests tended to be relatively consistent as measured by per capita grain output despite the population increase from 1968 through 1970, an average of $2.89 \%$ per year, higher than any other three consecutive years the PRC's history, and implying a doubling of population in about 24 years. ${ }^{108}$

The implementation of the one-child policy in September 1980 represented a long-term policy to cut the growth rate of the population and to ultimately reduce the demand for food. Demographic Transition Theory "Stripped to essentials it states that societies that experience modernization progress from a pre-modern regime of high fertility and high mortality to a post-modern one in which both are low" (Kirk: 1966, 361). ${ }^{109}$ It refuted Malthusian concerns of the population growing beyond the food supply. ${ }^{110} \mathrm{Cau}-$ sality for the transformation comes from many sources including medical, economic, and ideational, among others. For our purposes, the following are most important: 1) agriculture moves beyond the subsistence level, freeing the peasantry to pursue more productive economic activities; 2) improved healthcare results in increased life expectancy and decreased infant mortality, reducing the need for a high birth rate to assure infant survival to care for elder parents in the future; and 3) urbanization occurs increasing the cost of rais-

\footnotetext{
${ }^{108}$ The chaos of the GPCR encouraged people to avoid becoming a target and led to people staying at home as a means of protection. Too much staying at home was the cause of the spike in population growth.

109 "The demographic transition theory was formulated by the Office of Population Research in Princeton as a culmination of or abstraction from previous work on The Future Population of Europe and the Soviet Union, which was published in 1944 on behalf of the League of Nations" (Kirk: 1996, 363).

${ }^{110}$ Malthus maintained the population expanded geometrically and food production only arithmetically and would lead to insufficient food per capita.
} 
ing children provided a financial incentive to cut the birth rate. This is a multi-generational transition. The agriculture reforms started the movement away from subsistence and, as will be seen, non-agriculture employment began to increase. However, with the largest population in the world and a fear of being unable to feed it, a deeply rooted preference for male offspring and large families, especially in rural areas, and internal controls on migration, could the PRC wait for a demographic transition and meet Deng's development goals? The answer was no and the one-child policy became law; an intrusion of the state into society to the highest degree as well as one that would have impact for generations to come.

The one-child policy was a successful securitization. It had been a politicized discussion among the CCP leaders for decades. The referent object was the size of the population itself and the resources it would take to feed, clothe, educate, and care for--from cradle to grave--a population growing from such a large base. Deng was the securitizing actor and the Standing Committee was the audience. The functional actors were those who had the responsibility for implementing and maintaining the program.

Yet, old customs are hard to overcome. Land distribution was based on household size and then on commune work points, the latter favoring males and the number of males in a household. The re-allocation of land rewarded larger families and those with the most males, therefore reinforcing the tradition of large families and a preference for males. The relative impact of the larger family on income also served as a deterrent to the one-child policy, especially in rural areas. To offset this issue, one-child families were to receive private plot land for a family of four, a practice that was not consistently followed. Encouragements to have only one-child included the high cost of maintaining and 
educating children, an urban issue that ran counter to the rural experience (White: 2006, 115-7).

The economy was stimulated by material incentives; enforcement of the one-child policy was the opposite. It could be brutal with forced abortions and sterilizations or through fines and female infanticide, non-registration of females or of second children. Non-registration would effectively make these children non-persons, from a government point of view, for life.

\section{Summary}

During the period of Deng's leadership, there were two examples of extreme changes going in opposite directions in the PRC state-society relationship as it relates to food security. First there was the de-collectivization of agriculture, a step-by-step withdrawal by the state from the agricultural activities of the peasant via the all-powerful commune system. This was enthusiastically embraced by the peasants so quickly that it precluded a return to the commune. The material incentives and the removal of overbearing oversight led to an increase in the supply of food, but not always in grain production. Kueh maintains that price increases alone were insufficient, for "...the large response needed to increase output above increased peasant consumption it had to be directly translated into income benefits for the individual peasant families, and this could only be accomplished by decollectivization" (Kueh: 2006, 717). The state-society relationship as it applies to the public good, food, shifted away from the state towards society.

Second, the one-child policy relied on a combination of disincentives as the state intruded into human reproduction using minor incentives but mainly coercion to achieve 
its goal of reducing the rate of population growth and future demand for food, a necessity according to Deng if the living standards of all of the PRC were to increase. ${ }^{111}$ By the time the one-child policy was modified to allow two children, the population pyramid of the PRC was distorted by gender and by an insufficient younger population to support an aging one. In effect, the state decided that uncontrolled birth rates were not a public good and therefore inserted itself into human reproduction making the one-child policy a public good that the state would control.

\section{$\underline{\text { Economic Development }}$}

The impacts of economic reforms by Deng were far reaching and eventually transformed the PRC economy from an agricultural one to an increasingly industrialized one and one that recognized the importance of light industry as well as heavy industry. This section will focus on the development of township and village enterprises (TVE), and the introduction of special economic zones (SEZ) that impacted the coastal areas and brought foreign funds and expertise to the PRC in exchange for inexpensive labor and excess agricultural labor. This section will also look at an aspect of trade that did not change: how export and import quantities of grain are determined and executed.

Town and Village Enterprises (TVE)

Historically, Chinese peasants had engaged in sideline occupations during the slack times of the year for farming. These occupations generally involved adding value

\footnotetext{
${ }^{111}$ There were a number of exceptions to the one-child policy, including the number of children minorities could legally have and a decreasing level of enforcement in rural areas over time.
} 
to agricultural products that were sold to urban areas or at local markets. They were an important source of rural income. In the 1950's, mandatory state procurement of agricultural output removed the supply source for many of these sideline occupations. Communes had been the institution that the CCP had used to promote rural industry with mixed results. However, as the communes transformed themselves into townships, they provided a base for the resumption of a vigorous rural economy through TVEs. The System Reform Commission of 1984 encouraged the rural processing of agricultural products where economically feasible and once that was accepted it opened the door for any other activity for which there was a market (Naughton: 2007, 274). Whether as a commune or a township, the TVEs were collectively owned and therefore politically acceptable to conservatives.

TVEs were not subject to the labor laws and restrictions imposed on state owned enterprises (SOE), and were quite successful competing with or acting as sub-contractors to SOEs. TVEs were instrumental in employing surplus agricultural labor, reaching 123 million in 1993 (Cai et al: 2008, 171), which in turn served to reduce unwanted rural to urban migration. The TVEs tended to flourish in areas bordering the major industrial centers rather than being spread more evenly about the country (Naughton: 2007, 279).

\section{Special Economic Zones (SEZ)}

SEZs were introduced in 1978 by Deng, the "opening" in Deng's policy of reform and opening. ${ }^{112}$ The rationale for the establishment of such zones was based on several

\footnotetext{
${ }^{112}$ The original term for these zones was simply "special zones." Chen Yun had "economic" added to the name in order to prevent or dissuade these zones from becoming zones that would include political reform (Vogel: 2011, 413).
} 
reasons. First, the economic development of the Asian Tigers (Hong Kong, Taiwan, South Korea, and Singapore), had shown that an export oriented economic development policy could be very successful. Second, foreign investment in these zones would transfer technologies and management expertise to the PRC, priorities for Deng's economic development plan. Third, the PRC's primary factor endowment was labor, both in quantity and low wages by international standards. Fourth, the use of foreign direct investment (FDI) reduced the amount of internal capital needed to develop the zones. Fifth, these zones served as locations to experiment with economic policies. ${ }^{113}$ The first were in Shenzhen, Zhuhai, Xiamen, and Shantou. The locations of these zones were chosen in order to attract investment from overseas Chinese investors from Southeast Asia, Hong Kong, and Taiwan. The growth in the number of SEZs can be tied to the reform process. The expansions of SEZs in 1984 and 1992 were indicative of waves of liberalization (Naughton: 2007, 406).

The SEZs had four prominent impacts on the PRC. First, their establishment created unprecedented interdependence between the PRC and the rest of the world. It was initially seen as a one-way street with the PRC gaining from what the West had and without the imposition of western ideas the PRC did not want. The West's reaction to Tiananmen interrupted creeping interdependence but that shortly afterwards led to a general acceptance of the mutual benefits of trade (Robinson: 1994, 190-1). ${ }^{114}$ Second, the

\footnotetext{
${ }^{113}$ Initially, SEZs were cordoned off from the rest of the PRC. The Shenzhen SEZ was fenced off and authorization papers were needed for any PRC citizen to enter.

${ }^{114}$ Of course the West engaged in trade not only for economic benefits but also with the hopes that increased trade, wealth, and exposure to western ideas democracy would transform the PRC government into a more pluralistic one.
} 
domestic impact of the SEZ was to continue the bifurcation of PRC society. In addition to the existing urban-rural bifurcation, the concentration of the SEZs in eastern coastal areas precluded inland areas from participating in SEZ successes, at least for several decades. This was a further example of non-egalitarian development. Third, the coming increase in the export earnings of SEZs provided the PRC with a new major source of FX, thereby reducing the burden on agriculture to provide exports to earn FX to finance development. Finally, as with TVEs, SEZs utilized excess agricultural migrant labor to fill production positions, though not to the extent of the TVEs. This increased incomes in rural areas via remittances.

While the SEZs first went into use in 1978, they were experimental and required not only PRC approval but foreign interest. They grew slowly until the 1989 Tiananmen incident and then remained relatively constant. In the post-Tiananmen period the developed world and the PRC turned their respective backs on each other. In 1992, Deng toured the SEZs in the south and made the comment that the PRC was open for business. This initiated a rush of foreign investors to come to the PRC to take advantage of its labor force or to penetrate the PRC market. It signaled once again that the PRC was dependent on the outside world for its rapid development, something that could not be achieved without outside investment, technology, and skill transfers. Deng introduced the SEZ concept, but it was in the post-Tiananmen times under Deng / Jiang and then Jiang that they flourished. 


\section{Summary of the Food Paradigm under Deng}

Deng's agricultural reform of the PRC economy and the opening of the economy to the world served to unleash the innate abilities of the population to make better lives for themselves, a reversal of Mao's ideological and political operational method. Two policy changes, agriculture reform and the one-child policy, sought to remove the fear of food insecurity in the short term through supply and the long term through demand respectively. For the period of Deng's rule, the policy changes worked. The population was allowed to make more decisions as to what was best for themselves, but only within limits that continued to be imposed by the CCP. Those limits included the continuation of the hukou system and the imposition of the one-child policy.

The agricultural reforms implemented beginning in 1978 had an immediate impact on grain output as seen in Table 4.1. The increase in output was only temporarily impacted in 1985 with the re-instatement of mandatory quotas. This was due to the reduction in sown acreage for grain crops resulting from farmer choices to plant cash crops. From 1986 on the per capita grain production averaged $363 \mathrm{~kg}$ per capita, well above the $311 \mathrm{~kg}$ amount in 1978. Total annual grain output rose from 304 million tons to 445 million tons between 1978 and 1994.

From the food security point of view, Deng's rule resulted in a significant improvement in food security with an approximate $26 \%$ increase in $\mathrm{K} /$ cal per capita grain 
availability and $16 \%$ in grain production. ${ }^{115}$ By 1982 , per capita availability had exceeded 2300 calories per day and continued to grow (Table 4.2). The PRC continued to be interdependent on world agricultural trade but there was no vulnerability issue.

\begin{tabular}{|c|c|c|c|c|}
\hline \multirow[t]{4}{*}{ Material Incentives a } & \multirow[t]{4}{*}{ d the Ir } & \multirow{3}{*}{$\begin{array}{c}\text { pact on Grain Out } \\
\text { Total Grain } \\
\text { Production }\end{array}$} & \multirow{3}{*}{$\begin{array}{l}\text { put } \\
\text { Total Grain } \\
\text { Production }\end{array}$} & \multirow{3}{*}{$\begin{array}{l}\text { Arable } \\
\text { Land }\end{array}$} \\
\hline & & & & \\
\hline & & & & \\
\hline & & Millions of tons & $\underline{\mathrm{Kg}}$ /capiata/vear & $\underline{\text { Ha./capita }}$ \\
\hline $1978-82,20 \%$ reduction in quotas and agriculture taxes & 1978 & 304.8 & 311.1 & 0.099 \\
\hline $\begin{array}{l}\text { Compensation method changed, choice of what to plant, } \\
\text { quota and above quota prices raised } 30 \% \text { and } 50 \%\end{array}$ & 1979 & 332.1 & 334.5 & 0.098 \\
\hline \multicolumn{5}{|l|}{ Dissolution of communes begins } \\
\hline \multirow[t]{2}{*}{ HRS impemented } & 1980 & 320.6 & 318.6 & 0.096 \\
\hline & 1981 & 325.0 & 318.6 & 0.096 \\
\hline \multirow{2}{*}{$\begin{array}{l}\text { After quota fulfillment, non-government distribution } \\
\text { channels available at negotiated or market prices }\end{array}$} & 1982 & 354.5 & 342.7 & 0.094 \\
\hline & 1983 & 387.3 & 369.1 & 0.106 \\
\hline Land leasehold extended to 15 years & 1984 & 407.3 & 382.4 & 0.105 \\
\hline \multicolumn{5}{|l|}{ Communes eliminated } \\
\hline Mandatory quotas eliminated & 1985 & 379.1 & 350.5 & 0.112 \\
\hline \multicolumn{5}{|l|}{ Use of IOU's for payments for grain (see Ch. 5) } \\
\hline \multirow[t]{2}{*}{ Mandatory quotas re-instated for rice \& wheat } & 1986 & 391.5 & 356.2 & 0.110 \\
\hline & 1987 & 404.7 & 362.2 & 0.109 \\
\hline \multirow[t]{3}{*}{ Use of IOU's expands } & 1988 & 394.1 & 346.8 & 0.108 \\
\hline & 1989 & 407.6 & 353.0 & 0.107 \\
\hline & 1990 & 446.2 & 380.9 & 0.106 \\
\hline \multirow[t]{3}{*}{ Grain bureaus and ration shops converted to self-supporting } & 1991 & 435.3 & 366.6 & 0.105 \\
\hline & 1992 & 442.7 & 368.2 & 0.103 \\
\hline & 1993 & 456.5 & 375.4 & 0.100 \\
\hline Total grain production up 45\% from 1978 & 1994 & 445.1 & 362.2 & 0.099 \\
\hline \multicolumn{5}{|l|}{ Population increased by 25\% from 1978} \\
\hline \multicolumn{5}{|l|}{ Sources: } \\
\hline \multicolumn{5}{|l|}{ Population: FAO Statistics } \\
\hline \multicolumn{5}{|l|}{ Total grain production: State Statistical Bureau 2001} \\
\hline Arable land: FAO Statistics & & & & \\
\hline
\end{tabular}

${ }^{115}$ Note the definition of grain availability from the previous chapter. 


\begin{tabular}{|c|c|c|c|c|c|c|c|c|c|}
\hline \multirow{2}{*}{$\begin{array}{l}\text { Table } 4.2 \\
\text { Year }\end{array}$} & \multicolumn{9}{|c|}{ Indicators of Food Security / Insecurity } \\
\hline & $\underline{1978}$ & $\underline{1979}$ & $\underline{1980}$ & $\underline{1981}$ & $\underline{1982}$ & $\underline{1983}$ & $\underline{1984}$ & $\underline{1985}$ & $\underline{1986}$ \\
\hline$\%$ change in total grain output (1) & $7.8 \%$ & $8.9 \%$ & $-3.3 \%$ & $1.2 \%$ & $8.6 \%$ & $9.6 \%$ & $5.2 \%$ & $-6.9 \%$ & $3.4 \%$ \\
\hline$\%$ change in population & $1.38 \%$ & $1.34 \%$ & $1.36 \%$ & $1.38 \%$ & $1.40 \%$ & $1.44 \%$ & $1.49 \%$ & $1.55 \%$ & $1.62 \%$ \\
\hline \multirow[t]{2}{*}{$\mathrm{K} / \mathrm{cal}$ availability per capita per day (2) } & 2062 & 2077 & 2146 & 2164 & 2328 & 2399 & 2433 & 2429 & 2424 \\
\hline & & & & & & & & & 1978-1994 \\
\hline Year & $\underline{1987}$ & $\underline{1988}$ & $\underline{1989}$ & $\underline{1990}$ & $\underline{1991}$ & $\underline{1992}$ & $\underline{1993}$ & $\underline{1994}$ & Average \\
\hline$\%$ change in total grain output (1) & $3.3 \%$ & $-2.7 \%$ & $3.6 \%$ & $9.3 \%$ & $-2.5 \%$ & $1.6 \%$ & $3.1 \%$ & $-2.5 \%$ & $2.80 \%$ \\
\hline$\%$ change in population & $1.68 \%$ & $1.68 \%$ & $1.61 \%$ & $1.49 \%$ & $1.35 \%$ & $1.24 \%$ & $1.14 \%$ & $1.08 \%$ & $1.43 \%$ \\
\hline K/cal availability per capita per day (2) & 2439 & 2416 & 2404 & 2504 & 2431 & 2456 & 2538 & 2604 & 2367 \\
\hline \multirow{2}{*}{\multicolumn{10}{|c|}{$\begin{array}{l}\text { 1) Production } 1977-1992 \text {, PRC State Statistical Bureau, various years } \\
\text { 2) FAO Statistics Division }\end{array}$}} \\
\hline & & & & & & & & & \\
\hline \multicolumn{10}{|c|}{ Shaded areas indicate years in which population growth exceeded grain output increases. } \\
\hline
\end{tabular}

Agriculture still needed to be a net contributor to FX reserves to finance at least part of the modernization. After an initial negative balance, the agriculture balance of payments turned positive and throughout Deng's rule exports exceeded imports by nearly $40 \%$ as shown in Table 4.3. The positive trend was established by increased exports of primarily labor-intensive crops as well as increased grain production. From an agricultural balance of trade point of view, once it turned positive in 1984 the PRC was self-sufficient in total while being only self-reliant in some foodstuffs, including wheat.

Table 4.3

\begin{tabular}{|llllllllll|}
\hline $\begin{array}{l}\text { Year } \\
\text { Balance }\end{array}$ & $\frac{1978}{(671)}$ & $\frac{1979}{(1,300)}$ & $\frac{1980}{(2,354)}$ & $\frac{1981}{(2,235)}$ & $\frac{1982}{(1,950)}$ & $\frac{1983}{(136)}$ & $\frac{1984}{1,639}$ & $\frac{1985}{3,006}$ & $\frac{1986}{3,688}$ \\
$\begin{array}{l}\text { Year } \\
\text { Balance } \\
\text { Source: FAO Statistics }\end{array}$ & $\frac{1987}{3,203}$ & $\frac{1988}{2,878}$ & $\frac{1989}{984}$ & $\frac{1990}{2,849}$ & $\frac{1991}{4,656}$ & $\frac{1992}{4,932}$ & $\frac{1993}{6,383}$ & $\frac{1994}{5,460}$ & $\frac{1978-1994}{31,032}$ \\
\hline
\end{tabular}

From a food security point of view, the reforms were a success, yet incomplete. The use of subsidies for agricultural inputs, procurement prices from farmers, and subsidies for urban food consumption required ongoing adjustments. Each constituency 
needed to be kept content and the government had to be able to afford the subsidies it granted. This was made more difficult by the annual and natural fluctuation of crop production regionally and nationwide.

From an industrial point of view, the TVEs provided employment in rural areas and absorbed some excess farm labor into light industry. The creation of SEZs brought the outside world into the PRC to take advantage of its natural endowment, inexpensive labor, while beginning the process of transferring technology and management techniques, a process which would gain steam after 1992. This was a trade of labor for knowledge. If successful, it is an example of an absolute gain from a realist point of view and rapid advancement towards development. If it failed to achieve knowledge transfer, it might have created a dependency on labor exports and a much longer path to development.

\section{Foreign Policy under Deng}

Just as the food paradigm changed significantly under Deng's leadership so did foreign policy. In this section, the major changes in foreign policy will be addressed. The overall foreign policy of "peace and development" (Wang: 1997, 485-6) commenced in the early 1980's. ${ }^{116}$ As many have stated, PRC foreign policy flowed from domestic

\footnotetext{
${ }^{116}$ Kim delineates PRC foreign policy during this time into smaller time blocks: 1) Mid-1978 to mid-1981, anti-Soviet policy on a parallel track with the US. 2) Mid-1981 to mid-1984, an independent foreign policy. 3) Mid-1984 to mid-1989, the peace and development policy. 4) The post-Tiananmen period when the "notion of sovereignty-bound international order coupled with the rhetoric of economic interdependence became the lingua franca of Chinese international relations in a frantic quest for international legitimation" (Kim: 1984, 130).
} 
concerns. Deng's primary concern was the development and modernization of the PRC and for that to occur he needed peace. Peace, including the absence of threats against or by the PRC, would provide the time and funds for development. ${ }^{117}$ Peace would also enable Deng to use foreign assistance in economic development so that the PRC could speed development rather than relying on Mao’s self-reliance model.

The PRC had joined the UN in 1971. It continued and then deepened participation in both IGO and international non-governmental organizations. This represented a distinct increase in IGO participation, especially in securing IGO financing for economic development. Under Mao, the PRC was a revisionist state. Now it was becoming a status quo state interested in using the developed world to meet its modernization goals.

\section{$\underline{\text { The International System }}$}

When Deng assumed the leadership at the top of CCP hierarchy, the international system was still embroiled in the Cold War, a bi-polar domination by the US and USSR. The collapse of the USSR in 1991 resulted in a uni-polar international system dominated by the US, a significant event in international politics. The PRC had played a role in that system aligning itself with whichever super-power was the least threatening and that could assist the PRC with its development.

The PRC maneuvered within the international system during this time. Detente with the Soviets removed its threat and allowed the PRC to follow an independent foreign

\footnotetext{
${ }^{117}$ Note that the four modernizations included military modernization. However, this was fourth in order of priority, giving credence to the desire for peace.
} 
policy. This followed the thaw in relations between the US and USSR following Gorbachev's rise to power in the USSR. Contrary to other periods of détente between the two super-powers, this was a benefit to the PRC as it lessened the risk of war and would contribute to the peace that the PRC needed for development (Shambaugh: 1997, 204).

Bringing Taiwan back into the PRC was an ongoing effort that caused friction with the US if the threat of force was used. The US contributed to that friction whenever it sold arms to Taiwan or did anything that made the PRC think that the One China Policy was being violated. Finally, Deng used IGO's and his opening policy to finance and acquire technology needed for domestic development.

There were other aspects to PRC foreign policy that did not fit with peace and development. In the early period of Deng's rule and in some cases continuing into the 1990's, the PRC transferred nuclear technology for weapons production to Algeria and Pakistan, missile technology and launchers to Pakistan, and sold advanced missiles to Iran, Iraq, and Saudi Arabia. The West, at least, thought to be a bad idea. ${ }^{118}$ These actions were justified by the PRC based on its accession to the Non-Proliferation Treaty occurred just after the shipment to Algeria. The Missile Technology Control Regime, to which the PRC has not joined, applied to missiles with a range of 300 kilometers or more; the PRC claimed that the missiles sold had only a range of 290 kilometers (Robinson: 1997, 5889).

118 The US had intended to sell Pakistan missiles and lost the contract to the PRC. 
We will look in detail at three major aspects of PRC foreign policy: détente with the USSR, relations with the US, and the use of IGOs to finance development. The interactions with the USSR and the US allowed the PRC to follow an independent foreign policy.

\section{Détente with the Soviets}

When Deng rose to power, the PRC had already achieved a tacit defense arrangement with the US. ${ }^{119}$ The PRC could not compete militarily with the US or USSR, it was not a great power, nor could it be said that it was even a regional power. Yet its geographical spread and population made it a threat to any country with whom it shared borders. Geography allowed the Soviets to increase pressure on the PRC by entering into an alliance with Vietnam, which included Soviet naval access to Cam Ranh Bay and Danang, both on the South China Sea. This put Soviet military forces on the PRC border from the North Pacific to Afghanistan, a weak Soviet ally, India, on the southwest border, and Vietnam on the southeast border along with its allies in Southeast Asia. This was nearly complete encirclement of the PRC. As in ancient times, the PRC security was most concerned with what Gao refers to as an inner vassal state (see Chapter II) and Nathan and Scobell refer to as the "second ring" of states. ${ }^{120}$

\footnotetext{
${ }^{119}$ There was no formal defense agreement, yet the principle threat to each country was the USSR. Therefore it would be expected that either the PRC or US would react negatively towards the USSR should either become involved militarily with it.

${ }^{120}$ The first ring of concern is the PRC state itself and its internal security, the second is adjacent states, the third is the six multi-state regional security systems, and the fourth would become the rest of the world once the PRC became a power with international interests (Nathan and Scobell:2012, 3-7).
} 
Deng reacted to this situation with a short-lived invasion of northern Vietnam to "punish" the Vietnamese, both for the engagement with the Soviets and for its ousting of the PRC-backed Khmer Rouge government of Cambodia (Nathan and Scobell, 2012, 150). The invasion has not been viewed as a success for Deng.

In early 1979, the PRC refused to extend its 30 year old Treaty of Friendship with the USSR set to expire in 1980 (Hook et al: 1979, 677). By late 1979, the PRC and USSR began meetings, without preconditions, to normalize relations. For normalization to occur, the Soviets would need to unilaterally reduce forces on the PRC border, remove all forces from Mongolia, end all support of Vietnam, and settle existing border disputes with the PRC. Each of these conditions for normalization addressed Soviet encirclement and the second ring of security.

The Soviet invasion of Afghanistan put a quick end to these talks for several years, and withdrawal from Afghanistan was added as a requirement for normalization (Zagoria:1983, 855). By 1982, both sides were talking again and the Soviets engaged in confidence-building measures to signal the desire for normalized relations. ${ }^{121}$ They culminated with a Gorbachev - Deng summit in 1989 just prior to the Tiananmen crackdown and only two years prior to the dissolution of the USSR. ${ }^{122}$ These discussions took place against a background of increasing US support for Taiwan: the passing of the 1979

\footnotetext{
${ }^{121}$ The Reagan military buildup, directed at the USSR, provided additional inducement for the Soviets to engage with the PRC.

${ }^{122}$ Gorbachev came to power in 1985 and reacted to PRC concerns faster than might otherwise have been expected (Nathan and Scobell: 2013, 83).
} 
Taiwan Relations Act, and arms sales to Taiwan. These two aspects of US-PRC relations greatly infuriated Deng, especially the Taiwan Relations Act (Vogel: 2013, 480).

Détente with the USSR, while maintaining friendly relations with the US, improved the PRC's military security. Preceding this, Deng made substantial moves to facilitate modernization through the use of international organizations without which such rapid advancement would have been improbable.

\section{International Government Organizations}

From 1966 to 1989, the PRC increased its membership in NGOs and IGO's to 37 and 677, respectively, from practically zero. The most notable membership was admission to the UN and to the Security Council. With that came admission to the United Nations Development Program (UNDP) in 1972, the WB and its subsidiary organizations and the IMF in 1980, and application for WTO status in 1986. These Bretton Woods organizations, formed by the West, were the principal international economic regimes affecting states that chose to join, and naturally ones that ran contrary to what the PRC had stood for but simultaneously, if it so desired, provided an opportunity to use these institutions and/or add its input to shaping the rules. Kim also makes the point that the PRC follows a "maxi/mini”" strategy when dealing with IGOs. It maximizes security while minimizing the normative costs that are part and parcel of IGOs (Kim: 1992, 155).

With the rise of Deng, the use of the UNDP, WB, and IMF suddenly changed. Previously the PRC had been a minor contributor to the UNDP and uninvolved with the other two. Kim refers to the PRC at this time as the Group of One (G-1) for its refusal to join the G-77 and the Non-Aligned Movement, the two principal developing world 
groups of which it considered itself one and where its international behavior was more symbolic than substantive (Kim:1997, 407). This all changed when Deng declared that the PRC was a developing country, not a provider of aid, and by 1992 had received over $\$ 270$ million in funding from UNDP. From the IMF, it received \$2.1 billion to facilitate balance of payment issues. The WB and its subsidiaries funded $\$ 13.3$ billion in loans and credits for 109 projects (Feeney: 1994, 226-33). Total funds distributed, less repayments, by the WB from 1980 through 1994 totaled $\$ 23.5$ billion in current USD (World Bank Indicators: 1994). ${ }^{123}$ Once the PRC decided to pursue the development route with earnest, its foreign policy of using IGO's provided the funds it needed; its endowment was labor, not capital. The downside of these actions was to reduce the amount of funds available for other developing states, yet the PRC was the only developing country that had contributed funds for development without receiving any, until this point (Kim: 1997, 409).

In turning to the outside world to finance development, the PRC abandoned its self-reliance stance on development and its support of the new international economic order in practice. Under Mao, self-reliant development was achieved by “... each [country] doing the utmost for itself as a means toward self-reliance for new growth, working independently to the greatest possible extent, making a principle out of not relying on others, and not doing something only when it really and truly cannot be done.... Reliance on other countries . . is most dangerous" (Qouted in Wu: 1981, 456). Deng would not have

\footnotetext{
${ }^{123}$ Joining these institutions, whether from a realist perspective for relative gains or from a liberal perspective seeking only absolute gains, the PRC was successful in acquiring development funds, and its interests were met from both points of view. Its success in securing funds is attributable to development organizations wanting to do the most good for the most people. Therefore, with $20 \%$ of the world population, it represented an opportunity to move a great deal of people out of poverty that would eventually happen.
} 
been able to achieve the Four Modernizations rapidly under such a definition. So selfreliance was reinterpreted to be "socialist modernization with Chinese characteristics" (Kim: 1984, 615). This included the use of foreign capital, foreign learning, and foreign technology which together signaled a move towards an interdependent PRC.

\section{Foreign Policy and Food Security}

As seen above, the issue of food security improved dramatically from 1978 through 1994 as measured by available calories per day per capita based on domestic production. Concentration on labor-intensive crop production (fruit and vegetables) was a major reason in turning the agricultural balance of trade from negative to positive. But so was grain. As shown in Figure 4.1, the PRC continued as an importer of wheat, an exporter of rice, and became a net exporter of maize and soybeans in 1984 and 1983, respectively. Though the imports of wheat reached large numbers, on a per

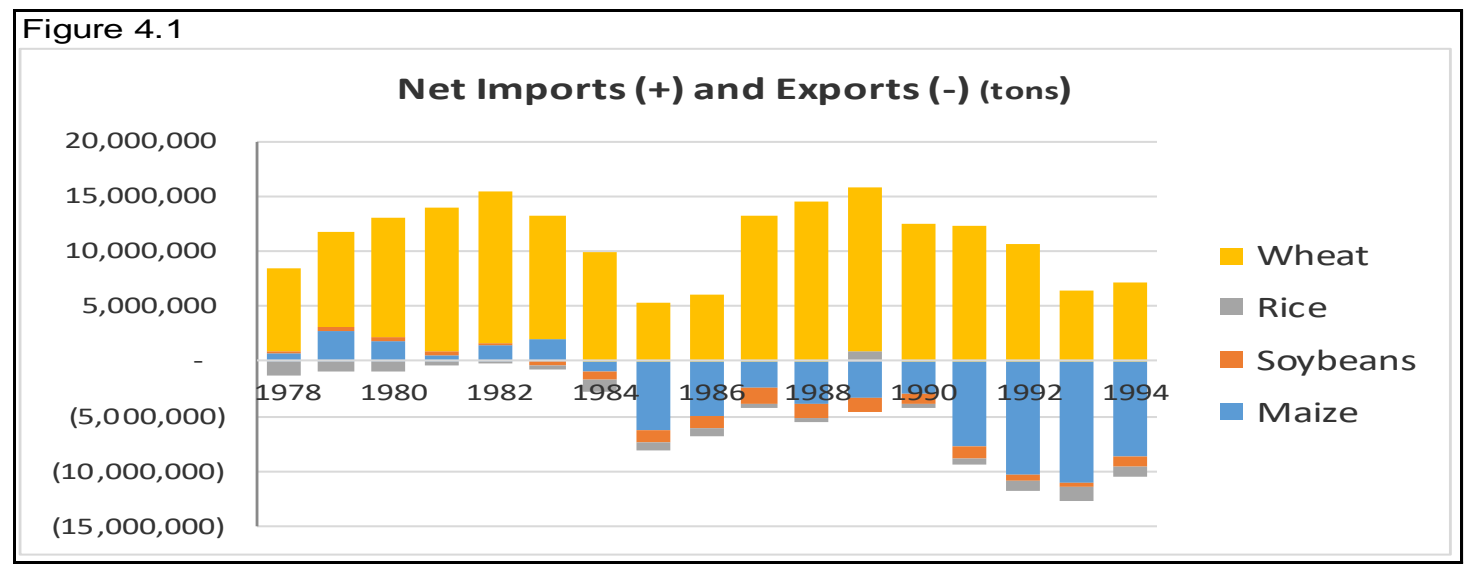

capita basis they averaged just under $2 \%$ of domestic output. Interdependence continued and dependency on the rest of the world to supply grain did not occur. The level of domestic grain production was sufficient on a national basis, according to generally accepted measures of food security; it made up for the lack of transportation infrastructure 
to move grain from growing areas to population centers. ${ }^{124}$ More ever, the surge in domestic grain and other foodstuffs output permitted a window of opportunity for the PRC to use grain exports as a tool to improve relations with the USSR and its allies.

Because of its large population, the PRC was a major factor in the world grain markets and therefore had the ability to use grain / food purchases to influence its suppliers or its customers, a tool of foreign policy. In this period, we will see both positive and negative uses of the trade in grain in rewarding and punishing suppliers or customers as a method to influence the behavior of other states. Simply using the grain trade to reward or punish states is not that simple in a world where the grain exporters are concentrated (wheat, maize, and soybeans). A number of other factors must be considered. First, the price paid is a major consideration and is affected by the vagaries of the weather, carryover stocks, and producer country subsidies. Even the availability of ships affects the supply and demand. A state does not wish to pay too much in any case. Second, given the limited number of supplying states, a diversified source of supply is needed but difficult to achieve. ${ }^{125}$ This can cause a buyer to be unable to use failure to purchase as punishment. Rewarding another state's behavior can come from altering the purchase amounts among the major suppliers to the favor of good behavior from the PRC point of view.

\footnotetext{
${ }^{124}$ In the late 1990 's the PRC ranked $73^{\text {rd }}$ in the world in paved roads per million people. India was ranked $66^{\text {th }}$, Russia $27^{\text {th }}$ and the US 7th. For rail transport, the PRC had $0.16 \mathrm{~km} / \mathrm{km}^{2}$ while Russia had 0.3 , the US 0.65 and India 0.73 (Pittman: 2004, 310). The inability to move grain around the country also led to major regional price discrepancies.

${ }^{125}$ In 1979, 90\% of wheat imports were from the US, Australia, Canada, and Argentina (Maidenberg: 1979, $6 / 22, \mathrm{D} 1)$.
} 


\section{Improved Relations with USSR}

The re-opening of talks with the Soviets in 1982 paved the way for resumption of agricultural trade with the USSR in 1984. The Soviets first purchased soybeans in 1984, added maize to the mix in 1985, and in 1986 a five-year USSR-PRC trade deal was signed covering maize and soybeans with annual volumes of 1.5 and .5 million tons respectively. Similar agreements were signed with East European countries (China Situation: 1986, 6). The grain trade with the USSR should be viewed as a confidence-building measure on the part of the PRC along the road to normalization of relations. Soviet satellite countries of Eastern Europe began importing grain from the PRC. Rice and maize exports started in 1985 and soybeans exports in 1986. Between 1984 and 1990, exports of soybeans to the East Bloc represented between $50 \%$ and $32 \%$ of total soybean exports. For maize, between 1985 and 1991 exports to the East Bloc represented between 49\% and $14 \%$ of total maize exports. In both cases, the USSR was by far the biggest purchaser. The percentage of exports to the USSR dropped after the first few years due to increased PRC exports and lower purchase volumes by the Soviets.

Given this sharp increase in exports to the USSR, the question must be asked as to whether this forced the PRC to reduce exports to other countries. The short answer is no. From the banner production year of 1984, the PRC became a net exporter of maize and soybeans. As seen in Figures 4.2 and 4.3, the switch from net importer to net exporter was dramatic. This came about through a combination of increased harvested area, yield improvements, material incentives and most likely, inventory levels. ${ }^{126}$ The East Bloc

\footnotetext{
${ }^{126}$ Area harvested is the number of ha. actually harvested disregarding the area sown.
} 
was not the only area to benefit from PRC soybean and maize exports nor were these the only "new" agricultural exports to the USSR. South Korea emerged as a principal maize buyer.
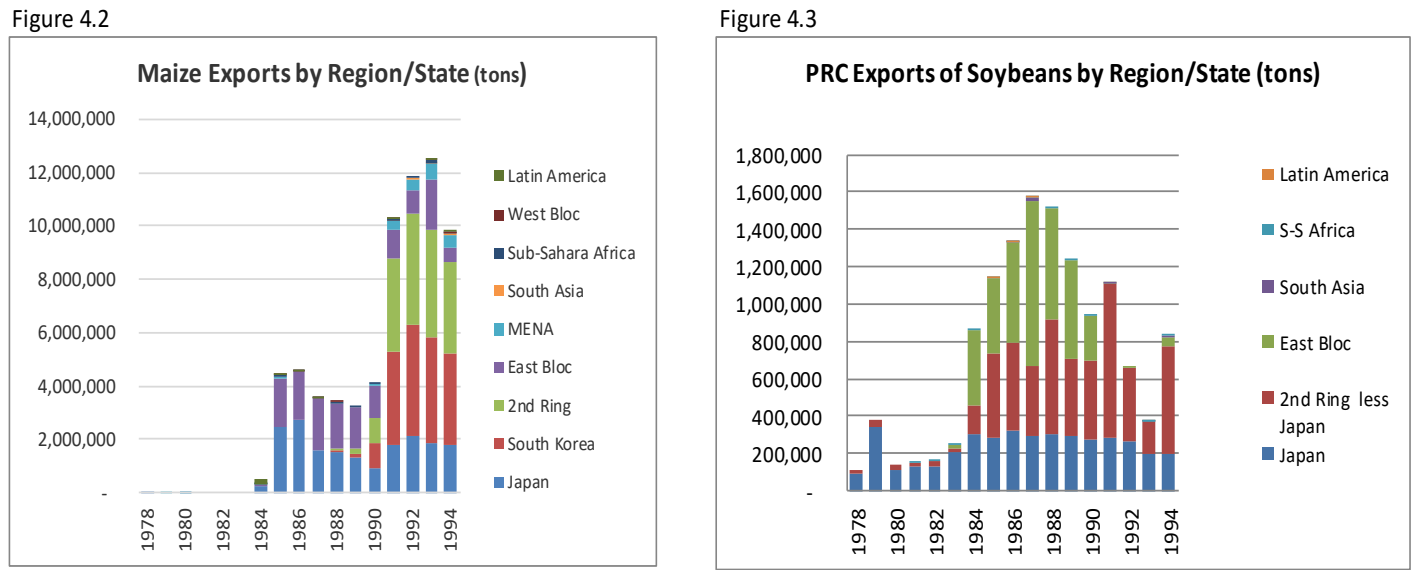

These exports served as a confidence-boosting measure that Deng could use to demonstrate intentions to the Russians that the PRC was interested in pursuing normalized relations. There was no risk to Deng if the Soviets opted not to pursue better relations or failed to meet PRC conditions for normalization. The Soviets were a frequent user of the world grain markets and the PRC would simply be another supplier for a period of time. The falloff in grain trade with East Bloc states is coincident with the dissolution of the Soviet Bloc and subsequently the USSR itself.

Arms Sales to Taiwan

Arms shipments to Taiwan were and are a considerable source of concern for the PRC. The PRC considers Taiwan as part of the mainland, a territory to be reclaimed by the PRC to complete the revolution. Therefore, it is considered part of the PRC's internal affairs, one that other nations should steer clear of as the PRC would do according to the 
most important tenet of the Five Principles of Peaceful Coexistence: a state should not become involved in the internal affairs of another state. The Netherlands, France, and the US have been involved with arms shipments to Taiwan and therefore exposing themselves to retaliation by the PRC and possibly in the sales or purchases of agricultural products.

The Netherlands agreed to sell Taiwan two submarines in 1981 with the encouragement of the US (Sterba, 1/19/1981, A14). In 1982, the US sold military aircraft to Taiwan, though not the most advanced, to the dismay of Beijing that maintained that the US would suffer a sharp PRC reaction and possibly a downgrading of diplomatic relations (Wren: 1/13/1982, A1). The US repeated the sale in 1992 with more advanced aircraft. That sale was immediately followed by the sale of advanced aircraft and arms to Taiwan by France. In retaliation for the submarine sale, the Dutch ambassador was expelled and official relations were downgraded to the charge d'affairs level. ${ }^{127}$ France was forced to close its consulate in Guangzhou in retaliation, an area where there was much French FDI, and the PRC ceased participation in international arms reduction talks (WuDunn: 11/19/1992, A12). ${ }^{128}$ Further, no new imports of French wheat occurred until both sides decided to mend fences in 1994 at which time wheat purchases re-started after a two-year absence. In contrast to the Dutch and French punishments, the US was spared

\footnotetext{
127 This remained in place until 1984 when the Dutch government denied a Taiwanese request for four additional four additional subs (New York Times, 2/2/1984, A4).

${ }^{128}$ The Germans were also rumored to be considering arms sales to Taiwan at the time. The PRC indicated that it might cancel orders for Airbus planes if German sales proceeded. The Germans did not make the sale but it demonstrates that with a multi-country manufacturing firm in Europe, like Airbus, the actions of one country could impact other countries thereby increasing the leverage of, in this case, the PRC.
} 
any major issues by Beijing due to arms sales to Taiwan. ${ }^{129}$ In fact, it appears that the PRC went out of its way to maintain normal trade relations. In 1982, the Sino-US agreements let the sales to Taiwan occur without issue so long as negotiations on ending arms sales continued. That said, the US did suffer. From 1985 through 1987, the US provided only 10\% of PRC wheat imports and from 1986 through 1988 only 67\% of maize imports. Both were far below its historical share.

In the 1992 case, the decision to sell the F-16s was primarily a domestic US political gambit to maintain employment to assist G. H. W. Bush's re-election possibilities. The PRC considered this sale to be a breach of the agreement reached in 1982 (Cheung: 2001, 76). Yet, right after Bush's defeat, the PRC placed an order for two million tons of wheat as a "present" for the victorious Clinton (Kristoff: 11/29/1992, 4). The absence of retaliation against the US can be explained by its economic and military capabilities relative to the Dutch and French. From the military point of view, in 1982 the PRC was still dependent on the US to keep the Soviets at bay. By 1992, the USSR had ceased to exist. From an economic development point of view, the PRC needed the combined economic power of all three to invest in 1982 and most importantly in 1992, in the aftermath of Tiananmen and coincident with Deng's southern tour. Finally, in agriculture the US was the leading grain exporter to the PRC, France was a player but fourth or fifth ranked, and the Dutch were non-participants. It is only natural that the PRC would do as little as possible to antagonize the US while simultaneously punishing the behavior of other states

\footnotetext{
${ }^{129}$ A Dutch journalist was quoted asking a PRC spokesman "Why is the American ambassador still here?" following the sale of F-16s in 1992 (Kristoff: 11/29/1992, 4)
} 
with fewer capabilities. The US did not suffer as it had following the 1982 arms sale. The US share of the import market remained relatively constant in the following years. Or is there a different explanation for part of the punishments handed out by the PRC at differing times? During the 1982 arms sale, there was another trade dispute occurring between the US and PRC. PRC textile manufacturers were having textiles "finished" in Hong Kong and claiming them as products of Hong Kong, thereby evading US tariffs for PRC goods. The US demanded compensation to resolve the issue. Prior to resolution in 1983, the PRC retaliated by reducing agricultural imports from the US purchasing only $2 / 3$ of the contract amounts for wheat and maize and was expected to be unable to make up the difference in its 1984 purchases. The textile issue was the reason for the 1983 shortfall and other excuses, either real or delaying tactics, were the cause of the shortfall in 1984 (Wren: 9/29/84, 29). The answer to the question is an absence of need. First, the PRC had record harvests of wheat and maize in 1983 with growth of nearly $19 \%$ and $13 \%$, respectively. Thus need was lessened. This increase in output was not a one-off event but was maintained and later grew even more. Second, the value of the USD was quite high and it behooved the PRC to buy from other countries with room to negotiate with regard to FX rates. Third, the PRC was running a trade deficit with the US and un-needed grain imports would exacerbate the issue. Fourth, if it did fulfill its contract obligations, in USD, it would have sold the excess in the world market almost surely at a loss, and anger other exporters.

The situation in 1992 was similar. The PRC was a net exporter of soybeans, maize, and rice in 1992-4 and had substantial reductions in wheat imports. Punishing 
France with suspension of imports was a simple decision that would probably have occurred anyway. The most likely explanation is a combination of both explanations. First, the absence of need was the starting point. Second, the PRC was able to make two political statements: first, to France and the world, as a matter of principle, for interfering in the internal affairs of the PRC; and second, to recognize the distribution of capabilities the US had and the need that the PRC would have for those capabilities.

\section{The Second Ring}

It would also be appropriate to examine the Second Ring, the ASEAN countries, plus Japan, South Korea, and North Korea after 1991. The expansion of agricultural output triggered by the Deng reforms led to an expansion of grain trade between the PRC and these countries. Both maize (Figure 4.4) and soybeans (Figure 4.5) followed a similar pattern for total exports of the crops under consideration as shown in Figure 4.1. As the Deng era commenced imports of both continued but nearly ceased as Deng's reforms drove production up.

Figure 4.4

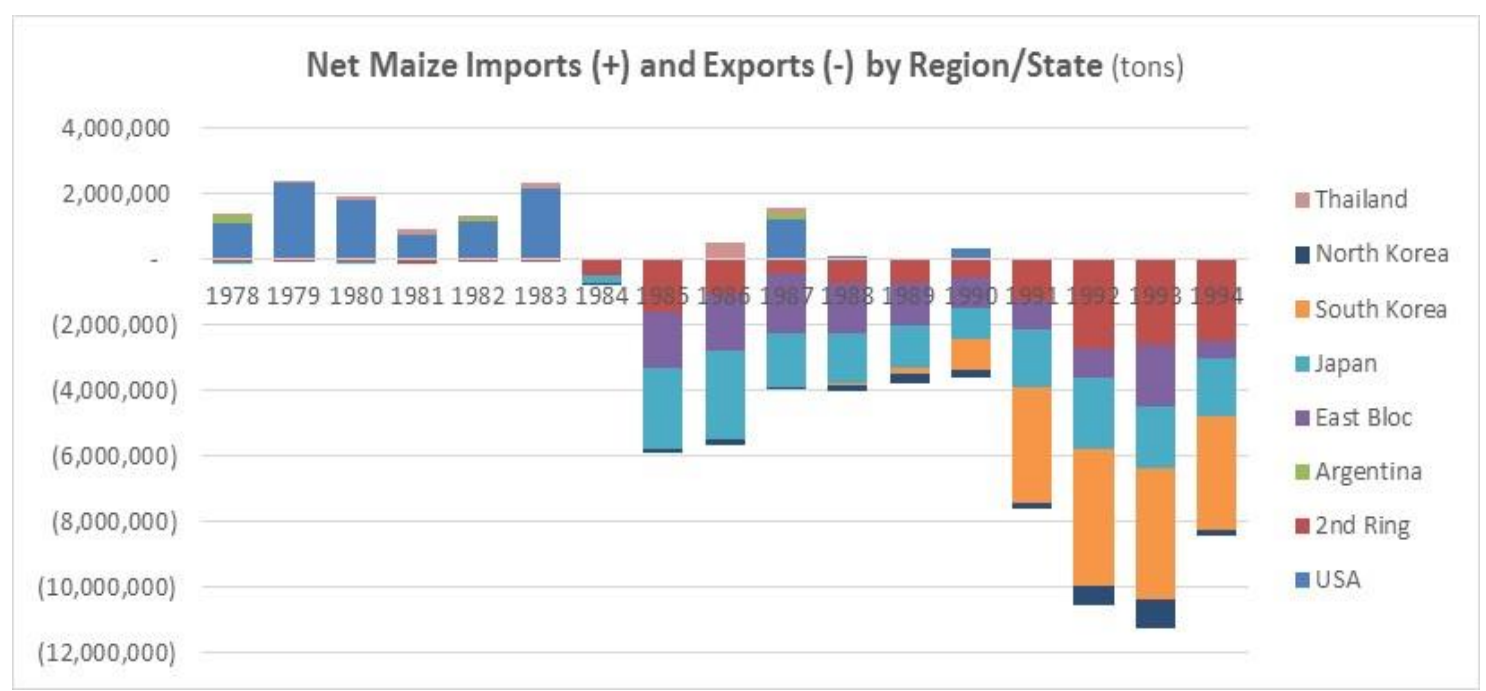


Thailand was a sometimes client state of the PRC. Harding maintains that the use of Thailand, in this case, was as a counterweight against Vietnam from 1975 and into the mid-1980's, a continuation of a long-term rivalry. Thailand was also useful to the PRC as a conduit to ship aid to Cambodian factions opposed to Vietnam (Harding: 1997, 3867). Though Thailand is a major agricultural state in Asia, trade in maize with the PRC was not normal. However, from 1978 through 1987, the PRC bought 1.4 million tons of maize from Thailand, an action that does not appear to be needed from a PRC-wide food security viewpoint. One can speculate that the un-needed maize purchases were a type of repayment to Thailand for whatever assistance they provided to the PRC interests in Cambodia. One logical explanation is that the maize went directly to Cambodia as aid from the PRC for which the PRC paid Thailand.

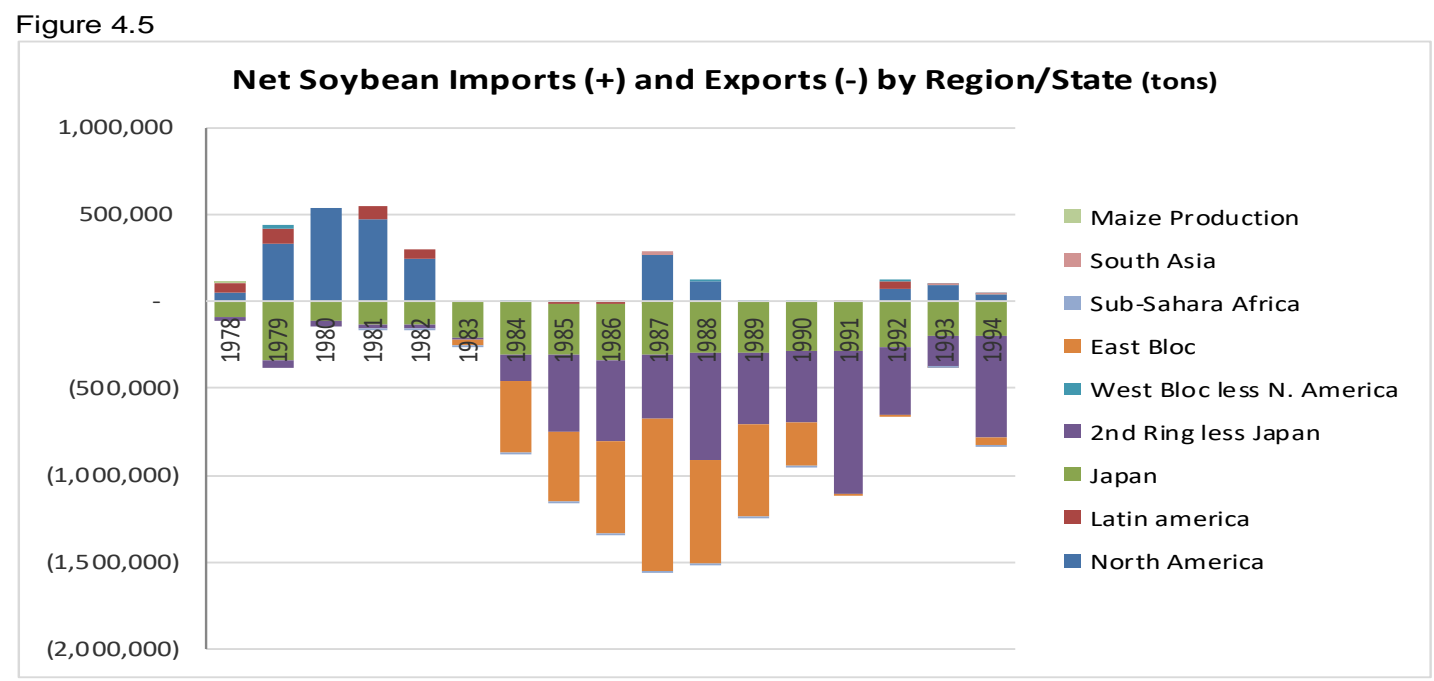

We also see the importance of Japan as a destination of PRC grain exports. Klein maintains that "Japan is vastly more important to China than any European nation. Except for the United States and perhaps the former Soviet Union, China's most important bilateral relationship is with Japan" (Klein: 1997, 120). When the PRC was unable to 
fulfill its committed purchase of a steel complex from Japan, partially due to reduced oil output, Deng was left to explain to Japanese business and government officials that the PRC's lack of experience had led to mistakes (Vogel: 2011, 432-3). ${ }^{130}$ Japan was a source of technology, and an important source of chemical fertilizers and fertilizer production facilities for agricultural use. At this time the PRC also ran a trade deficit with Japan. As previously mentioned, the PRC tried to keep bilateral trade balanced; consistent maize and soybean sales to Japan were part of the trade that helped to keep the deficit with Japan from getting worse.

With maize, we see the arrival of a new major customer for PRC maize, South Korea. Figure 4.4 shows exports to South Korea starting in 1990. However, an article by Chung, citing non-public information, states that South Korea started importing PRC maize following the 1984 harvest. This was conducted through Hong Kong to avoid the source and destination from becoming public. This trade was not made public due to PRC concerns over its relations with North Korea. Trade with South Korea was deemed to be beneficial for the PRC for mid-range technology products but the risk it ran was having North Korea turn to the Soviets permanently should commercial activities be formalized with the South (Chung: 1988, 1039-40). In 1990, South Korea and the USSR established diplomatic relations, eliminating the PRC's North Korean concerns; trade offices opened shortly thereafter to PRC-South Korean trade. In 1991, South Korea surpassed Japan as the major maize customer.

\footnotetext{
${ }^{130}$ Vogel goes on to say that Deng was too impatient and failed to listen enough to Chen Yun.
} 
In a somewhat similar situation, Vietnam and the PRC became engaged in agricultural trade. As USSR / PRC relations warmed, Gorbachev urged its ally, Vietnam, to mend fences with its northern neighbor. In 1991, the USSR ceased to exist but Vietnam had started discussions with the PRC. Following resolution of the Cambodian situation where each backed opposing factions, normal relations were restored between Vietnam and the PRC in 1991. Though border disputes, on land and in the South China Sea, continued--trade began again between the two (Thayer: 1994, 352-7), including grain. The PRC imported in excess of 700 thousand tons of rice from Vietnam from 1992 through 1996 and exported 53 thousand tons of maize to Vietnam in 1993.

Following the collapse of the USSR, its client state, Mongolia, began importing rice from its southern neighbor, the PRC; a further indication of changing trade patterns resulting from the Soviet demise.

Expanding grain trade with all countries within the second ring continued to take more maize and soybean exports from the PRC. Both were readily available on world markets but the proximity to the PRC reduced transport costs and delivery times. It served to help create a pattern of trust between the PRC and its closest neighbors. Given the suspicions of many of its neighbors concerning the PRC's rise and its ultimate intentions, the liberal view that trade reduces the possibility of conflict is appropriate at this juncture.

\section{Sub-Saharan Africa and the Middle East and North Africa}

Rice was an export product to the second ring (prime rice growing areas) and to other regions of the world. Rice exports to Sub-Saharan Africa continued to grow during 
Deng's time. African countries as well as small island states were a source of competition between the PRC and Taiwan for diplomatic recognition, a competition that often involved sufficient aid to effect the change. ${ }^{131}$ Rice exports to Africa followed the diplomatic recognition patterns. Not all states that recognized the PRC bought PRC rice. Only one that bought PRC rice recognized Taiwan, Cote d'Ivoire, and did so in relatively high volumes prior to switching recognition in 1983. Recall that diplomatic recognition was not a prerequisite for trade with the PRC.

During the 1980's, the PRC increased rice exports to the Middle East, primarily to Libya, Iran and Bahrain. All are oil producers, an issue that concerns the PRC as its Daqing oil field has less reserves that anticipated. Libya and Iran are arms customers of the PRC, and Iran received nuclear development assistance from the PRC from 1985 through $1990^{132}$ (Kim: 1994, 146-9). Buying rice from the PRC is most likely not a quid pro quo arrangement for arms and nuclear technology. It should be considered as establishing trade links that could facilitate trade in oil in the future.

\section{Conclusion}

The international situation that Deng initially faced was a continuation of the Cold War. Mao had started as an affiliate of the Soviets and an enemy of the West but left Deng with the West as a partner and the Soviets as a threat. Deng's initial domestic reforms in agriculture, implementation of the HRS and the incentives that it contained and

\footnotetext{
${ }^{131}$ In addition to recognition of Taiwan, whether a state opposed PRC UN admission prior to 1971 could influence the PRC's behavior towards that state (Harding: 1997, 387).

${ }^{132}$ As did Iraq in 1989-90.
} 
would create increased agricultural output and rural incomes. The additional agricultural production was available to feed labor in the urban areas and for export as well. The creation of SEZs took advantage of low cost and excess agricultural labor formed the backbone of export-led economic development in urban eastern coastal areas. It was in the SEZs where the use of the West's technology, knowledge, and capital was first applied and where the exports originated. Together, the agriculture reforms and the export-led development model began moving the PRC towards a market economy.

The CCP remained quite capable to compel citizens to act as it determined was best. The one-child policy was implemented to reduce population growth and decrease future food demand by diminishing demand. Student protests were crushed at Tiananmen late in Deng's rule when they refused to disperse.

The question now is whether grain was a strategic good during Deng's term of office. Whether it was strategic or non-strategic depends on the issues of sensitivity or vulnerability resulting from internal limitations or by the potential actions of other states. As noted, food security is always a concern. The increase in export businesses using agricultural products, i.e. cotton, on a decreasing quantity of arable land offered the population and the CCP additional worries concerning long term food security.

There are three reasons why grain might not be considered a strategic good. First is the increasing grain production. For our four major grains, production had increased annually, excepting normal crop output variations, throughout Deng's time. Between 1978 and 1984 and between 1987 and 1990, the PRC was a net importer of these grains. From 1991 through 1994, it was a net exporter of soybeans and maize and a minor exporter of rice. (Figure 4.1). This demonstrates that the HRS and subsequent adjustments 
were working as exports and increases in $\mathrm{k} / \mathrm{cal}$ per capita consumption were increasing. However, the improvement in output is not sufficient to remove grain as a strategic good, especially as imports of wheat continued.

Second, the total balance of payments turned positive for good in 1994. Except for one year, it had been positive since 1990. This put the PRC in a position to purchase whatever food they did not raise domestically in the world markets. It would no longer need to be self-reliant; the foundation had been laid by the earnings of export-led development to be self-sufficient in grain.

Third, suspension of food exports was no longer considered a legitimate punishment tool in the absence of war. ${ }^{133}$ Despite the Tiananmen crackdown and the international reaction to it, grain shipments were not suspended from the main suppliers, the US, Canada, France, and Australia. It could be assumed that imported grain would continue to be available to the PRC regardless of international distaste of its domestic politics. Yet, the PRC was susceptible to international pressures. The execution of the development plans, at least in the speed of attainment, led to the PRC having to accept US arms sales to Taiwan. Any non-verbal rebuke ran the risk of alienating the US government, which could have slowed US business investment in the PRC or limited access to the US market.

\footnotetext{
${ }^{133}$ The embargo of Iraq following the 1991 Gulf War was constructed so that domestically unavailable products for infant nutrition and medicines could be imported by Iraq and paid for by oil exports. This was recognition that the innocent should not suffer due to the government. While well-meaning, it appears not to have happened as planned as those needed products were re-exported to earn FX for non-essential goods. However, the failure of $\mathrm{N}$. Korea to meet its nuclear commitments did lead to a cutoff of grain shipments from the US and others.
} 
We must now consider whether grain is a strategic good. One that is essential for state survival or defense (Keohane and Nye) or if insufficient grain availability (domestic or imported) would produce "rapid and negative effects on a wide range of economic and military activities" (Ripsman and Blanchard: 2000, 60).

The increase in production was a step forward in food security. However, it was a step made in a longer journey. Two variables keep grain as a strategic good: the ability to keep the output growing and the loss of arable land. Output growth has occurred due to increasing use of chemical fertilizers, better seeds, better farming practices, incentives for farmers and partial reform of purchasing practices. An unanswered question is the whether the rate of production growth keep up with demand. According to some statistics the arable land per capita had increased during Deng's time. That increase had been the conversion of ponds to farmland. This helped but was limited and would not offset the conversion of arable land to other uses brought on by modernization. These two factors are critical. Continued production growth will not go on indefinitely and the rate of loss of arable land will increase for at least a while. The uncertainty surrounding these issues combine to keep grain a strategic good.

As a balance of payments issue, agriculture was a net contributor to exports despite large wheat imports, a condition of agriculture interconnectedness. The export driven economy was just starting to generate net positive FX. It was too soon to rely on manufacturing alone for FX. The PRC needed to repay loans and re-accumulate FX reserves. Agriculture was a proven method to do so, though its contribution will decrease in proportion to manufacturing. Other reason for maintaining grain as a strategic good are 
the domestic ramifications of importing grain in times of shortage and the impact on inflation. Paying for imports at a higher than domestic price necessitated the use of subsidies to control inflation; a costly, but necessary, exercise for Beijing.

The Tiananmen incident reaction from much of the world was decidedly negative. Despite the decidedly negative response to Tiananmen, grain shipments from primarily Western countries continued. Similar responses to rash domestic PRC policies might not stop grain shipments but could cause a slowdown in investment and exports thereby retarding the PRC's ability to generate FX. Such a situation would return the onus of FX generation back to agriculture, a situation that would delay modernization. Until FX reserves are sufficient and consistent grain will remain a strategic good.

The overwhelming policy action that designated grain as a strategic good was the one-child policy; fears of the ability of self-reliance to feed the population. Such an intrusion into the normal cycle of life and culture is the securitization of the rate of growth of the population. Once such drastic measures are taken, it must follow that all other aspects of preserving food security through domestic means, self-reliance, must be taken. Imports will be part of this but only as a backstop to a robust domestic effort. Grain continues to be a strategic good and one that remains interdependent sensitive.

The improvement in grain output provided Deng with the opportunity to use grain exports for FX as well as for influence. The five year soy and maize contract with the USSR is a case in point: an opportunity to demonstrate to the Soviets that the PRC was interested in restoring normal relations. Other than the five year contract with the Soviets, the vast majority of PRC grain exports went to the $2^{\text {nd }}$ Ring countries. Trade with the neighborhood is always a good idea, especially as the memories of many neighboring 
states were negative concerning the PRC. Grain trade with oil producers such as Libya, Iran, and Bahrain created influence that could lead to oil purchases from those countries. Similarly, Deng was able to send negative messages to the US and France by ceasing or reducing grain purchases following arms sales to Taiwan. The success of the HRS, in addition to the domestic benefits, provided the opportunity to punish each by reducing grain purchases.

At the conclusion of Deng's rule, progress had been made agricultural production in grains and other labor intensive agricultural activities. Grain continued to be a strategic good despite improvements. Yet, Deng's peace and development strategy limited his foreign policy options. Development required peace, and development required the cooperation of the international community. As the PRC chose to join additional IGOs he became constrained by the regime rules, the price of admittance. Any egregious international action triggered by the PRC that ran contrary to Western normative behavior, as Tiananmen did, ran the risk of long-term suspension of technology transfer, FDI, and exports, and ran the risk of retarding development for an extended period of time. ${ }^{134}$ In effect, Deng's development strategy made the PRC vulnerable to the rest of the world and primarily on the West for its development / modernization. It could not insulate itself from events that took place in the West. ${ }^{135}$ Failure in the development policy would create more pressure on agriculture, forcing it to re-emerge as the source of modernization.

\footnotetext{
${ }^{134}$ Western normative behavior is important as a significant portion of technology transfer and FDI were of Western origin and the West was the primary export markets.

${ }^{135}$ Deng risked his development strategy through military technology transfers and missile sales to countries that were considered unsuitable according to the US and contrary to international law intentions, though the PRC was yet to sign those agreements.
} 


\section{Chapter V - FOOD and the LEADERSHIP of the THIRD GENERATION}

\section{Introduction}

This chapter will focus on the rule of Jiang Zemin, the General Secretary of the CCP from 1989 to 2002, President from 1993 to 2003, and Chairman of the CMC from 1989 to 2004. This was an important period in the PRC. Domestically, the urban - rural and the coastal -western split separated income and opportunity in favor of urban eastern coastal areas. The development of the eastern coast first had been the plan, but the rural and western areas were getting restless. Attempts by Beijing to delegate management of provincial and local matters to the respective levels led many officials to abuse their positions. This corruption was felt most harshly by the peasants. Still, Beijing could force change in rural areas as it did to fight food inflation, an administrative action that would lead to a level of grain security for the nation not enjoyed for quite some time.

Internationally, the PRC would have to learn to live in a uni-polar world even as it spoke the language of a multi-polar one. The PRC would join the WTO near the end of Jiang's time in office and become a participant in regional organizations involving Russia and Central Asia as well as joining regional groupings focusing on ASEAN. The increase in grain output provided confidence-building trade opportunities with each of these organizations for a period of time, though horticulture products were the best and most sustainable opportunities. Building confidence with ASEAN countries was important given the increasing tensions in the South China Sea.

As has been done previously, we will first examine the food paradigm of the PRC, the domestic aspects of food security. We will then examine the foreign policy of the PRC to see its impact on achieving and / or maintaining food security as well as using 
grain as a foreign policy tool. The degree that the PRC can be self-reliant or sufficiently self-sufficient in grain will increase its foreign policy options.

\section{The Food Paradigm}

This chapter on the food paradigm will examine the domestic politics of the time and proceed through the state-society relationship, economic development, and population issues. The last section will examine the food paradigm and its effect on food security.

\section{$\underline{\text { Domestic Politics }}$}

Jiang assumed his position at the top of the CCP hierarchy during a time of great change. First, he assumed the position of General Secretary and Chairman of the CMC following the Tiananmen Square demonstrations and subsequent shootings. The previous General Secretary, Zhao Ziyang, was dismissed by Deng and other party elders for his objection to the use of force to end the demonstrations. Jiang was previously Mayor of Shanghai and was a surprise choice for the position. ${ }^{136}$ He was the first CCP leader not to have his communist roots in the revolutionary phase of the Party. Nor did he possess the prestige and charisma of Mao and Deng, but he did enjoy the support of Deng, who nonetheless "listened from behind the curtain."

\footnotetext{
${ }^{136}$ Dittmer maintains that Jiang was not Deng's personal choice (Dittmer: 2002, 233).
} 
Second, there was the transition from a "traditional agrarian society to a modern society, from a state-socialist economy to a market economy, and from a Leninist political system to something else." (Teiwes: 2002, 255). While Mao had centralized political leadership and Deng had decentralized it in order to enliven the economy, Jiang "had the more technically difficult task of separating the political system from the economy in ways that maintain a sufficiently strong state without stifling the economy" (Fewsmith: 2002, 265). Decentralizing control was a necessary tool in revitalizing the economy, but it was also an invitation to corruption by provincial and local cadres who now had at their disposal significant funds that were not always used as Beijing intended.

For Jiang, these formidable transitions and tasks were to be undertaken under the cloud of the Tiananmen Square demonstrations and suppression. His marching orders were to bring tranquility to the PRC by avoiding drama and extremes and focusing on management before politics. His guiding principles were to preserve the party's monopoly of power, which was in the PRC's best interest as well as his own (Pye: 2002, 209).

To maintain its position, the CCP needed to demonstrate its legitimacy, something that was increasingly in question following Tiananmen. “...the fragility of the regime's legitimacy - a fragility due to an official ideology few believe in, the inability of leadership to curb rampant corruption, and the fact that a legitimacy based on economic performance is inherently vulnerable" (Teiwes: 2002, 255). Just as the CCP suffered a legitimacy gap, so did Jiang himself, given the circumstances of his rapid rise and the relative obscurity from which he came. Further, Jiang took the responsibility of negotiating GATT (soon to be WTO) membership, one that potentially could damage the gains that 
the peasants had made during the era of agricultural reform by exposing them to competition from world markets.

\section{$\underline{\text { State-Society Relationship }}$}

The state-society relationship during Jiang's rule was a continuation of the policies set forth by Deng. There was no dramatic change at the highest levels of government as there was between Mao and Deng. One area of change in the state-society relationship was the delegation of responsibilities to provincial and local levels; it was difficult to manage a country the size and scope of the PRC exclusively from the top down. A second area of change was Jiang's "three represents" policy; the CCP represented the broad mass of the population, the advanced culture, and the most advanced forces of production. The broad mass of the population also included capitalists, and a year after he articulated the "three represents" Jiang expanded CCP membership to include private entrepreneurs, a controversial decision among CCP conservatives (Fewsmith: 2002, 265).

This section will focus on three issues. First was the issue of state-owned enterprises (SOE) and the "iron rice bowl", the cradle-to-grave care the state provided to SOE employees. The inability of many SOEs to cope with the need to make profits and meet their obligations to the iron rice bowl disrupted the state-society relationship. Second is the rural situation that developed and led to farmers being paid in IOU's when the cash to pay them was used for other purposes in the early to mid-1990s. A common element of both was triangular debt. Third, the food price inflation of the late 1980s and mid 1990s presented challenges to the central government, provincial budgets, and urban incomes. Yet, it provided income opportunities for peasants. A return to more government control, 
dictated from the top but implemented and managed at the provincial level, was the automatic response to a problematic situation with these three issues.

\section{State Owned Enterprises}

From the time of the takeover of private enterprise by the CCP following the 1949 victory, the government had assumed responsibility for urban employment. The danwei, or social organization of the employees and their families, took responsibility for education, housing, medical care, and proper communist thinking for all during employment and retirement. This high level of "benefits" precluded the need for high salaries and therefore minimized the amount of money that could be saved by individuals. It was the "iron rice bowl," cradle-to- grave security administrated via the state's agent, the SOE. In 1978, the large SOEs produced $77.6 \%$ of total industrial output. By 1996, output had declined to $28.8 \%$ of total industrial output yet the SOEs still employed $57.4 \%$ of the urban workforce (Lin et al: 1998, 422).

Lin notes that most SOEs were profitable at the start of reforms and provided much of the government tax revenue. ${ }^{137}$ Recall that Deng raised urban wages as well as raising the price of grain paid to farmers; wages rose at an annual rate of $16 \%$ from 1978 to 1996 while productivity increased at only 7.6\% annually (Lin et al: 1998, 425), a sure sign of decreasing profitability. As profits fell, debt increased. Manufacturers would sell their goods and their customers would pay part of the bill, in turn the manufacturer would pay part of the bill to its supplier. The shortages would be made up by bank loans which

\footnotetext{
${ }^{137}$ Hughes states that the tax receipts of industrial SOEs accounted for $65 \%$ of total industrial tax revenues (Hughes: 1988, 71).
} 
would only be partially repaid. This triangular debt was estimated to be $\$ 24$ billion in 1994 (Hughes: 1998, 74).

To solve the inefficient state-owned enterprise problem, firms were sold to the workers and management, sold to the public, merged into more profitable firms, entered into joint ventures with foreign investors, or forced out of business. A common thread in all of these solutions was workforce rationalization; those laid off continued to be paid but at lower rates. The retired were transferred to local government supported pension plans, increasing the burden on those government entities. Unemployment was becoming a problem in the workers' paradise. ${ }^{138}$ The unemployment problem was worst in the northeast, the PRC's "rust belt", where there was a concentration of state-owned heavy industry. The iron rice bowl was broken and for all practical purposes so was Marxism. The engine of economic growth was no longer the SOE; it was replaced by the export-led model that will be discussed under Economic Development.

\section{Crops for IOU's}

Not all was good in rural areas either. Peasants were more and more becoming subject to arbitrary and excessive taxes and fees. Most were not sanctioned by Beijing or the province. The intended use of these extra funds was to provide public goods at the local level that higher level authorities were unwilling to fund. These extra funds were

\footnotetext{
${ }^{138}$ Hughes points out that a method of avoiding a cut in benefits was to have one family member work as a civil servant where benefits were not being cut (Hughes: 1998, 72). In a similar fashion, a family could be better off with one person working for a foreign joint venture where wages were the highest and another within the state system where benefits were not being cut or were provided by the JV. Management level $\mathrm{JV}$ employees might be provided housing that generally reverted to the employee after a certain number of years of employment.
} 
sometimes used to purchase land from peasants. Compensation for voluntary or forced sales was often inadequate. The acquirers, oftentimes local officials and developers, could make significant monetary gains from developing that land. Rural unrest, and sometimes violence, was the result as peasants attempted to maintain the gains made previously under the reform agenda (Bernstein: 2004, 1-3).

Another rural issue arose as early as the mid-1980s as counties did not have sufficient funds to pay farmers for their grain. This peaked in the post-1992 investment boom. Rather, they were paid in IOUs. ${ }^{139}$ The grain bureaus that purchased grain for the state had become responsible for their own financial affairs. Given the normal lag time between a purchase (at harvest time) and a sale of grain (over time to the next harvest), there was the need for loans. They came from the Agriculture Bank of China (ABC) that was created for such purposes. If the $\mathrm{ABC}$ did not have the funds to make the loans they could call on the People's Bank of China (PBOC) for funds, the lender of last resort. The lag times between the purchases and sales created overdue loans and left the grain bureaus short of funds, so, they started issuing IOUs to farmers. This was the rural version of triangular debt. The problem was exacerbated by a recession in 1989-90 and by good harvests in 1990 through 1992. The recession slowed payments for raw materials and the good harvests increased the amounts of grain that had to be purchased by the grain bureaus. As sales were subsidized (lower sales price than purchase cost), higher purchases, lower sales, and delayed payments increased the burden on provincial and lower levels of

\footnotetext{
${ }^{139}$ Unless indicated, the information of IOU's comes from Wedeman: 1997, 810-824.
} 
government that were already strapped for cash. So, IOUs took the place of cash payments.

The IOU problem worsened further after what would be called Deng's southern tour of SEZs that re-ignited the economic boom. Deng bypassed the Central Committee in conducting the tour (Teiwes: 2002, 240); it was his method of telling the world that the PRC was open for business and it worked. ${ }^{140}$ In effect, this ended the period of postTiananmen austerity and increased the demand for capital. This sent interest rates and inflation higher and presented banks and grain bureaus at provincial and local levels with opportunities to misappropriate funds and transfer them to the capital-starved eastern coastal provinces in search of greater returns, either for the local entity or for personal gain, or both. The rush for development also occurred in rural areas, prompting further misallocation of funds to finance those activities, further compounding the lack of cash in rural area. To solve the immediate problem, more IOU's were issued. IOU's were used not only for crop purchases but also for remittances from those working in urban areas, for pay, and for company bonds coming due that employees had been forced to purchase (Chu: 7/4/92,1). There was no surety as to when the IOUs would be repaid nor were they interest-bearing which worsened the impact in a high-interest, high-inflation rate environment. The situation was partially caused by and continued to be ripe for fraud.

Getting rich might be glorious but getting rich quickly by circumventing rules and regulations created unintended problems. As would be expected, there was peasant unrest. Protests were common with some devolving into violence. To correct the problem,

\footnotetext{
${ }^{140}$ The southern tour was a rebuke of Jiang but not a challenge to his position (Teiwes: 2002, 244).
} 
the PRC government ordered all IOUs to be repaid by mid-January 1993, and banks were reorganized. ${ }^{141}$ Over the following year, nearly all senior government and CCP leaders made comments concerning the need for peasant welfare and stability within agriculture.

The peasant response to the IOU issue can be seen in the change in crops planted. As seen in Figure 5.1, the total grain areas sown decreased and the sown areas of cash crops-- vegetables, orchards, tobacco, cotton, and oil bearing crops (excluding

Figure 5.1

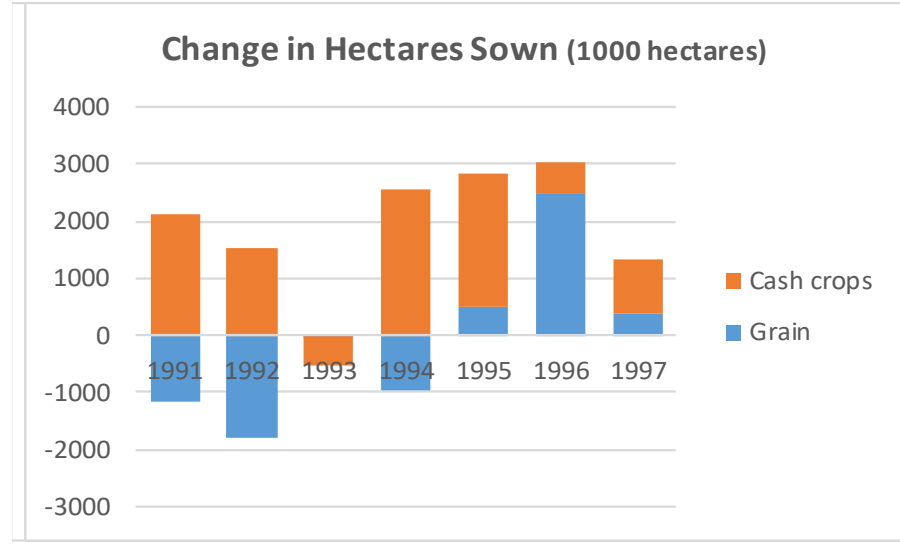

Source: NBSC soybeans) increased--thus avoiding having to sell a portion of production to the state. ${ }^{142}$

Wedeman acknowledges that there was individual corruption but calls the IOU issue one of institutional corruption. One

where "the problem is not simply degenerate agents, but rather a breakdown in the institutional mechanisms putatively designed to prevent agents from engaging in illegal acts... Despite regulations prohibiting the use of procurement funds to make commercial loans, banks, procurement agencies and local governments colluded together, ignored their fiduciary responsibilities, and systematically misappropriated vast sums in the hope of reaping windfall profits..." (Wedeman: 1997, 830). ${ }^{143}$

\footnotetext{
${ }^{141}$ Repaying debts at Chinese New Year is a common practice which usually falls during this time of year.

${ }^{142}$ The areas sown include multiple cropping, more than one crop per piece of land in a year.

${ }^{143}$ Wedeman assumes that the IOU problem led to an increase in migration from rural areas to urban areas. "Because data on the extent of rural out-migration and farmers' precise motives for abandoning farming and joining the ranks of the "floating population" are difficult to obtain, it is hard to tell with any certainty to what extent the IOU crisis directly contributed to the flow of rural residents into the cities. Nevertheless,
} 


\section{Food Inflation}

We have seen that the steps that the PRC had taken to improve grain production-the HRS, increasing farmer decision making abilities, material incentives, and expanding market opportunities--first led to an increase in output of grain. The steady increase in state purchase prices of grain moved grain prices towards and then above world levels by 1994 (Findley: 1998, 15). With those increases also came inflation, a scourge that had visited China during the first half of the $20^{\text {th }}$ century. Maintaining low-to-reasonably priced grain for the urban population was considered an imperative for economic growth and to promote urban tranquility. ${ }^{144}$

As it did when inflation occurred in 1988-9, Beijing intervened in the grain trade in 1994-5 following the decontrol of the procurement and retail price of grain (Lin and Zhang: 1998, 16). The interventions in both cases involved: control over grain production that had decreased in favor of cash crops; procurement policies; and the use of urban price controls. The first reaction to inflation came from local governments that implemented inter and intra-provincial trade barriers (Park et al: 2002, 68). In late 1994, Beijing implemented the Provincial Governor's Grain Responsibility System (PGRS) that put the provincial governors in charge of balancing the supply and demand for grain in

\footnotetext{
there is evidence that out-migration increased in the wake of the 1992 IOU crisis (Wedeman: 1997, 825-6). The NBSC only began reporting the "floating population" statistics in 2013.

${ }^{144}$ In urban areas about $50 \%$ of household income was spent on food, so the impact of food inflation was important.
} 
their provinces. ${ }^{145}$ The objective was to increase output and therefore reduce prices via administrative controls that included governing sown areas, local stocks, and managing inter-provincial grain transfers. ${ }^{146}$ The inefficient and inadequate transport system, coupled with PGRS created market distortions and led to further impediments that reduced the opportunity to use comparative advantage in increasing output. This was consistent with the past use of regional self-reliance ${ }^{147}$, a continuing misallocation of resources. ${ }^{148}$

The market distortions were caused by policy changes in both grain deficit and surplus provinces. In grain deficient Guangdong province, where there were many other profitable uses for land, incentives were raised and farmer taxes were reduced to encourage grain production. Grain surplus areas had incentives reduced and taxes increased as the grain was not needed, thereby reducing output. Therefore, in grain rich but economically poor Jiangxi, a province without the extent of non-agricultural opportunities that bordering Guangdong enjoyed, prices were lowered and taxes raised and income opportunities reduced. Trade was reduced by grain exporting provinces through the use of administrative controls or export taxes or even blockades as in Qing times. Importing provinces could subsidize imports but then had to use blockades to prevent re-exports in

\footnotetext{
${ }^{145}$ A similar program, the Mayor's Responsibility System was used to assure a sufficient supply of fruits and vegetables, had been put in place earlier. This was less onerous than the PGRS as fruit and vegetable crops tended to be produced and consumed locally.

146 The PGRS also served to provincialize / localize grain production and pricing, an activity that Beijing had realized was better performed at those levels rather than centrally.

${ }^{147}$ Recall that the definitional differences between self-reliance, reliance on using the means available within the PRC or a region thereof to meet its needs without outside assistance, and self-sufficiency; the state can provide food from domestic sources and have the financial ability to purchase the balance.

${ }^{148}$ The PRC acted as if it were a customs union, a country with common exterior tariffs and regulations but with inter-provincial trade retarded by administrative controls and differing price and tax regimes.
} 
search of higher prices (Findley: 1998, 23-4). These actions hurt farmers that had just begun to enjoy the higher grain prices.

Despite the market distortions that the PGRS created, it fulfilled its objective of increasing output. This had an impact on the PRC grain trade (see Figure 5.2) and it will

Figure 5.2

Net Imports (+) and Exports (-) (tons)

$30,000,000$

$20,000,000$

$10,000,000$

$(10,000,000)$

$(20,000,000)$

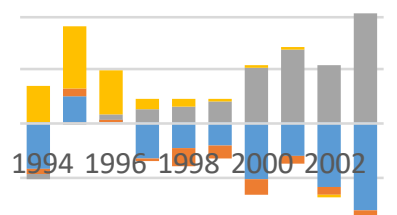

$(30,000,000)$ be seen repeatedly in trade patterns.

For example, high imports and low

exports in 1995-6 addressed the shortfalls in grain production and high inflation. This was followed by five years of exports exceeding im-

ports of the four grains we focus on. If soybeans are excluded, the PRC was a net exporter of grain through the end of Jiang's term of office. ${ }^{149}$

However, there was an upside to domestic prices catching up with world prices. ${ }^{150}$ It opened up the PRC to imports that would have otherwise been inflationary when domestic prices were lower than world prices. If not, additional subsidies would have been necessary to bring higher import prices in line with lower domestic prices, a further demand on government funds. Should domestic prices exceed international prices, imports could be used to lower inflation. However, this would be the case only if PRC use of international markets was marginal and did not drive world prices higher.

\footnotetext{
${ }^{149}$ Increasing soybean imports made the balance of payments of these four products increasingly negative.

${ }^{150}$ PRC prices exceeded world prices in the last half of the decade.
} 


\section{State-Society Summary}

The reforms ushered in by Deng introduced a "socialist market economy", one that in 1993 meant that the economy was "market-oriented and market-driven for growth, just as in capitalist economies, but it is for a socialist purpose; 'socialism' is intended to mean above all a mixed state and private economy that comes with social equity, summed up by the expression 'getting rich together"' (Huang: 2012, 620). ${ }^{151}$

The change from a communist or state-directed economy to a market-based economy, whether a "socialist market" one or a completely laissez-faire one, creates winners and losers. Peasants were initial winners with the HRS and higher crop prices. SOE workers were losers as their employment ended due to firm inefficiencies. Peasants became temporary losers when paid with IOU's or permanent losers if not receiving fair value for their land. Many in the western regions were neither winners nor losers but were simply ignored as state policy was to focus economic development in the coastal regions before expanding westward.

Whenever the economic transition issues became serious, the government response was to temporarily retreat from marketization and/or institute government-mandated controls or create new institutions to alleviate the issues at hand. This was a constant theme within the agricultural realm that continued under Jiang's administration as it had under Deng. The intentions of the interventions were to make what had been created work better, and to keep all segments of society happy or on the path to happiness and

\footnotetext{
${ }^{151}$ For a good discussion on various aspects of the definition of "socialist market economy" see Huang (2012) and Wang Shaoguang "The Compatibility of Public Ownership and the Market Economy: A Great Debate in China," World Affairs, Vol. 157, No. 1 (Summer 1994), pp. 38-49.
} 
prosperity. This was key for the CCP. Without that, the ability of the CCP to survive would be brought into question.

\section{$\underline{\text { Economic Development }}$}

While employment opportunities were decreasing in the SOEs, a new source of employment opportunities was emerging, the foreign invested enterprise (FIE), initially located in Deng's SEZs. ${ }^{152}$ Initially, most FIEs came in search of low cost PRC labor for export purposes rather than domestic sales; therefore the employment created by exportoriented FIEs was nearly all incremental. The explosion in FDI began in 1984, re-ignited after Deng's post-Tiananmen southern tour, paused after the 1997 Asian financial crisis, and then resumed its strong upward pace as shown in Figure 5.3. ${ }^{153}$

Figure 5.3

\section{Foreign Direct Investment}

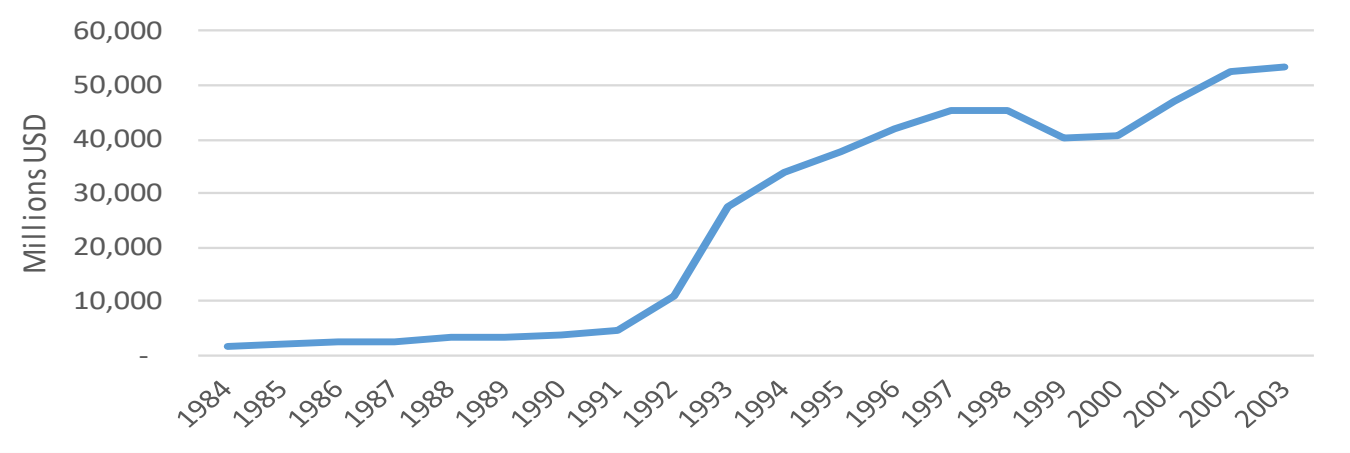

Source: UNCTAD

\footnotetext{
${ }^{152}$ Joint ventures gradually expanded from foreign ownership being limited to less than $50 \%$ prior to expanding. A wholly owned foreign enterprise (WOFE) involved 100\% foreign capital.

${ }^{153}$ Starting after Deng's southern tour, a number of FIEs were established to penetrate the PRC market rather than just for export. Exports were required to balance FX needs but the business opportunity was first and foremost the PRC market. These operations were also a source of employment in the PRC and one that employed a wide range of skills rather than just assembly labor.
} 
In 1993, FIEs employed 1.65 million PRC citizens. By 2002, employment in FIEs reached just under 7.6 million, more than $1 \%$ of total PRC employment. Employment in FIEs could not offset the employment losses from SOEs, but it helped. The vast majority of FIE employment was manual assembly type labor that employed primarily females for their manual dexterity. Many were from rural areas, excess agricultural labor that contributed to rural income via remittances to their home towns.

As shown below in Figure 5.4, the surge in FDI for purposes of export was the key factor in establishing the export-led development of the PRC. In 2001, FIE exports (primarily manufactured goods) comprised 50\% of total PRC exports from all sectors of the economy. ${ }^{154}$ The creation of the SEZs and the subsequent investment had created an export juggernaut that relieved the pressure on agriculture as a source of foreign funds to finance modernization. However, as will be seen later the growth of industrial production created a need for more manufacturing facilities, more infrastructure, and more and better housing. All of these would place greater demand on the decreasing supply of arable land.

\footnotetext{
${ }^{154}$ The government maintained strict control over scarce FX so that among other reasons, FX earned by FIEs ended up in the coffers of the government. However, foreign investors received tax breaks that PRC companies did not receive. To obtain these tax breaks, domestic companies would begin taking profits overseas, mainly in Hong Kong initially. A Hong Kong registered PRC business could create FIE's in the PRC to get the tax advantage.
} 


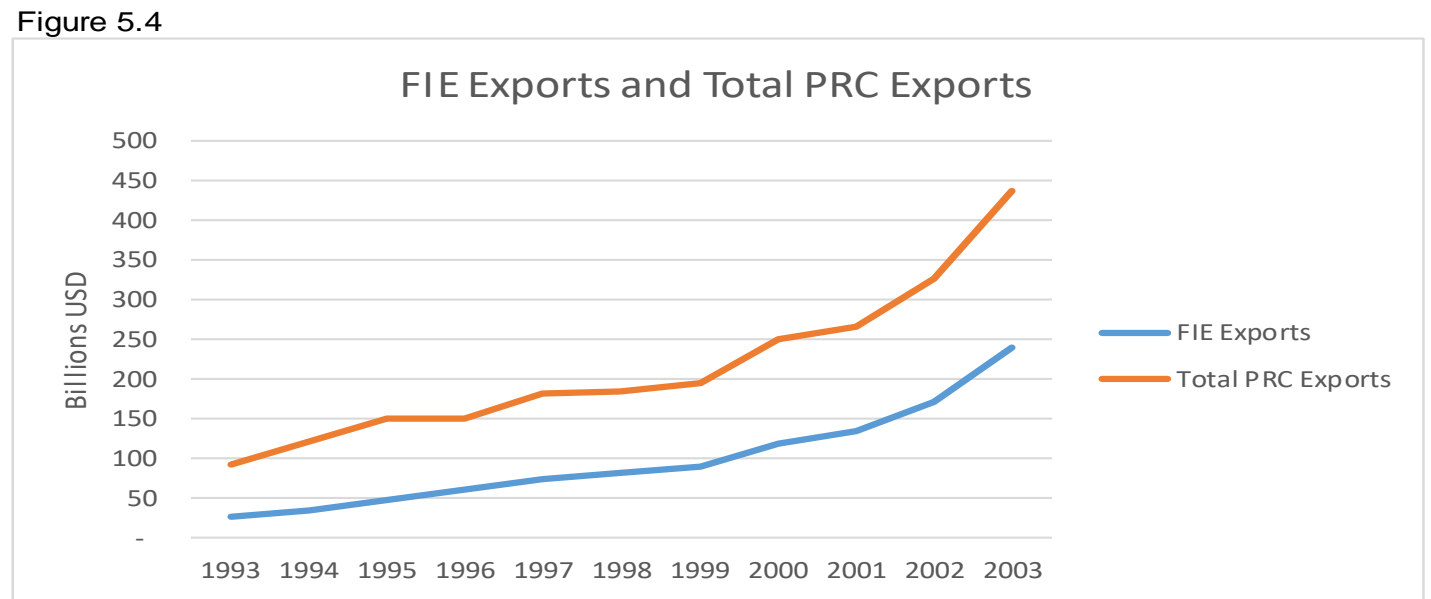

Source: China Statistical Yearbook, various issues

\section{$\underline{\text { Population }}$}

The impact of the one-child policy continued. Between 1993 and 2002, the rate of population increase fell to $0.58 \%$ from $1.14 \%$ annually. Yet, this was an increase of just under 100 million people.

The hukou system that was put in place to restrict rural-to-urban migration devolved to local-based control. The need for labor in the SEZs and for urban construction had grown immensely. To fill the demand for labor, migrants could now obtain temporary residency in urban areas but receive none of the benefits that permanent residents were entitled to, including health care and education. As a result, temporary migrants seldom brought their families with them (Willmore et al: 2009, 162).

\section{Analysis of the Food Paradigm under Jiang}

Overall, the food security situation during Jiang's rule was mixed as can be seen in Table 5.1. Available calories per day rose each year and in total by $14.8 \%$ from 1992 
through 2003. However, most of the gain came before 2001. Yet, total grain output and the population growth remained practically constant, some of which was attributable to the decreasing population growth rate brought on by the one-child policy. This is indicative of grain playing a relatively lesser role in calorie consumption, though still the major source of calories. Grain availability in $\mathrm{kg}$ per capita during the reform era peaked in 1996. Additional and increasing calories more and more came from meat and non-grain plants (FAO Food Balance Sheets). Increasing meat consumption is consistent with increasing societal wealth. As can be seen in Table 5.2, the output of grain that had been growing since the reforms of Deng levelled off in the 1992-4 era, recovered and increased with the implementation of the PGRS before falling again beginning in 2000. On a per capita basis, grain production also fell starting in 2000.

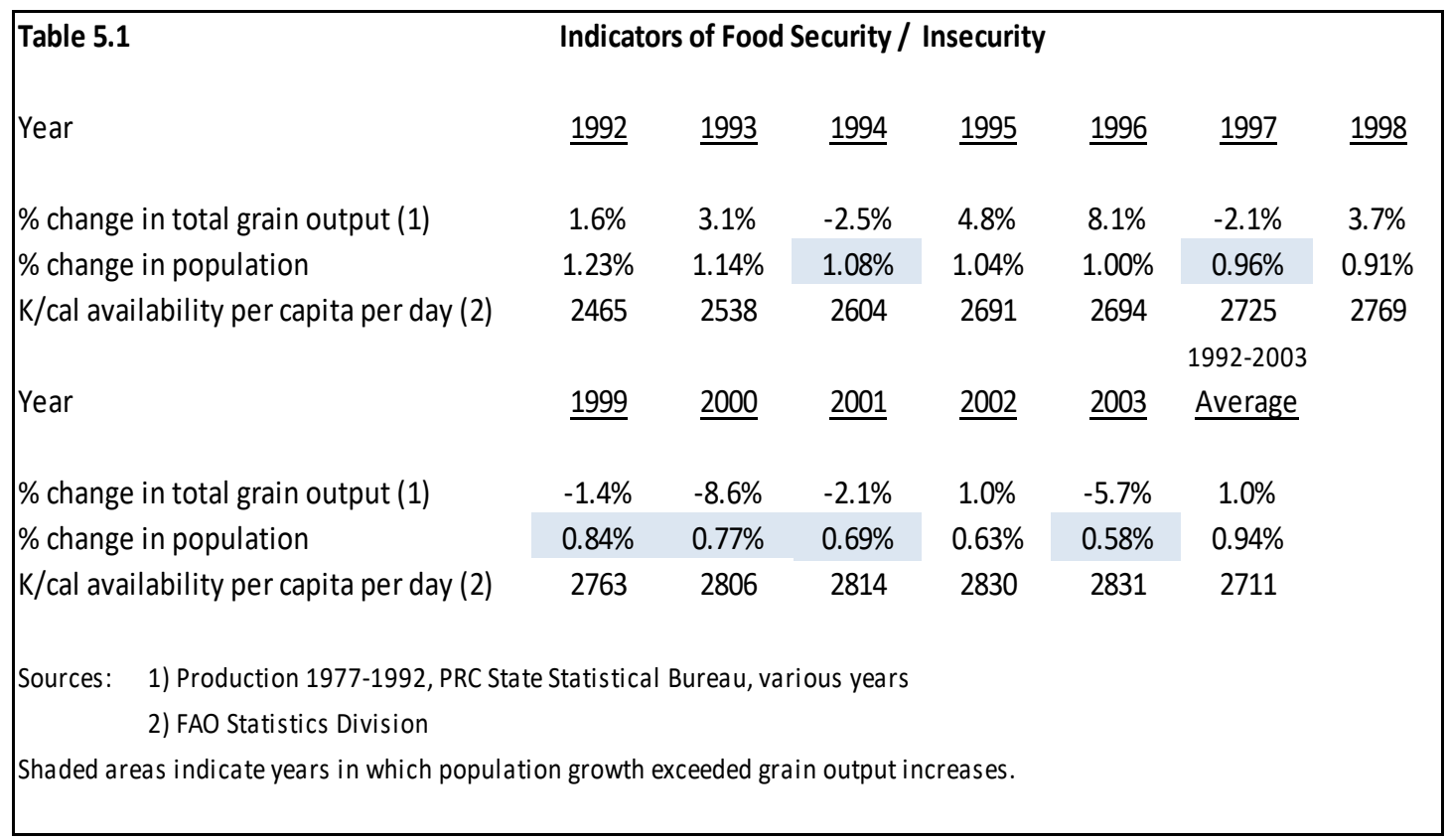


Table 5.2

\begin{tabular}{|c|c|c|c|c|c|}
\hline \multicolumn{6}{|c|}{ Grain Production and Arable Land and Self-Reliance } \\
\hline & \multirow[b]{3}{*}{ Year } & \multirow{3}{*}{$\begin{array}{l}\text { Total Grain } \\
\text { Production } \\
\text { Mil. of tons } \\
\end{array}$} & \multirow{3}{*}{$\begin{array}{c}\text { Total Grain } \\
\text { Production } \\
\text { Kg./capita/year }\end{array}$} & \multirow{3}{*}{$\begin{array}{c}\text { Arable } \\
\text { Land } \\
\text { Ha./capita } \\
\end{array}$} & \multirow{3}{*}{$\begin{array}{c}\text { Self- } \\
\text { Reliance } \\
\text { Ratio* }\end{array}$} \\
\hline & & & & & \\
\hline & & & & & \\
\hline Payment by IOU peaks & 1992 & 442.7 & 368.2 & 0.1035 & 102.2 \\
\hline IOU's to be repaid, ABC reorganized & 1993 & 456.5 & 375.4 & 0.1003 & 102.3 \\
\hline \multirow[t]{2}{*}{ PGRS Implemented } & 1994 & 445.1 & 362.2 & 0.0991 & 101.4 \\
\hline & 1995 & 466.6 & 375.8 & 0.0983 & 97.0 \\
\hline 95\% self-sufficiency policy & 1996 & 504.5 & 402.3 & 0.0967 & 98.4 \\
\hline Arable land conversion ban & 1997 & 494.2 & 390.3 & 0.0949 & 99.8 \\
\hline Land tenure extended to $30 \mathrm{yrs}$. & 1998 & 512.3 & 401.0 & 0.0952 & 99.3 \\
\hline \multirow[t]{5}{*}{ Arable land conversion ban ends } & 1999 & 505.4 & 392.3 & 0.0939 & 98.7 \\
\hline & 2000 & 462.2 & 356.0 & 0.0932 & 98.1 \\
\hline & 2001 & 452.6 & 346.2 & 0.0918 & 95.5 \\
\hline & 2002 & 457.1 & 347.4 & 0.0904 & 97.6 \\
\hline & 2003 & 430.7 & 325.5 & 0.0882 & 96.3 \\
\hline \multicolumn{6}{|l|}{ * for rice, wheat, soybeans and maize } \\
\hline \multicolumn{6}{|l|}{ Sources: } \\
\hline \multicolumn{6}{|l|}{ Population: FAO Statistics } \\
\hline \multicolumn{6}{|c|}{ Total grain production: State Statistical Bureau } \\
\hline \multicolumn{6}{|l|}{ Arable land: FAO Statistics } \\
\hline \multicolumn{6}{|c|}{ Self-Reliance ratio: calculated from FAO statistics } \\
\hline
\end{tabular}

Three aspects have not been mentioned. First is the publication of the Lester Brown book, Who Will Feed China? Second is the declared level of food self-reliance that the PRC should maintain. Third, the application to join the WTO. The WTO will be covered in the foreign policy section below.

Brown's book was published in 1995 and raised the possibility of a food supply crisis given the continuing population growth of the PRC. In the time since it was published, many of the assumptions and claims made have been shown to be improper or excessive, but it was a wakeup call for the PRC that the supply of foodstuffs was more than a method of financing economic development. Brown's book not only looked at the ability of the PRC to feed itself but also at its impact on the world food situation. This served to focus the world on food security, not just the PRC. 
Second, there were two troubling aspects of food security that began to be addressed during Jiang's time, the previously mentioned decrease in arable land and the reduction in grain self-reliance. The decrease in arable land was attributable to economic development. Increasing urbanization required additional housing estates for new arrivals as well as schools, parks and retail outlets. Increasing manufacturing required more industrial parks. Increasing economic activity required additional transportation in the form of roads, railroads, and airports. Increasing TVEs required land on which to operate. Land formerly used for grain crops was converted to pasture land to raise livestock to support the increasing demand for meat brought on by higher income levels. All of these land-using activities decreased the amount of arable land available for crops. Using FAO arable land statistics, arable land increased to 116.7 million ha. in 2003 from 103.4 million in 1961. But, during the same time the population nearly doubled. And, between 1992 and 2003, arable land decreased by 7.7 million ha. ${ }^{155}$

This decrease of arable land was dealt with by increasing the number of harvests that a single piece of land could achieve (multiple cropping), a common practice in China (Ash and Edmonds: 1998, 855-7). Also instrumental was the continuing adaptation and use of chemical fertilizers, better seed, and increased irrigation to drive yields higher.

\footnotetext{
${ }^{155} \mathrm{FAO}$ arable land calculations exclude permanent crops such as orchards, an important source of fruit.
} 
Beijing wanted to keep sufficient arable land for grain production. Provincial and local

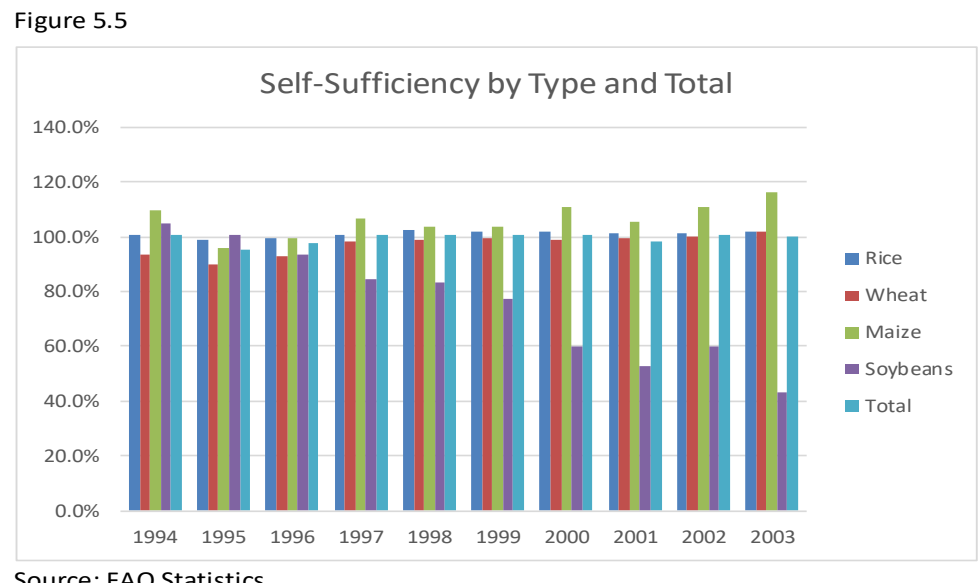

Source: FAO Statistics interests could conflict with Beijing's when it came to using land for more lucrative purposes. Often local land acquisition would occur via abuse of power or extra-legal means as previously men-

tioned that served to enrich local officials. To combat this practice and preserve arable land for agriculture, the State Council and Central Committee banned arable land conversion to non-agriculture land use from 1997 through 1999 (Lin and Ho: 2005, 411). However, there remained a number of ways to transfer arable land to non-arable, both legally and illegally. ${ }^{156}$

The idea of PRC of a self-reliance target for grain was first made public in the "White Paper on Grain Production" in 1996 and called for the PRC to maintain a minimum of $95 \%$ self-reliance in grain. As with the PGRS, this target was most likely brought about by the decrease in output in 1994 and in reaction to Brown's book. As can be seen in the Figure 5.5, wheat and rice and the total of the four crops being followed re-

\footnotetext{
${ }^{156}$ For a detailed discussion on land transfer issues in the PRC, see Lin and Ho, "The State, Land System, and Land Development Processes in Contemporary China" in Annals of the Association of American Geography, Vol. 95, No. 2 (Jun., 2005), pp. 411- 436.
} 
main close to self-reliance while maize increases over time and soybeans fall dramatically. ${ }^{157}$ The reduction in soybean output was maintained as a choice. Relative comparative advantage favored substituting rice and wheat for soybeans that could be produced more efficiently abroad, according to South China Agriculture University President Wen Simei (referenced in Wong and Huang: 2012, 122). A more in-depth explanation comes from Rozelle and Huang. They attribute the decline in soybean production to a systemic reduction in tariffs and trade barriers and relaxed trade restrictions related to soybeans starting in 1997 as a "sure sign that China has committed during the past decade to import crops that they do not have an advantage in producing" and one that was beneficial to both the urban consumer and the rural consumer, to a lesser degree (Huang \& Rozelle: $2004,18-21,36-7) .{ }^{158}$

If the impact of soybeans is removed from the self-reliance calculations, the PRC was more than self-reliant in wheat, maize, and rice, in total, from 1997 through 2003. In excess of 70 million tons were exported over that time period. The decrease in soybean production was accompanied by an increase in maize production; they share the same climate conditions. The PGRS ignored domestic competitive advantage but the re-emphasis on grain production did increase grain output. In doing so and in conjunction with loosening trade restrictions on soybeans, this led to opportunities to export rice and maize, which the PRC did extensively.

\footnotetext{
${ }^{157}$ Self-reliance is calculated as follows: Production divided by production plus imports minus exports.

158 The self-reliance rate would be even lower if soybean oil was included. Though not rising consistently, the soybean equivalent of soy oil imported in 1997 was 4.4 million tons and increased to 9.1 million tons in 2003.
} 


\section{Foreign Policy and Food Security}

The objective of this section is to identify the impact that foreign policy has had on food security and the impact that food security has had on foreign policy. To accomplish this, we will first examine the PRC foreign policy for this time period and the international system in which it operated. Second, we will look at five specific foreign policy situations where food security can or does play a role. Finally, we will identify the impact on food security arising out of those situations or the impact on foreign policy arising from food security issues.

\section{Foreign Policy}

Jiang's foreign policies of came in two parts. First, while Deng was still alive Jiang followed Deng's policies that facilitated maintaining peace so that economic development could continue, continued integration into the world political and economic orders, and pursuit of an independent foreign policy that Deng had started following reconciliation with the USSR. Following Deng's death, Jiang began referring to the PRC as a great power (within a relatively wide list of great powers) and with that staking a claim that the PRC would be a responsible shaper of the international order, promote globalization, and further military modernization (Miller \& Liu: 2001, 139-45). ${ }^{159}$

\footnotetext{
159 Two occurrences during Jiang's time created a degree of uncertainty as to whether the PRC military could cope with modern warfare and necessitated the modernization of forces. The first incident was the 1991 (Jiang was formally in office then) US led coalition attack against Iraq following the Iraqi invasion of Kuwait. The use of precision weapons, long-range air strikes, mobility and all the technology those entailed was witnessed on TV by Beijing. Second, the ill-fated attack in Belgrade that hit the PRC embassy was delivered by stealth bombers flying from Missouri.
} 
The domestic aspect of foreign policy manifested through "nationalism or patriotism became the only means of generating a sense of national unity" as socialism could no longer accomplish such (Yahuda: 2007, 342). This was the "official" CCP top-down version of nationalism that focused on continued economic development, national unity and interdependence, plus international status that could be obtained through IGOs. It competed with the bottom-up nationalism inspired by the incidents with Taiwan and the US, the bombing of the PRC's Belgrade by the US, and mild government responses to other real or perceived provocations by Japan and the West (Chen: 2005, 51-2). ${ }^{160}$

Internationally, Rozman, identifying the PRC as a great power, suggests that even after the end of the PRC-USSR-USA strategic triangle the PRC continued to visualize the world in strategic, yet regional, triangles: the PRC-USA-Japan triangle and the PRC-

USA-Russia triangle.

[The] Chinese have gravitated to the triangle as the building block to link existing unipolarity and eventual multipolarity. In a triangle, each side exerts its energy to block the other two sides from coinciding, hence a triangle places a limit on unipolarity. However, the multipolarity that is emerging over the long term will make triangles less stable than they were during the Cold War, because fourth and fifth parties can more easily intrude (Gou \& Niu quoted in Rozman: 1999, 400).

\footnotetext{
160 The "bottom-up" nationalism was most likely encouraged by CCP inspired or facilitated public demonstrations in response to these incidences.
} 
An overriding PRC desire for a multi-polar world is demonstrated above. Interestingly, these triangles focus on Northeast Asia, an indicator that the PRC, while maintaining that it is a great power, still prioritizes the regional view over a world view. There is also the recognition, from a neorealist point of view, that with multi-polarity comes the increased possibility of conflict as opposed to bi-polarity (Waltz: 2004, 16870). ${ }^{161}$ The inclusion of Japan indicates that its economic power, especially at that time, was a material capability that could not be ignored. Japan could also be used by the US as a forward base in the event of armed conflict with the PRC. The inclusion of Russia, an economic basket case at the time, reflected its military power and the long border that the PRC and Russia shared.

At the beginning of the Hundred Flowers campaign, Mao called for "a hundred schools of thought to contend." This was a ruse to smoke out those not fully committed to Mao's revolution, the only school of thought. Since Mao's death, the number of contending schools of thought has grown. ${ }^{162}$ David Shambaugh examines the spectrum of identities and interests that influence foreign policy found in the PRC. These identities or schools of thought range from Nativists at one extreme to Globalist at the other. Briefly, these identities are: 1) Nativists, a collection of populists, nationalists, and Marxists that distrust the outside world and are extreme nationalists. 2) Realists, the dominant identity,

\footnotetext{
${ }^{161}$ Waltz reasons that a uni-polar world will not last long. Uni-polar states tend to "take on too many tasks beyond their own borders" and "...international politics abhors unbalanced power... some states try to increase their own strength or they ally with others to bring the international distribution of power into balance" (Waltz: 2000, 28).

${ }^{162}$ A contributing factor to the rise of differing schools of thought was the use of think tanks and universities to provide leaders with points of view outside of the central government. Zhao Ziyang was an early user of think tanks (Shambaugh: 1984, 82)
} 
take the nation-state as the principal level of analysis, pursue PRC power, either hard or soft, and view the outside world, especially the US, pessimistically to the extent that they can foresee conflict with the US in the future. 3) The Major Powers school which holds that the major powers, the US, EU, and Russia should be the focus of attention to the detriment of the developing world and multilateralism. 4) The Asia Firsters, those that wish to improve national security through being good neighbors, making them prosperous so both feel secure. 5) The Global South School that emphasizes China's past relationship with imperialism and colonialism and thus should emphasize its relations with those that have suffered the same. 6) The Selective Multilateralists, those that advocate expanding the PRC's international involvements only to the point where national interests are involved. 7) The Globalists who wish to see greater involvement in global governance but are limited by the PRC's power and influence. This group is similar to liberal institutionalists in the West (Shambaugh: 2013, 26-43).

The realists are the predominant school of thought, but as will be seen deviations from realism do appear in the PRC's foreign policies. What is consistent is that circumstances or opportunities presented by the international system, either planned or reactive, tactical but probably not strategic, can pull the foreign policy prescription of another school of thought to the forefront for the benefit of the state's interests. This will be seen in the following section.

\section{The International System}

Shortly after Jiang's appointment, the international system underwent the most profound change since WWII: the USSR collapsed and in late 1991 ceased to exist. It 
was replaced by 15 different countries, the principal one being Russia. Nearly overnight the bi-polar world that had existed since 1945 was over and replaced by a uni-polar world led by the US, a country with the world's largest economy, the world's leading military power, and the country that had led the creation of the West's "world" following WWII.

At nearly the same time the first Gulf War took place, an American-led coalition set up to drive Iraq out of Kuwait. This action was approved by the UN. The PRC abstained in voting on this measure in the Security Council. ${ }^{163}$ Disregarding the capabilities of the Iraq military, the initial thrust had a profound effect on the world's view of US capabilities. It served to awaken the PRC military that it was severely lacking the ability to compete with the US militarily. Such a realization served to reinforce the existence of a unipolar world from the PRC point of view.

The spread of liberalism via IGOs also influenced the international system during Jiang's leadership. The WTO was created from the GATT agreement, strengthening the world trade regime. Regional trade agreements expanded with the North America Free Trade Zone and Mercosur in South America among Brazil, Argentina and Uruguay; the EU took in several former East Bloc countries, and trade agreements would also spread in Asia. ${ }^{164}$ The liberal economic trading regime was boosted by WTO membership, the success of regional trade agreements, and the PRC's export-oriented develop-

\footnotetext{
${ }^{163} \mathrm{Wu}$ points out that the PRC objected to the invasion of Kuwait by Iraq and objected to the use of force to remove Iraq. Abstaining did not hurt relations with the US and did not violate PRC principles. A pragmatic solution to a difficult problem (Wu: 2001, 297-8).

${ }^{164}$ Regional trade agreements are easier to conclude as there are fewer participants to satisfy as opposed to worldwide agreements such as the WTO.
} 
ment model. In this section, we will examine the PRC's foreign relations with international organizations and the PRC's relationship with Taiwan, its "breakaway" province. Regarding international organizations, we will examine three areas: First is the PRC's long march to join the WTO. This was a key aspect of foreign policy as it further incorporated the PRC into the global community established by the US-led Bretton Woods agreements, yet was viewed by many as a threat to PRC agriculture. Second, we will look at regional organizations including the post-USSR breakup and the creation of the Shanghai Cooperation Organization (SCO), dominated by the PRC and Russia. It is a realist-based organization aimed at mutual security needs (anti-terror and energy) and ultimately intent on keeping the US out of the area. Third will be the PRC's interactions with the ASEAN countries. This focuses on ASEAN methods of engaging the PRC economically and constraining it militarily, both elements of ASEAN security. The SCO and ASEAN hold the potential of using agricultural trade as being a confidence builder, consistent trading partner, or alternative supply source for the PRC. Shambaugh identifies the time frame of the 1980s and ' 90 s as one where the PRC learned and participated with respect to IGOs, thereby setting the stage for a more confident and outspoken IGO participation in the 2000s (Shambaugh: 2013, 125).

Relations with the US are involved in each aforementioned multi-lateral and bilateral relationships. The US became the world's only superpower, and its relationship with the PRC became the world's primary bi-lateral relationship. 


\section{The PRC and GATT / WTO Negotiations}

GATT was initially approved by 23 countries in $1947 .{ }^{165}$ The objective was to achieve "reciprocal and mutually advantageous arrangements directed to the substantial reduction of tariffs and other barriers to trade and to the elimination of discriminatory treatment in international commerce."166 This agreement did include agricultural products, but there were insufficient constraints to prevent trade-distorting activities. The WTO agreement addressed those constraints by reducing distortions such as non-tariff barriers, eliminating types of export subsidies, and types of domestic support programs. The WTO also dealt with capital transfers, intellectual property, and trade in services. Most states are WTO members.

After 15 years of arduous negotiations were completed, the PRC officially joined in December, 2001. ${ }^{167}$ Accession was a major step in the integration of the PRC into the

\footnotetext{
165 GATT was the tariff agreement incorporated into the International Trade Organization (ITO). It was one of the Bretton Woods agreements. The US Congress refused to ratify this agreement. GATT substituted for the ITO by managing international trade in goods but was a generally ineffectual way of doing so as there was no dispute settlement aspect that could be enforced.

${ }^{166}$ GATT agreement preamble pg iii

${ }^{167}$ From the US point of view, negotiations were a two-level game. There were the US - PRC government negotiations and those between the US President and the US Congress (Sen: 2003, 131) representing various constituencies. The PRC side could also be considered to be playing a two level game. Below the government-to-government discussions, the PRC had to gain agreements from a variety of governmental constituencies. The Ministry of Foreign Trade and Economic Relations (MOFTEC) led the negotiations with the US Trade Representative. Domestically, their negotiations occurred with the Ministry of Foreign Affairs (MFA) and the Bank of China as well as with various Leading Small Groups representing various groupings at the Politboro level as well as various industry and regional groups and those factions representing conservative and reform-minded economic points of view. The objective of which was to gain the agreement of Zhu Rongji at the vice-premiere level and ultimately at the Standing Committee of the Politboro (Pearson: 2001, 346-50). The length of the negotiations obviously led to a non-uniform approach, due to changing personnel and the prevailing world situation, on both sides of the negotiation.
} 
world economy and continuation of engagement in multilateral organizations. This is reflective of the identities of Selective Multilateralists and the Globalists that Shambaugh identified.

Feeney lists several benefits the PRC expected from WTO membership: 1) increased trade; 2) avoiding the annual domestic US political battle over extending Most Favored Nation (MFN) status to the PRC; 3) ensuring gains by achieving MFN from all WTO signatories; 4) belonging to an institution that makes the rules, and 5) assisting in the economic development of the PRC as a source of information to help with its policy agenda and promoting and legitimate reform agenda. The desire to obtain permanent MFN status is indicative of the needs of industry superseding those of agriculture. The success of the manufacturing export-led development strategy made agricultural-led development obsolete.

The cost of joining was to require the PRC to adhere to WTO norms regarding trade. This necessitated lower tariffs, decentralized trading entities (allow private trade and allocate trade activities to private entities), limiting import substitution, phasing out import licensing, improving foreign market access via competitive bidding, eliminating export subsidies, loosening FX accessibility, and to assuring that FIEs were treated equally with SOEs. ${ }^{168}$ Transparency had to be increased, including full and timely disclosure of all trade policies, rules and regulations, pricing policies, and data releases (Feeney: 1994, 242).

\footnotetext{
${ }^{168}$ Diminution of the role of the state in trading is the political motive favoring capitalism.
} 
Entry was on "commercial terms" rather than as a developing country. That created obligations such as tariff reductions and internal policies that a developing country would not be required to meet for a longer period of time. The costs of joining, given above, also included a provision that allowed other WTO members to implement emergency safeguard provisions against PRC exports for 12 years should exports damage their economies (Lawrence: 2006, 7-8). This was in recognition of the PRC's abilities to disrupt foreign markets with large amounts of inexpensive goods. ${ }^{169}$ Despite objections by the PRC, it was deemed to be a non-market economy for 15 years. This designation permitted more onerous rules to be applied in anti-dumping investigations (Halverson: 2004, 330).

With respect to agriculture, entry into the WTO and the agreements that required implementation were already trending in that direction. The general movement towards marketization of agriculture was underway but with fits and starts and applicable mainly to non-strategic items such as horticulture products. But with the WTO came the commitment (and legal responsibility) of the PRC to abide by those commitments. The commitments fell into three general categories: market access, export subsidies, and domestic support programs.

Market access came from tariff reductions, the use of tariff rate quotas (TRQ), and the elimination of non-tariff barriers (NTB). TRQs provide a low tariff for a specific amount of imports after which a higher tariff rate will apply. A principal NTB aspect addressed was elimination of the monopoly state import and export of grains by inclusion of

\footnotetext{
${ }^{169}$ A major reason for the more onerous terms of accession was the trade surplus that the PRC was running with the US (and would get bigger). It was not politically acceptable to the US domestically for the PRC to enter the WTO as a developing country.
} 
private trading companies along with a quota of trading reserved for the private companies (Huang et al: 2007, 250). Export subsidies involve government rebates to exporters after each transaction. These would no longer be allowed under the WTO. Such rebates might have been advantageous in accumulating FX in the past; they were no longer needed in $2001 .^{170}$

Domestic support programs, common in the EU, US, and Canada are permitted under the WTO so long as they are not price distorting. Generally these are either incentives for non-planting of specific crops or they are related to the acreage planted, but never output. The number of possible subsidies also applies to agricultural inputs, either direct or non-direct. In total, these may not exceed $8.5 \%$ of the total value of a "basic agricultural product" (Huang et al: 2007, 252-3). For developing countries, the limit is $10 \%$. As with all countries, the transparency of such subsidies is not great and not necessarily accurate.

Jiang maintained: "Joining the WTO is a strategic policy decision by the Chinese government under the situation of economic globalization; it is identical with China's objective of reform, opening up, and establishing a socialist market economic structure." Not convinced, Kim asks "why take some unprecedented sovereignty-diluting steps to gain WTO entry?" (Kim: 2009, 63). The principal reason was to assure foreign market access for manufactured exports in order to maintain the drive towards modernization.

\footnotetext{
${ }^{170}$ However, there are examples of export subsidies in corn and rice (Fuller et al: 2003, 406). An explanation for these comes from the self-reliance policies that require a large inventory to protect against poor harvests or other threats. Deterioration of the grain quality over time drives down the value. So the question becomes are these subsidies or are they simply a realistic price for the poorer quality of the grain being exported?
} 
Fewsmith suggests an answer to the question, citing the need for fundamental domestic reforms. WTO accession would permit "competitive foreign pressures to force restructuring" of the SOEs and financial system (Fewsmith: 2001, 574). Put another way, reformers could not accomplish all they wanted due to conservative opposition. Compliance with the rules and regulations of an IGO would force domestic changes that otherwise might take years to accomplish. In rural areas, this would include facilitating labor mobility and the implementation of social safety nets, both of which would assist peasants hurt by increased grain imports.

\section{The WTO and Food Security}

Within agriculture, the challenges and opportunities of joining the WTO are best summed up by Minister of Agriculture Du Qinglin:

"We are fully aware that accession to the WTO also imposes great challenges to agriculture in China. Generally speaking, major land-intensive agricultural products will be greatly affected. However, due to the fact that labor-intensive products, in which the country has a comparative advantage, lack the strength to penetrate new markets, it is difficult to imagine that they will witness major developments in the near future. These factors will make it more difficult to raise farmers' income levels and to provide more employment opportunities...[via] restructuring agriculture and rural economy, increasing farm income, \& improving competitiveness of agricultural products...[to] promote quality over quantity, farmer income and 
depredations, shift from extensive growth to methods that focus on sustainability and economic benefits, \& shift from emphasizing domestic production towards more active participation, co-operation, and specialization at the international level" (OECD: 2002, 16).

To an observer of the PRC agricultural system, particularly as it applied to grain, a comparison with the world grain-producing powers would lead the rational observer to suspect that the PRC farmer would be unable to compete. After all, given the average farm size of about 0.6 ha. and operated by a family with little if any machinery compared to multi-hundred acre farms (or more) using advanced equipment, the comparison was either comical or sad. Accession to the WTO would seem to doom the PRC grain farmer.

Agriculture based on comparative advantage did flourish. Labor-intensive crops such as fruits and vegetables had a comparative advantage that land-intensive crops did not. The WTO served this type of agriculture well just as it did for manufactured products.

Membership in the WTO did not remove the use of trade as a political tool. The PRC still could buy and sell grain to whatever country with which they could successfully conclude an agreement. The combination of the TRQs, in-quota tariffs, and the amount and direction of private trading quotas serve as an indication of the PRC's relative need to control strategic grains and comparative advantage (see Table 5.3). The more dependent on imports, the more the state controlled trading. With wheat, a major 
import, the state controls $90 \%$ of the trading. There is comparative advantage with specific types of rice, and therefore non-state traders control half of the trade. ${ }^{171}$ Soybeans and soy oil reflect the absence of comparative advantage and dependence on the market to secure domestic needs. Maize was becoming increasingly competitive and therefore had export potential. Private trading was a method of decreasing state involvement, but private traders could also be influenced to follow the desires of the state. ${ }^{172}$ The TRQ served to limit imports as out-of-TRQ rates are too high. ${ }^{173}$ Further, the 2002 TRQ

Table 5.3

\begin{tabular}{|c|c|c|c|c|c|}
\hline \multicolumn{6}{|c|}{ Post-WTO TRQ's and Trade Quotas } \\
\hline & \multirow{2}{*}{\multicolumn{2}{|c|}{$\underline{T R Q}$ (millions of tons) }} & \multirow{2}{*}{\multicolumn{2}{|c|}{ Tariff Rate \% }} & \multirow{3}{*}{$\begin{array}{c}\text { Quota for non-State } \\
\text { Enterprises \% } \\
\underline{2000 \text { to } 2005}\end{array}$} \\
\hline & & & & & \\
\hline & $\underline{2002}$ & $\underline{2005}$ & In-Quota & Above Quota & \\
\hline Wheat & 7.3 & 9.6 & 1 & 65 & 10 \\
\hline Maize & 4.5 & 7.2 & 1 & 65 & $25-40$ \\
\hline Rice & 2.6 & 5.3 & 1 & 65 & 50 \\
\hline Soybean Oil & 1.7 & 3.2 & 9 & 121 & $50-90$ \\
\hline \multicolumn{6}{|c|}{ Note: Soybean import tariff was $3 \%$ beginning in 2000 , down from $114 \%$} \\
\hline Source: Huang & g et al: 200 & & & & \\
\hline
\end{tabular}

amounts, measured as a percentage of 2001 imports are, $1.1 \%$ for wheat, $12.0 \%$ for maize and $1.0 \%$ for rice. The impact of private trading is limited at best as of the time of accession to the WTO.

\footnotetext{
${ }^{171}$ It should be noted that the percentage of rice production that enters world trade is only $5 \%$, much less than many grains.

172 This is especially true with grain as the state trading company, COFCO, often served private traders as procurers of domestic grain for export.

173 The out of quota tariff rate was the highest that could be charged (the "bound" rate according to PRC / WTO regulations.) In the event that imports in excess of the TRQ were needed, the bound rate could be lowered as the PRC saw fit.
} 
While WTO accession occurred during Jiang's time in office, there was no discernible change in agricultural trade in grains in the two years following. Fruit and vegetable exports increased $39 \%$ and imports by $71 \%$ in value terms from 2002 through 2004 , an indication of the WTO membership increasing trade. The positive balance of trade in fruit and vegetables increased to $\$ 5$ billion from $\$ 3.6$ billion, an indication of the PRC's comparative advantage in labor intensive agricultural products (FAO Statistical Data Base).

\section{The Breakup of the USSR}

The breakup of the USSR created three new countries on the PRC's western border, Kazakhstan, Tajikistan, and Kyrgyzstan. The PRC organized the Shanghai Five, the new bordering states and Russia, for purposes of confidence-building and disarmament along their borders in 1996. In addition to border disputes that were promptly settled, these five countries plus Uzbekistan, which joined in 2001, formed the SCO. ${ }^{174}$ The PRC and Russia are the principal parties in the SCO, a realist reaction to a uni-polar world. Tang views the SCO as the result of NATO pushing eastward into the former USSR, the strengthening of the US - Japan alliance, and a newly uni-polar world where both felt a sense of unease. While Moscow and Beijing had reason to move closer together, there were also reasons not to move too close. First, there were historical differences that were not too far in the past. Second there was the sparsely inhabited Russian Far East sitting next to an over-populated PRC and where PRC traders were making significant inroads.

\footnotetext{
${ }^{174}$ Blank writes that since the borders were established there has been "repeated instances of China 'rectifying' these border treaties, primarily, but not exclusively, with Central Asian states, to reclaim previously conceded territory." It has been successful with Tajikistan and Kazakhstan.
} 
Third, Russia was a Eurasian-based state but one that faced west first and was unsure of where its future would be. Russia supplied advanced arms to the PRC (that could be used against Russia) but also did the same with India, an historical antagonist of Beijing (Tang: 2000, 361-4).

All had common interests in Central Asia. The PRC was in need of energy sources that Russia and Central Asia could provide. ${ }^{175}$ All wanted to control radical Islam. Russia and the PRC were concerned over separatist movements of domestic minorities. In the case of the PRC, it is the Uighers, ethnic Turkic inhabitants of Xinjiang. An unknown number have separatist leanings that have the potential to coincide with those Uighers residing in new SCO states. Following the 9/11 attacks, interests included counter-terrorism. The US move into Afghanistan and the leasing of bases in Uzbekistan and Kyrgyzstan provided both Beijing and Moscow with the common goal of getting rid of those bases and US influence as soon as possible. Without those bases and with a US pullout from Afghanistan, geography would keep the US out of landlocked Central Asia. Both also acted to offer economic incentives to counter US influence so as to defuse the potential of "color revolutions" that had occurred in some former USSR states and was a possibility in Kyrgyzstan (Goldsmith: 2006, 4). ${ }^{176}$ The principles of the SCO bear a striking resemblance to the PRC's Five Principles of Peaceful Coexistence.

\footnotetext{
175 The PRC started to purchase natural gas from Central Asia in 2008 and to construct a gas pipeline from Russia in 2015. For Russia, this was a step towards Asia following European concerns over energy dependencies from Russia and backlash over Russian activities in Ukraine.

176 The US requested "observer status" with the SCO and was rebuffed. However, other countries within the region have been granted the same. Such a position against the US keeps the US at bay in the backyards of the PRC and Russia. India and Pakistan were granted admittance to the SCO in 2015 and are expected to join in 2016.
} 
Russia, Central Asia, and Food Security

The demise of the USSR in 1991 and the creation of the SCO in 1996 presented the PRC with an opportunity to use agricultural trade to create goodwill with its new neighbors. The former East Bloc diminished into a minor market for rice, maize, and soybeans. There were two reasons for this reduction. First, was the reduction in grain output that led to the PGRS. Second, the USSR (its successor states / regions) and other East Bloc countries had established trading arrangements and suffered financially as they tried to reorient their economies. There was a slight recovery beginning in 1996 but only to about $20 \%$ of the pre-breakup volumes.

The USSR had been a major buyer of maize since 1985. Following the breakup, Russia continued to purchase until 1995 when PRC exports to all states fell close to zero. (Figure 5.6) Subsequent purchases were inconsistent and small volumes. From 1992 to 1995, the new Central Asian states of Kazakhstan, Kyrgyzstan, and Uzbekistan bought maize but that ended also due to a decrease in PRC output. Following the implementation of PGRS, shipments of rice became a potential means of confidence-building with SCO states but primarily with Russia. There are several reasons that the grain trade has not flourished between the PRC and the new Central Asian states and with Russia. First, there is the issue of geography. Central Asia and the PRC are divided by mountainous terrain. Interstate transportation is underdeveloped. Central Asia and the populous areas of Russia are a long way from the prime growing areas for grain in the PRC. This brings 
other possible suppliers into competition even though the PRC is a bordering state. ${ }^{177}$

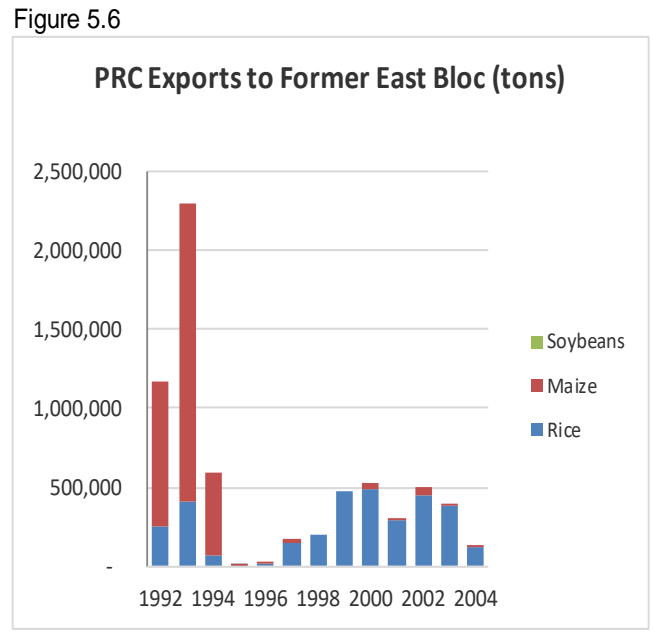

Source: FAO Statistics

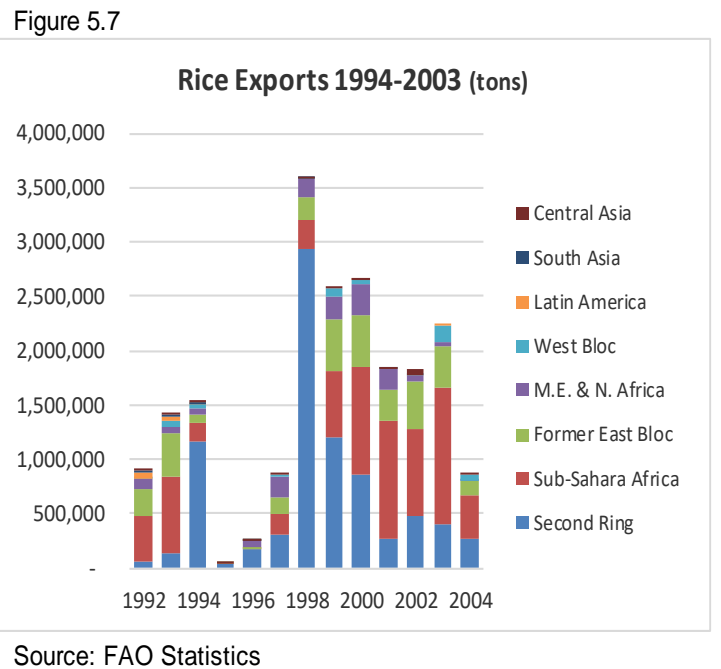

Source: FAO Statistics

Second, PRC concerns over radical Islam entering the PRC from Central Asia and con-

cerns over independence-minded local Uighurs may dampen any government desire to

facilitate trade. Third, competition from Vietnam, Thailand, India, and the former USSR

republic of Kazakhstan for the rice Russian market. However, agricultural exports to

SCO states did continue for non-grain items. Fruit and vegetable exports to Russia, especially, and the other SCO states jumped beginning in 2001 . $^{178}$

On the import side, wheat imports plummeted starting in 1997 following the increase in output brought on by the PGRS. By 1994, Russia had become a major exporter as had Ukraine, a former part on the USSR. Interestingly, neither became a supplier to

\footnotetext{
${ }^{177}$ Within the PRC, comparative advantage by crop and region affects trade possibilities. Maize and soybeans are produced least efficiently in the western PRC, which would logically reduce its export potential (Fang \& Beghin: 2003, 192). However, transport costs also must be taken into consideration, which could offset inefficient production and allow export to land-locked Central Asia states.

${ }^{178}$ During the last three years of the USSR, annual apple imports from the PRC averaged 42 thousand tons per year. The first 4 years of the Russian Federation, the average was 71 thousand tons per year. Starting in 1996, the start date of the SCO, Russian imports have averaged 123 thousand tons per year. Kazakhstan and Tajikistan have averaged purchasing 58 million tons, annually, since 1996. Previously, they were very minor purchasers of apples.
} 
the PRC. Most likely this was a function of transportation costs, either by rail or ship. Russian wheat markets tended to run from Central Asia to the Mediterranean.

The breakup of the USSR led to major changes in international politics. It neither offered the PRC a serious opportunity to gain influence through the sale or purchase of grains nor to improve domestic food security nor to earn FX from the former USSR. In any case, it was the SCO agreement that would carry much more influence than the grain trade could provide. However, it was during this time that rice exports to Africa allowed the PRC to earn political points with Sub-Saharan Africa (SSA) through selling rice rather than fighting proxy wars with the Soviets. Between 1993 and 2003, rice exports to SSA were second only, in volume, to the $2^{\text {nd }}$ Ring. (See Figure 5.7) Most likely, this was a result of the "going out" strategy in combination with the PRC's traditional interest in the Global South. Agricultural investment in Africa will be discussed in more detail in the following chapter.

\section{ASEAN Agreements and Trade}

The PRC had been a member of Asia-Pacific Economic Cooperation (APEC) since 1991. This regional group, that includes nations from both sides of the Pacific Ocean, has been marginally successful in discussing economic issues, ecological issues, and in promoting, with minor success, a reduction in tariffs.

In 1992 the ASEAN Free Trade Agreement (AFTA) was created with the goal of increasing trade within ASEAN and in creating a larger economic entity "to meet the economic challenge of China's attractiveness to foreign investments... Without this, the ASEAN countries will be left out by international investors" (Lee Kwan Yew quoted in 
Lincoln: 2004, 169). ASEAN was concerned that its economic success, based on an export-led development strategy, was seriously being threatened not only by the PRC's own export-led development but also by the size of its domestic market - $20 \%$ of the world's population. The combination of export opportunities from the PRC and the opportunity to enter the domestic market made the PRC very enticing for foreign investors, oftentimes at the expense of ASEAN states.

Lurking in the background was the PRC claim of sovereignty over the vast majority of the South China Sea (SCS) and the islands therein. ${ }^{179}$ The claim, based on historical occupation of the islands, is dubious at best. The area contains rich fishing grounds and potential oil and natural gas reserves, two resources that the PRC needs. To maximize the potential for the PRC, the claims of sovereignty over various islands, shoals, and reefs would permit each marine structure to have a territorial sea of 12 miles and, in the case of islands, an exclusive economic zone (EEZ) of 200 miles. The disputes centered mainly over the ownership of the Spratly Islands in the SCS between ASEAN states, primarily Vietnam and the Philippines, and the PRC.

The Asian Regional Forum (ARF), initiated by ASEAN in 1994, was designed as a security dialogue among all major powers in the Asia Pacific region. While none of the ASEAN countries could be considered major powers, as a whole they did carry weight, especially in economic matters. It was in this time period that the US was perceived to be

\footnotetext{
${ }^{179}$ This claim was originally made by Taiwan and then taken up by the PRC. In 1974 the PRC took the Paracel Islands from South Vietnam a year prior to PRC ally North Vietnam taking over South Vietnam.
} 
in decline and losing interest in East Asia. ${ }^{180}$ At the same time, the PRC was rapidly expanding economically as well as militarily, including at the expense of ASEAN states in the SCS. As a result, a power vacuum was being created, and the PRC would most likely fill it. The economic asymmetry advantage the PRC held over ASEAN also applied militarily.

He Kai suggests that the ARF was a deliberate attempt by ASEAN at institutional balancing in order to maintain the economic advantages that engagement with the PRC could bring while keeping PRC military power at bay. Institutional balancing is a combination of neorealist balancing, hard power, and neoliberal interdependence. By using the ASEAN framework, ASEAN members were able to create a grouping, ARF, and create and utilize the agenda of the new grouping to achieve its ends through soft power balancing within the institution that included the both US and PRC so that its security concerns were addressed as were its economic interests. He Kai maintains that institutional balancing is a realist strategy that reacts to the distribution of capabilities and strong economic interdependence. In this case, the objectives of ASEAN were achieved through inclusion of the problematic parties, the US and PRC, binding them to institutional norms and rules. With both the US and PRC as members of the ARF, the US was kept involved in the region and ASEAN was able to negotiate with the PRC over the SCS islands. The

\footnotetext{
${ }^{180}$ The eruption of Mt. Pinatubo led to the closure of the US air base located in the immediate vicinity and the subsequent closure of the navy base at Subic Bay at the request of the Philippine government. The dismissal of the US "big brother" from the immediate area removed a constraint for the PRC. Years later, Philippines President Macapagal-Arroyo stated "we are glad to have China as our big brother in the region" (Greene: 2007, A21). This statement did nothing to stop the PRC activities within the Philippine SCS claim and could be interpreted as a statement of subordination as a tributary state.
} 
Treaty of Amity between ASEAN and the PRC established the need for peaceful settlement of SCS issues and provided ASEAN with legal and moral principle on which to stand (He Kai: 2008, 500-4). ${ }^{181}$

The 1997 Asian Financial Crisis led to a steep decline in the currencies of a number of Asian states, many of which were competitors of the PRC for exports. There was a natural temptation for the PRC to devalue its currency to maintain a competitive balance with other Asian exporters. The decision was made not to do so. The PRC had devalued its currency to 8.28 / USD in $1994 .{ }^{182} 1997$ was a time of high inflation in the PRC. A devaluation would have increased the cost of imports, offsetting part of the export benefits derived from any devaluation. Finally, the PRC was enjoying a strong balance of payments; any increase resulting from devaluation would have been less than acceptable with trading partners and competitors.

The decision not to devalue was received quite well by the Asian countries suffering from the crisis. If devaluation of the RMB did occur, it might have led to another round of competitive devaluations. The PRC also contributed to the IMF backed bail-out funds for Indonesia and Thailand and avoided the debates over the IMF proposals on how to address the issues. Further, it accepted IMF oversight of regional (SE Asia) macroeconomic policies, a departure from a strictly independent foreign policy (Zha: 2002, 65-6). The PRC was not acting as the only member of G-1.

\footnotetext{
${ }^{181}$ The Treaty has not stopped the PRC from exercising its will in the SCS but it may have slowed it down.

182 The PRC had maintained two currencies for a number of years; Foreign Exchange Certificates (FEC) were used for foreign transactions and for purchases of foreigners in the PRC at a rate of about 5.3 / USD. The rate for the RMB, used for domestic transactions by PRC citizens and organizations, was 8.28 / USD. When the FEC was eliminated, the unified rate became 8.28 / USD.
} 
Meanwhile, the US took a hands-off approach to the Asian financial crisis and backed IMF prescriptions to address the crisis. The harsh remedies proposed by the IMF were not well received by suffering countries, Malaysia in particular. “...the crisis revealed the vulnerability of Asian economies caused by their over-dependence on the US and US-led international financial institutions" (He Kai: 2008, 508). This led to the creation of the "ASEAN+3, a regional grouping of ASEAN states plus the PRC, South Korea, and Japan. Each had been hurt to some extent by the Asian financial crisis. The first near-term achievement was a currency swap arrangement among members that would hopefully stop or reduce another currency crisis. ${ }^{183}$ He Kai looks at the ASEAN+3 as an example of exclusion in institutional balancing. "...ASEAN states intend to use the ASEAN+3 to emphasize their relevance in the region and hopefully to increase their bargaining power with the US and the West [through exclusion....and] China plays an indispensable role in strengthening ASEAN+3 cooperation. For China, ASEAN+3 is not only an exclusive institutional balancing strategy to undermine US influence in the region, but also an inclusive institutional balancing policy to further engage ASEAN" (He Kai: 2008, 508-9).

Increasing ties with SE Asia, reminiscent of the tributary system, would meet the needs of the Asia First, Realists, Selective Multilateralists, and Global South foreign policy advocates. The SCS claims made would increase the resources of the PRC in fish and potentially energy. Securing these resources has taken place through using military

183 The ASEAN+3 would evolve into the East Asia Summit in 2005. 
power to take and fortify shoals and reefs in the SCS at the expense of states unable to compete with the PRC economically or militarily, an example of realist power.

\section{The Second Ring}

The Second Ring was becoming more and more important as a trading partner for PRC grains. This is consistent with the gravity theory of trade that maintains states trade most frequently with their neighbors and particularly with those of relative economic size. The PRC was much larger than its neighbors when the entire economies are compared but they are much closer together when measured on a per capita basis. In terms of the grain trade, trade with neighbors would be expected as the diets would not vary to a great extent, especially with regard to basic grains.

The soybean decision cut PRC exports of soybeans from a high of nearly 1.1 million tons to about $20 \%$ of that amount after 1996. Indonesia and Malaysia, former big buyers, essentially disappeared. North Korea continued with about the same amount per year while South Korea began buying an amount similar to the North. Japan continued to be a major buyer but on a decreasing scale. Sales to Japan, denominated in yen, would be attractive to the PRC due to its appreciation potential.

A major contributor to PRC grain trade has been South Korea. Since the initial shipments via Hong Kong, South Korea became the largest Second Ring buyer of PRC maize, surpassing Japan. The post-1996 boom in exports was taken up primarily by the Second Ring states. By 2003, exports of maize to the Second Ring were just under 14 million tons. This increase in exports hurt other suppliers. Thailand, Argentina, and the US were the victims losing shipments to Malaysia. The US lost volume on shipments to 
South Korea in the years 1992-4 and 1998-2003. There is no need to cry for Argentina or the US as both would reassume their favored positions in Malaysia and Korea, respectively, in 2004. Thailand did not recover.

It is worth noting that according to FAO statistics, the PRC sold a total of 5.78 million tons of foodstuffs including four million tons of rice, soybeans, maize and wheat to North Korea during the period of 1994 through 2004, the period of its famine. In contrast, during the same period for the same products, South Korea bought in excess of 39 million tons. ${ }^{184}$ However, the PRC shipped 1.44 million tons of declared food aid to the DPRK between 1996 and 2004 plus an additional 510 thousand tons in 2005 (Choo: 2008, 352). ${ }^{185}$ The food aid was made in the self-interest of the PRC. Worsening famine and economic conditions in the DPRK potentially threatened the PRC for two main reasons. First, there were the same reasons that they entered the Korean War; the DPRK continued to serve as a buffer state between the PRC and South Korea. Now, as then, the collapse of the DPRK would certainly lead to a takeover of the North by the South and its contingent of US troops. Second, it could cause an exodus of DPRK refugees into the PRC. The PRC wanted neither.

In 1994, the PRC occupied Mischief Reef in the SCS, a natural marine structure also claimed by the Philippines. The SCS dispute seems to have had no effect on the

\footnotetext{
${ }^{184}$ While the PRC was a wheat importer in all years since 1960, there were times when they had an excess, and it would be sold on the international market. The excess was caused by over-importing, more than expected production, too much inventory, or a combination of thereof.

${ }^{185}$ As the PRC was a net importer of wheat and soybeans during this time, the aid in these products was essentially bought from third countries and then donated to the DPRK. Food aid does not have to be from food surplus countries only (Uvin: 1992, 298).
} 
grain trade between the Philippines and the PRC. In preparation for poor harvests due to an El Nino weather effect in 1997, the Philippines began importing rice and maize from the PRC. ${ }^{186}$ From 1997 to 2000, it imported 1.8 million tons of rice and 667 thousand tons of maize. ${ }^{187}$ For maize, this reflects a decrease in Philippine domestic production from 1995-98 and a dramatic falloff in rice production in 1998. The trade in anticipation of severe weather and the subsequent shipments gave the PRC an opportunity to lend a "helping hand" to a state in need and potentially reduce animosity resulting from the Mischief Reef issue, an Asia First response to the Nativist and Realist schools of thought. A crude measure of the prices paid by Manila for PRC maize puts them at the high end of prices paid by other 2nd Ring countries, though less than the US prices for some years. ${ }^{188}$

The SCS was also a point of contention with Vietnam. In 1994-6, both Thailand and Vietnam were sources of rice for the PRC. Thailand is the world's leading exporter of rice, and Vietnam is a major exporter. The decision to purchase 700 thousand tons of rice from Vietnam can be seen as a reflection of improved relations between the two. Vietnam had unilaterally withdrawn troops from Cambodia in 1989. Relations were normalized between the two in 1991 (Womack: 1996, 80). It therefore follows that when rice imports were needed two years later, purchasing from Vietnam was a method of re-

\footnotetext{
${ }^{186}$ The Philippines also bought rice from Vietnam, Cambodia, and Thailand (The Filipino Express, 11/23/1996, pp. 33).

${ }^{187}$ FAO import figures from the Philippines are inconsistent with the export figures of the PRC. I have opted to use the PRC figures.

${ }^{188}$ Prices are determined by dividing value by quantity (FOB PRC) based on FAO statistics. There is no indication of grain quality in these prices.
} 
ward for the Cambodian withdrawal, the normalization of relations, as well as to keep Vietnam from drifting too close to the US. In the cases of the Philippines and Vietnam and the SCS, we see a realist application of relative PRC power to continue slicing away the SCS for its own use. Simultaneously, the PRC extended help to the Philippines and sent positive signals to Vietnam. This was an indication that the Asia First and Global South schools of thought also had influence.

\section{The PRC and Taiwan}

Jiang Zemin added his stamp to Deng's Taiwan policy of reunification through the "one country two systems" approach by way of his Eight Points Initiative to draw Taiwan into the PRC, an overriding goal of the CCP. Yet, issues continued with the US over Taiwan. Jiang's initiative followed US President Clinton's decision to "upgrade" unofficial relations with Taiwan in September 1994 that had followed the sale of F-16's

to Taiwan in 1992 (Tylers: 9/11/1994, 14). Further, the election of Lee Teng-hui in 1993, the first directly elected and non-KMT president of Taiwan, increased the independence rhetoric in Taiwan. This was manifested by Taiwan's interest in joining or rejoining various international organizations the PRC had forced it to leave, including the WTO. The PRC thought the idea of one China was devolving into a one China one Taiwan policy. Jiang's initiative was rather mild suggesting the start of a dialogue to iron out differences (Swaine: 2001, 313-9).

In early 1995, the Clinton administration gave President Lee permission to visit Lee's university alma mater in the US. As Lee was the current Republic of China (ROC) president, this was viewed in Beijing as another ROC - US action designed to counteract 
the one China policy of the US. The PRC reacted swiftly with diplomacy and with military threats. First was a propaganda campaign attacking the Taiwan independence movement and a cancellation of the second round of talks between the PRC and ROC that grew out of the Eight Points. Second, the PRC ambassador was recalled from the US, and high-level military talks between the US and PRC were cancelled. Third, a diplomatic campaign directed at Asia, Europe, and Russia was initiated to reduce US diplomatic leverage in this matter and to reassure Taiwanese businessmen that their investments in the PRC, of which there were many, were safe.

The military threats, coming between the first and second diplomatic initiatives, featured war games simulating an amphibious landing on Taiwan and missile tests. The missile tests were quite provocative. Missiles were fired that overflew Taiwan or landed close to the island (Swaine: 2001, 320-1), and that prompted PRC warnings to commercial aircraft to avoid the area. The US responded to the PRC intimidations by stationing naval forces at either end of the Taiwan Straits, a counter intimidation.

No physical blows were struck by the PRC against Taiwan nor between the US and the PRC. However, Swaine maintains that the results of this crisis demonstrated to all that the PRC would use force against Taiwan if necessary, that Taiwan was vulnerable to PRC political and / or military pressure, and that Taiwan was vulnerable economically to PRC threats as indicated by the degree of capital flight. Yet, it failed to reduce Taiwanese domestic support for Lee, though it produced verbal rebukes of Lee by some of his party associates. It led to a vigorous US response and gave additional strength to proTaiwan members of the US Congress, and disturbed or angered other Asian countries. 
Subsequently, the PRC attempted to encourage the US to bring Taiwan to the negotiating table under a one-China umbrella (Swaine: 2001, 326-9). ${ }^{189}$

From the PRC point of view, the issues with Taiwan were not international; Taiwan was a breakaway province and therefore an internal affair. The PRC foreign policy guidelines (the Five Principles of Peaceful Coexistence) preclude interference in the internal affairs of another state. From its perspective, the US was interfering in PRC domestic affairs. Yet, as mentioned, this is not the first time that the US had interfered; selling arms to a breakaway province could be nothing more than internal interference, therefore strengthening the PRC's realist view of the world and its relations with Russia.

\section{Taiwan and Repercussions with the US}

If the PRC had wanted to deliberately punish the US for its actions during the Lee saga and the Taiwan Straits intimidation, the grain trade was not going to be an effective method. At first blush, it appears that wheat imports from the US were cut back substantially (See Figure 5.8). In 1995 and 1996 the US shipped just over six million tons of wheat to the PRC; for the next seven years only 1.4 million tons were shipped. While this appears to be penalizing the US for its actions it was not. Total PRC wheat imports for those seven years (1997-2003) only amounted to 6.3 million tons. The US market share fell, but all suppliers lost business. Canada, the principal supplier, lost about half of

\footnotetext{
${ }^{189}$ Swaine also points out that Beijing could not count on the US for a consistent one China policy or not to sell additional arms to Taiwan due to the unpredictability of US policy. This concern is evidenced by the March, 1986, invitation by US Senator Jesse Helms to Lee Teng-hui, at the height of the crisis, to visit Washington and meet other Republican Congressmen who had kicked off the Lee issue by "forcing" Clinton to approve the visa (South China Morning Post, 3/28/1996, 20)
} 
its average shipments in 1995 and 1996 over the following seven years. The same occurred with maize. The US shipped five million tons to the PRC in 1995 but only 600 thousand tons over the next eight years. The reduction of maize and wheat imports was a function of increased PRC output following the implementation of the PGRS. Maize became a major grain export for the PRC through 2003.

With regard to wheat, the need to import was significantly reduced from 1997 through 2003. There were no other sources that could supply what might be needed in the future but the US and its major allies. So again, the reduction in imports was not a deliberate attempt to punish the US, but simply a function of improved domestic output. ${ }^{190}$

Soybeans were a different story. (See Figure 5.9) From 1994 to 2004, annual imports grew to more than 20 million tons from 50,000 tons. The US market share fell but it steadily shipped more each year, reaching 10 million tons in 2004 , hardly a punishment. The biggest change in the share of the PRC soybean market was enjoyed by Argentina and Brazil. Both previously had been intermittent suppliers. By 2004, each had shipped for ten consecutive years, with roughly equal market shares, reaching a combined 12 million tons in 2003.

\footnotetext{
${ }^{190}$ Russia was an obvious possibility to supply wheat to the PRC but it had its own customer base as mentioned. Its customers would not appreciate having to obtain wheat from the US or Canada given the increased transport cost versus nearby Russia.
} 


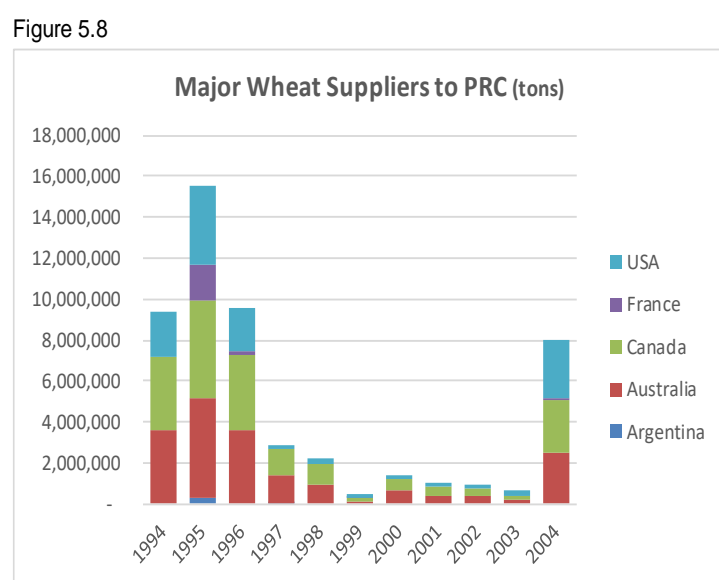

Source: FAO Statistics

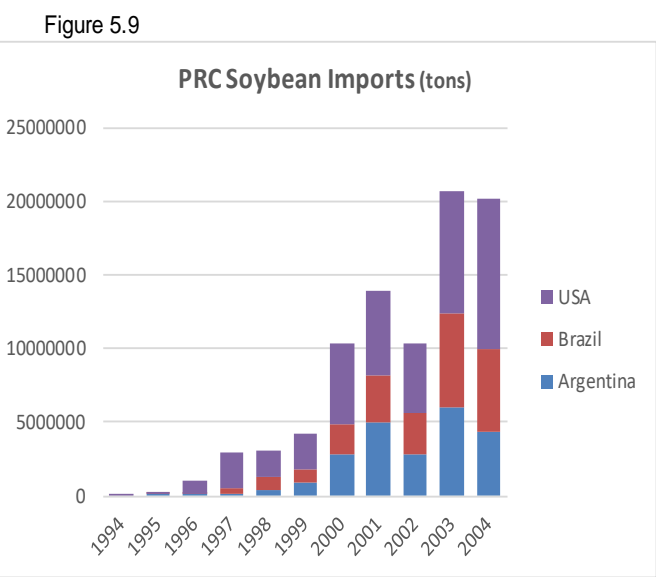

Source: FAO Statistics

The cases of soybeans and wheat are very similar in regard to how the PRC dealt with soybeans, a situation with anticipated inadequate domestic production, and wheat where there was a sharp increase in domestic production. With soybeans, the PRC increased its purchases from the US while upgrading relations with Brazil and Argentina through increased and consistent purchases. In addition to expanding the supply base, this action also diversified growing regions and gave the importing country additional arbitrage opportunities for a fungible product.

With wheat, the PRC already had a diversified supply base geographically but one that was by and large of the same foreign policy interests. The downturn in import needs was met by reducing imports from the three major and consistent suppliers, Canada, US, and Australia, and ceasing imports from minor suppliers such as France. While the percentage of the three major suppliers volume varied to an extent, the rank order remained constant, as given above. Each major supplier suffered equally; thereby, the PRC showed no favoritism in anticipation of maintaining the relationship with all three. 
There was no political decision to punish the US over its behavior regarding the Taiwan issues of the time in a way that involved the grain trade. The increase in domestic output removed that as a method of punishment with respect to wheat and maize. For soybeans, imports from the US increased as they would have to, given the decisions already made by the PRC plus the US role in the international soybean market. The increased participation by the other two major suppliers was a rational diversification of the source of supply.

It should be noted that Taiwan agreed to purchase maize from the PRC beginning in 2002. Subsequent purchases were made in 2003-4 and 2008-9. Taiwan had refused to purchase maize from the PRC for 50 years (China Daily: 11/12/2002). The decision to do so was the result of labor unrest in US west coast ports. The choice of the PRC (as a lower price supplier than the US) may have been a positive outgrowth of Jiang's Eight Points.

\section{Expanding Horizons?}

In 1996, Jiang made his first public pronouncement that PRC firms should "go out". Going out meant that "We should grant to enterprises and to science and technology research institutes the power to engage in foreign trade, and we should encourage enterprises to expand their investments abroad and their transnational operations" (Jiang quoted in Shambaugh: 2013, 175). This statement was directed at the SOE sector and it was hoped that by increasing the foreign exposure they would be able to become stronger international companies in more modern industries rather than simply companies purchasing natural resources to make up for the PRC's absence of certain endowments. In 
the "going out" strategy, there is something for each of the identities that Shambaugh noted. Even the nativists could support it as it would eventually lead to a stronger state. "Going out" will weigh heavily in the next chapter and involve purchases of foreign food and seed companies, investments in foreign agricultural lands, and agricultural assistance to Africa.

The PRC had had a strong interest in Africa since the days of Bandung. In 1995 it had trade with Africa totaling about 5 million USD, mostly in oil. Rice also played a role. Between 1994 and 2004, the PRC shipped nearly 6 million tons to SSA. From 2000 through 2009, SSA imported more rice from the PRC than any other region. As in Deng's time, the vast majority went to Cote d'Ivoire, a country where the PRC had number of type projects. The next chapter will look closer at the PRC's efforts in Africa to improve food security, directly for Africa and indirectly for the PRC. After all, any improvement in food output increases the world supply, and, as Brown's book pointed out, the world supply is ultimately what matters most.

\section{Conclusion}

In this section, we wanted to determine whether food security was achieved for the PRC during Jiang's time as CCP General Secretary. Success can be via self-reliance, a situation where all grain is supplied domestically, or through self-sufficiency, a combination of self-reliance and available FX to purchase what cannot be produced domestically. Self-sufficiency requires trade with the rest of the world, and therefore requires a foreign policy that facilitates the state's interest in achieving it. Self-sufficiency brings with it measures of interconnectedness or interdependency, and whether the absence of 
self-reliance presents an existential threat. But first, it needs to be determined whether the international system presents a situation as to when food should be considered a strategic good.

Grain had been a strategic good from the beginning of the PRC. It was the bottleneck in increasing industrialization. Grain production increases have come through a combination of incentives (land redistribution and HRS) and coercion (PGRS). Together they brought forth significant increases in output. Fear of the inability to feed its own citizens has continued, even with the one-child policy. The PGRS served to limit peasant choices on what crop to plant and how much to plant in order to address food inflation. This policy led to an increase in grain output beginning in 1996 (but at the deliberate expense of soybeans) and to an explicit statement by the PRC that it could not be $100 \%$ self-reliant in wheat, rice, maize, and soybeans, only 95\%. The combination of the HRS and the Jiang-inspired PGRS put the PRC in a food security position unseen since the onset of collectivization.

Starting in 1996, the case can be made that grain was not a strategic good. The rationale for this is as follows: First, the success of the PGRS, through Jiang's term, demonstrated that the PRC was capable of compelling a change in what and how much grain to plant to offset production shortfalls and inflation, and that it could be accomplished rather quickly. Wheat imports declined from an average of nearly 6.9 million tons annually from 1994 through 1998 to less than a tenth of that amount annually from 1999 through 2003. Maize again became the leading grain export. This decreased sensitivity and vulnerability of other states to affect food security in the PRC. Second, the success of the export-led development strategy provided sufficient FX to allow, without 
sacrificing other spending options, a move to self-sufficiency from self-reliance as was done in the case of soybeans. By 2004, the PRC was running nearly a \$24 billion trade surplus with the rest of the world, seven times that of 1994, and it would continue to grow. This was more than enough to become self-sufficient in soybeans. ${ }^{191}$

Third, the decision to rely on soybean imports converted the PRC from a minor exporter into one relying on 20 million tons of imports by 2003 , a quantity that would triple by 2012. To avoid PRC dependence on a single supplier of soybeans, the US, Brazil and Argentina each accounted for about a 50\%, 25\%, 25\% ratio, respectively, of total soybean imports. ${ }^{192}$ Fourth, rice and wheat, the primary grains for human consumption, increased in output making the PRC essentially independent of the rest of the world for these key products. ${ }^{193}$ Finally, while the international system was described as relatively benign, there were still areas of disagreement between the PRC and the US, still the unipolar power. In the event that military conflict were to arise in East Asia, it would most likely be a conflict of choice for the PRC and involve the US. Therefore, they should be able to prepare for all potential shortages in goods that would become strategic in the

\footnotetext{
${ }^{191}$ Though not part of this study, barley imports followed a path similar to soybeans.

192 This can also be seen as part of South-South Cooperation (SSC), an FAO-facilitated organization to reduce food insecurity and poverty in developing countries. In South America, all countries other than Brazil, Uruguay, Chile, and French Guiana are host countries (receiving assistance) while Brazil, Uruguay, and Chile are providers of assistance. The PRC is active in Africa as a provider state. Trading activities between Southern Hemisphere states are generally referred to as south - south cooperation whether the FAO is involved or not.

${ }^{193}$ For rice, exports were greater than imports from 1997 to 2003. Wheat imports from 1997 to 2003 were only $0.88 \%$ of production and that dropped to $0.63 \%$ from 1999 to 2003 . In total, from 1997 to 2003 , rice exports exceeded wheat imports by about 1.4 million tons per year.
} 
event of conflict. ${ }^{194}$ However, any conflict that would potentially involve the US was unlikely as it would require Jiang to abandon Deng's strategy of peace and development, nearly an unthinkable turn of events.

Is grain still a strategic good or was the 1996-2004 time frame simply a respite from a never-ending task to assure food security, especially in grain? In a world with a benign international system, it is reasonable to sustain food security through international trade. Sensitivity remains but is generally in the areas of the impact of poor harvests overseas on domestic inflation. What is not addressed in declaring that grain is not a strategic good is what will happen in the future. The competition for arable land is a battle that will continue and intensify. The number of mouths to feed continues to rise despite the one-child policy. Environmental degradation is an ever-increasing issue. All of which will further strain domestic output per capita. At the highest levels of government, the overall increase in grain output cannot be considered as anything but a temporary condition. After all, the one-child policy was the securitization of the population increase that occurred to improve the long-term viability of the domestic food supply from vulnerability. Diversification of the soybean supply by supplier and geography was a supply strategy (or tactic in food security strategy) of common sense and comparative advantage. The increased emphasis on human food, wheat and rice, as opposed to animal feed, corn and soybeans, improved human food security. ${ }^{195}$ When looking forward, grain remains a

\footnotetext{
${ }^{194}$ As seen during Mao's time, Canada, Australia, and France would serve their own best interests by exporting wheat to the PRC when the US would not. Nevertheless, a PRC military attack on Taiwan very possibly could lead to an embargo where all Western states participate.

${ }^{195}$ It is worth noting that at this point in time, the PRC was generating a net surplus in wheat and rice, those grains used primarily for human consumption. In the event of the suspension of the grain trade, for what-
} 
strategic good for the PRC regardless of the domestic improvements seen during this time. The future remains filled with uncertainty, especially in a non-benign international system.

Foreign policy initiatives by the PRC during this time focused on accession to the WTO and increasingly on $2^{\text {nd }}$ Ring states, particularly ASEAN. The WTO created the path for increased foreign access to the PRC market for all items as well as grain. At the same time, we see increased grain trade with South Korea and the DPRK as part of famine relief to that country, a strategic necessity for the PRC.

Following the closure of US bases in the Philippines, PRC military activity increased in the SCS and was aimed at the Philippines. Yet, they arranged to buy grain from the PRC nearly simultaneously. Vietnam, another country with SCS problems and long periods of enmity with the PRC, arranged to sell large quantities of rice to their former foe. ASEAN countries were well aware of the "China threat" (too many, too strong, too rich, too near) and sought continued US involvement in SE Asia to counter the PRC in regional forums. Japan and India were also welcomed by ASEAN. The PRC-ASEAN problem over the conflicting SCS claims continues. ${ }^{196}$

Taiwan continued to be an issue with PRC-US foreign policies. Grain imports from the US had declined due to domestic output. When they started to pick up in 2000,

ever reason, the PRC would be able to convert maize and soybean production to wheat and rice. An absence of sufficient animal feed would lead to a reduction in meat consumption following an initial mass slaughter of farm animals. Protein consumption would have to revert to plant-based products.

196 "The much-awaited rulings of the Permanent Court of Arbitration in The Hague-in response to the Philippines' 2013 submission over the maritime entitlements and status of features encompassed in China's expansive South China Sea claims — were released this morning [7/12/16]. Taken together, the rulings were clear, crisp, comprehensive, and nothing short of a categorical rejection of Chinese claims." (Liow: 2016). 
South American countries were increasing their share of PRC business at the expense of the US. The PRC even took Taiwanese maize business from the US for a short period of time.

SSA had reappeared on the PRC foreign policy radar in the rice trade. From 2000 to 2004, it was the main market for rice exports. This will be covered in the next chapter. While still strategic, the grain trade during the PGRS led to a period of interconnectedness / interdependency for all of grain as well as the four specific types we focus on. (Though soybeans are the primary imports, they are a trade-off that could change to another grain.) Perhaps the one group that was dependent on PRC wheat imports was the wheat farmers of its major suppliers. Wheat prices peaked in May, 1996, and were $\$ 70$ to $\$ 150$ per ton less costly for the following seven years. Would the same occur with South American soybean farmers? 


\section{Chapter VI - LAND GRABS: MAKING LAND MOBILE?}

\section{Introduction}

In this chapter we will explore the new and different methods and approaches that the PRC has taken to achieve food security. In the last chapter it was shown that it was no longer self-reliant in grains, but through the export-led development model and the FX it generated, the PRC was easily self-sufficient in food. However, it is maintained that the PRC was not only food secure, but from 1997 through 2003 grain did not have to be considered a strategic good as it had demonstrated the ability to compel quick and effective changes to agriculture to move towards self-reliance if needed.

The new and different potential solutions to food security were necessitated by the continuing growth of the population and the continuing economic growth that encroached on arable land. Pollution, water shortages, food safety concerns, and the decreasing efficacy of the PGRS mandates served to exacerbate the situation.

\section{The Food Paradigm}

The food paradigm under Hu Jintao begins to change in a number of areas ranging from food safety concerns to dietary changes that alter food consumption habits. Decreasing arable land continues to be an issue as do water availability and purity. In effect, the food paradigm is changing due to the continued economic growth, rising incomes, and the unfortunate aspects of trying to "get rich quick" by cutting corners. 


\section{Domestic Politics}

Hu Jintao, elected by the CCP National Congress, succeeded Jiang Zemin as General Secretary of the CCP (2002-2012), President (2003-2013), and Chairman of the CMC (2004-2012). Hu was designated by Deng to succeed Jiang. Hu was succeeded by $\mathrm{Xi}$ Jinping in all of the positions $\mathrm{Hu}$ held. Both $\mathrm{Hu}$ and $\mathrm{Xi}$ grew up during the rule of the $\mathrm{CCP}$ but were not of the revolutionary cohort and are referred to as the fourth and fifth generation of leaders, respectively. ${ }^{197}$ This chapter will focus on $\mathrm{Hu}$ and add relevant information germane to food security and foreign policy in the early years of Xi's time in office.

The success of economic development had moved the PRC from an underdeveloped state to a middle-income state in 24 years, positively impacting the lives and opportunities for many citizens. To improve the lives of the rest, there continued to be challenges, primarily creating employment for new entrants to the workforce each year and for the excess agricultural labor that continued to exist. Still, the development had been uneven geographically and by this time vast fortunes were being accumulated by a small segment of society, especially by those connected to high level CCP cadres or through corruption. Further, the economic success had been accomplished at the expense of the environment where degradation continued.

$\mathrm{Hu}$ approached the above problems with two policies (sometimes referred to as slogans): Scientific Development Concept, and the Harmonious Society. Scientific Development was a "catchphrase for developing the economy in a more balanced manner,

\footnotetext{
${ }^{197} \mathrm{Xi}$ is the son of a high ranking party official under Mao.
} 
paying less attention to gross domestic product (GDP) growth and more attention to such things as the ecological costs of the headlong rush for development" (Fewsmith: 2008, 88). The Harmonious Society, a goal, "should feature democracy, the rule of law, equity, justice, sincerity, amity, vitality, and orderliness as well as the harmonious coexistence of people and nature" (Hu Jintao quoted in Yu: 2009, 169-70). It should be noted that democracy, in this case, is applicable only to the Central Committee where there is electoral democracy, yet there is "signaling" that occurs to let prospective candidates know if they should proceed (Fewsmith: 2008, 94) ${ }^{198}$ Despite the claims of the policies above, Saich maintains that "Hu made it clear that he was not interested in significant political restructuring but rather an improvement in the quality of public administration" (Saich: 2006, 37) .

Domestic politics were influenced by Beijing's reliance on provincial and lower government levels to enforce the laws and regulations that came from the center. By 2004, lower levels of government received $45 \%$ of tax revenues, but were responsible for $72 \%$ of the spending. Generating more and more tax revenue through more and more growth (Bergsten: 2008, 77-8) worked at cross-purposes with Hu's declared objective of balancing development and the environment.

\footnotetext{
198 The PRC is a supporter of democracy in IGOs. Part of the reason for this is that many IGOs are creations of the Bretton Woods agreements, and other post-WWII organizations are dominated by the founding states or by the funding contributions that determine voting weights; one country one vote in these institutions would increase the power of the PRC and others at the expense of the current dominant power(s).
} 


\section{$\underline{\text { State-Society Relationship }}$}

In this section we will focus on three aspects of the state-society relationship that are interrelated: the environment, food safety, and corruption as related to food security. The discussion of the environment will focus on two elements: the actual and potential of climate change to effect arable land, and the availability and quality of water. Modern food safety has become a concern due to adulteration to increase profits or through ignorance. As we have seen, corruption has played a role in the decrease of arable land, primarily through cheating peasants via the purchase price of their land. It also plays a role in polluting land and water through illegal or improper disposal of toxic materials. As mentioned above, Hu's statements on the environment and actions by local officials can work at cross-purposes. One way to bring these two into line is via the press. The local press, under local control, can be dissuaded from reporting on abuses. The press from outside a local area can shed light on abuses. That is no longer possible as Beijing "banned the practice of reporters traveling to other areas to report on illegal or corrupt practices of local officials" (Saich: 2006, 40). ${ }^{199}$

The PRC has become the world's largest emitter of carbon dioxide $\left(\mathrm{CO}_{2}\right)$ while the US continues to be the largest emitter on a per capita basis. Greenhouse gases, including $\mathrm{CO}_{2}$, are considered the leading causes of global warming, a situation that will cause sea level rises, temperature increases, and changes in precipitation patterns world-

\footnotetext{
${ }^{199}$ This ban was implemented to reduce the publicity of large-scale demonstrations that were becoming more common and were generally targeted at local officials. Media reporting on environmental pollution and public health issues caused by environmental disasters is permitted (Saich: 2006, 40).
} 
wide. Wang et al surveyed the literature on the effects of global warming on PRC agriculture. First of all, agriculture is a contributor to global warming; $15.4 \%$ of the PRC's total emissions came from agriculture as did $88.6 \%$ of nitrous oxide and $59.4 \%$ of methane in 2005. Both nitrous oxide and methane contribute much more to global warming than does carbon dioxide, 296 and 23 times more, respectively. In general, climate change will produce the following effects in the PRC: 1) Non-irrigated land will see a decrease in yields (but cotton yields would increase); 2) a longer growing season in northern areas will increase the opportunity for multiple cropping as well as in the Yangtze River valley; 3) the $\mathrm{CO}_{2}$ fertilization effect will increase grain output; 4) increasing temperatures and the likelihood of more droughts in the North China Plain where there is a shortage of water already will decrease crop yields; 5) weather events will be more severe than normal; and, 6) livestock production will decrease. This is predicated on the farmer adjusting to the climatic changes appropriately, continued seed development, and efficient use of fertilizers and pesticides. The net result is little change in the PRC output of rice, wheat and maize when projected to 2030 , but the population continues to grow (Wang, Huang, Rozelle: 2010).

China, as other geographically large countries, suffers from unequal distribution of rainfall across the country. The northwest is dry, and most water resources are in the south of the country. About $45 \%$ of agricultural land in the PRC is irrigated, and the water table is falling in some areas as a result. This is the case in the North China Plain, China's traditional breadbasket. Extensive use of water, for agriculture and non-agriculture use, has even caused the Yellow River to cease flowing to the sea during part of the year. The long-term solution is the South to North Water Transfer Project from the 
Yangtze via two routes to the North China Plain. Whether this is a long-term solution is questionable (You et al: 2011, 6).

Clean water is the number one environmental problem; "300 million rural residents drink polluted water, and 90 percent of the water passing through cities is polluted. There is one 'sudden environmental accident' every other day on average in China, and most of these accidents involve water pollution" (Pan Yue quoted in Craig: 2007, 114). Sudden environmental accidents can also cause international issues; the Songhua River chemical spill flowed downstream into Russia. Within the PRC, most chemical plants are located on rivers that flow through densely populated areas, a potential hazard of great proportion (Craig: 2007, 114). Polluted water was also a cause of land pollution. Though not necessarily related to water-borne pollution, heavy metals contaminate 12 million tons of grain each year (Ash: 2007, 803).

Food safety has become a major concern. While an industrial chemical spill may be accidental, most food contamination is premeditated and is referred to as "poisonous food", as opposed to food poisoning, an unintended contamination (Yan: 2012: 710). Yan differentiates between four types of poisonous foods: adulterated, toxic food additives, pesticides used as preservatives, and fake foods. Probably the most well-known incident was the addition of the chemical melamine (used to make plastic and tan leather) to increase the protein levels of Sanlu baby formula and other dairy products in 2008.

Deliberate production and sale of poisonous food has created an element of distrust within society that "contribute[s] to the crisis of social trust: namely, distrust of the market due to faulty goods and bad service, distrust of service providers and strangers, distrust of friends and even relatives, distrust of law enforcement officers, distrust of the 
law and legal institutions, and distrust of basic moral values" (Peng Siqing quoted in Yan: 2012: 719). Following the Sanlu episode, the public reaction served to "expand distrust in strangers, to distrust in food experts, regulatory agencies, and modern society in general" (Yan: 2012: 719).

Within the state-society relationship, the issues that are most important are those related to water safety and availability and food safety. Public distrust of a widening portion of society reflects the inability of Beijing's intents to be executed at the local level related to food and water, among other concerns. The insufficient attention of the state to the public good of safe food and water provided by the state is negatively affecting the population as a whole. Hu's inconsistent actions to influence local officials to follow the laws and regulations set forth by the center increased the distrust. ${ }^{200}$ Publishing information on environmental disasters is a very indirect method of correcting existing issues and preventing new ones. ${ }^{201}$

\section{$\underline{\text { Economic Development }}$}

The domestic economy continued to grow. Between 2002 and 2012 the annual balance of trade surplus grew by 6.5 times to $\$ 230$ billion in current currency values. During Xi's first two years in office, the surplus grew by another $66 \%$ (United Nations Commission on Trade and Development data base). The structure of the PRC economy

\footnotetext{
${ }^{200}$ The inability of Beijing to control the periphery is consistent with Chinese dynasties of the past where the comment similar to "the mountains are high and the emperor is far away" served to permit the periphery to do as they pleased.

${ }^{201}$ In his first two years in charge, Hu's successor Xi Jinping cracked down on corruption within the CCP. However it remains unclear as to whether the crackdown is politically motivated or aimed at improving the efficacy of local government.
} 
was changing also. The tertiary sector grew to $46.1 \%$ of GDP in 2013 from only $41.5 \%$ in 2002 (National Bureau of Customs Statistics). Much of the economic growth since 1978 had been driven by investment. During Hu's term, efforts were made to drive growth via domestic consumption, an effort that has yet to produce the intended results.

The "going out" strategy was quite evident in natural resources. In agriculture, the most controversial aspect is what is referred to as "land grabs". (This will be taken up in detail later in this chapter.) Foreign corporations based on agriculture were purchased by SOEs. For example, in 2008 COFCO took a $4.95 \%$ interest in Smithfield Foods, a US based meat processor, mainly pork. In 2013, Shuanghui International, a conglomerate, purchased all of Smithfield. Also in 2013, Tully Sugar of Australia was purchased by COFCO. COFCO purchased the remainder of Noble Agri Ltd, that it did not own in December 2015. Noble Agri is a grain merchandising operation (Kane and Watts, 1/8/2016). ${ }^{202}$ Syngenta, a Swiss seed development and agri-chemical company, agreed to be purchased by an SOE in 2016. Taken together, these acquisitions can be characterized as "food security mercantilism" (Keulertz and Woertz: 2015, 13).

For non-renewable resources such as oil, copper, and iron ore, the race was on to acquire these from states where they are a natural endowment. Though these commodities are not part of the focus, they will play a role in the foreign policy discussions.

\footnotetext{
202 The Agricultural Cultivation Bureau of the Ministry of Agriculture Director, Wang Shoucong, wrote that $\mathrm{Xi}$ Jinping is in favor of the PRC creating a grain merchandising company to rival the largest US and European ones (Zuo: 2014, 3). The acquisition of Noble Agri is a step in that direction.
} 
Going out presented another issue that affected trade relations with developing countries. The PRC continued to need export markets to utilize domestic production capacity. Countries that provided raw materials, ores, and agricultural commodities provided an opportunity to do so. Through new trade arrangements or through the Chinese diaspora communities, PRC SOEs found markets for low-end goods that could be supplied to low-income countries priced very attractively. So much so that imports negatively impacted domestic business (Sutter: 2008, 280, 385. Congressional Research Service: $2008,127-8)$.

\section{Population}

There are several policy decisions and milestones that affected the population as a whole during Hu's reign and in the early years of Xi's. These occurred against the interminable increase in population by about by 71 million.

In 2011, the urban population exceeded the rural population for the first time during the rule of the CCP and probably for the first time ever in China. This is indicative of the continuing industrialization.

In 2015, the one-child policy was changed to allow for two children. A second child required government approval and penalties for more than two children were enforced as before (SCMP: 10/31/15, A4). While the increase in population was slowed by the one-child policy, it had negative demographic impacts. The gender ratio was abnormally skewed to males. The reduced birth rate created a 'hole' in the population, a situation where there is a potential shortage of labor to maintain PRC economic growth. Further, while there were two parents and four grandparents to coddle each "little emperor," 
that little emperor is faced with the potential of having to support a spouse, child, four parents and surviving grandparents in a country where the social safety net is poor. ${ }^{203}$

\section{Analysis of the Food Paradigm under Hu}

During the time of $\mathrm{Hu}$ and into the term of office of his successor, Xi Jinping, the PRC continued to improve its food security position. In this section, we will examine the statistics that confirm the improvement, answer the questions as to why the successes occurred, identify the challenges that still exist, and the methods that can be used to meet those challenges.

Hu's domestic policies, emphasizing equity and balanced growth, were particularly relevant to the income and opportunity disparities between urban and rural areas. Efforts to improve rural income opportunities were renewed starting in 2003. A pilot program was implemented in two provinces that reduced agriculture taxes to zero, while other provinces had those taxes cut to $5 \%$ from $7 \%$. For 2006, the policy of zero agriculture taxes was expanded nationwide. ${ }^{204}$ This raised per capita rural incomes by $150 \mathrm{RMB}$ and total rural income by 125 billion RMB. In addition to tax relief, agricultural subsidies were added. This started in 2004 with direct grain, seed, and machinery subsidies in some areas only. In 2007, livestock production subsidies began. These subsidies put an

\footnotetext{
203 This situation helps to explain the continued high savings rate in the PRC and the slowness of developing a consumer-led economy.

204 The taxes involved were the agriculture tax, local agriculture tax, and livestock farming tax. All other taxes, such as income taxes, continued.
} 
additional 80 billion RMB in the hands of the rural PRC. ${ }^{205}$ The third leg of these plans was the development of rural infrastructure that covered transportation, electrification and water quality, among others (Chen, X: 2009, 125-6). This program must be considered a success as rural household incomes rose at a compounded rate of greater than $12 \%$ from 2005 through $2013 .^{206}$

As can be seen in Table 6.1, the available k/cal per capita continued to rise annually and in total increased $9.8 \%$ from 2002 through 2013. Facilitating this was the continuing diminution in the rate of population growth. Food security as measured for the

Table 6.1

\begin{tabular}{|c|c|c|c|c|c|c|c|}
\hline \multicolumn{8}{|c|}{ Indicators of Food Security / Insecurity } \\
\hline \multicolumn{2}{|l|}{ Year } & $\underline{2002}$ & $\underline{2003}$ & $\underline{2004}$ & $\underline{2005}$ & $\underline{2006}$ & $\underline{2007}$ \\
\hline \multicolumn{2}{|c|}{$\%$ change in total grain output (1) } & $0.4 \%$ & $-6.3 \%$ & $8 \%$ & $2.5 \%$ & $2.3 \%$ & $0.2 \%$ \\
\hline \multicolumn{2}{|c|}{$\%$ change in population } & $0.561 \%$ & $0.556 \%$ & $0.549 \%$ & $0.541 \%$ & $0.536 \%$ & $0.535 \%$ \\
\hline \multicolumn{2}{|c|}{ K/cal availability per capita per day (2) } & 2830 & 2831 & 2857 & 2879 & 2883 & 2919 \\
\hline \multicolumn{2}{|l|}{ Year } & $\underline{2008}$ & $\underline{2009}$ & $\underline{2010}$ & $\underline{2011}$ & $\underline{2012}$ & $\underline{2013}$ \\
\hline \multicolumn{2}{|c|}{$\%$ change in total grain output (1) } & $4.8 \%$ & $-0.1 \%$ & $2.4 \%$ & $4.0 \%$ & $2.7 \%$ & $1.6 \%$ \\
\hline \multicolumn{2}{|c|}{$\%$ change in population } & $0.535 \%$ & $0.536 \%$ & $0.537 \%$ & $0.537 \%$ & $0.535 \%$ & $0.526 \%$ \\
\hline \multicolumn{2}{|c|}{ K/cal availability per capita per day (2) } & 2977 & 2994 & 3044 & 3081 & 3100 & 3108 \\
\hline Sources: & $\begin{array}{l}\text { 1) Production } 2002-2013 \\
\text { 2) FAO Statistics Division }\end{array}$ & tatistical & au, variou & years & & & \\
\hline
\end{tabular}

${ }^{205}$ The removal of the agriculture tax and the addition of subsidies were good for farmers and rural society as a whole. This decreased tax revenue at local and provincial levels as well as adding subsidies that had to be paid. As Zha and Zhang point out: "The conflicts of interests between central and local governments means that China's food security system is very fragile, and it is an uphill task to maintain the high grain production level" Zha and Zhang: 2013, 463).

${ }^{206}$ The increase in incomes reflects not only the tax cuts and subsidy increases, but also price levels and output. 
whole of the PRC increased well beyond average minimums determined by UN agencies. ${ }^{207}$ It does not take into account the urban - rural differentials. Income disparities and physical distribution bottlenecks account for part of the differentials.

The decrease in arable land per capita (Table 6.2) continued due to urbanization, pollution, and desertification - an increasing problem. Despite that, grain production surpassed 600 million tons in 2013 and averaged 517 million tons from 2002 through 2013. The interesting aspect of Table 6.2 is in the self-reliance aspect of the crops we focus on. In total, maize, rice, soybeans and wheat see the self-reliance decrease to $86.8 \%$ in 2013 , far below the $95 \%$ target. However, if we look at human food, rice and wheat, the selfreliance rate remains well above $95 \%$. Animal feed, the primary use for maize, fell from being a net export to a marginal import by 2013. The PRC became the largest importer of soybeans in the world during this time.

Why would the PRC decide to import soybeans rather than another grain? Rice and wheat are the primary human food grains. Maintaining self-reliance in these grains serves to underwrite the priority of food security in the public's mind and allows greater control of domestic prices. Maize, primarily animal feed, was growing in demand as consumption of animal protein increased. Maize production is concentrated in the US, a potential international political issue for the PRC. Finally, soybean production was increasing in South America, presenting an opportunity to benefit South-South relations and decrease dependence on the US. As mentioned previously, the decrease in soybean production came from a reduction in import tariffs and price increases between maize and

${ }^{207}$ The PRC was a recipient of food aid from the World Food Program from 1980 to 2006. 
soybeans. In 1996 the per ton price for maize moved above that for soybeans and maize already produced more to tons per ha. than soybeans, quite a disincentive.

\begin{tabular}{|c|c|c|c|c|c|c|c|c|}
\hline \multicolumn{9}{|l|}{ Table 6.2} \\
\hline \multicolumn{9}{|c|}{ Grain Production and Arable Land and Self-Reliance } \\
\hline & & \multicolumn{3}{|c|}{ Total Grain } & \multirow{3}{*}{$\begin{array}{c}\text { Self-Reliance } \\
\text { Ratio - Maize, } \\
\text { Rice, Wheat, }\end{array}$} & Self-Reliance & Self-Reliance & \multirow{4}{*}{$\begin{array}{c}\text { Self- } \\
\text { Reliance } \\
\text { Ratio } \\
\text { Soybeans }\end{array}$} \\
\hline & & Total Grain & Production & Arable & & Ratio & Ratio & \\
\hline & & Production & Kg./capita/ & Land & & Human Food & Animal Feed & \\
\hline & Year & Mil. of tons & Year & Ha./capita & Soybeans & Rice, Wheat & Maize & \\
\hline & 2002 & 457.1 & 355.9 & 0.0926 & $100.6 \%$ & $100.7 \%$ & $109.6 \%$ & $33 \%$ \\
\hline Agriculture tax policy trial & 2003 & 430.7 & 333.5 & 0.0903 & $100.0 \%$ & $101.7 \%$ & $114.2 \%$ & $-33 \%$ \\
\hline \multirow[t]{2}{*}{ Some subsidies implemented } & 2004 & 469.5 & 361.5 & 0.0941 & $94.3 \%$ & $97.7 \%$ & $101.8 \%$ & $-14 \%$ \\
\hline & 2005 & 484.0 & 370.7 & 0.0906 & $95.2 \%$ & $98.9 \%$ & $106.2 \%$ & $-60 \%$ \\
\hline Agirculture tax eliminated nationwide & 2006 & 498.0 & 379.4 & 0.0900 & $94.8 \%$ & $100.4 \%$ & $102.0 \%$ & $-80 \%$ \\
\hline Livestock subsidies implemented & 2007 & 501.6 & 380.1 & 0.0829 & $95.1 \%$ & $101.0 \%$ & $103.2 \%$ & $-139 \%$ \\
\hline \multirow[t]{3}{*}{ Worldwide rice price increases } & 2008 & 528.7 & 398.5 & 0.0819 & $92.6 \%$ & $100.2 \%$ & $100.1 \%$ & $-138 \%$ \\
\hline & 2009 & 530.8 & 398.0 & 0.0825 & $91.3 \%$ & $99.9 \%$ & $100.0 \%$ & $-182 \%$ \\
\hline & 2010 & 546.5 & 407.5 & 0.0830 & $88.7 \%$ & $99.7 \%$ & $99.2 \%$ & $-262 \%$ \\
\hline \multirow[t]{3}{*}{ Urban population exceeds rural } & 2011 & 571.2 & 423.7 & 0.0828 & $89.5 \%$ & $99.6 \%$ & $99.2 \%$ & $-261 \%$ \\
\hline & 2012 & 589.6 & 435.0 & 0.0781 & $87.4 \%$ & $98.2 \%$ & $97.6 \%$ & $-346 \%$ \\
\hline & 2013 & 601.9 & 441.8 & 0.0776 & $86.7 \%$ & $97.8 \%$ & $98.5 \%$ & $-429 \%$ \\
\hline \multicolumn{9}{|l|}{ Sources: } \\
\hline \multicolumn{9}{|c|}{ Population: FAO Statistics } \\
\hline \multicolumn{9}{|c|}{ Total grain production: State Statistical Bureau } \\
\hline \multicolumn{9}{|c|}{ Arable land: FAO Statistics } \\
\hline \multicolumn{9}{|c|}{ Self-Reliance ratio: calculated from FAO statistics } \\
\hline
\end{tabular}

Arable land, the ultimate limiting constraint for self-reliance in grain production, has become the PRC's "red line" that cannot be crossed. The $11^{\text {th }}$ Five-Year Plan of 2006 stated that arable land should not drop below 120 million ha. Should that line be breached, it is said that self-reliance (at the 95\% level) will become impossible and possibly threaten the "economic miracle" (Cui and Kattumuri: 2010, 10). However, as arable land per capita is decreasing, the demand for agricultural products is increasing. Increased meat consumption and the use of plant materials to produce ethanol or biofuels were two reasons for this increase in demand. In these two cases, there are direct tradeoffs between grain self-reliance and other areas of self-reliance and self-sufficiency. 
Will the red line be an example of a failed securitization? The referent object was sufficient arable land to maintain 95\% self-reliance, a PRC definition of food security. The idea may have been good, originating from Hu with the Standing Committee as the audience. The functional actor is the Ministry of Land and Resources. However, implementation is scattered among national actors such as those responsible for agriculture, transportation, urban and industrial development, and housing to mention a few and includes authorities at state, provincial, and local levels, all with differing objectives (Schwoob: 2012 1-2). As seen before in the history of the PRC, actual results may be manipulated for political reasons and what Beijing desires can be ignored by local officials. The statistics on arable land are being questioned as to whether or not they adjust land for quality, not just quantity (Zhang: 2011, 2). That said, efforts are underway to adjust for land quality in determining the actual production capabilities of the land (Liu et al: 2014,9$)$.

PRC reported cultivated land (which includes multiple cropping) at 130 million ha in 2006, which fell to 121 million two years later before leveling out. The FAO estimates PRC arable land, which excludes multiple cropping, at 106 million ha and that it has been below 120 million ha since 1998 (FAO Statistics). Regardless of which figures are correct and how they are determined, the relentless urbanization seems intent on crossing the red line.

As income rises, the consumption of animal protein also increases. This phenomenon puts additional pressure on agriculture to provide the grain, primarily corn, to feed the livestock. In 2013, the PRC produced approximately 218 million tons of maize. The combined weight of meat harvested of cattle, chicken, and hogs amounted to 81.4 million 
tons. To achieve that meat output would require almost 246 million tons of maize, and $75 \%$ of that would be fed to hogs. ${ }^{208}$ Obviously this cannot be sustained. In the past, and less nowadays, hogs and chickens would forage for food. However, the increasing use of feed lots for cattle and hogs will increase the demand for feed grains such as maize. The same will be true with chickens as "industrial" style concentrated production evolves. Grain self-reliance is at odds with meat self-reliance.

In order to reduce petroleum imports (minimally at best), plant-based ethanol and biofuels have become an alternative. The PRC initiated such programs in 2003 to produce ethanol from corn and wheat, a step towards meeting the State Council's goal of $15 \%$ of energy usage to be from non-fossil sources by 2020.

Recall that the PRC has large reserves of grain and those reserves deteriorate over time if not properly managed. Using aged stocks for ethanol production seemed to be a good way to utilize those stocks. However, there were insufficient supplies to fully operate the production facilities; therefore some usage of fresh maize and wheat was required. This presented authorities with a grain self-reliance issue. The solution to this issue was to limit maize and wheat-based conversion plants to the five existing ones. Additional capacity was to come from other agricultural feedstock such as cassava, jatropha, and waste edible oils. These would make biofuels for diesel engines (Chang et al, 2012, 4-6). The interesting aspect of this decision is that the feedstocks still had to be grown, a potential use of scarce arable land. There were 23 million ha. of land, deemed as "marginal",

\footnotetext{
${ }^{208}$ This assumes that beef requires $6 \mathrm{lbs}$. of grain to produce $1 \mathrm{lb}$. of beef, for hogs the requirement is 3.5 lbs. and for chicken it is $1.8 \mathrm{lbs}$. The maize requirement stated above refers only to "meat", not to total animal weight, therefore the feed requirements are understated.
} 
available to grow biofuel feedstocks. No water or fertilizer was allowed to be used on these crops. But are these lands really marginal? Chang notes that "marginal lands do need water resources, fertilizers and so on. If these resources are provided, one might argue that the land can be used for production of food instead of biofuels, if food security is the primary concern of the country" (Chang et al: 2012, 6).

Ethanol and biofuel production is heavily subsidized. It takes a large volume of feedstock to make a small amount of fuel, and more energy is used making it than the fuel produces. In 2006, $20 \%$ of the US maize crop was used for ethanol and provided only $1 \%$ of national petroleum use (Pimentel: 2010, 186). Agriculture-based fuel does not appear to be an energy solution.

Increased meat consumption and ethanol / biofuel production present a challenge to arable land and sustaining the red line. As time goes by, this challenge will be more and more difficult to meet; the two-child policy is starting and urbanization continues. Authorities will need to determine the optimum use of arable land within the sphere of PRC agriculture in light of the perceived risks. So far, Hansen et al maintain that domestic policy levers have been used to address imports and exports of agricultural commodities despite the liberalization mandated by WTO accession. These include the allocation of TRQ import licenses between state and private trading companies, changes in value added taxes for imports and exports, and minimum domestic purchase prices (Hansen et al: 2011, 9-10). More substantive issues will have to be faced. For example: Should the PRC grow crops for ethanol / biofuels? What is the minimum production quantity of grains for human consumption? Is importing beef better than raising cattle domestically? What actions taken will relieve the pres- 
sure on arable land and not create a situation where food security can be compromised by geopolitical security? In the foreign policy section to follow, we will see how the PRC is going about answering these types of questions.

While grain was not a strategic good from 1996 to 2003, in 2004 the situation began to change. Net exports of rice, maize, and wheat edged towards zero through 2010 while soybean imports increased rapidly (see Figure 6.1). Though imports and exports continued, by 2011 all of the major grains were net imported products and would continue as such into Xi's administration. The agricultural balance of payments fell from a US\$ 2.8 billion surplus

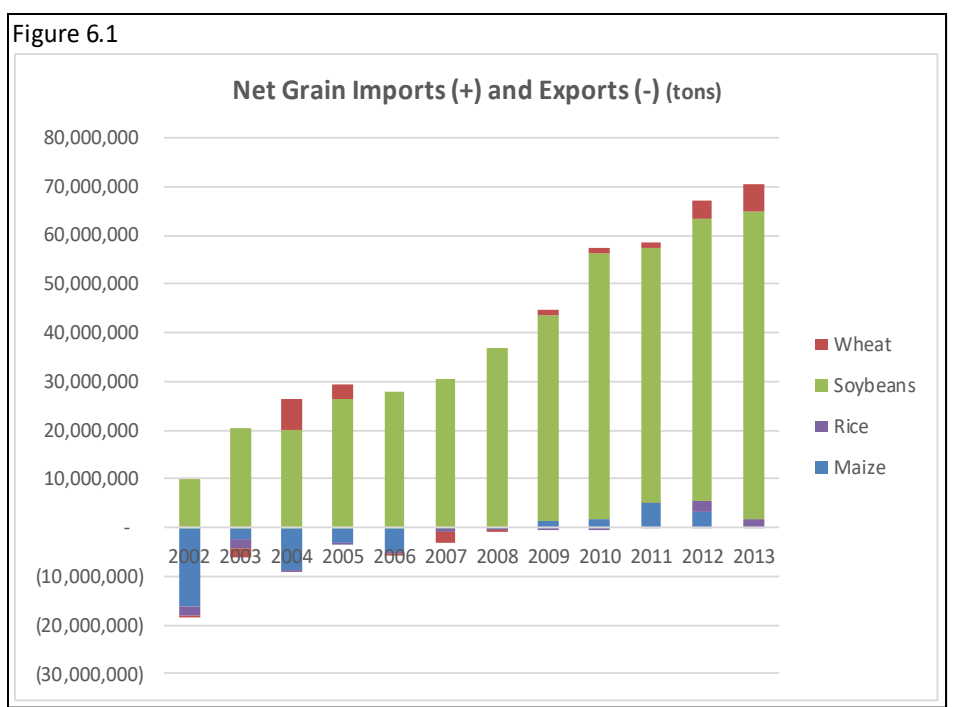
in 2002 to a US\$ 68.9 billion deficit in 2013. Net soybean imports over that period of time exceeded US\$207 billion and accounted for $32 \%$ of all agricultural imports.

Self-reliance in the four major grains was no longer possible, but self-sufficiency for all agriculture continued given the total FX that the country's export-led economy generated. So, has grain become a strategic good, one that presents an existential threat from a lack of supply, domestically or internationally or in combination? That question cannot be answered unless a strategy involving food and non-food crops is devised and done so considering water availability, climate, pollution, etc. Deciding on importing the vast majority of soybean needs, assuming the decision was made on relative water usage, is an implemented aspect of such a strategy. Another example is cotton. If cotton, a raw material for industrial use, was imported and the land converted 
to wheat production, would the PRC be in better or worse shape food-wise, industrially, and economically? These questions are easily answered as "we want the food" as it fuels all. But what are the ramifications of such a decision domestically and with the presumed supplier of cotton? ${ }^{209}$ In effect, the question that needs to be addressed is how to use the red line of 120,000 ha. of arable land. The following sections look at how the PRC and other states are approaching similar predicaments.

\section{Foreign Policy}

The foreign policy of $\mathrm{Hu}$ Jintao grew out of his domestic policy of creating a Harmonious Society and was appropriately called the Harmonious World, one "where all civilizations coexist and accommodate each other." In 2005, he described the Harmonious World as one that: 1) embraced multilateralism and rejected the Cold War mentality; 2) embraced multilateral trade that was fair, open, and non-discriminatory; 3) preserved international diversity, made the world more democratic, and allowed states to follow their own paths; and, 4) reform the UN according to the three previous points when necessary (Blanchard: 2008, 2-3). ${ }^{210}$ A year earlier in a speech at the Boao Conference, Hu

\footnotetext{
${ }^{209}$ It would be difficult for the CCP to suggest opting for cotton rather than wheat given the history of starvation in China and Mao's decisions regarding the GLF.

${ }^{210}$ The Harmonious World concept grew out of two previous slogans, Peaceful Rise and Peaceful Development. The basic premise was to assure the world that the advancement of the PRC was not to be similar to the rises of Japan and Germany that resulted in WWI \& II, but peaceful. The term "rise" was removed for a variety of reasons including the possible need to use force in the case of Taiwan or to defend itself. So, Peaceful Development was adopted. It was meant to assure the world that it would not be a revisionist state, though the concept between Rise and Development had not changed (Glaser and Medeiros: 2007).
} 
stated "'China always practices what it preaches,' namely, 'We pursue a policy of bringing harmony, security, and prosperity to neighbors and dedicate ourselves to strengthening mutual trust and cooperation and cooperation with fellow Asian countries, easing up hot-spot tensions, and striving to maintain peace and tranquility in Asia"" (Quoted in Shirk: 2008, 109).

Nathan and Scobell maintain that the PRC's strategic objectives continue to be: 1) territorial integrity, including the SCS and East China Sea; 2) preventing domination of Asia by an outside power while expanding PRC influence; 3) maintaining conditions for economic growth; and, 4) having a voice in shaping the international order (Nathan and Scobell: 2012, 33-4). One would suspect that the first two strategic objectives are difficult to achieve without contradicting the essence of the Boao speech and "allowing states to pursue their own paths" as mentioned in the Harmonious World. The inclusion of continuing "fair, open, and non-discriminatory trade" in the Harmonious World and "striving to maintain peace and tranquility in Asia" in the Boao speech are consistent with Deng's peace and stability policy to provide the PRC with the space to continue its economic development and the third objective.

The going out strategy introduced by Jiang was continued under Hu and Xi. There are three aspects of this strategy that concern us. First is the explicit inclusion of foreign sources of food as a method of meeting food security concerns. The National Food Security and Long-term Planning Framework (2008-2020) called for "Active use of international supply and demand of domestic market regulation. Under the premise of protecting domestic food self-sufficiency (self-reliance) involves the rational use of the import and export market swap. Continue to play the role of state trading enterprises in 
the import and export of food. Strengthening inter-governmental cooperation, establish long-term stable, agricultural (grain and oil) partnership[s] with some important grainproducing countries...Implementation of agriculture 'going out' strategy to encourage domestic enterprises to 'go out' to establish a stable and reliable import...security system, [and to] improve the ability to protect the domestic food security..." (State Administration of Grain: 2008, 13). Similar statements continue to be found in the recent No. 1 Central Documents issued by the Central Committee of the Chinese Communist Party and the State Council. While there has been trade in grain for nearly the entire history of the PRC, this is an official document that includes food security as part of foreign policy. ${ }^{211}$ This will be the focus of the next section of this chapter.

Second, Xi, in 2016, has made non-traditional security part of his "Overall Security Concept," and especially food security as a potential threat to PRC security. Xi's concept brings together a full range of issues, both traditional (foreign policy and military security) and economic (such as food security). Domestic economic realities will increasingly affect Chinese external security decision-making (Wood: 2017,1). Additionally, a

\footnotetext{
${ }^{211}$ At this point, the question as to whether the "red line" or the fact that the highest levels of CCP have included in the foreign policy going out strategy the need to actively search for consistent sources of food from foreign sources, are either of these an act of securitization against an existential threat? Given the degree of high-level attention to food security, one would be tempted to say that there had been a speech act (securitized by the Central Committee) securitizing food security as an existential threat. Yet, has an appropriate referent object been identified that would threaten survival? Arable land would seem to be the appropriate referent object, the domestic land to produce the food for the PRC-- to securitize. But that fails as there is insufficient policing of land use policies at all levels of government, thereby undercutting the extent of the threat, making it politicization rather than securitization. The inclusion of food security via selfsufficiency as the foreign policy calls for, also puts food security in the realm of the political. Cui and Kattumuri suggest that the ultimate threat would be the "economic miracle," a more likely referent object would be the continued rule of the CCP.
} 
Xinhua article indicates that the $\mathrm{Xi}$ is concerned about over-reliance on foreign sources of raw materials and the potential disruption of supply (Xinhua: April 19,2016).

Third, there is also another aspect of going out that is the development and expansion of soft power. Hard power is the ability to get others to do what they would not otherwise do. Soft power, a concept introduced by Nye, attempts to get others to want what you want. "If its culture and ideology are attractive, others will more willingly follow. If it can establish international norms consistent with its society, it is less likely to have to change. If it can support institutions that make other states wish to channel or limit their activities in ways the dominant state prefers, it may be spared the costly exercise of coercive or hard power" (Nye: 1990, 167).

One can see that achievement of the Harmonious World foreign objectives and those in the Boao speech can be interpreted as being consistent with the soft power concept. Both Li and Shambaugh discuss differing points of view among PRC scholars and officials on what soft power actually is and how it is to be achieved. Shambaugh suggests that culture is the key to PRC soft power, yet there are differing interpretations of what aspects of culture are important. Those range from values culture to ideological culture to political culture to developmental culture. But proponents of each agree that there is a lack of PRC soft power (Shambaugh: 2013, 211-15). Li adds to the discussion the defensive nature of soft power. It can be used to counter the "China threat" aspect of the PRC's rise as well as to "fend off excessive influence and penetration of foreign cultures in China, particularly ideologies or beliefs that might harm the legitimacy of the ruling party” (Li: 2008, 300). 
There is a consensus that the PRC lacks sufficient soft power. Improvement efforts are being made through several means. First is the cultural approach, which has included Confucius Institutes that have been built in many areas of the world and radio stations in several African countries as well as university scholarships for African students. The successful Beijing Olympics and various cultural touring events are others. In the economic realm, there are several notable activities: 1) the so-called Beijing Consensus, the terms under which loans are made to developing countries that do not include the structural adjustments that the so-called Washington Consensus requires; ${ }^{212}$ 2) interestfree and low-interest loans as well as write-offs of existing debts of developing countries. When such loans are given for construction projects, the construction is often done by PRC labor. While this may keep PRC labor employed, it does not assist the receiving country in local employment or skill development; 3 ) there has been a concerted effort by the PRC to develop agriculture in Africa. This has been aided by demonstration farms to improve farming techniques in many Sub-Saharan countries and is considered to be successful (Sheng: 2010, 110-2); and 4) particularly germane to the subject, between 2012 and 2016 the PRC contributed USD 32.6 million to the general funding of the World Food Program (this figure excludes bilateral aid, aid that comes with conditions). This ranks $32^{\text {nd }}$ in the world for contributions; Malawi ranked $30^{\text {th }}$ and Ethiopia $27^{\text {th }}$ (World Food Program).

${ }^{212}$ A criticism of the Beijing Consensus is that loans may be disbursed but there is insufficient follow-up to assure that funds are not taken by corrupt local officials in the receiving country. 
While going out refers to economic and political issues, it can be said that the PRC is going out in terms of military power also. The PRC has embarked on the construction of a "blue water" navy, one that has the ability to operate in deep-water seas and across oceans. This is a natural activity for a great power with an extensive coast line. In the Western Pacific the objective is one of access-denial aimed at the US, the naval power of the Pacific. "...the United States regards sea control as essential to its economic and security interests in East Asia, and China is no less adamant that U.S. sea control threatens Chinese interests and even Chinese territory" (Gompert: 2013, 24). Accessdenial is not a war winning capability but rather a capability that keeps US ships farther from any potential hot-spot and thereby decreases its capability or increases its vulnerability (Gompert: 2013, 59). An immediate area of concern where naval forces might come into contact is the SCS. While the PRC promotes a Harmonious World, it actively seeks to lessen or prevent domination of Asia by an outside power while expanding PRC influence.

The blue water navy will also be a method, if needed, to protect PRC shipping, an aspect of security that the PRC implicitly depends on the US Navy to provide now. ${ }^{213}$ Again this is important to safeguard imports of grain and oil.

\footnotetext{
${ }^{213}$ The PRC participated in anti-piracy activities in the Gulf of Aden, its first naval activity away from its coastal areas.
} 


\section{Making Land Mobile}

Since the 2008 overall increase in commodity prices, including grain and particularly rice, the term "land grab" has become popular. ${ }^{214}$ It refers to FDI in agricultural land in a pejorative sense. "Whether FDI in agriculture is perceived as a "land-grab," depends largely upon pre-existing local conditions. In countries with large uncultivated land reserves, foreign ownership is muted” can be considered FDI “... whereas countries with limited or densely-populated farmland will find foreign involvement hard to stomach and investments will be resisted by the population" can be considered land grabs. Agriculture FDI is generally considered a development opportunity while land grabs are "an institution where people lose their access to and control over production lands or its resource" (FSN Forum: 2009, 1). Land grabs tend to be associated with less-developed states where there are insufficient legal protections for land rights. Africa is such an area as well as parts of SE Asia. FDI is associated with developed countries with unused land. A major example is Australia. Brazil, most likely, qualifies for both.

Those investing in overseas agriculture, that is raising crops or livestock, do so for a variety of reasons. First, it can be a financial investment to raise crops and sell them.

\footnotetext{
214 The "rice crisis" of 2008 occurred during a year when worldwide rice production increased by 32 million tons over the previous year. It was the result of poor policies in India and Vietnam (export restrictions despite higher production than in 2007), panic buying in the Philippines, a weaker USD, higher fuel prices and a belief that prices would go higher. Eventually, Africa endured food riots and export bans, and Caribbean and Asian countries encountered hoarding and purchase limits. The PRC also suspended rice exports for a period of time (Slayton: 2009). Paarlberg holds that domestic policy changes are the single biggest factor in prices increases. He cites restrictions on exports to maintain domestic prices. In addition to those countries mentioned, the PRC, Argentina, Russia, Malaysia, Indonesia, Egypt, and, Cambodia increased export taxes or banned exports during this time for products ranging from grain to palm oil (Paarlberg: 2010, 24).
} 
Second, for states with high population-to-land constraints or those with inhospitable climates they may invest to assure their home countries a supply of food controlled by itself. For example, Japan, Korea, and the PRC are states with population-to-land constraints and the Gulf States have an inhospitable climate. Third, a state that is reliant on imports may seek to insulate itself from market prices in times of short supply. Finally, if a state raises its own food overseas, or buys directly from growers, it can bypass paying grain merchandisers a commission on its purchases.

The actual investors in FDI or land grabs range from foreign private investors to local private investors to states. States provide the largest pool of investors through SOEs and sovereign wealth funds (SWF). Private investors sometimes invest with SWFs.

There are issues with both FDI and land grabs. In developing countries the concern is that corrupt government officials will inappropriately sell or lease land to foreigners that deprive traditional "owners" of their livelihoods while gaining personally. Promises by the acquirers for housing and jobs for the dispossessed are frequently not met in developing countries (Borras et al: 2011, 210-11). As crops are raised for export, both groups fear that in times of poor harvests at home or in the country of destination the food they grew would go somewhere else leaving them with too little. ${ }^{215}$ In the case of

\footnotetext{
${ }^{215}$ Sovereign states can embargo exports of foodstuffs should it be in their best interest as happened during the 2008 rice crisis, regardless of whether another state has purchased the land and grown the crop. Under Part VI, Article 12 of the WTO Agreements on Agriculture, 2003, the exporting country must take into account the impact on the importers food security as well as notifying all interested parties as to the expected length of the suspension. Sovereignty is not lost due to foreign purchase of domestic lands. However, this does not stop the originator of the FDI from pursuing any means possible to export its crop through extralegal means. The possibility of using extra-legal means increases in weak states subject to corruption, a situation that exists in many states with agricultural FDI for land purchases. During the Indian famines of
} 
PRC involvement, especially in FDI areas, there is the fear of the "China threat." The PRC has so many people and so much money that they will be able to purchase an entire province and consume what should naturally be that of the fruits of the host country. Put another way, the PRC is making land, like labor and capital, mobile. The land may stay in place but what the land produces will move to the PRC.

It is suggested that the PRC prefers investments to trade as they "are less fluid than trading ties, providing the basis for a longer-term - and, hence, more stable - economic relationship" (Thomas: 2013, 551). ${ }^{216}$ Yet, there are drawbacks to such an outlook: First, land "grabbed" by the PRC with the help of local officials provides a permanent source of grievance directed at the PRC. In the minds of the local dispossessed, it is the "occupying" entity that remains behind as a permanent reminder of what was lost as opposed to the local facilitator of the acquisition. This is an example of hard power, the "China threat," as opposed to the soft power that the PRC aspires to. As will be seen in the case of Brazil, trade, facilitated by purchasing crops from local farmers and building local processing plants that employ locals presents a "win-win" situation the PRC attempts to create with the local population. Second, programs can be enhanced or created by financing skill improvements of local farmers to increase output or to expand production onto unused land. In these cases, the total world supply of grain in increased that can

\footnotetext{
the 1890's, the British exported wheat to the UK while locals starved (Late Victorian Holocausts). This was not a case of extra-legal actions but one of power, in this case colonial power.

${ }^{216}$ A current rationale for such fears, not relating to food but to the absence of natural resources, can be seen in the PRC's decision to cut off or delay shipments of rare-earth metals to Japan following a collision between PRC and Japanese military vessels in the East China Sea near islands claimed by both.
} 
be purchased to help feed the PRC, as will be seen in the case of Africa. Finally, whether or not the PRC can be protected from world price swings in grain is immaterial. Price differentials will always exist. Given its size, the issue exists within the PRC itself whenever grain must be moved from one area to another when harvests vary. When worldwide grain is plentiful and harvests are poor in the PRC, imports lower overall costs. When the opposite occurs, export opportunities may increase profits. When harvests are low in the PRC and in the world, grain costs will be a national hardship but one that we can expect to be relieved via domestic grain subsidies or tariff reductions and the next harvest. Regardless of the relative strength of the PRC, it is not practical to assume that foreign-grown crops on PRC owned land in another sovereign state that is also suffering will be permitted to feed the PRC at the expense of its own population's food supply. In other words, trade works and if it does not, the problem is one of a temporary cost.

\section{Food Security and Foreign Policy}

This section will explore the interface of foreign policy and food security to determine how they interact to increase or decrease PRC food security. It will focus on regions and individual countries where appropriate and emphasize the specific activities in which the PRC engaged to deepen its involvement in local grain production through land acquisition or other less controversial activities. ${ }^{217}$

\footnotetext{
217 The question as to the extent of international "land grabs," by all countries, is suspect. There are a number of groups that claim to collect statistics on this issue but all are suspect. Many rely on press reports that relate to intentions but not necessarily signed contracts, the amount of land is always suspect, and the terms are not necessarily known. This is especially true in lesser developed countries. I have opted to use the Land Matrix data as my source. It includes more complete information and more detail than others.
} 


\section{$\underline{\text { South America }}$}

As we have seen, South American countries, primarily Argentina and Brazil, have been grain suppliers to the PRC since the early 1960's when Argentine corn shipments helped the PRC recover from the GLF. However, real agricultural cooperation began around 1995 when Brazil, Argentina, and Uruguay became consistent suppliers of soybeans to the PRC. Roughly coincident with the increase in soybean imports were the increasing imports of iron ore (Brazil, Peru), copper (Chile, Peru, Mexico), and other ores. These raw materials were needed to feed industries to meet local and world demand for PRC finished products.

Prior to these times, PRC diplomacy with South America was minor. There was the competition between the PRC and Taiwan for diplomatic recognition, the SouthSouth cooperation, and PRC and Brazilian desires for a multi-polar world (Shambaugh: 2013, 113). Choo maintains that South America and the PRC share several goals: anticolonialism, anti-hegemonism, and the desire to follow independent foreign policies, all dating from the Cold War (Choo: 2009, 74). The developing world became important to the PRC as it searched for friends following the Tiananmen incident (Choo: 2009, 78). South America is an area it turned to. Deng's southern tour restarted the rapid economic boom, and South America gained further importance to the PRC; it needed markets for its goods, natural resources to supply its industrial base, and more and more raw materials such as grain (Choo: 2009, 75). South America had oil, iron ore, copper, forests, grain, and market potential. 
For South America, Choo suggests that the PRC's "policy priority lies in political relationship that is based on mutual respect and equal treatment" (Choo: 2009, 80). Once a sound political bond is formed, mutually beneficial economic cooperation can start and both can be backed up by the application of soft power (Choo: 2009, 80-1).

Additional issues complicated the Brazil - PRC relationship: international politics and dependent development. Politically, Brazil had supported the PRC in the UN, expecting in return a seat on the permanent Security Council. When that opportunity arose, the PRC vetoed changes to the Security Council as Japan would have also become a permanent member (de Souza: 2006, 11). The specter of dependent development, trading raw materials for finished goods, potentially a situation that retards economic domestic development, is one that Brazil claims to have endured. In 2004, as part of a bilateral trade agreement Brazil recognized the PRC as having a market economy, as opposed to the WTO designation of three years earlier. Brazil agreed without obtaining any concessions from the PRC. The result was a flood of manufactured goods from the PRC that undercut Brazilian manufacturers at home and in their foreign markets. Brazil began filing dumping complaints with the WTO in 2005 (Horta, 2015, 24). A Brazilian high-tech investment in the PRC was made by aircraft manufacturer Embraer to build aircraft there. Results are not what was expected and Embraer believes that the PRC used Embraer technology to produce and sell its own planes at Embraer's expense (Horta: 2015,22). Ultimately, Brazilians would question whether the trade was mutually beneficial or simply a new phase of dependencia, Brazilian raw materials and grains for PRC manufactured goods. 
The PRC quest for grain supplies focused on Brazil, Argentina, and Uruguay. In contrast to the PRC, open lands and a concentration of wealth resulted in a combination of massive farming operations and smaller peasant farms. The Land Matrix lists 152 agriculture-related foreign investments in all of South America. This excludes-forestry related investments, but does include crops intended for biofuels. Only three have an area exceeding 200,000 ha. Investors come from all over the world, but the one that is noticeably small is the PRC. There is one PRC owned farming operation of 13,000 ha. in Argentina and one in Bolivia of the same size. Both grow soybeans. In effect, the PRC has been locked out of Brazil and Argentina, and other countries, by new or re-applied laws relating to foreign ownership. The Argentine law limits foreign ownership to $1000 \mathrm{ha}$. and the Brazilian law applies to foreign investments in domestic firms also (Valente: 5/11/2011). Brazil began restricting foreign land ownership in 1971, relaxed the rules when foreign capital was needed, and the law was re-interpreted to its original intent in 2011. The trigger for re-applying existing law came from negotiations to purchase large tracts of land, 200,000 ha. in Brazil by Chongqing Grain Group (Bao: 11/24/2011), 800,000 acres in Argentina by Heilongjiang Beidahuang Nongken Group, and a 500,000 acre sale/lease to Saudi Arabia (Moffett: 9/1/2011, A3). Chongqing and Beidahuang projects were scaled back and the Saudi one, already signed, continued as the re-application of foreign land ownership was not applied retroactively.

Also important in controlling PRC investments in Brazil was a statement from former minister Antonio Delfim Netto who "recommends caution with selling of lands to Chinese State-controlled companies, or to companies with a State participation... 'busi- 
nesses' undergo a change of meaning when the investments are subordinated to the strategic reasons of a foreign State. In the cases of natural resources and agriculture-land, a proper evaluation of such strategy becomes a security-issue participation" (O Estado de Sao Paulo 2010, A3).

To an extent, Netto's concerns were addressed by Chen Xiwen, the director of the Office of the Central Rural Work Leading Group: "Buying or leasing lands in foreign countries to produce agricultural products is only one of the ways China can expand overseas....We can also go to some grain exporting to set up processing facilities, help expand local employment and provide technical and economic assistance" (Yap: 2/2/2012). In fact, that is what happened to the Chongqing project in Brazil; it secured sufficient land to build a processing plant and chose to purchase soybeans from local farmers (Xinhuanet: 9/28/2012). The PRC wants to avoid paying the grain merchandizers to purchase and ship grain to the PRC. With the change in the scope of the Chongqing operations, that is what they have become in this instance, and they will be in direct competition with grain merchandizers.

In the case of soybeans in South America, we have seen that when there is demand the market will fulfill the need. This raises the question as to whether FDI in agricultural land will increase world output. For Brazil and Argentina, that is the case. Both countries received extensive FDI and output increased rapidly. In the case of Brazil, it suffered a lack of capital that resulted in an increase in FDI. The market met the increased demand for exports to the PRC but did so without meaningful PRC FDI. Netto's concerns about foreign-state involvement must raise questions about land purchases or long-term leases in the minds of PRC officials. Such concerns can lead to a strategy 
modification, as Chen suggested, that in Brazil led to local soybean purchasing and processing; a less capital intensive method to achieve the desired results.

\section{$\underline{\text { ASEAN }}$}

The overall economic and political relations between the PRC and ASEAN, both as a group and as individual states, are mixed. The ASEAN China Free Trade Association went into effect in 2010 for the original six members and in 2015 for the new, and much poorer members (Cambodia, Lao DR, Vietnam, and Myanmar). ASEAN prefers to negotiate as a whole while the PRC prefers bilateral negotiations. The PRC is the largest trading partner of each ASEAN state, and ASEAN as a whole is the third largest trading partner for the PRC (Thomas: 2013, 537). The disputes in the SCS continue with the PRC building islands and militarizing them. The PRC has used its "client" state, Cambodia, to fracture ASEAN consensus decision-making norms.

Singapore Prime Minister Lee Hsien Loong asks whether the PRC “"'is going to be benign and not only play by the rules but leave space for other countries that are not as powerful to prosper.' In this context, America is welcome in the region precisely because it 'wants the region to prosper. . . countries to do well' and importantly is 'prepared to help them."' (Lee: 2015,4). This sentiment is reflected in the actions of some ASEAN states. External balancing in reaction to PRC activities is occurring the Philippines, inviting US forces back into the country as part of its defense treaty with the US, and Singapore has opened its ports to US naval ships. Internal balancing is occurring in the Philippines, Vietnam, Malaysia, Indonesia, and Singapore as they increase the military capabilities. Other than the Philippines, the remaining four countries are also soft balancing 
through strengthening security ties. Vietnam is considering hosting US naval ships without basing rights. India and Japan are also states with which these countries are pursuing soft balancing strategies. None of the four is considering is formal treaty ties (Lee: 2015, $5)$.

PRC land acquisitions in ASEAN are concentrated in Cambodia and Laos and are used primarily for rubber, timber, and palm oil and cassava for biofuels. Additionally there are a few mixed-use crops, maize and sugar cane, that can be used for either ethanol, biofuel, feed, or human consumption. Investors from the PRC include $\mathrm{SOEs}^{218}$ and private companies. Many countries are investors including ASEAN states, Japan and Korea. In most cases, there is a local partner involved. However, the local partner may be a foreign invested entity. All investments serve to meet growing PRC demand and/or the lack of domestic resources. Rubber provides tires to feed the burgeoning auto business. Fast-growing timber meets the need for pulp for domestic manufacturing or harvesting of tropical hardwoods. Palm oil and cassava meet the need for non-petroleum-based energy for transportation. The benefit for the PRC is freeing domestic land to produce grain crops while Cambodia and Laos produce primarily non-grain agricultural products for industry. $^{219}$

\footnotetext{
${ }^{218}$ Investors may be SOEs or provincial owned enterprises; all will be referred to as SOEs.

${ }^{219}$ The "Golden Triangle", the opium-growing region encompassing the parts of Myanmar and Laos that border Yunnan Province in the PRC, supplied much of the heroin consumed in the PRC. To halt those imports, the Opium Replacement Plan was developed: Economic investment in the border regions of Myanmar would offer peasants alternative methods to earn a living while, in the case of rubber, provide the PRC with a commodity it needed. Incentives were offered to PRC firms, subsidies, tax waivers, and import quotas. Rubber plantations were constructed by PRC companies on the lands of the dispossessed peasants when their incomes severely declined. The subsidies offered by the PRC were to be used to develop alternative livelihoods for the dispossessed (former poppy growers), but were kept by the companies. The net
} 
Objections to PRC, or any entity or state, come from several concerns: 1) forcing peasants from their land, legally or not; 2) deforestation of natural plant growth that is replaced by tree plantations; 3) disruption of normal food production that runs the risk of creating local food insecurity; and 4) increasing ownership by foreign entities and the insecurity of not knowing the ramifications of such. This is an important point. The PRC has significant influence over the Cambodia and Laos governments. The going out strategy relating to agriculture is a national priority and PRC SOEs or privately owned firms can bring the influence of the state to bear. The Cambodian and Lao governments have significant power and influence over their populations, and many government officials may be serving their own interests, aided by a lack of transparency. The least powerful is the peasant who may be at the mercy, ultimately, of the PRC government, an example of extreme asymmetry for two sides with differing objectives (Luo et al: 2011, 291).

The Philippines present a more interesting situation. While the People's Liberation Army Navy (PLAN) was gradually slicing off SCS islands, claimed by both the Philippines and the PRC, other PRC companies were attempting to lease / buy large chunks of Philippine farmland.

President Arroyo's plan, The Medium Term Philippines Development Plan 20042010, called for the development of two million ha. of underdeveloped farm land and marginal or idle lands to provide jobs and to make food plentiful and competitively priced (The Medium Term Philippines Development Plan 2004-2010: 2004, 29). A large

result was an increase in opium planting and heroin processing by the peasants that had lost their land (Kramer and Woods: 2012, 2-9). 
portion of that objective was achieved in early 2007 with an agreement between Philippine government entities and PRC provinces and companies for 18 farming and aquaculture projects. One of these was with Jilin Fuhua and Jilin Province for one million ha. to grow rice, maize, and sorghum. Another with Guangxi covered 40 thousand ha. for biofuel crops (de la Cruz: 2011,6). Under negotiation at the time was an investment covering 200 thousand ha. for unspecified crops (Freeman: 2010, 18). Shortly afterwards, the PRC company ZTE was accused of bribery in a non-related investment that eventually led to the suspension of two of the land deals included in the 18 PRC invested projects (Thomas: 2013, 540). This led to civil society groups, Congressional inquiries, and the Supreme Court looking at the land deals and terminating the larger ha. projects and suspension of talks on the smaller. The legal aspect was directed at the use of public lands with respect to size (1000 ha. maximum) and minimum ownership of such lands by Filipinos, $60 \%$. A closer look at the Jilin project determined that the investor was not investing slightly less than four million USD into the Philippine economy, but rather was going to pay out that amount from profits of the venture over 25 years (de La Cruz: 2011, 1, 9$10) .^{220}$

Land Matrix holds that there are only four agriculture projects, totaling 56,350 ha., with PRC investment in the Philippines. One of those is a 40 thousand ha. project mentioned above. GRAIN, a non-profit NGO, maintains that all of the 18 projects were "suspended."

The interesting aspect of the intended PRC investments is that they were predominantly for palm oil for biofuels or for mixed-use crops in the Philippines. In Indonesia,

\footnotetext{
${ }^{220}$ Indicative of the factual or non-factual information regarding "land grabs."
} 
the investments are in rubber and rice. In Cambodia, Laos, Indonesia, and the Philippines, the PRC investments are not for grain, but rather for crops the PRC does not have in much quantity, rubber, and for biofuels that can reduce carbon emissions and reduce oil imports to a minor extent. This allows the PRC to keep its floor level of arable land, 120 million ha, producing rice and wheat for human consumption and meeting its $95 \%$ self-reliance target. The countries supplying these products see their respective food security threatened in areas of investment and perhaps overall (the Philippines and Indonesia are both net importers of rice).

Vietnam has not been a destination for agricultural FDI from the PRC to any great extent. There have been rubber investments by bordering provinces and leasing of land to grow sweet potatoes where land rentals earn peasants more than they could earn growing them. ${ }^{221}$ Vietnam is a major supplier of rice to the PRC but on a trading basis. Thomas points out that there is a reservoir of ill feelings in Vietnam directed at the PRC, and that would increase should trade be curtailed and be replaced by extractive investment (Thomas: 2013, 549).

ASEAN+3 cooperation has included a regional rice reserve to strengthen food security in the region, supplementing the ASEAN agreement with the same purpose. ${ }^{222}$ The initial PRC contribution was 300,000 tons of rice (Arase: 2010, 828). At present,

\footnotetext{
${ }^{221}$ The PRC farmer raises high quality sweet potatoes for export to the Japanese market. Few Vietnamese farmers are sophisticated enough to export on their own.

${ }^{222}$ The ASEAN reserve did not function during the 2008 rice crisis due to policy decisions that reduced or eliminated exports, despite the original intentions of the agreement.
} 
member countries have commitments to supply stated quantities of rice in times of emergency, including natural disasters. Commitments are for specific amounts, not a "setaside" of stocks for emergency purposes. This reduces / eliminates the need for designated supplies and the resulting storage cost and risk of degradation. ${ }^{223}$ It also raises the question, in off-shore farming for export and in emergency situations, as to whether a country experiencing a rice shortage would export to another country in a similar or worse situation.

\section{$\underline{\text { Africa }}$}

As in other areas, the extent of "land grabs" in SSA is not fully known and most likely exaggerated. ${ }^{224}$ The fact that many governments have poor governance related to land tenure, government corruption is not uncommon, and there is an ongoing search for oil and minerals, all add to a conclusion that foreign land grabbing must be excessive. In a continent that suffers from food insecurity, land grabbing for export of agriculture crops is not well received by civil societies at home nor by NGOs abroad.

\footnotetext{
${ }^{223}$ Such a scheme may work in the event of a localized natural disaster. However, in the case of a regional drought, for example, such a scheme will only further increase higher than normal prices if the contributing states only supply funds, not rice. To avoid raising prices for everyone, emergency rice would have to come from out-of-area suppliers or state specific emergency supplies.

${ }^{224}$ For a good summary of the issues concerning the reliability of reported land grabs, see Marc Edelman "Messy Hectares: Questions about the Epistemology of Land Grabbing Data" Journal of Peasant Studies, 40:3, 485-501.
} 
In the case of the PRC, the initial reports of large-scale purchases were false. However, there is extensive PRC-backed agricultural activity. ${ }^{225}$ The political aspects of PRC involvement in Africa come from the Bandung Conference that attempted to unite the developing world, from the PRC's attempt to obtain and keep diplomatic recognition of African states for itself rather than allow it to go to Taiwan, and from the Soviet - PRC competition of the 1970's and ' 80 's.

Starting in the 1960's, the PRC constructed large-scale farms in Guinea, Benin, Togo, Madagascar, Tanzania, and Sierra Leone. Crops included rice, tea, and sugar and were considered as aid by the PRC. The success of these operations was largely dependent on PRC management remaining in control of operations. ${ }^{226}$ For example, the scale of operation in Tanzania rose to 3200 ha. of irrigated rice fields in 1967. Tanzanian President Nyerere, a socialist admirer of the PRC, eventually resorted to forced collectivization in 1973 to assure participation by local farmers. Within two years, output plummeted and food grain imports rose (Brautigam: 2011, 39). The PRC projects, like those of Western countries, tended to fail when management was passed on to local officials (Easterly, 2006, 189-90). Prior to the GLF, Zhou Enlai had urged Africans "that China was a model not 'to emulate' but a kind of 'reference point'” (Brautigam: 2011, 38). In the case of Tanzania, Nyerere could not be dissuaded from emulating the collective model, and suffering the consequences.

\footnotetext{
${ }^{225}$ There have been and are substantial PRC investments in other resources in Africa, the prime examples being copper and cobalt in Zambia and oil in Angola.

${ }^{226}$ See Brautigam, The Dragon's Gift, for details.
} 
These projects were considered aid by the PRC. Oftentimes, as with resource extraction projects, infrastructure development was included. This facilitated both the growing of crops as well as roads for access and ports for export.

Taiwan followed a different path. It built demonstration farms aimed at improving the efficacy of traditional small landowners in African countries rather than largescale farms (Brautigam: 2009, 688). Following PRC admission to the UN, the PRC took over Taiwanese demonstration farms in states that had switched diplomatic recognition to the PRC. The PRC built more of these demonstration farms as its trial-and-error approach to African aid developed.

The second phase of PRC involvement in African agriculture involved the reconstruction of previous projects that had fallen into disrepair following PRC exits from those projects. According to a PRC official: "almost all of them without exception have gone through the odd cycle of "quick starting, quick results and quick decline"” (Brautigam: 2009, 692). The PRC turned to SOEs to reverse that trend by including a profit motive that paved the way for continued SOE involvement following the start-up phase (Brautigam: 2009, 691-2). This included the use of feasibility studies, rationalizing existing projects, management decentralization, and an opening to African countries to partially fund projects (Xu et al: 2016, 83).227

From 1987 through 1995 exports from SSA to the PRC tended to be in cash crops -- cotton and tobacco--sourced from individual farms, and an increasing amount of tree

\footnotetext{
${ }^{227}$ In 2007 the PRC agreed to provide irrigation for 250,000 ha. of maize in Zimbabwe. The project was cancelled when Zimbabwe failed to make its financial contribution to the project. This is indicative of the revised approach both in terms of project rationalization, host country funding, and the profit motive.
} 
nuts and cocoa, as well as periodic shipments of grains from the major grain producers, Zimbabwe (at the time) and South Africa. There were shipments of sugar from states with PRC-financed sugar operations as well as shipments to Europe that could be imported duty free from Africa.

The current agricultural activities in Africa are centered around the Agricultural Technology Demonstration Centres (ATDC), and reflect the cumulative learning of the PRC experience in Africa to date. This program was announced in 2006 in conjunction with the Forum on China-Africa Cooperation (FOCAC). The creation of the demonstration center involves three stages: 1) Infrastructure development for the center for two years. 2) Technical cooperation for three years, the key to the plan. This involves demonstrating methods and techniques superior to the existing practice that will improve output and that will be spread beyond the immediate area to other parts of the country. 3) A program on sound financial footing that will allow ongoing operation. This involves the sale of superior seeds and farm implements to local farmers (Xu et al: 2106, 84, 88). Ultimately, there is mixture of aid and sustainable business. The ADTCs are representative of PRC soft power even though they are ultimately a money-making operation run by SOEs.

However, problems continue to exist with ADTCs. Xu et al examine four, one each in Tanzania, Ethiopia, Zimbabwe, and Mozambique and find among other things: 1) Satisfying the expected results of PRC state organizations, PRC provincial organizations, and host government organizations is difficult. 2) The PRC believes that its expertise lies in rice and not maize; therefore an emphasis on rice where an emphasis on maize is needed results in a mismatch between expertise and needs. 3) Extension activities are 
expected from the host government and are inconsistent. 4) Locals prefer local rice that is "better" than hybrid rice; therefore, the better yield of the hybrid does not matter. 5) Who can/will buy advanced (relatively) technology? (Xu et al: 2016, 87-8). In summary: "As a platform for a whole array of activities, the Centres provide an important symbol of Chinese development experience and perceptions. As a future model for agricultural development, these first phases of the ATDCs have been an important learning experience, but there will be challenges to achieve full commercialization and a business platform that can fund aid activities" (Xu et al: 2016, 89).

The PRC has not made land mobile for food products in Africa. According to the Land Matrix, the PRC (state or provincial owned enterprises) has 24 agricultural projects (excluding ADTCs) in SSA covering just over 150,000 ha. ${ }^{228}$ Two are for biofuels, two produce mixed food/biofuel crops, and the remaining 20 produce food crops. ${ }^{229} \mathrm{FAO}$ import and export data show no meaningful or sustained exports from SSA to the PRC for wheat, rice, soybeans, or maize. Cotton continues to be a major export to the PRC as well as sesame seeds and $\operatorname{cocoa}^{230}$.

\footnotetext{
${ }^{228}$ This excludes private investment by PRC individuals, many of whom were laborers for PRC aid projects who decided to stay in Africa.

${ }^{229}$ There is one PRC logging operation according to the Land Matrix, in Liberia covering 10,000 ha.

${ }^{230}$ It should be noted that Brautigam mentions that the PRC uses resource-secured loans to finance aid projects in some instances. In the case of a dam built in Ghana, the compensation for the construction included the export of 40,000 tons of cocoa beans, annually over the course of the 20 year loan (Brautigam: 2011a, 212). This compensatory trade, development goods and services for local products also involved oil from Angola, minerals from Congo, and copper from Zambia, among others (Brautigam: 2011,55). Local products could also be used to repay loans.
} 
Brautigam offers four conclusions concerning the PRC in SSA. First, there is a small but growing involvement of public and private investment in SSA agriculture. Second, the use of contract growing (outgrowing) has been occurring and is increasing but is not a possible source of food security for the PRC. Third, SSA issues with infrastructure and inefficient governance will keep investment down. Finally, SSA governments and private citizens are increasingly involved in JVs with and learning from the PRC (Bratigam: 2013, 1690-1).

A fitting example of the complicated issue of "land grabs" and/or development opportunities in SSA can be seen in the example of rice production in Mozambique. Horta and Brautigam have engaged in a running dispute over PRC involvement in agriculture in Mozambique. ${ }^{231}$ The question boils down to whether the PRC is investing in the Zambesi Valley of Mozambique to increase rice production to 500,000 from 100,000 tons annually in order to export the increment to the PRC as local demand is only 100,000 tons, the position Horta takes. Brautigam maintains that the PRC objective is to provide rice domestically so that imports can be reduced as domestic demand is 500,000 tons. Based on FAO Statistics, production, import, and export data from Mozambique, there has been an improvement in rice production in Mozambique to 149,000 (2012-13) with a peak of 264,000 (2010-11) from 107,000 tons (a two-year average of 1994-5). Imports have increased to 453,000 tons in 2013 from 51,000 tons in 1994. Imports have come primarily from Thailand and Pakistan, some has come from the PRC. Exports, 3\%

\footnotetext{
${ }^{231}$ Horta's initial article and his response to Brautigam's critique are at http://csis.org/publication/zambezivalley-chinas-first-agricultural-colony. Brautigam's article is at http://www.chinaafricarealstory.com/2012/01/zambezivalleychinasfirst.html
} 
of total imports, have all gone to SSA countries plus Bangladesh. There are none to the PRC. Brautigam was correct.

Whatever incremental agricultural production occurs in Africa increases the world output and therefore indirectly helps with PRC food self-sufficiency. If Mozambique can become self-reliant in rice, that is 400,000 tons more than the world has today.

\section{$\underline{\text { Russia - No Need to Grab }}$}

In the Russian Far East (RFE), there is no reason to grab land; there is lots of it, there are few people, and the Russian government is fairly agreeable to permitting PRC investments and labor to work in its far backyard. The total RFE population (of Russian citizens) is somewhere around 7 million. The population of Heilongjiang, the PRC province bordering the eastern-most area of RFE has a population of nearly 40 million. The three provinces closest to the RFE, including Heilongjiang, have a population in excess of 100 million. This presents an opportunity to use abundant PRC assets, labor and capital, on abundant RFE land to increase the food supply for the PRC and Northeast Asia; an opportunity that would benefit both countries.

Following the breakup of the USSR, there was a flood of Russians that departed the RFE for more hospitable parts of Russia. The state farms were broken up and land was given to the occupants of those farms. The RFE was an exception as redistribution did not occur. The PRC had, since the 1980s, provided labor support to RFE farms. This accelerated in the 1990s due to the outmigration as Russians sought better living conditions. The RFE government had no problem with leasing the land that was not redistributed, but did so with an extreme bias in favor or large-scale operations. However, this 
did not prevent leases to individuals, generally of PRC origin but from other parts of the world as well. ${ }^{232}$

Consistent with "going out" larger PRC companies, private and province owned, started operations through purchase of existing Russian operations or leasing land. This included Beidahuang, a company also involved in South America. However, much of the produce was used to feed the existing population of RFE due to transportation costs (Zhou: 2015, 9-15).

FAO export data from Russia to PRC and PRC import data from Russia, through 2013, is consistent with the RFE consumption thesis. PRC vegetable imports from Russia are small, perhaps representing the degree of small acreage farming operations or local consumption. Large-scale farming requires development time which may be the reason that they fail to register in PRC imports to any great extent. Noticeably absent is the lack of pig meat imports. A PRC company began operating a hog farm, in Russia, close to the border in 2001 (Stanway: 2013), yet there are essentially no pig meat imports from Russia.

While this situation may be a perfect pairing of resources, there is a lingering fear of "sino-zation" of RFE. Nonetheless, it also fits into Russia plans to create a "Far East Grain Corridor" capable of producing, for export, 10 million tons of grain per year by 2020 (Zhou: 2015, 13). Provided there are sufficient export facilities, Korea and Japan could be beneficiaries of such a plan in addition to the PRC.

${ }^{232}$ As with other agricultural FDI in other parts of the world, specific information on foreign investment tends to be anecdotal and should not be used to identify the quantity of lands used by the PRC in Russia. 


\section{Australia and the "China Threat"}

As a developed country with a functioning legal system, Australia is an FDI destination country. Following the 2008 grain price increases, it became a destination for SWFs, private investment, and public investment from Brazil, USA, Canada, Dubai, Japan, UK, Singapore, Switzerland, Qatar, South Korea, Spain, and the PRC, among others. Australian companies were actively involved also. The investment targets ranged from existing agri-business companies to farms to vacant land. "Australia offered these investors high quality production assets, relaxed government regulations, significant export surplus, favourable fundamentals and proximity to growing Asian demand." This was evidenced by $\$ 12$ billion (Australian) in agriculture investments over the previous four years (Lamont and Manning: 2011, 4).

The Australian Foreign Investment Review Board was responsible for approving foreign investments that exceeded $\mathrm{A} \$ 231$ million. Lesser amounts were reviewed by mid-level Treasury officials (Cai: 2013,6$).{ }^{233}$ As with Brazil, Australia was concerned about SOE investment. They were major investors in Australian resources and ultimately reported to the $\mathrm{CCP}$, thus creating the question of normal commercial transactions vs. PRC strategic interests. This issue was addressed by a "national interest test," a set of criteria that, it appears, can be weighted differently for differing investments. It could

\footnotetext{
${ }^{233}$ In contrast, New Zealand officials must approve all foreign land purchases exceeding five ha.
} 
also be used to resolve issues with creative solutions. By 2008, the Board was required to approve all SOE and SWF investment applications (Cai: 2013, 6). ${ }^{234}$

PRC acquisitions include land for organic dairy farms, the largest farm in Australia--Cubbie Station--and 13,000 ha. along the Ord River in Western Australia. This is a fifty-year lease arrangement that includes the construction of a sugar mill. It is in an area that Australia hopes to develop into a prime agricultural "food bowl" (Clarke: 2012). Approval is not always granted to PRC companies. Shanghai Pengxin, a private company, was rejected on national security grounds from purchasing Australia's largest privately owned tract of 101,000 sq. kilometers. Part of the purchase included military testing grounds (Elliot: 2015, 28).

Perhaps the most interesting question is why the Australians themselves had not invested in food production for export rather than deferring to non-Australians. "Australia is a capital-hungry country that is in desperate need of foreign investment, especially in the agricultural sector" (Cai: 2013,6). It was the lack of domestic capital that led to the sale of Cubbie Station. If it had not been sold, it would have closed (Cai: 2013,6). Capital may be the ultimate answer. Another might be that like their counterparts in the PRC, the farmer might wish to live in a city rather than the countryside.

\footnotetext{
${ }^{234}$ When the Australia-PRC FTA went into effect in 2015, Australia raised the FIRB approval level to A $\$ 1094$ million for non-sensitive investments. Agri-business and agricultural land investments will all be reviewed at a lower threshold level, and all SOE investments will be reviewed (China-Australia FTA).
} 


\section{Conclusion}

The going out strategy started out under Jiang and was focused on non-agricultural firms to go out and be involved in the world economy. Under the export-led development model, foreign firms came to the PRC to manufacture and/or to sell in the PRC market. The emphasis under Hu was expanded to include agriculture and included investment in foreign agri-businesses and to obtain crops from overseas for domestic consumption, either through farming or through increased involvement in the agri-business supply chains. Success in the agriculture ventures can be measured in several ways: 1) Growing crops and bringing them back to the PRC for consumption; 2) Improving the agricultural output of countries so that the world supply is increased, thereby making more crops available to be purchased in the world markets; 3) Growing non-grain crops overseas so that domestic land can be used for grain; and, 4) By inserting PRC companies into grain supply chains. This allows needed grains to be purchased directly from the growers or by purchasing companies that can alter their sales patterns to include exports to the PRC.

In the cases that we have examined, the results are mixed. In the cases of Russia and Africa, PRC farmers in Russia are improving food output for consumption in the RFE. In SSA, it is PRC aid that is attempting to do the same. In Australia, we see examples of green-field investment for products that will be shipped back to the PRC as well as the "food bowl" concept of the Australian government to create food from land that only the PRC has contracted to develop. Russia's "Far Eastern Grain Corridor" is similar in concept but not past the talking stage. In the case of Cambodia, and probably under development in Laos, is growing mixed-use crops on foreign lands for biofuels so that 
food crops can be grown in the PRC for food security. Cambodia exported 22 million and 51 million tons of cassava to the PRC in 2012 and 2013, respectively. That number will increase and the plantation organization is expected to have a negative impact on local food security.

The case in South America is one based on demand and not supply. When the demand is there, the supply will follow. Prohibition of large-scale land purchases led the PRC to focus on less capital intensive soybean collection from local farms, then processing, and shipping to the PRC. In response to growing PRC imports, the ha. of soybeans harvested increased by 5.9 million between 2006 and 2013. This increase did not displace other crops as the total ha. harvested for all of Brazil increased by 10 million. The same occurred in Argentina where soybean ha. harvested increased by 4.3 million while total ha. harvested increased by 5.9 million. Given the increase in total ha. harvested, it can safely be assumed that this was new output on previously unused land.

The case of Brazil and Argentina has been successful for the soybean supply for the PRC. There, as in Australia and the Philippines, these countries reacted to the investment attempts of the PRC, as well as other countries and SWFs, by more strictly controlling foreign investment in agricultural lands. Japan, Korea, and private companies had been engaging in similar activities long before 2008. The China threat seems to be the factor that led to more control over domestic agricultural lands. However, in the case of the Philippines, Australia, and for a while, Brazil, all suffered from a lack of capital to invest in agricultural projects. Such situations need creative solutions that play a role in improving Philippine food security (a demonstrable need) and Australian agricultural 
projects, both of which increase world food security and therefore PRC food security indirectly. 


\section{Chapter VII - CONCLUSION}

There are several themes that run through the story of achieving and maintaining food security in the PRC and its interaction with foreign policy. First, agriculture needed to fill three distinct roles in the PRC: food for the population, raw materials for industry, and a source of FX. Second, the overall view of the CCP was that food security was to be generated by domestic actions: land redistribution, the HRS, and the PGRS. However, recent trends indicate that further domestic supply may be insufficient. Third, since Mao, there has been a loosening of state control of some aspects of life and the use of incentives rather than coercion to improve grain outputs. Finally, PRC foreign policy is a reflection of domestic conditions and interests. That brought the international system into play, a system where the PRC is a major player, and served to limit trading partners and the items that could or would be traded. In keeping with the format already in use, we will draw conclusions on food security from the constituent parts of the food paradigm; domestic politics, the state-society relationship, and economic development. We will then look at the foreign policy aspects of achieving food security and how these two, food security and foreign policy, interacted in achieving and maintaining food security.

\section{Domestic Politics}

Overall, domestic politics began as a totalitarian state (complete subservience to the state) in 1949 and has moved to an authoritarian state (strict obedience to authority), beginning with Deng's rule. Food security has improved whenever incentives were created. The land redistribution under Mao and the HRS system under Deng are the two 
prime examples. Deng's adjustments included price incentives and multiple market channels. Coercion had the opposite effect. The move to collectivization caused falling output and famine. Under Jiang's time at the top of the PRC, the PGRS employed compellance but it was modified through the use of price incentives.

The nature of the totalitarian state made matters worse when coercion was used to force change. Under Mao, top-down planning put central bureaucrats in charge of agriculture decisions best made by farmers who knew what and when to plant. The GLF famine was worse than it might have been as officials exaggerated production results for fear of retribution, thereby leading to decisions not based on reality. The compellance aspect of the PGRS (in an authoritarian state) was executed at the provincial level and that at least put decision-making closer to farmer than was the case under Mao.

As the state transitioned to an authoritative one, we see a movement away from Marxism to an ideology with a more liberal bent, albeit within an overall realist approach. The dividing line was Deng's ascent to power. Mao's first move was redistribution of farmland, a very Marxist attempt at equalizing society by allocating the holdings of the wealthy to the poor. It was successful in increasing grain output as the peasant was able to fully enjoy the fruits of his labor after taxes, an incentive to which the peasant responded. Collectivization, the epitome of Marxism, led to a decrease in output as the incentive for increased production led to a free-rider issue, among other things.

Deng stepped away from Marxism with the dissolution of the commune and the implementation of the HRS, a decidedly non-egalitarian approach. To get rich was now the mantra and the peasant was the first to enjoy this. Choice of what to plant was introduced along with financial incentives. This was consistent with liberalism, relying on a 
bottom-up approach to generate incremental output. This situation worked well but ran into problems when peasants began to choose to plant cash crops at the expense of grain. The result was a reduction in choice of what to plant and was implemented via the PGRS. Financial incentives were retained but were limited in grain surplus provinces and adjusted as necessary to encourage planting of what the Provincial Governors thought was best.

The total output of wheat, rice, maize, and soybeans grew to 563 million tons in 2014 from 80 million in 1952, a seven-fold increase. ${ }^{235}$ The organization of agricultural society has been a trial-and-error evolution. Science, the development of better seeds, and incentives have been major sources of increased output. Yet, the increase was not enough. The population had grown 2.5 times. The PRC imported these grains annually from 1960. It was not self-reliant but self-sufficient. In 1996, it officially lowered its self-reliance factor to $95 \%$. A major reason for this was decreasing arable land. Arable land in 2013 was only $42 \%$ of the amount in 1950 . By 2006, maintaining arable land at an absolute minimum of 120 million ha was a national priority.

\section{State-Society Relationship}

The state-society relationship ebbed and flowed just as domestic politics did. The government took over responsibility for the cradle-to-grave needs of urban citizens via the danwei. Personal choice was limited. Urban rationing of foodstuffs controlled demand, and citizens were watched lest someone exhibit anti-CCP behavior. For the urban

\footnotetext{
${ }^{235}$ Soybean production was not reported until 1961.
} 
population, the state provided all it considered necessary. Rural residents, the majority of the population, were left on their own, prior to collectivization. The hukou system of registration prevented unwanted movement to urban areas from rural ones. The rural population was needed to remain in agriculture to produce food for urbanites, raw materials for industry, and food for export.

Deng both imposed and removed the state from daily life. The state involvement reached its height with the implementation of the one-child policy, aimed primarily at urban residents. The implementation of this draconian policy was the fear of the state that it would be unable to feed the population should the rate of growth continue. It was a possibility from the earliest times of the PRC but not used until the spurt of growth during the GPCR. Nearly coincident with the one-child policy was the dissolution of the collectives and the redistribution of commune land. The state may have entered the bedrooms of society, but it also provided choice in economic endeavors that had been missing since 1957-8, a continuation of the totalitarian state.

The pursuit of modernization provided citizens with more choices and opportunities as well as fears. Modernization demanded skills that required more education, much of which was to be obtained overseas with only minimal caveats. More labor was needed for the SEZs, and that led to migration opportunities for rural residents despite the existence of hukou. Wages increased, but so did the cost of living. The hukou was part of the totalitarian state, and as time passed it became more of an authoritarian tool that was used only to keep the floating population under control in the major cities. It still is in use, but is less stringent than it was originally. 
Among the improvements, there were setbacks. Farmers lost land and were paid in IOUs due to mishandling of monetary resources and greed by those in charge or outright corruption. Employees of bankrupt SOEs lost their pensions or pensions were reduced as were the benefits provided by the danwei. Pollution--land, air, and water--has become a major health concern with little hope in sight. Poisonous foods have created scandals and reduced societal trust. It is in the lack of trust in the authorities to follow through on the social contract with SOE employees and the expansion of corruption and deceit that has caused the major loss of trust and increasing demonstrations against this behavior in rural areas throughout the country (The Economist: 9/29/2005 and 1/28/2012). The absence of civil society organizations, beyond what the government permits, prevents grievances to be heard and addressed until the demonstrations develop...or not at all.

Finally, in 2015 the one-child policy was relaxed and increased to two, albeit with penalties should that limit be exceeded. Whether or not this relaxation will help alleviate the issues the one-child policy caused is questionable. The demographic transition is in full swing in the PRC. One-child may be the choice of child-bearing women today.

\section{Economic Development}

The original emphasis on economic development was on heavy industry. Steel production became a measure of development rather than what was made from that steel. The failure of the GLF made agriculture the priority. This led to seed development and increased fertilizer use but not to economic development. If development was to be done 
domestically, the choice Mao made in backing away from the Soviets, the road to modernization would be quite long.

Deng's adoption of the export-led development model was a fortuitous and necessary change of development strategy. ${ }^{236}$ It paved the way for FX earnings from PRC assembled and manufactured goods far beyond what agricultural commodities could earn. Once these foreign investments started exporting, the fiscal need for the PRC to be selfreliant in grain was obsolete as it was then able to purchase what it needed without running an FX deficit. It could be self-sufficient, if desired.

It is with the change of development strategies that we see a shift towards capitalism and liberalism in the PRC. Capitalism was invited into the country to take advantage of low wages and a population that was, on the whole, non-productive economically. Teaming up with PRC companies (SOEs) FX was generated, employment and wages increased, new skills and technologies were introduced for future use, and possibly best of all, it was done with other people's money. All-in-all, it was a major success and one that has created unprecedented growth in moving people out of poverty in a short period of time. Eventually, this led to domestic entrepreneurs emerging to create new economic opportunities. There became a viable bottom-up aspect of economic growth based on individual incentive, completely consistent with liberalism. However, this has not solved the problem of inefficient SOEs, something the government is reluctant to tackle due to the social benefits they continue to provide.

\footnotetext{
236 The case can be made that this was the most important decision in China in the $20^{\text {th }}$ century.
} 
Under Jiang, the PRC joined the WTO, a necessity for export-led economic development. This further ingrained liberal ideas of free trade as well as requiring adherence to the rules and norms of the trade regime it joined.

The downside to economic development, as far as it relates to agriculture, is the loss of arable land to grow crops. Transportation, housing, and recreation, among other land needs, have dramatically cut into arable land. This is complicated by the fact that prime agricultural land is located where much of the population and competing demands are located.

Even with self-sufficiency, there is concern over domestic grain production as evidenced by the continuing emphasis on agriculture in the annual No. 1 Document. Securitization of arable land at a minimum of 120 million ha. is the amount the government believes is necessary, not to be self-reliant, but to maintain a reasonable level of self-reliance in a world of self-sufficiency. Maintaining this level is a challenge.

A key policy decision by Jiang was for PRC businesses to "go out" and expand their exports to the rest of the world and to expand their investments abroad and operations abroad. The export-led economy that started under Deng needed to be expanded into more advanced products that could be found overseas at the source of marketing, manufacturing, and technological innovation. This is an explicit statement by Jiang that further economic advancement would need to rely more directly on what was being done abroad rather than depending on the portion done abroad and brought to the PRC.

Hu took going out a step further and emphasized agriculture. After all, economic development was decreasing arable land, and there was more overseas than at home. The PRC was generally unable to acquire land overseas to plant crops for consumption at 
home. It has managed, to an extent, to use the going out strategy to improve total agriculture production. It is not an increment for the PRC but for the world. It is an absolute improvement but not a relative one. "Going out" is another example of creeping economic liberalism.

\section{Foreign Policy}

The PRC's approach to foreign policy is "diplomacy is an extension of internal affairs." It follows that we can see elements of its food security in its foreign policies. Foreign policy can be divided into two different planes, international politics or high politics, and low politics or trade. In the post-WWII era, until the dissolution of the USSR, high politics revolved around the Soviet-sponsored East Bloc and the US-led West Bloc. The PRC was a player in this game. It was aligned with the Soviets, then in opposition to both Blocs, followed by a tacit alignment with the US for defensive purposes, all under Mao. Several years into Deng's rule, the USSR and PRC began mending fences, and the PRC pursued an independent foreign policy. Alignment with either Blocs served to limit trading opportunities. There was little trade between the US and USSR and trade relations between members of opposing Blocs were limited, but greater than US - USSR trade. Low politics was restrained by high politics. But low politics was a tool that could be used to influence or signal (dis)satisfaction with high politics as the PRC pursued its own interests.

For the PRC, food security and international trade created issues based either on need or on opportunity. Need refers to either short-term real needs or long-term perceived needs. Opportunity refers to its choice of states to trade with, and that can be used 
to influence or signal PRC intentions and/or (dis)satisfaction with other states' policies. These can take place within the normal interdependent trade relations or when special situations arise.

There are three cases of need where the international community contributed or is contributing to PRC food security. First, of course, are the West's and Argentina's shipments of wheat and maize to reduce the impact of collectivization and GLF-caused famine, a short-term real need. Second is the developing situation of sourcing grain from overseas via investment in other countries, primarily done by Hu extending the "going out" strategy to agriculture. The purpose is to satisfy long-term perceived needs for a stable food supply that included foreign-sourced grains, to meet increasing demand. We have seen that the PRC is not generally involved in land grabs, other than in Laos and Cambodia. It was legislated out of land acquisitions in Brazil and Argentina and has changed its approach to act as a grain merchandizer, buying direct from farmers and shipping soybeans back to the PRC. In Australia, it has bought and leased land to grow crops and transport them back to home. In the case of leased land, they are bringing uncultivated land into cultivation and thereby increasing world output, a positive situation in any case. In the RFE, mainly individual PRC citizens have been growing crops in Russia for consumption in Russia. This is another case of increasing production, this time in an area where production had declined following the fall of the USSR. In Africa, after various attempts to involve itself in African agriculture, the use of small-scale demonstration farms is now the chosen method to increase output. These activities are all efforts to pro- 
duce more crops worldwide, in some cases for the PRC itself and in some cases to increase world supply that will be an indirect benefit to the PRC. Both types of efforts address the long-term concerns the PRC has for its own food security.

The third area where need comes into play, at least indirectly, resulted from rapprochement with the US. This gave the PRC access to the US breadbasket. A grain-insecure state would want access to the leading grain trading state. This would have benefits economically as the greater competition for sales to the PRC held out the possibility oflower prices. $^{237}$ For the PRC, it reduced the possibility of the US influencing members of the West Bloc to abstain from selling grain to the PRC for international political reasons.

Normal interdependent trade was important to the PRC in order to generate FX, and agriculture products were needed to accomplish this until the development strategy changed. It was limited by the international political situation. As an East Bloc member, trade within the Bloc was generally on a barter basis, and did not generate needed FX. The soybean exports to Western Europe generated scarce FX. Trade with Japan was initially on a barter basis, but the exchange terms were better than those within the East Bloc. The role of Hong Kong as a transshipment port for PRC grain crops grew steadily over time and contributed FX.

As long as there was grain to ship or grain to purchase, there were opportunities to influence, signal, reward, or punish other states when it benefitted PRC interests. In

\footnotetext{
237 The actual amount of grain would only be increased when new acreage was planted in grain-producing countries. Though the US was not selling to the PRC, its production was already part of the world supply and therefore included in the international prices. Only competition for sales to the PRC could lower prices.
} 
Mao's case, there is also another reason; Mao used grain as an instrument of spite. When faced with criticism by Khrushchev on his collectivization plans, his general dislike of the Soviet leader, and his own ego, caused Mao to leave the Soviet orbit. In the midst of his collectivization and falling grain output, he repaid Soviet loans with his scarce commodity, grain. Subsequently, some grain purchased from abroad was transferred to Albania since Albania was quarreling with Moscow. Mao punished his own people.

Mao also used the grain to further punish (or irritate) the Soviets and influence members of its Bloc. The PRC sold rice to the Cubans between 1961 and 1969 and bought sugar from them. It is reasonable to conclude that Mao was attempting to demonstrate that PRC communism was superior to the Soviet version and to lure Castro into allying with the PRC rather than the Soviets. ${ }^{238}$ Other than with Cuba, and a bit with Albania, all trade with the East Bloc stopped after 1962, a signal to the East Bloc that the PRC did not need them.

To make up for the loss of East Bloc markets, the PRC began to focus more on $2^{\text {nd }}$ Ring states, particularly on Japan and Malaysia, and Sri Lanka (as Ceylon was known after 1972). The latter two were sources of rubber as well as buyers of PRC grain. Relations with SE Asia were negatively influenced by Mao's pursuit / support of communist revolts in several of those countries.

On the import side, Argentina continued as a maize supplier and a sometime wheat supplier. This, of course, presented an opportunity, as opposed to need, to continue trade with all of the suppliers that helped to relieve the GLF famine. Argentina was

\footnotetext{
${ }^{238}$ It can also be explained by normal interdependent trade, rice for sugar; trading of which you have in excess for that that you need. This trade stopped in 1969 when the Sino-Soviet disputes turned hot.
} 
a politically less sensitive state than any other states from the West. While Canada and Australia continued as consistent wheat suppliers, following rapprochement the PRC made large purchases of maize and wheat from the US between 1972 and 1974, a reward for political progress between the two. Purchases from the US then stopped for three years. This was the time of intense internal PRC conflict between the Gang of Four and the less radical forces that eventually toppled the Gang. Australia, Canada, and France were less politically sensitive than the US, a reflection of domestic policy influencing foreign policy. Similarly, Brazil, a developing country, was more politically tolerable than the US for soybeans and consistent with the south-south orientation of the PRC. Shipments from the US restarted under Deng in 1978.

Deng followed a more pragmatic domestic and foreign policy, and he used the opportunity to influence other states with trade in a pragmatic manner. The HRS produced more grain that enabled it to be used in trade and potentially as influence. The export-oriented economy told the world that the PRC was open for business and that economic development, not revolutionary fervor, was to be the way forward. This removed the political threat that existed under Mao and allowed the $2^{\text {nd }}$ Ring to become a major importer of PRC soybeans and maize. South Korea, which would become a major trading partner, initially received grain imports via Hong Kong, a surreptitious transaction that would delight the South Koreans as it would be behind the back of the North.

We have seen how Deng punished the US, France, and the Netherlands for arms sales to Taiwan. The US suffered less than the others; it was a superpower militarily, economically, and agriculturally. Deng also demonstrated good intentions by renewing 
grain trade relations with the Soviets. That included an element of influence that eventually led to the re-establishment of diplomatic relations, a necessity for Deng's independent foreign policy. Trade re-started with Vietnam late in Deng's tenure. New grain customers included Iran and Libya. The PRC was getting more and more dependent on foreign oil, so being a supplier of grains to these countries was a method of strengthening the trade relationship.

The expansion of grain exports began in 1995 and continued under Jiang. The HRS output improvement increased the opportunities to use grain sales for influence. Jiang's PGRS spurred output after several less-than-acceptable harvests, and by 1997 the PRC was again a net grain exporter, due in large part to a substantial decrease in wheat imports. Despite exports to the Soviets and MENA, the real strength in exports was to the $2^{\text {nd }}$ Ring. During Jiang's term of office, 1994-2003, of the PRC's exports, approximately $100 \%$ of maize, $61 \%$ of rice, and $85 \%$ of soybean went to $2^{\text {nd }}$ Ring countries. More than 99\% of rice imports came from SE Asia (FAO Statistics Data Base).

Second Ring countries were the natural trading partner of the PRC. Yet, there were political issues developing with the Philippines and other SE Asian states over the SCS, and they continue today. Under Jiang's watch, this did not affect PRC food security or affect the grain trade in the area. However, it cannot be said that it helped PRC relations with SE Asia. Rather, it served to prod ASEAN states bordering the SCS into searching for outside powers to remain involved in the area. 
The PRC was an active participant in the "rice crisis" of 2008, following the rest of the rice producing countries in banning exports in fear of inadequate supplies and domestic inflationary pressures. ${ }^{239}$ This prompted Hu's going out strategy for agriculture that started in the land grab direction and ended up with a less intrusive, and less controversial solution that benefitted both the supplying country and the PRC. Not all foreign efforts turned out to raise total worldwide production. PRC attempts in the Philippines created a backlash against the PRC, no doubt a Philippine reaction to the SCS crisis. An alternative solution, as happened in South America, was not pursued.

\section{The Future}

For a country with $20 \%$ of the world's population but only $7 \%$ of its arable land, the challenge of food security for the PRC will continue, as the world population is expected to rise $50 \%$ by 2050 . Activities that increase world output are welcomed by all.

In this section we address three interrelated issues concerning the present and developing challenges facing the world and its food security. Second we will look at how these problems will affect the combination of PRC foreign policy and its trade, primarily agricultural trade. Finally, we will look at issues that may be the solution, or at least mitigate food security issues.

\footnotetext{
${ }^{239}$ This was not an issue in the PRC. The output of the four grains in question was the highest of all times. Rice output increase by five million tons from 2007, but was 5\% below the highest level of rice output at the time, in 1997.
} 


\section{Food Security Challenges}

Of the challenges the world faces, three prominent issues will have an effect on food security. These issues will impact various countries and regions differently but will be felt worldwide. First, is the issue of climate change, the warming of the planet, an issue that affects worldwide agriculture. Climate change, caused by the accumulation of greenhouse gases in the atmosphere, of which the burning of fossil fuels for power is considered the major source, presents a number of problems that will affect agriculture around the world. Cropping patterns will have to adjust to a warming climate, the growing seasons will change as will precipitation patterns. Extreme weather events are expected to increase in frequency and intensity. On the other hand, the use of grain and other plant types can be used to replace the use of fossil fuels for some types of energy. This presents an interesting tradeoff; is climate change to be reduced or delayed by using arable land to grow raw materials for "green" fuels or should that land be used to grow crops for human consumption in a world where the total population is expected to grow by $50 \%$ in a little more than 35 years? This is a decision that individual countries will probably make given their commitments to reducing fossil fuel emissions, the state of their food security, and the condition of their economy. The decision will be heavily influenced by the market prices of crops, energy, and the alternative uses of land. President Hu's policy of balanced growth has made the environmental considerations part of investment decision making process in the PRC. Subsequently, Xi's recognition that food security must be an integral part of PRC non-traditional security concerns, acknowledges that if not adequately addressed it could threaten the legitimacy of the CCP, if not its existence. 
Second, just as the PRC has lost arable land to economic development, the same can be expected in other developing countries. South Asia (India, Pakistan, and Bangladesh) accounts for approximately $23 \%$ of the world population and in total only about $34 \%$ in urbanized (CIA FactBook). Increasing urbanization in South Asia and Africa will reduce arable land as it did in the PRC, though the extent remains uncertain. Economic development will probably result in less food output.

Third, as mentioned above, there is the continued growth in population. The PRC used the one-child policy to slow the rate of population growth. Most likely, this will not be possible in a democracy such as India, soon to be the most populous country. However, increased urbanization, according to Demographic Transition Theory, should reduce the birth rate and the rate of population growth over the long term.

\section{$\underline{\text { PRC Foreign Policy and Meeting Food Security Challenges }}$}

With the challenges mentioned above, how does PRC foreign policy interact with its food security? The PRC has committed to being a continuing importer of grain to meet its food security needs. Other countries have done the same, but not with the scale of demand that the PRC has. In 2012 and 2013 it was a net importer of all four of the grains we are discussing. The PRC has decreased its dependency on the US for soybeans by diversifying its sources, politically and geographically, but is increasing its total dependency by planting and producing substantially less than demand. It has decreased its dependence on the West for wheat by increasing yields. Its dependence on countries near and far for maize has been reduced by planting and producing more. It has increased its dependency on rice in the ASEAN countries. Most ASEAN countries are wary of PRC 
power and intentions. Yet, it is some of these countries that may become the most important grain suppliers to the PRC as Vietnam and Thailand, are major rice producers. The use of soft power may be a method that maintains sources of imports and increases the availability of grains, especially in SE Asia.

While grain imports grow and exports decrease, this limits, but does not mean that the PRC's grain trade cannot be used to reward, punish, or influence other countries. Rewards and influence still continue via imports to a greater extent than before and potentially have greater influence potential as they contribute to the national income of the exporting country. The only limiting aspect is the number of countries than can provide the quantities the PRC will need. In 2013, the PRC imported 20.7\% of the world's soybean production and that accounted for $59.7 \%$ of the world's exports. Outside of the top four soybean producing countries, PRC imports exceeded the production of all other countries by 34\% (FAO Data Base). For rice, the PRC both imports and exports providing the opportunity for its trade to reward, punish, and influence other states. Most imports and exports are with $2^{\text {nd }}$ Ring states but in 2012-13 the PRC imported nearly one million tons of rice from Pakistan. It was an attempt to influence the Pakistanis, a long-time US ally, as US relations with India, Pakistan's enemy, improved.

The PRC has used soft power most dramatically by entering into business arrangements with Brazil and Argentina to purchase and process soybeans. This was a backup plan for land acquisition in both countries that ended up as a commercial endeavor -- thus avoiding land grabs, a political and sovereignty issue, and a large initial outlay of capital, an economic benefit. The success of this project serves as a demonstration to other states with unused arable land that PRC companies can provide the demand 
that local farmers can meet. One could say that this is an example of soft power via commerce.

The PRC will run into criticism if it engages in further land grabbing in states where property rights are ill defined. In states with defined property rights, it should be allowed to invest, even if the crops are normally shipped back to the PRC. SOEs investments would be less welcomed than purely private investment as SOE "investments [can be] subordinated to the strategic reasons of a foreign state," as Netto suggests.

There are other areas closer to home, in SE Asia, where soft power can also increase agricultural output. PRC rice production per ha. ranges between approximately 50\% and 100\% greater than its ASEAN neighbors (Yu \& Fan: 2009, 5). Sharing the PRC's expertise in achieving higher yields through better farming practices and better seeds holds the possibility of a dramatic improvement of output in the $2^{\text {nd }}$ Ring. Such assistance would increase the total rice supply, as well as reducing Philippine and Indonesian imports. It would be beneficial to the PRC as its import of rice now comes exclusively from SE Asia and rice imports are growing.

The use of soft power in SE Asia by the PRC is not new. It is questionable whether its potential can be maximized or if the PRC's military activities, an application of "hard power," in the SCS are offsetting the benefits of successful use of soft power. The PRC has yet to define its controversial "9-dash line" in the SCS other than to say "it" is sovereign PRC territory based on historical claims that pre-date the claims of any other littoral state. This not only concerns those states with claims but also any state whose ships, commercial or military, transit the SCS under freedom of navigation laws. 
As the population grows and the arable land diminishes, the question must be asked as to whether scarce resources are allocated to maximize grain output. Riccardo demonstrated comparative advantage using numbers of people to do a specific task. Today, the world has come to allocate resources based on price and the income that a resource will generate. The question is whether this method of resource allocation, sufficient to keep the necessary amounts of arable land and water in an area with a suitable climate that is free of pollution, can provide food security for all at reasonable prices.

PRC soybean imports from Brazil and Argentina provide an example of how resource allocations might apply to where crops are grown. The decision to rely on soybean imports was an economic / political decision. A subsequent explanation -- not a rationale for the change, but a post-change analysis -- comes from Liu et al. They suggest that it is the intensity of water usage for the soybeans that makes it the crop of import preference as opposed to the other three we are discussing. It takes 3203 cubic meters of water per ton of output for soybeans versus 844 for wheat, 975 for maize, and 1190 for rice (Liu et al: 2007, 80-90). Liu et al maintain that this was not a deliberate water-saving decision to arbitrage water usage among various crops. It does demonstrate that when water availability is an issue, soybeans should not be grown when rice, wheat, and maize can be.

Similarly, a PRC company's acquisition of Smithfield Foods, a meat concern in the US, offers the PRC a source of pork products that can be exported to the PRC. As mentioned in Chapter VI, this is an opportunity to transfer the raising and feeding of pigs to an area where arable land and grain are not issues. 


\section{$\underline{\text { Multi-Lateral Action or Every State for Itself }}$}

Should a world that is concerned about the ability of the world resources to feed ever- growing populations, would it be possible to allocate crops to specific areas and assure they would be distributed as planned and needed? One answer to this question is yes. In places where there is a choice of what to plant and a transportation system that gets the crop to market efficiently, farmers will generally plant the crops that provide the greatest yield. In the case of the PRC, the answer to that question is no. The PRC does not allocate grain production by natural resource availability. ${ }^{240}$ The PGRS requires provinces to produce the grain it needs within each province, a situation that ignores comparative advantage. Grain output would increase if comparative advantage was used and if the transportation systems could move the grain to where it was needed when it was needed. If it only works in limited areas, it cannot be expected to work worldwide.

ASEAN+3 established a regional rice reserve to minimize the impact of crop failures. However, the cost of maintaining a reserve in rice was too expensive and rather than storing rice, a fund was established that could purchase rice in times of such an event. This does not increase the rice available but serves only to have the funds available to purchase rice when there is insufficient supply -- if there are sufficient funds, others will suffer, not us. The US maintained large amounts of grain in storage that could be used in the event of shortages in the world (though, it was not established for that reason). It, too, was suspended due to costs.

\footnotetext{
${ }^{240}$ Nature does allocate by climate and soil conditions as evidenced by the grains primarily consumed in various climates. Traditionally, wheat is prevalent in drier climates, North China, and rice in wetter climates, South China.
} 
Allocating crop production around the world to maximize output based on comparative advantage, including natural resource optimization, would require an extreme degree of global governance and a loss of sovereignty. The possibility of the countries of the world attempting such a feat is incomprehensible at this time. At the country level, PRC does not allocate crop production by comparative advantage domestically. At the regional level, ASEAN+3 will not maintain a reserve of rice. No aspect of global governance is in place to compel or to persuade participation in such a scheme. There are international food regimes; the FAO monitors crop production in an attempt to provide early warnings in the event of production shortfalls. The World Food Program focuses on capacity building and relief and views the PRC as a major success in reducing hunger. Such programs focus on improving local conditions so that local communities can be self-reliant or self-sufficient. The WTO establishes trading norms, including foodstuffs, and a dispute settlement mechanism. World food security remains an issue addressed by individual countries. Worldwide improvements, focused on maximizing world output and resource optimization, will only come about when individual countries do so. Once that is successful, it can be expanded regionally and further if necessary. Most likely, it will take an extreme disaster for sufficient impetus to occur.

The practical ways to assure food security until other solutions are found remains: 1) Trade surpluses for shortages; 2) subsidize basic foodstuffs when prices are high; 3) maintain arable land; 4) utilize science to improve crop yields; 5) maintain reserve stocks; 6) improve physical distribution capabilities; and, 7) take advantage of one country's unused agricultural assets so that the trading partner can pursue other agricultural opportunities. Otherwise, a state that does not have an ongoing positive balance of trade 
will need to be self-reliant in grain or receive aid to cover their needs. A state can have an ongoing positive balance of trade, as the PRC does, then self-sufficiency in grain is not an issue... at least for now. 


\section{APPENDICES}

\section{Appendix I}

\section{Data Sources and Issues}

Compiling trade statistics on a bilateral basis for maize, rice, soybeans, and wheat produces only an estimate of what actually was traded by the PRC, both in terms of quantity and trade partners. There are several reasons why obtaining this information is difficult. First, the statistics from the PRC are incomplete. Following a long civil war and a world war, one can easily imagine that it would take some time before statistics for production, let alone trade, could be considered reliable. This situation was aggravated by domestic political turmoil, principally during the GLF and the famine it caused. During the initial stages of the GPCR, 1966-69, and at its conclusion, following Mao's death and the rise and fall of the Gang of Four, statistics were unavailable or unreliable. Second, the use of transshipments obscured the source or destination of shipments. In the case of North Korea, the PRC did exactly this. The extent to which other similar trades took place is unknown. The PRC has frequently shipped grain to Hong Kong and Singapore in excess of what could possibly be consumed locally. In the case of Hong Kong, its trade statistics do not indicate an ultimate destination, other than returns to the PRC and transshipments to Macao. A third issue is that states may produce agricultural statistics, including trade, on a calendar year basis or a crop year basis. When they were presented in both ways, the calendar base was used, if presented in only one way, it is assumed to be on a calendar basis. Third, cross-checking shipments by a supplier to a destination to verify both parties are claiming the same volumes does not always work as the comparisons are on an FOB basis for shippers and a CIF basis for receivers. That carries with it an 
error unless one has access to bills of lading. Also, shipments in transit at the close of an accounting period will be shown as a shipment by the shipper and omitted by the receiver as the shipment is yet to be received.

For purposes of this dissertation, the first objective is to determine the total amount of imports and exports for the four agriculture products being examined. Export quantities for rice and soybeans were obtained from the Ministry of Foreign Economic Relations and Trade (MOFERT) as published by the USDA (Colby: 1992, 282). They encompassed the years 1950-1989. Exports of wheat and maize were sourced from the USDA for the years 1950-1969 (Kirby: 1992, 33). Kirby also had export statistics for rice and soybeans that were quite different from Colby's but differences became smaller over time. For imports, Colby provides statistics for wheat only, the principal grain import by the PRC (Colby: 1992, 285). Kirby provides import quantities for all four of the products under study using FAO yearbooks for his information. Beginning for the year 1961, the FAO began publishing online the total imports and exports by commodity. For purposes of this study, annual export totals for rice and soybeans provided by Colby were used for the period 1950-1960. Kirby's figures were used for wheat and maize for the same period. The annual import totals for wheat came from Colby's statistics and rice and maize from Kirby. From 1961 on, the FAO reported numbers were used. Both Kirby's and Colby's figures converged with those published by the FAO and in some cases were identical. The FAO updates its records as needed. The FAO statistics used for this study are those available in December 2015. 
The most important issue is determining the bilateral trade in these products between the PRC and its trading partners. For the period 1950-1969, Kirby used the PRC's trade partners to determine what was exported by what the other countries imported from or exported to the PRC, an issue identified above. The method that Kirby used could only include those countries that published trade information; that eliminated intra-East Bloc trade as those countries did not publish trade information. However, there are references of specific shipments to specific countries that appear in the literature (i.e., Eckstein, Chen, and Chao) and in newspapers that add to the quantities reported by Kirby. These are extremely important for the period of the GLF when significant quantities of grain were shipped to the USSR during the famine, statistics unavailable to Kirby and his method of data collection.

The period from 1970 through 1986 comes from a variety of sources including USDA - Economic Research Service, National Bureau of Economic Research (NBER), China Customs Statistics, and United Nations World Trade Annual. None of these sources was sufficiently complete (including availability), nor were they necessarily presented the same way. For example, the NBER trade statistics were presented at various degrees of milling that necessitated conversion to a common unit of measure. The USDA information was for major import and export countries. The NBER data, in some cases, had large export or import volumes for the PRC that did not identify the source or origin. China Customs Statistics were not uniformly available nor was the UN World Trade Annual, which was extremely difficult to work with. As a general rule, shipments to major customers and shipments from major suppliers were relatively close from different 
sources. They could be very different for customers or suppliers where trade was inconsistent. Sometimes the quantities were similar but for two years but one data source, for example, had the shipments in one year and the other in the next year. In cases where a trading partner was not in the statistics of one source but was in another, the source reporting trade was used. From 1987 to the present the primary source of trade data, by source for imports and by origin for imports, comes from the FAOSTAT - Detailed Trade Matrix.

The question must be answered as to whether the sum of the bilateral trade between the PRC and its partners matches with the total imports and exports, by product, on an annual basis. The closer those numbers are increases the level of confidence that bilateral trade has been accounted for. As seen in Table A1.1, as time passed, bilateral trade as a percentage of total import or export, as would be expected.

The difficulty in compiling statistics for the PRC, regardless of the source, presented issues in the early years for the PRC. Following the successful CCP revolution, domestic data collection and reporting mechanisms needed to be established and could not happen overnight. The situation is further aggravated by the nearly continuous political campaigns during Mao's time that led to statistics not being collected or not being published or were falsified. It is safe to say that reliable statistics did not become available until Deng had been in office for several years. However, that did not solve the problem completely as Hong Kong and Singapore were used as transshipment points to obscure the destination or source of exports and imports. 


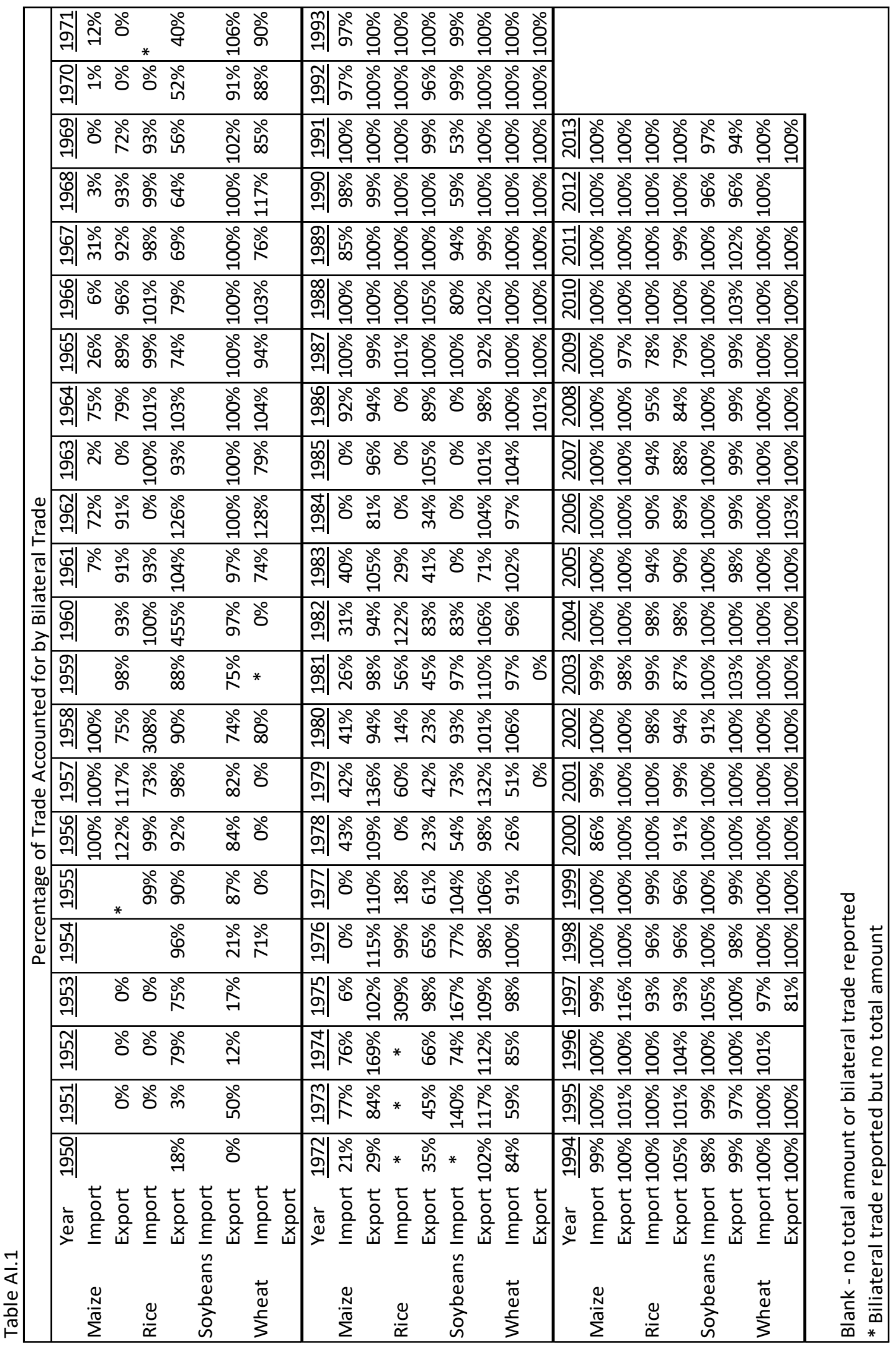


The same problem exists with grain production statistics, especially during Mao's rule. In fact, there seems to have been a cottage industry seeking to determine the actual production of major grain crops throughout most 1950s. I have opted to use Chen's statistics for 1952-57 (Chen: 1967, 338-9), Piazza for 1950-1 and 1958-60 (Piazza: 1986, 183), and FAOSTAT for 1961 on. 


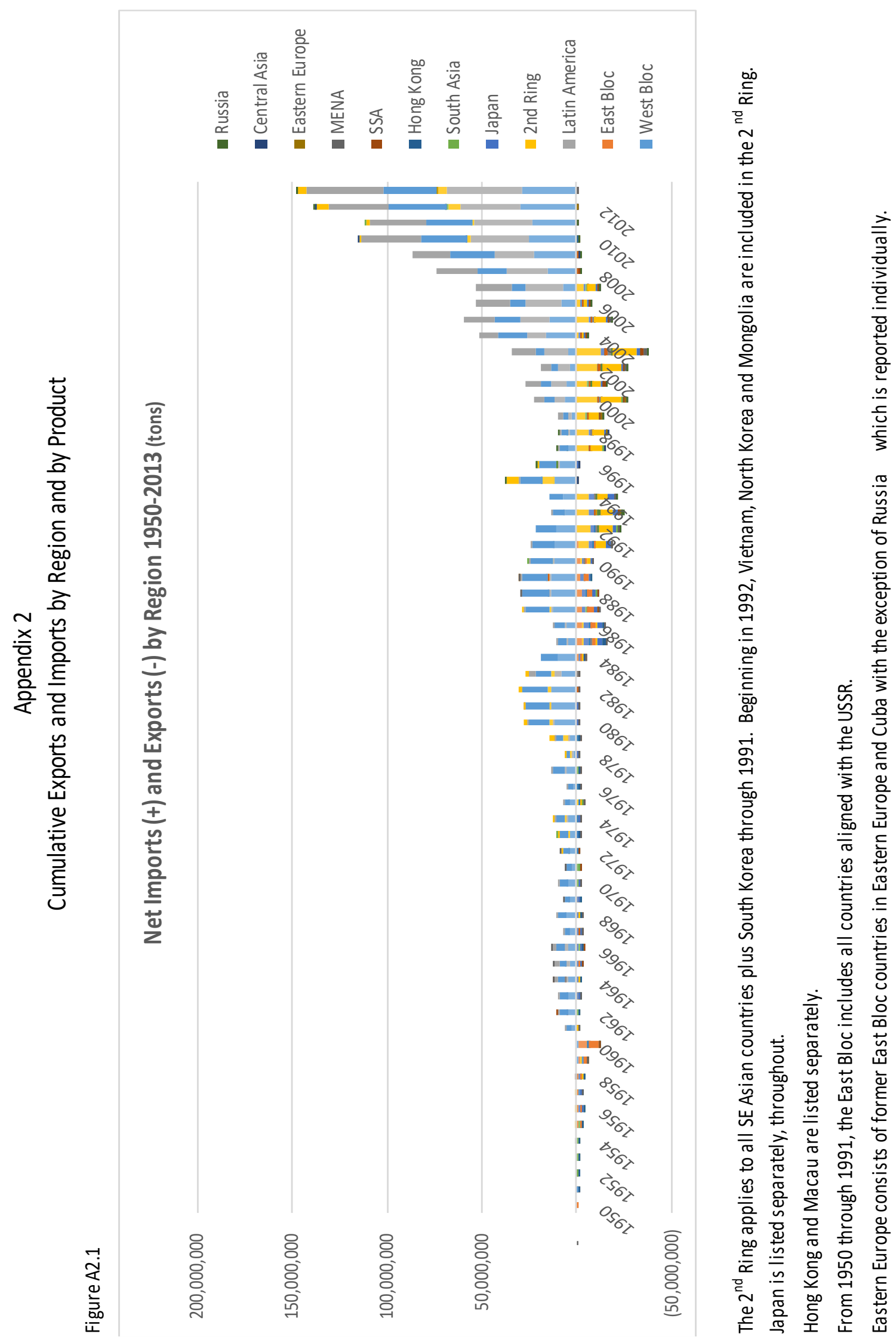




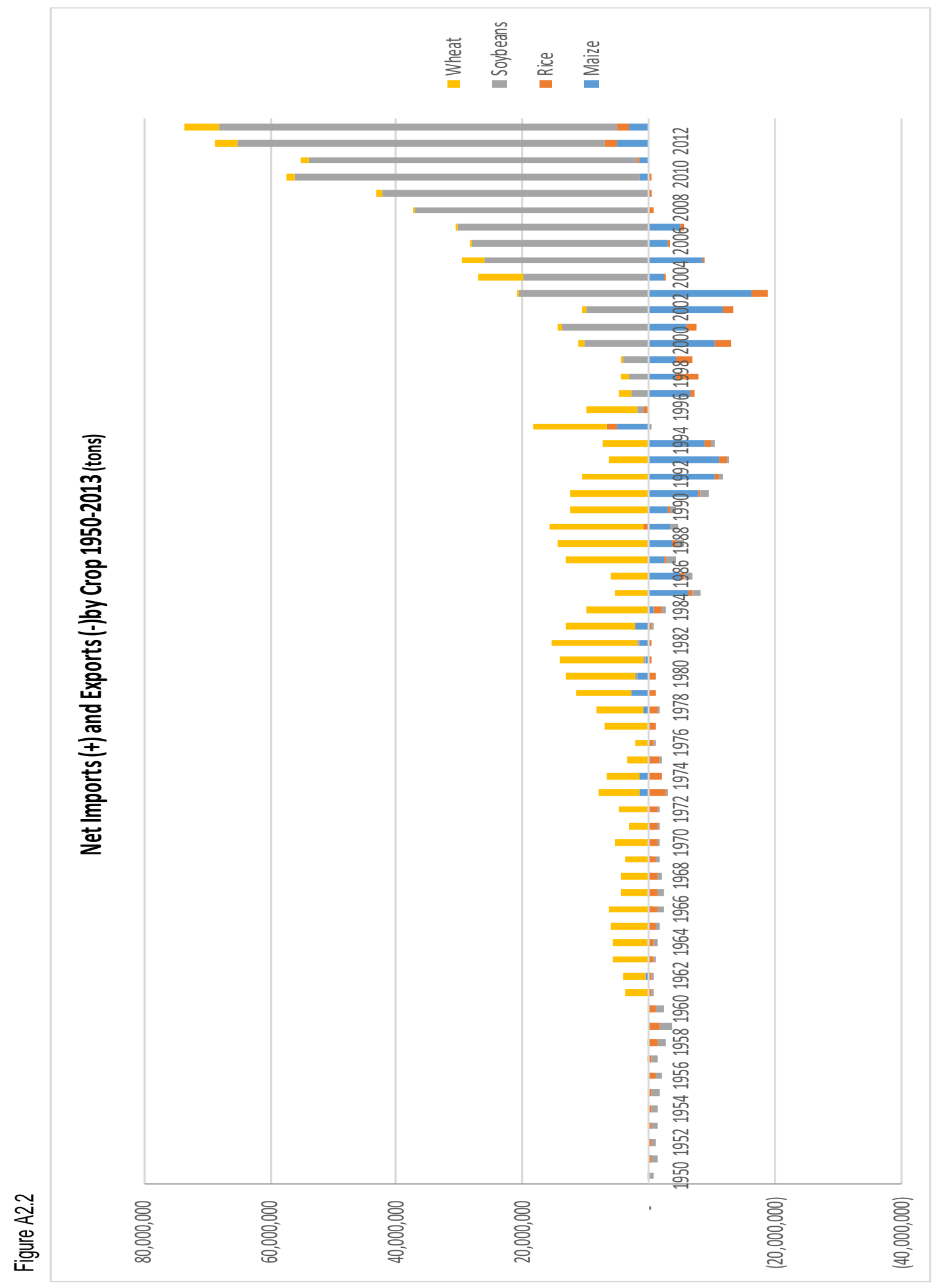




\section{BIBLIOGRAPHY}

Arase, D., "Non-Traditional Security in China-ASEAN Cooperation: The Institutionalization of Regional Security Cooperation and the Evolution of East Asian Regionalism", Asian Survey, Vol. 50, No. 4 (July/August 2010), pp. 808-833.

Ash, R.F., "The Evolution of Agricultural Policy", The China Quarterly, No. 116 (Dec., 1988), pp. 529-555.

Ash, R., "The Grain Issue in China: Domestic and International Perspectives" China Review, (1997), pp. 135-160.

Ash, R., 2007 “China's Legal System: New Developments, New Challenges”, The China Quarterly, No. 191, (Sep., 2007), pp. 796-821.

Ash, R., \& Edmonds, R., "China's Land Resources, Environment and Agricultural Production,'The China Quarterly, No. 156, Special Issue: China's Environment (Dec., 1998), pp. 836-87.

Ba, A., "Reflections on Analytic Eclecticism and the Field," Qualitative \& Multi-Method Research, Fall 2010, 14-17.

Bao C., "CGG Is Setting Up a Soybean Base in Brazil," China Daily, 11/24/2011.

Becker, J., Hungry Ghosts: China’s Secret Famine, John Murray, London, 1999.

Bergsten, C.F., Freeman, C., Lardy, N., Mitchell, D., China's Rise, Peterson Institute for International Economics and Center for Strategic and International Studies, Washington D.C., USA, 2008

Blanchard and Guo, "Introduction" in 'Harmonious World' and China's New Foreign Policy, Guo S. and Blanchard, J-M F. (eds), Lexington Books, Lanham, Maryland, USA, 2010.

Blank, S., "Revising the Border: China's Inroads into Tajikistan", China Brief, Volume: 11 Issue: 14 July 29, 2011.

Borras Jr., S., Hall, R., Scoones, I., White, B., \& Wolford, W., "Towards a Better Understanding of Global Land Grabbing: An Editorial Introduction,, The Journal of Peasant Studies, 38:2, 209-216, 2011.

Brautrigam, D. and Tang, X., "China's Engagement in African Agriculture: 'Down to the Countryside"" The China Quarterly, 2009, pp. 696-706. 
Brautigam, D., The Dragon's Gift, Oxford University Press, 2011.

Brautigam, D., "Chinese Development Aid in Africa What, where, why, and how much?" in Rising China: Global Challenges and Opportunities, (eds) Golley, J., Song, L., ANU Press, 2011.

Bräutigam, D. \& Zhang, H., “Green Dreams: Myth and Reality in China's Agricultural Investment in Africa”, Third World Quarterly, 2013, 34:9, 1676-1696.

Buzan, B., "From International System to International Society: Structural Realism and Regime Teory Meet the English School”, International Organization, Vol. 47, No. 3 , 1993, pp 327-352.

Burns, J., "Australia assured by Peking” The Christian Science Monitor (1908-Current file); Jul 12, 1971; pg. 1, ProQuest Historical Newspapers.

Buzan, B., Waever, O., de Wilde, J., Security: A New Framework for Analysis, Lynne Rienner Publishers, 1998.

Bennett, A., \& George, A., "Process Tracing in Case Study Research", MacAurther Foundation Workshop on Case Study Methods, October 17-19, 1997, uers.polisci.wisc.edu/kritzer/teachings/ps816/ProcessTracing.htm Accessed 4/17/2012.

Breslin, T.A., Beyond Pain, Praeger Publishers, Westport, CT, USA, 2002.

Cai, P., "Delicate balancing act for the foreign investment board", The Sydney Morning Herald, (Australia) - October 26, 2013, Business, p.6.

CIA Intelligence Report, 4/4/68, released 5/2007, "Ten Years of Chinese Communist Foreign Policy: South and Southeast Asia".

CIA “The World FactBook", https://www.cia.gov/library/publications/the-worldfactbook/

Chan, H.K., "The 'Chinese Barbarian Officials' in the Foreign Tributary Missions to China during the Ming Dynasty" Journal of the American Oriental Society, Vol. 88, No. 3 (Jul. - Sep., 1968), pp. 411-418.

Chan, H.L., "The Chien-wen, Yung'Lo, and Hsuan-te reigns, 1399-1435", Mote and Twitchett (eds) in Cambridge History of China, Vol. 7, The Ming Dynasty 1368-1644, Cambridge University Press, 2004.

Chan, K.W., "The Chinese Hukou System at 50", Eurasian Geography and Economics, 2009, 50, No.2, pp. 197-221. 
Chen, Z., "Nationalism, Internationalism and Chinese Foreign Policy", Journal of Contemporary China, (2005), 14(42), February, 35-53.

China-Australia Free Trade Agreement, "Fact Sheet: Investment”, 1/5/2016.

Clarke, T., "WA opens the Ord to China", Sydney Morning Herald, 11/21/2012, http://www.smh.com.au/business/waopenstheordtochina2012112029o1k.html

Chang, K.C., "Introduction" in Food in Chinese Culture, K.C. Chang, ed., Yale University Press, 1977.American Geographers, Vol. 71, No. 2 (Jun., 1981), pp.202-21.

Chang, S., Zhao, L., Timilsina, R., Zhang, X., "Development of Biofuels in China Technologies, Economics and Policies" WPS6243, The World Bank Development Research Group Environment and Energy Team, October 2012

Chao, K., Agricultural Production in Communist China 1949-1965, The University of Wisconsin Press, Madison, WI, 1970.

Chen, N.R., Chinese Economic Statistics, Aldine Publishing Co., Chicago, 1967.

Chen, L.Y., \& Buckwell, A., Chinese Grain Economy and Policy, : C.A.B. International, Wallingford, Oxon, UK, 1991.

Chen, X., "Review of China's Agricultural and Rural Development: Policy Changes and Current Issues", China Agricultural Economic Review, Vol. 1: 2, 2009, pp. 121 - 135.

Chen, Y.X., "Cold War Competition and Food Production in China, 1957-1962", Agricultural History, Vol. 83, No. 1 (Winter, 2009), pp. 51-78.

Cheng, T. and Selden, M., "The Origins and Social Consequences of China's Hukou System”, The China Quarterly, No. 139 (Sep., 1994), pp. 644-668.

The China Quarterly, No. 13, “Quarterly Chronicle and Documentation” pp. 258-262.

The China Quarterly, No. 59, "Quarterly Chronicle and Documentation" pp. 625-661.

The China Quarterly, No. 26, "Quarterly Chronicle and Documentation", pp. 206-224. China Situation and Outlook Report, USDA, Economic Research Service, July, 1986, p.6.

Cho Y.N., \& Jeong, J.H., "China's Soft Power: Discussions, Resources, and Prospects", Asian Survey, Vol. 48, No. 3 (May/June 2008), pp. 453-472.

Choo, J., "Mirroring North Korea's Growing Economic Dependence on China: Political Ramifications", Asian Survey, Vol. 48, No. 2, 2008, pp. 343-372. 
Choo, J., "China's Relations with Latin America: Issues, Policy, Strategies, and Implications", Journal of International and Area Studies, Vol. 16, No. 2, 2009, pp. 71-90.

Clark, D.N., "Sino-Korean tributary relations under the Ming", Mote and Twitchett (eds) in Cambridge History of China, Vol. 8, The Ming Dynasty 1368-1644, Cambridge University Press, 1998.

Cheung, T..M., “The Influence of the Gun: China's Central Military Commission and Its Relationship with the Military, Party, and State Decision-Making Systems" in The Making of Chinese Foreign and Security Policy in the Reform Era, D.M. Lampton (ed), Stanford University Press, 2001.

Chinn, D.L., "Basic Commodity Distribution in the People's Republic of China", The China Quarterly, No. 84 (Dec., 1980), pp. 744-754.

Chu, K., "Peasants More than Just in the Red", South China Morning Post, 7/4/1993, p. 1.

Chung, J.H., "South Korea-China Economic Relations: The Current Situation and Its Implications", Asian Survey, Vol. 28, No. 10 (Oct., 1988), pp. 1031-1048.

Collier, D., "Understanding Process Tracing", Political Science and Politics, 44, No. 4, 2011, pp 823-830.

Congressional Research Service, "China's Foreign Policy and 'Soft Power'in South America, Asia, and Africa”, April 2008.

Cooley, J.K., "Peking exploits opening: How Red China's political forays in North Africa have Multiplied", The Christian Science Monitor(1908-Current file); Apr 9, 1970;

Craig,S., "Chinese Perceptions of Traditional and Nontraditional Security Threats", Army War College, Strategic Studies Institute, 2007, Carlisle, PA, 17013-5244

Crook, F.W., Langley, S.,Tuan, F., “An Analysis of PRC Government Involvement in Domestic and Foreign Trade of Wheat, Rice, Corn and Soybean Products," "China's Role in World Food Markets: A Workshop," Proceedings of the fifth symposium of the Western Coordinating Committee "Assessing the Chinese Agricultural Market," February 8-9, 1999, in San Diego, CA.

Cui, Z., "Introduction to Tang Tsou's 'Interpreting the Revolution in China'", Modern China, Vol. 26, No. 2 (Apr., 2000), pp. 194-204.

Cui, S. and Kattumuri, R., "Cultivated Land Conversion in China and the Potential for Food Security and Sustainability”, LSE Asia Research Centre Working Paper 35, 2010 
De Bary, W.T, \& Bloom, I., Sources of Chinese Tradition Vol. One, $2^{\text {nd }}$ Edition, Columbia University Press, New York, 1999.

Dernberger, R.F., "Prices, the Exchange Rate, and Economic Efficiency in the Foreign Trade of Communist China", in Brown and Neuberger (eds), International Trade and Central Planning, University of California Press, Berkeley CA, 1968.

Dittmer, L., "The Changing Form of Dynamics of Power Politics", in The Natural of Chinese Politics, J.Unger (ed). M.E. Sharpe, Inc., Armonk, NY, 2002.

Dosch, J., "China and Southeast Asia: A New Regional Order in the Making?", in China and the Developing World, and the New Global Dynamic, (ed) Dittmer, L. and Yu, G.T., Lynne Rienner Publishers, Boulder, CO, 2010.

Duliusin, L., "The Influence of China's Domestic Policy on Its Foreign Policy", Proceedings of the Academy of Political Science, Vol. 38, No. 2, The China Challenge: American Policies in East Asia (1991), pp. 53-62.

Easterly, W., The White Man’s Burden, Penguin Press, 2007.

Eckstein, A., Communist China's Economic Growth and Foreign Trade, Council on Foreign Relations, NY, 1966.

The Economist, "A Dangerous Year”, 1/28/2012.

The Economist, "The Cauldron Boils", 9/29/2005.

Elliot, T., "Kidman's kingdom”,Sydney Morning Herald, The (Australia) - November 21, 2015 News Review Page: 28.

Elvin, M., The Pattern of the Chinese Past, Stanford University Press, Stanford, CA, 1973.

Fairbank, J.K., and Teng, S.Y.,"On The Ch'ing Tributary System", Harvard Journal of Asiatic Studies, Vol. 6, No. 2 (Jun., 1941), pp. 135-246.

Fairbank, J.K. "The Reunification of China", Cambridge History of China, Volume 14 The People's Republic Part I: The Emergence of Revolutionary China 1949-1965, , MacFarquahar \& Fairbank (eds) Cambridge University Press, Cambridge, UK, 1995.

Fang, C. \& Beghin, J., "Pretection and Comparative Advantage of Chinese Agriculture: Implications for Regional and National Specialization", in Agricultural Trade and Policy in China, Rozelle \& Sumner (eds), Ashgate Publishing, Aldershot, England, 2003. 
FAO Statistics Data Base, http://www.fao.org/faostat/en/

Feeney, W.R., "China and the Multilateral Economic Institutions" in China and the World, Kim S., (ed), Westview Press, 1984.

Feenstra, R. C., Lipsey, R.E., Deng, H., Ma, A.C., \& Mo, H., "World Trade Flows: 1962-2000," NBER Working Paper no. 11040, 2004. Accessed from UC -Davis and www.nber.org/data

Feuerwerker, A."Relating to the International Community", Proceedings of the Academy of Political Science, Vol. 31, No. 1, China's Developmental Experience, Mar., 1973, pp. $42-54$.

Feuerwerker, A." Chinese History and the Foreign Relations of Contemporary China",: Annals of the American Academy of Political and Social Science, Vol. 402, China in the World Today (Jul., 1972), pp. 1-14.

Fewsmith, J., "The Political and Social Implications of China's Accession to the WTO", The China Quarterly, No. 167, Sept., 2001, pp 573-91.

Fewsmith, J., "The Evolving Shape of Elite Politics", in The Natural of Chinese Politics, J. Unger (ed). M.E. Sharpe, Inc., Armonk, NY, 2002.

Fewsmith, J., "China in 2007: The Politics of Leadership Transition", Asian Survey, Vol. 48, No. 1, 2008, pp. 82-96.

The Filipino Express, "Preparing for El Nino: Philippines Anticipates Rice Shortage, Orders from Asian Neighbors", 11/23.1996, pp. 33).

Findley, C., (eds) "Grain Market Reform in China: Global Implications", Australian Centre for International Agricultural Research, June, 1998.

Freeman, M., "Sung" in Food in Chinese Culture, K.C. Chang, ed., Yale University Press, 1978.

Freemen, D., Holslag, J., \& Weil, S., “China's foreign farming policy: can land provide security?" BICCS Asia Paper Vol. 3 (9)

Food and Agriculture Organization of the United Nations, "The State of Food Insecurity in the World", Rome, 2010, www.fao.org/publications/sofi3

Food and Agriculture Organization of the United Nations, Statistics Database

Førland, T.E., "Economic Warfare' and 'Strategic Goods': A Conceptual Framework for Analyzing COCOM", Journal of Peace Research, Vol. 28, No. 2, 1991, pp. 191-204. 
Fuller, F., Beghin, J., DeCara, S., Fabiosa, J., Fang, C., Holger, M., “China's Accession to the World Trade Organization: What Is at Stake for Agricultural Markets?", Review of Agricultural Economics, Vol. 25, No. 2 (Autumn - Winter, 2003), pp. 399-414

FSN Forum Discussion No. 44, Summary of "Land Grab or Development Opportunity", http://km.fao.org/fileadmin/user_upload/fsn/docs/SUMMARY_land_grab_or_development_opportunity.doc

Glaser, B., and Medeiros, E., "The Changing Ecology of Foreign Policy-Making in China: The Ascension and Demise of the Theory of "Peaceful Rise", The China Quarterly, No. 190, 2007, pp. 291-310.

Global Hunger Index 2012, IFPRI, Washington D.C., 2012

Goldman, M., "China Rethinks the Soviet Model”, International Security, Vol. 5, No. 2 (Autumn, 1980), pp. 49-65.

Goldsmith, B., "Here There Be Dragons: The Shanghai Cooperation Organization", Center for Defense Information, September 2005.

Gompert, D., "Theory and Lessons of History" in Sea Power and American Interests in the Western Pacific, Gompert, D., RAND Corporation, (2013.

Green, M., “America's Quiet Victories in Asia”, The Washington Post, 2/13/2007, p. A21.

Gurtov, M., "Changing Perspectives and Policies", in China and the Developing World, and the New Global Dynamic, (ed) Dittmer, L. and Yu, G.T., Lynne Rienner Publishers, Boulder, CO, 2010.

Halverson, K., "China’s WTO Accession: Economic, Legal, and Political Implications", Boston College Int'l \& Comparative Law Review, 2004, pp. 330.

Hao and Wang, "Changing Chinese Views of Western Relations 1840-1895", Fairbank (ed) in Cambridge History of China, Vol. 10, Late Ch'ing 1800-1911, Cambridge University Press, 1995.

Harding, H., "China's Co-operative Behavior", in Robinson and Shambaugh (eds), Chinese Foreign Policy, Oxford University Press, Oxford, UK, 1997.

Harsch, J.C., "State of the Nations: The Communist Food Crisis", The Christian Science Monitor; Jan 30, 1962; ProQuest Historical Newspapers: The Christian Science Monitor (1908-2000) pg. 1. 
Hansen, J., Tuan, F., Somwaru, A., (2011),"Do China's Agricultural Policies Matter For World Commodity Markets?", China Agricultural Economic Review, Vol. 3:1, 2011, pp. $6-25$.

He Kai, "A Strategic Functional Theory of Institutions and Rethinking Asian Regionalism: When Do Institutions Matter?" Asian Survey Vol. 54, No. 6 (November/December 2014), pp. 1184-1208.

He Kai, "Institutional Balancing and International Relations Theory: Economic Interdependence and Balance of Power Strategies in Southeast Asia," European Journal of International Relations, Vol. 14(3): 489-518.

Hinton, H.C., "China as an Asian Power", in Robinson and Shambaugh (eds), $\underline{\text { Chinese }}$ Foreign Policy, Oxford University Press, Oxford, UK, 1997.

Hofman, I. \& Ho, P., "China's 'Developmental Outsourcing': A Critical Examination of Chinese global 'land grabs' Discourse,' The Journal of Peasant Studies,39:1, 1-48, 2012.

Hook, B., Yahuda, M., Wilson, D., "Quarterly Chronicle and Documentation”, The China Quarterly, No. 60 (Dec., 1974), pp. 823-853.

Hook, B., Yahuda, M., Wilson, D., "Quarterly Chronicle and Documentation”, The China Quarterly, No. 70 (Jun., 1977), pp. 446-470.

Hopf, T., "The Promise of Constructivism in International Relations Theory", International Security, Vol. 23, No. 1 (Summer, 1998), pp. 171-200.

Hopkins, R., Puchala, D., "Perspectives on the International Relations of Food", International Organization, Vol. 32, No. 3 (Summer, 1978), pp. 581-616

Horta, L., "Brazil-China Relations", RSIS Working Paper 287, S. Rajaratnam School of International Studies, Singapore, 10 March 2015.

Hsiao, G.T., The Foreign Trade of China, University of California Press, Berkeley, CA, 1977.

Huang, J., Rozelle, S., “Trade Liberalization, Rising Imports and China's Food Economy: The Case of Soybeans", Report Submitted to the American Soybean Association 2004.

Huang, J., Jun, Y., Xu, Z., Rozelle, S., Li, N., “Agricultural Trade Liberalization and Poverty in China", China Economic Review vol.18 (2007), pp. 244-265.

Huang, P.C.C., "Profit Making State Firms and China's Development Experience: 'State Capitalism' or 'Socialist Market Economy'”, Modern China, 38(6) 591-629. 
Hudson, V., Foreign Policy Analysis, Rowman and Littlefield Publishers, Lanham, MD, 2007.

Hook, B., Wilson,D., Yahuda, M., "Quarterly Chronicle and Documentation”, The China Quarterly, No. 79 (Sep., 1979), pp. 644-687.

Hopper, B.C., "Narkomindel and Comintern”, Foreign Affairs, 7/1/1941, pp 737-50.

Hsu, Robert C., Food for one Billion, Westview Press, Boulder, CO, 1982.

$\mathrm{Hu}$, S. "Central Government Must Take the Lead on Hukuo Reform”, South China Morning Post, 8/13/2013, www.scmp/comment/insight-opinion/article/1295108/central-government-must-take-lead-chinas-hukuo-reform/

Huang, J., Otsuka, K., Rozelle, S., “Agriculture in China's Development”, Brandt and Rawski (eds) China's Great Transformation, Cambridge University Press, 2008.

Huang,J., Wang, X., \& Qui,H., "Small-Scale Farmers in China in the Face of Moderrnization and Globalization", International Institute for Environment and Development, London, 2012.

Huang, R., "'Lung-Ch'ing and Wan-Li Reigns", Mote and Twitchett (eds) in Cambridge History of China, Vol. 7, The Ming Dynasty 1368-1644, Cambridge University Press, 2004.

Hughes, N.C., "Smashing the Iron Rice Bowl", Foreign Affairs, Vol. 77, No. 4 (Jul. Aug., 1998), pp. 67-77.

Jackson, P., The Conduct of Inquiry in International Relations, Routledge, NY, 2010.

Johnson, D.G., "China's Grain Trade: Some Policy Considerations", ”, in Agricultural Trade and Policy in China, Rozelle \& Sumner (eds), Ashgate Publishing, Aldershot, England, 2003.

Johnson-Hanks, J., "Demographic Transitions and Modernity" Annual Review of Anthropology, Vol. 37 (2008), pp. 301-315.

Wu, K, and Watts, J. "Noble Group 's Bonds Plunge as Creditors Turn Pessimistic", Wall Street Journal (Online) [New York, N.Y] 08 Jan 2016.

Kam W. C. and Buckingham, W., "Is China Abolishing the Hukou System?" The China Quarterly, No. 195 (Sep., 2008), pp. 582-606.

Kang, D.C., East Asia Before the West, Columbia University Press, New York, 2010. 
Kang, X. and Han, H. "Graduated Controls: The State-Society Relationship in Contemporary China”, Modern China, Vol. 34, No. 1 (Jan., 2008), pp. 36-55.

Karns, P. \& Mingst, K., International Organizations, Lynn Rienner Publishers, Boulder, CO. 2010.

Kerr, D. "Has China abandoned self-reliance?"99933, Review of International Political Economy, 2007, 14:1, 77-104.

Keohane, R., and Nye, J., Power and Independence, Longman, NY, $2^{\text {nd }}$ ed., 1989.

Keuh, Y.Y., "Mao and Agriculture in China's Industrialization: Three Antitheses in a 50Year Perspective" The China Quarterly, No. 187 (Sep., 2006), pp. 700-723.

Keulertz, M., and Woertz, E., "States as Actors in International AgroInvestments" The Graduate Institute, Geneva 6,1, 2015, http://poldev.revues.orgbcrfj.revues.org/2023

Kim, S.S., China and the World, (3 ${ }^{\text {rd }}$ ed.), Westview Press, Inc., Boulder Co., USA, 1994.

Kim, S.S., "International Organizations in Chinese Foreign Policy", Annals of the American Academy of Political and Social Science, Vol. 519, China's Foreign Relations (Jan., 1992), pp. 140-157.

Kim, S.S. "China's International Organization Behavior" in Chinese Foreign Policy: Theory and Practice. Robinson, T.W. \& Shambaugh, D., (eds), Oxford University Press, New York, 1997 in Robinson and Shambaugh, pp. 603-633.

Kim, S.S., "China and Globalization: Confronting Myriad Challenges and Opportunities", Asian Perspective, Vol. 33, No. 3 (2009), pp. 41-80

Kirby, R.H., "Agricultural Trade of the People's Republic of China 1935 69", Foreign Agricultural, Economic Report, Economic Research Service, Washington, DC, Aug., 1972.

Kissinger, H., On China, Penguin Books, N.Y., 2012.

Klein, D.W., "Japan and Europe in Chinese Foreign Relations", in Robinson and Shambaugh (eds), Chinese Foreign Policy, Oxford University Press, Oxford, UK, 1997.

Kramer, T., Woods, K., "Financing Dispossession - China's Opium Substitution Programme in Northern Burma", Transnational Institute, Amsterdam, 2012.

Kridtalina, G., \& Pop, V., "EU Official Says Neglect Pushed China to Set Up Development Bank; U.S., Europe haven't been active enough in reforming World Bank, IMF," Wall Street Journal (Online), New York, N.Y 21 Mar 2015. 
Kristoff, N., "It's China Against the World with a Great Deal at Stake", New York Times, 11/29/1992, p 4.

Kuhn, P.A., "The Taiping Rebellion", in J.K. Fairbank (ed) The Cambridge History of China, Volume 10, Part One, Cambridge University Press, 1995.

Lamont, L., Manning, P., "Shut the gate: why cash-strapped landowners are selling the farm - Agribusiness - Who Owns NSW?", Sydney Morning Herald, The (Australia) - August 1, 2011, Business, p4.

Lardy, N., Agriculture in China's Modern Economic Development, Cambridge University Press, 1983.

Lardy, N., "Chinese Foreign Trade," The China Quarterly, No. 131, Special Issue: The Chinese Economy in the 1990s (Sep., 1992), pp. 691-720.

Lardy, N, "Economic Recovery and the $1^{\text {st }}$ Five Year Plan" MacFarquahar \& Fairbank (eds) Volume 14 The People's Republic Part I: The Emergence of Revolutionary China 1949-1965, Cambridge University Press, Cambridge, UK, 1995.

Lardy, N, "The Chinese Economy Under stress, 1958-1965" MacFarquahar \& Fairbank (eds) Volume 14 The People's Republic Part I: The Emergence of Revolutionary China 1949-1965, Cambridge University Press, Cambridge, UK, 1995.

Lawrence, R.Z., "China and the Multilateral Trading System”, Working Paper 12759, National Bureau of Economic Research, Cambridge, MA, 2006.

Lee, J., "China's Economic Leverage in Southeast Asia", The Journal of East Asian Affairs, Vol. 29, No. 1 (Spring/Summer 2015), pp. 1-21.

Lee, Seung-joon, Gourmets in the Land of Famine, Stanford University Press, 2011.

Lee, J., "China's Economic Leverage in Southeast Asia", The Journal of East Asian Affairs, Vol. 29, No. 1 (Spring/Summer 2015), pp. 1-21.

Li, Lillian M., Fighting Famine in North China, Stanford University Press, Stanford, Ca., 2007.

Li, Mingjiang, "China Debates Soft Power," Chinese Journal of International Politics, Vol. 2, 2008, 287-308.

Li, Ninghui, "China's Food Economy and the Implications for the Rest of the World", in Critical Issues in China's Growth and Development, Kwan, Y.K. and Yu, Eden S.H., (eds), Ashgate Publishing, Hampshire, England, 2005. 
Lieberthal, K. "The Great Leap Forward and the Split in the Yenan Leadership" MacFarquahar \& Fairbank (eds) Volume 14 The People's Republic Part I: The Emergence of Revolutionary China 1949-1965, Cambridge University Press, Cambridge, UK, 1995.

Lieberthal, K., Governing China, W.W. Norton, NY, 1995.

Lin, J.Y., "Collectivization and China's Agricultural Crisis in 1959-1961", Journal of Political Economy, Vol. 98, No. 6 (Dec., 1990), pp. 1228-1252.

Lin, J.Y., "The Needham Puzzle: While the Industrial Revolution Did Not Originate in China" Economic Development and Cultural Change, Vol. 3 No. 2, (Jan. 1995) pp.269292.

Lin, J.Y., Cai, F., Li, Z., "Competition, Policy Burdens, and State-Owned Enterprise Reform", The American Economic Review, Papers and Proceedings of the Hundred and Tenth Annual Meeting of the American Economic Association, May, 1998, pp. 422-427.

Lin, J.Y., Fan, Z., "The Effects of China's Rural Policies on the Sustainability" http://idrinfo.idre.ca/archive/corpdocs/118115/ Effects Agriculture in China Paper prepared for the 11th Biannual Workshop on Economy and Environment in SE Asia in Singapore on November 10-13, 1998 .

Lin, G.C.S., \& Ho, S.P.S., "The State, Land System, and Land Development Processes in Contemporary China," Annals of the Association of American Geographers, Vol. 95, No. 2 (Jun., 2005), pp. 411-436.

Lin Yutang, The Wisdom of Confucius, (Ed. and translated with notes by Lin Yutang), Random House, New York, 1966.

Liu, J., Zehnder, A., \& Yang, H., "Historical Trends in China's Virtual Water Trade," Water International, 32:1, 78-90, 2007.

Liu,Y, Fang, F., Li, Y., "Key lissues of Land use in China and Implications for Policy Making" Land Use Policy, 40 (2014) 6-12.

Lobell, S., Ripsman, N., Taliaferro, J., Neoclassical Realism, the State, and Foreign Policy, Cambridge University Press, Cambridge, UK, 2009.

Lu Ning, The Dynamics of Foreign Policy Decisionmaking in China, Second Edition, Westview Press, Boulder, Colorado, USA, 2000.

Ma, S.Y., "Recent Changes in China's Pure Trade Theory", The China Quarterly, No. 106 (Jun., 1986), pp. 291-305. 
Maidenberg, H.J., "Soviet Buying Lifts Grain Price: Soviet Buying Raises World Grain Price", New York Times, Jun 22, 1979, p. D1. ProQuest Historical Newspapers: The New York Times.

“Medium Term Philippine Development Plan”, National Economic Development Authority, Manila, 2004.

Mearscheimer, J., The Tragedy of Great Power Politics, W.W. Norton, New York, 2001 Miller, L.\& Liu, X., "The Foreign Policy Outlook of China's 'Third Generation' Elite", in The Making of Chinese Foreign and Security Policy in the Reform Era, D.M. Lampton (ed), Stanford University Press, 2001.

Moffett, M., "World News: Argentina Debates Foreign Land Buys", Wall Street Journal, Eastern edition [New York, N.Y] 01 Sep 2011: A.13.

http://search.proquest.com/news/docview/886565560/fulltext/2EFCB1C81EA840F7PQ/5 ?accountid=10901

Momargi, http://www.momagri.org/UK/focus-on-issues/The-East-Asia-Emergency-Rice$\underline{\text { Reserve-Gradually-building-a-tool-to-regulate-the-rice-market-in-East-Asia_990.html }}$

Morgenthau, H.J., Politics Among Nations, Knopf, New York, 1978.

Myers, R. and Wang Y.C., "Economic Developments, 1644-1800”, Peterson, W.J., (ed), The Cambridge History of China, Volume 9, Part One: The Ch'ing Empire to 1800, Cambridge University Press, 2002.

Nakajima, M., "Foreign Relations from the Korean War to the Bandung Line", MacFarquahar \& Fairbank (eds) Volume 14 The People's Republic Part I: The Emergence of Revolutionary China 1949-1965, Cambridge University Press, Cambridge, UK, 1995.

Nau, H.R.,"The Diplomacy of World Food: Goals, Capabilities, Issues and Arenas", International Organization, Volume 32, No 3, Summer 1978, pp775-809.

Naughton, B., "The Foreign Policy Implications of China's Economic Strategy", in Chinese Foreign Policy: Theory and Practice. Robinson, T.W. \& Shambaugh, D., (eds), Oxford University Press, New York, 1997.

New York Times, "Peking Heals Rift with the Dutch", Feb 2, 1984, p A-6; ProQuest Historical Newspapers.

New York Times, "Problem of Asia”, Jan 8, 1950, p 127; ProQuest Historical Newspapers

New York Times, Jun 3, 1952; “Chinese Reds List Trade 'Pact' Items: Disclose Details of Unofficial ...”, p 3. ProQuest Historical Newspapers. 
Norman, A.E., "Australians Warned On Wheat to Peking: Resale Warning Aired”, The Christian Science Monitor, Jun 23, 1961, p 12. ProQuest Historical Newspapers.

Nye Jr., J.S., “Soft Power”, Foreign Policy, No. 80, Autumn 1990, pp 153-71.

Paarlberg, R., "Food, Oil, and Coercive Resource Power," International Security, Vol. 3, No. 2 (Fall, 1978), pp. 3-19.

Park, A., Jin, H., Rozelle, S., Huang, J., "Market Emergence and Transition: Arbitrage, Transaction Costs, and Autarky in China's Grain Markets", American Journal of Agricultural Economics, Vol. 84, No. 1 (Feb., 2002), pp. 67-8.

Park, A., and Wang, S., “China's Poverty Statistics”, China Economic Review 12, 2001, pp. 384-398.

Pearson, M., "Accession to GATT/WTO", in The Making of Chinese Foreign and Security Policy in the Reform Era, D.M. Lampton (ed), Stanford University Press, 2001.

Perisse, J., "Energy and Protein Requirements”, WHO/FAO, Geneva: WHO, 1973 PRC State Grain Administration of Grain, "The National Food Security and Long-term Planning Framework (2008-2020), 2008.

Perkins, D., Agricultural Development in China, Aldine Publishing, Chicago, 1969.

Pettman, R., "Human Security as Global Security: Reconceptualising Strategic Studies", Cambridge Review of International Affairs, Vol. 18, No. 1, April, 2005.

Piazza, A., Food Consumption and Nutritional Status in the PRC, Westview Press, Boulder, CO., 1986.

Pimentel, D., "Biofuels versus Food Resources and the Environment", Review (Fernand Braudel Center) Vol. 33, No. 2/3, 2010, pp. 177-201.

Pittman, R., "Chinese Railway Reform and Competition: Lessons from the Experience in Other Countries" Journal of Transport Economics and Policy, Vol. 38, No. 2 (May, 2004), pp.309-332.

Pollack, J.D., "The Opening to America", Cambridge History of China, Volume 15 The People's Republic Part 2: Revolution Within the Chinese Revolution, , MacFarquahar \& Fairbank (eds) Cambridge University Press, Cambridge, UK, 1995.

Pye, L., “Jiang Zemin's Style of Rule: Go for Stability, Monopolize Power and Settle for Limited Effectiveness", in The Natural of Chinese Politics, J.Unger (ed). M.E. Sharpe, Inc., Armonk, NY, 2002. 
Rada, E.L., "Food Policy in China: Recent Efforts to Balance Supplies and Consumption Requirements" Asian Survey, Vol. 23, No. 4 (Apr., 1983), pp. 518-535.

Reuveny, R., \& Kang, H., "Bilateral Trade and Political Conflict/Cooperation: Do Goods Matter?” Journal of Peace Research, Vol. 35, No. 5 (Sep., 1998), pp. 581-602.

Ripsman N, \& Blanchard, J., "'Contextual Information and the Study of Trade and Conflict”, (eds) Sil \& Doherty in Beyond Boundaries?, SUNY Press, Albany, 2000, pp 57-85.

Robinson, T. W., "Interdependence in China's Foreign Relations", in China and the World, Kim S., (ed), Westview Press, 1984.

Rose, G., "Neoclassical Realism and Theories of Foreign Policy" World Politics 51 (October 1998), 144-72.

Rosecrance, R., The Rise of the Trading State, Basic Books, Inc., NY, 1986.

Rowe, W.T., "Social Stability and Social Change", Peterson, W.J., (ed), The Cambridge History of China, Volume 9, Part One: The Ch'ing Empire to 1800, Cambridge University Press, 2002.

Rozman, G., “China’s Quest for Great Power Identity”, Orbis, Summer 1999, pp.383402.

Russet, B. \& Oneal, J., Triangulating Peace, W.W. Norton, New York, 2001

Shinn, D.H., "Military and Security Relations: China, Africa, and the Rest of the World" in China into Africa: Trade, Aid, and Influence, Rotberg, R.T., (ed) World Peace Foundation, Brookings Institution Press. (2008).

Shih, C.Y., "National Role Conception as Foreign Policy Motivation: The Psycho-cultural Bases of Chinese Diplomacy," Political Psychology, Vol. 9, No. 4 (Dec., 1988), pp. 599-63.

Shirk, S. L., "The Delayed Institutionalization of Leadership Politics"; in The Natural of Chinese Politics, J.Unger (ed). M.E. Sharpe, Inc., Armonk, NY, 2002.

Slayton, T., "Rice Crisis Forensics: How Asian Governments Carelessly Set the World Rice Market on Fire", Working Paper Number 163, Washington, D.C.: Center for Global Development. Washington D.C., March 2009.

Spence, J., The Search for Modern China, W.W. Norton, New York, 1991.

Sil, R.. \& Katzenstein, P., Beyond Paradigms, Palgrave MacMillan, London, 2010. 
Sil, R., "The Questionable Status of Boundaries: The Need for Integration" (eds) Sil \& Doherty in Beyond Boundaries?, SUNY Press, Albany, 2000

Smil, V., "Food Production and Quality of Diet in China", Population and Development Review, Vol. 12, No. 1 (Mar., 1986), pp. 25-45

Snow, P., "China and Africa", ", in Chinese Foreign Policy: Theory and Practice. Robinson, T.W. \& Shambaugh, D., (eds), Oxford University Press, New York, 1997.

Stanway, D., "Insight: For Chinese farmers, a rare welcome in Russia's Far East", Reuters, 12/23/2013, http://www.reuters.com/article/uschinarussiaagricultureinsightidUSBRE9BL00X20131222

Sterba, J., "China Attacks U.S. on Dutch-Taiwan Deal: Explanation Called 'Untenable", New York Times, Jan 19, 1981, p A-14. ProQuest Historical Newspapers.

South China Morning Post, "First one child, now two - but China's birth policy is here to stay - Changing the number of children from one to two might lessen need for harsh enforcement, but it won't disappear altogether, experts say", (Hong Kong) - October 31, 2015Page: A4.

Sun, E.Z., "The Pattern of Railway Development in China", The Far Eastern Quarterly, Vol. 14, No. 2 (Feb., 1955), pp. 179-199.

Sun, L., "Societal Transition: New Issues in the Field of the Sociology of Development", Modern China, Vol. 34, No. 1, (Jan., 2008), pp. 88-113.

Swaine, M., "The Policy Analyst and Historical Perspectives", in Wills Jr. (ed), Past and Present in China's Foreign Policy, Merwin Asia, Portland, Maine, 2010.

Swaine, M., "Decision Making Regarding Taiwan: 1979-2000", in The Making of Chinese Foreign and Security Policy in the Reform Era, D. Lampton (ed), Stanford University Press, Stanford, CA, 2001.

Tang, S.P., "Economic Integration in Central Asia: The Russian and Chinese Relationship", Asia Survey, Vol. XL, No. 2, March/April, 2000.

Teiwes, F.C., "Establishment and Consolidation of the New Regime", Fairbank, J.K. "The Reunification of China", Cambridge History of China, Volume 14 The People's Republic Part I: The Emergence of Revolutionary China 1949-1965, , MacFarquahar \& Fairbank (eds) Cambridge University Press, Cambridge, UK, 1995.

Teiwes, F.C., "The Paradoxical Post-Mao Transition", in The Natural of Chinese Politics, J.Unger (ed). M.E. Sharpe, Inc., Armonk, NY, 2002.

Terrill, Ross. Mao: A Biography, Simon \& Schuster, New York, 1993. 
Thayer, C., "VIETNAM: Coping with China", Southeast Asian Affairs, (1994), pp. 351367.

Tow, W.T., "China and the International Strategic System", in Chinese Foreign Policy: Theory and Practice. Robinson, T.W. \& Shambaugh, D., (eds), Oxford University Press, New York, 1997.

Tuan, F.C., Ke, B., “A Review of China's Agricultural Policy: Past and Present Developments" in Agriculture in China and OECD Countries, OECD, 1999.

Tweeten, L., "The Economics of Global Food Security", Review of Agricultural Economics, Vol. 21 No. 2, pp 473-88.

Tylers, P. “China Warns U.S. on Relations With Taiwan,” New York Times 11 Sep 1994, A14.

Uvin, P., "Regime, Surplus, and Self-Interest: The International Politics of Food Aid" International Studies Quarterly, Vol. 36, No. 3 (Sep., 1992), pp. 293-312.

Valnete, M., "South America: Curbing Land Purchases by Foreign Investors" Marcela Valente*. IPS - Inter Press Service [Montevideo] 11 May 2011. http://search.proquest.com/news/docview/866094320/fulltext/2EFCB1C81EA840F7PQ/7 ?accountid=10901

VietNamNet. (2011) 'Chinese lease Vietnamese land to grow sweet potatoes', 11 July, accessed at http://farmlandgrab.org/post/view/18927, April 4, 2016.

Vogel, Ezra F., "Chen Yun: His Life” Journal of Contemporary China (2005), 14(45), November, 741-759.

Vogel, Ezra F., Deng Xiao Ping and the Transformation of China, The Belknap Press, Cambridge, Mass., USA, 2011.

Vogel, Ezra F. Deng Xiaoping and the Transformation of China. Cambridge, Mass. Belknap Press of Harvard University Press, 2011.

Wallensteen, P.,"Scarce Goods as Political Weapons: The Case of Food”, Journal of Peace Research, No. 4, Vol XIII/1976, pp. 277-98.

Waltz, K.N., Theory of International Politics, McGraw-Hill Education (Asia) Co. and Peking University Press, Beijing, 2004.

Waltz, K.N., "Structural Realism After the Cold War", International Security, Vol. 25, No. 1, 2000, pp.5-41. 
Wan, G.H., Chen. E.J., "A Micro-empirical Analysis of Land Fragmentation and Scale Economies in Rural China", Yang, Y.Z., Tian, W.M., (eds) in China's Agriculture at the Crossroads, St. Martin's Press, Inc., New York, 2000.

Wang, G., "Ming foreign relations: Southeast Asia", Mote and Twitchett (eds) in Cambridge History of China, Vol. 8, The Ming Dynasty 1368-1644, Cambridge University Press, 1998.

Wang. J., "International Relations Theory and the Study of Chinese Foreign Policy: A Chinese Perspective", in Chinese Foreign Policy: Theory and Practice. Robinson, T.W. \& Shambaugh, D., (eds), Oxford University Press, New York, 1997.

Wang, J., Huang, J., Rozelle, S., Climate Change and China's Agricultural Sector: An Overview of Impacts, Adaptation and Mitigation, ICTSD-IPC Platform on Climate Change, Agriculture and Trade, Issue Brief No.5, International Centre for Trade and Sustainable Development, Geneva, Switzerland and International Food \& Agricultural Trade Policy Council, Washington DC, USA.

Wang, Qingxin, "Cultural Norms and the Conduct of Chinese Foreign Policy", in China's International Relations in the $21^{\text {st }}$ Century, Hu, Chan, \& Zha (eds), University Press of America, New York, 2000.

Wang Yuan-kang, "Managing Regional Hegemony in Historical Asia: The Case of Early Ming China," The Chinese Journal of International Politics, Vol. 5, 2012, 129-153.

Wang, Z., "National Humiliation, History Education, and the Politics of Historical Memory: Patriotic Education Campaign in China", International Studies Quarterly, 2008, $52,783-806$.

Wedeman, A., "Stealing from the Farmers: Institutional Corruption and the 1992 IOU Crisis" The China Quarterly, No. 152 (Dec., 1997), pp. 805-831.

Wen, S.C, Yu, Side, "China's Agricultural Export and Import Behavior", in Agriculture Trade and Policy in China, Rozelle \& Sumner (eds), Ashgate Publishing, Burlington VT, 2003.

White, T., China's Longest Campaign, Cornell University Press, Ithaca, NY, 2006.

Whiting, A.S., "Dynamics of the Moscow-Peking Axis," Annals of the American Academy of Political and Social Science, Vol. 321, Jan., 1959, pp. 100-111.

Whiting, A.S., "ASEAN Eyes China: The Security Dimension”, Asian Survey, Vol. 37, No. 4 (Apr., 1997), pp. 299-322. 
Wilber, C.K., "The Role of Agriculture in Soviet Economic Development", Land Economics, Vol. 45, No. 1 (Feb., 1969), pp. 87-96

Willmore, L., Cao, G.Y., Xin, L.J., "Determinants of Off-Farm Work and Temporary Migration in China", Population and Environment, Vol 33, 2012, pp. 161-85.

Wines, M., "Majority of Chinese Now Live in Cities", New York Tim,es, 1/20/2012, www.nytimes/2012/01/18/world/asia/majority-of-chinese-now-live-in-cities.html

Wittfogel, K.A., "Agrarian Problems and the Moscow-Peking Axis", Slavic Review, Vol. 21, No. 4 (Dec., 1962), pp. 678-698

Womack, B., "Vietnam in 1995: Successes in Peace", Asian Survey, Vol. 36, No. 1, Jan., 1996, pp. 73-82.

Womack, B., "Recognition, Deference, and Respect: Generalizing the Lessons of an Asymmetric Asian Order", in Past and Present in China's Foreign Policy, Wills, J. E. Jr. (ed), Merwin Asia, Portland, Maine, 2010.

Womack, B., "Asymmetry and China's Tributary System", The Chinese Journal of International Politics, Vol. 5, 2012, 37-54.

Womack, B., "Recognition, Deference, and Respect: Generalizing the Lessons of an Asymmetric Asian Order" in Willis Jr., J.E., (ed), Past and Present in China's Foreign Policy, MerwinAsia, Portland Me., USA, 2010.

Wong, J., Huang, Y., "China's Food Security and its International Implications" China: An International Journal, Volume 10, Number 1, March 2012, pp. 113-124.

Wong, J., "Chinese Demand for South-East Asian Rubber, 1949-72" The China Quarterly, No. 63 (Sep., 1975), pp. 490-514.

Wong, R.B., China Transformed, Cornell University Press, Ithaca, NY, 1997.

Wood, P., "Food Security and Chinese 'Comprehensive National Security", China Brief, March 2, 2017

World Bank Development Indicators 1994

World Food Program, "Contributions to WPF: Comparative Figures and Five-Year Aggregate Ranking”, (as of April 17, 2016). 
World Trade Organization, “Agreements on Agriculture”, 2003 Wrens, C., "Peking Protests Sale of U.S. Planes to Taiwan: China Issues Strong ...”, New York Times, Jan 13, 1982, p A1 ProQuest Historical Newspapers.

Wrens, C., "China Lags on Buying U.S. Grain: China Fails to Meet U.S. Grain-Buying Quota", New York Times, Sep 29, 1984, p 29. ProQuest Historical Newspapers.

Wu, Friedrich W. Y., "From Self-Reliance to Interdependence?: Developmental Strategy and Foreign Economic Policy in Post-Mao China", Modern China, Vol. 7, No. 4 (Oct., 1981), pp. 445-482.

Wu Xinbo, "Four Contradictions Constraining China's Foreign Policy Behavior," Journal of Contemporary China, 2001, 10:27, 293-301.

WuDunn, S., "Chinese Angered by French Arms Sale to Taiwan”, New York Times, Nov 20, 1992, p. A12 ProQuest Historical Newspapers

Xinhua Insight: “Twists and turns for Chinese SOEs abroad”, English.news.cn | 20120928

Xinhua, "China to Guarantee $120 \mathrm{mln}$ ha Arable Land", August 14, 2008. Accessed August 12, 2013.

Xinhua, "Comment on the Chinese Implication of Overall Security View of Xi", April, 4, 2016.

Yahuda, M.H., "China and Europe", in Chinese Foreign Policy: Theory and Practice. Robinson, T.W. \& Shambaugh, D., (eds), Oxford University Press, New York, 1997.

Yahuda, M.H., "Chinese Foreign Policy after 1963: The Maoist Phases", The China Quarterly, No. 36 (Oct. - Dec., 1968), pp. 93-113.

Yahuda, M., "China's Foreign Policy Comes of Age”, The International Spectator, Vol. 42, No. 3, September 2007, 337-350.

Yan, Y.,'Food Safety and Social Risk in Contemporary China", The Journal of Asian Studies, Vol. 71, No. 3 (August 2012), pp. 705-729.

You, J., Gan, H., Tang, K., Jia, L., \& Niu, C., "Analysis of impact of South-to-North Water Transfer Project on groundwater exploitation in north China." Proceedings of the 2011 World Environmental and Water Resources Congress; May 22. 26, 2011, American Society of Civil Engineers.

Yu, B. \& Fan, S., "Rice Production Responses in Cambodia," IFPRI Discussion Paper 00939 December 2009. 
Zagoria, D. S., "The Sino-Soviet conflict and the West", Foreign Affairs ; Oct 1962; 41, pg. 171.

Zagoria, D.S., “The Moscow-Beijing Détente”, Foreign Affairs, Vol. 61, No. 4 (Spring, 1983), pp. 853-873.

Zelin, M., "The Yung-Cheng Reign", Peterson (ed) in Cambridge History of China, Vol. 9, The Ch'ing Dynasty to 1800, Cambridge University Press, 2002.

Zha, D., "The Politics of China-ASEAN Economic Relations: Assessing the Move toward a Free Trade Area", Asian Perspective, Vol. 26, No. 4, (2002), pp. 53- 82.

Zha, D. and Zhang, H., "Food in China's International Relations', The Pacific Review, 26:5, pp 455-479, 2013.

Zhang Feng "Rethinking the 'Tribute System':Broadening the Conceptual Horizon of Historical East Asian Politics", Chinese Journal of International Politics, Vol. 2, 2009, $545-574$

Zhang Hongzhou, "China's Food Security: Questioning the Numbers,"RSIS / Commentaries / East Asia and Asia Pacific / Non-Traditional Security 04 MAY 2011, CO11071 |

Zhang Yongjin and Barry Buzan, "The Tributary System as International Society in Theory and Practice", The Chinese Journal of International Politics, Vol. 5, 2012, 3-36.

Zhou, J., "Chinese Agrarian Capitalism in the Russian Far East", Working Paper 13, BRICS Initiative for Critical Agrarian Studies (BICAS), May, 2015

Zuo, M., "China turning state-owned farms into agri-corporations to take on world players", South China Morning Post, August, 4, 2014 http://www.scmp.com/news/china/article/1573077/china uringstateownedfarmsagricorporationstakeworldplayers 
PAUL D. RITTENHOUSE

Born, Chicago Heights, Illinois

1972

B.S. Business Administration

University of Missouri

Columbia, Missouri

1973-1979

The Quaker Oats Company

Chicago, Illinois

1978 MBA Degree

DePaul University

Chicago, Illinois

1979-1980

United Technologies

Des Plaines, Illinois

1980-1998

The Quaker Oats Company

Chicago, Illinois / Hong Kong

1999

Independent Consultant

Hong Kong

1999-2003

Avon Products Inc.

Hong Kong

2003-Present

Independent Investment Manager

Pembroke Pines, Florida

2008-2016

Ph.D. Candidate

Florida International University

Miami, Florida

2012-Present

Adjunct Professor (part time)

Florida International University

Miami, Florida 